MARCUS ZULIAN TEIXEIRA

\title{
Ensaio clínico quali-quantitativo para avaliar a eficácia e a efetividade do tratamento homeopático individualizado na rinite alérgica perene
}

Tese apresentada à Faculdade de Medicina da Universidade de São Paulo para obtenção do título de Doutor em Ciências

Área de concentração: Emergências Clínicas

Orientador: Prof. Dr. Milton de Arruda Martins

São Paulo

2009 
Dados Internacionais de Catalogação na Publicação (CIP)

Preparada pela Biblioteca da

Faculdade de Medicina da Universidade de São Paulo

Oreprodução autorizada pelo autor

Teixeira, Marcus Zulian

Ensaio clínico quali-quantitativo para avaliar a eficácia e a efetividade do

tratamento homeopático individualizado na rinite alérgica perene / Marcus Zulian

Teixeira. -- São Paulo, 2009.

Tese(doutorado)--Faculdade de Medicina da Universidade de São Paulo.

Departamento de Clínica Médica.

Área de concentração: Emergências Clínicas.

Orientador: Milton de Arruda Martins.

Descritores: 1.Homeopatia 2.Alergia e imunologia 3.Rinite 4.Ensaio clínico

controlado 5.Ensaio clínico controlado aleatório 6.Projetos de pesquisa

7.Efeito placebo

USP/FM/SBD-029/09 


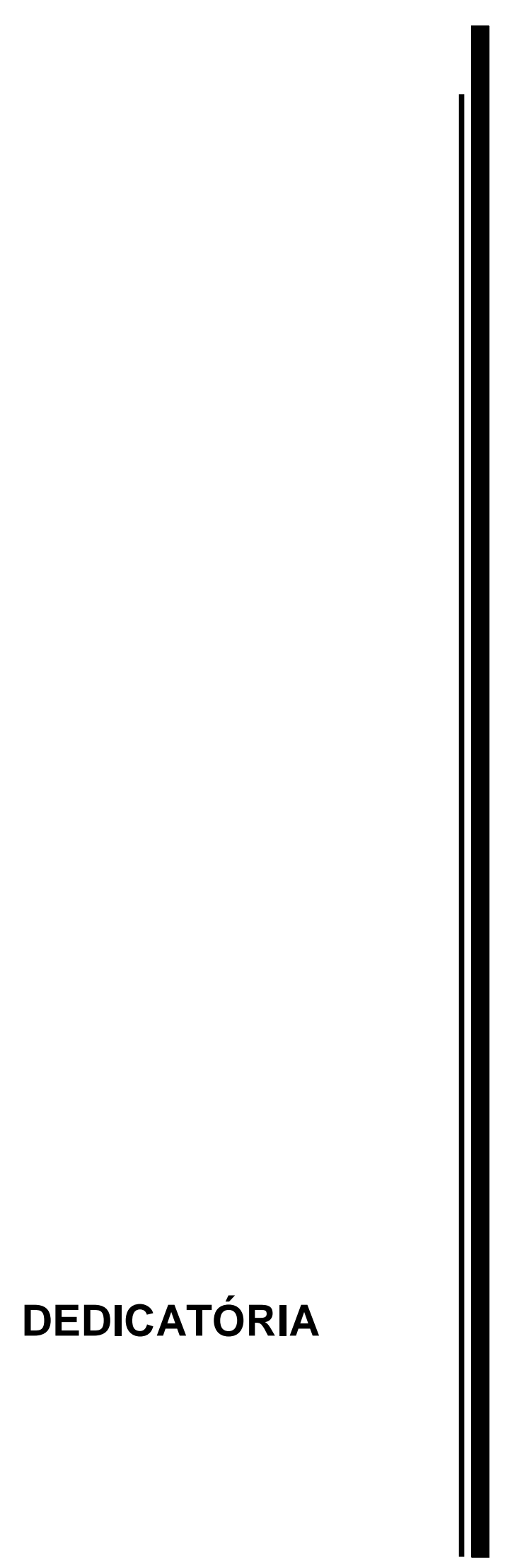


Em memória ao meu pai Luciano, pelo estímulo e apoio irrestrito à minha formação.

À Homeopatia, que amplia a minha prática médica com sua ciência, filosofia e arte de curar, satisfazendo os mais íntimos ideais.

À minha esposa Eliane e ao meu filho Pedro, que alegram e suavizam a minha existência com suas manifestações de amor e compreensão. 
AGRADECIMENTOS 
Ao Prof. Dr. Milton de Arruda Martins, mestre e tutor nos caminhos da ciência médica, que soube respeitar e aprimorar meus ideais latentes com sua sabedoria humilde, permitindo que os projetos nos campos do ensino e da pesquisa homeopática pudessem ser concretizados.

À Cristina Helena Ferreira Fonseca Guedes, colaboradora incansável em todas as fases deste projeto, sempre disposta e competente para auxiliar na solução das dificuldades emergentes, com paciência ilimitada.

À Patrícia Vieira Barreto, colaboradora conscienciosa nas avaliações clínicoalérgicas dos pacientes, que honrou o compromisso assumido em situação de extrema dificuldade, possibilitando uniformidade aos resultados em todas as fases do estudo.

Ao Serviço de Clínica Médica Geral do HCFMUSP, que me aceitou como pesquisador e disponibilizou sua estrutura física e operacional para que este protocolo pudesse ser realizado.

Ao Mário Kuipers (in memoriam), à Célia Salles e à Silvana da Silva, colaboradores solícitos na organização dos prontuários, recepção e agendamento dos pacientes, facilitando o nosso trabalho no Ambulatório da Clínica Médica Geral do HCFMUSP. 
Ao Prof. Fábio F. Morato Castro, que disponibilizou a estrutura física e operacional do Ambulatório de Rinite Alérgica do Serviço de Alergia e Imunologia Clínica do HCFMUSP, para que os exames complementares e as avaliações clínico-alérgicas dos pacientes pudessem ser realizados.

À Leoni Loconte Bacci, colaboradora prestimosa na coleta, digitação e encaminhamento dos resultados dos exames complementares coletados no Ambulatório de Rinite Alérgica.

À Farmácia HNCristiano, colaboradora inestimável no aviamento, na distribuição e no fornecimento gratuito dos medicamentos aos pacientes em todas as fases do estudo, permitindo que o esquema de tratamento fosse cumprido de forma ética, responsável e precisa.

A todos os pacientes que se propuseram a participar deste ensaio clínico e que contribuíram de forma indispensável e valorosa ao entendimento da racionalidade científica do modelo homeopático. 
EPÍGRAFE

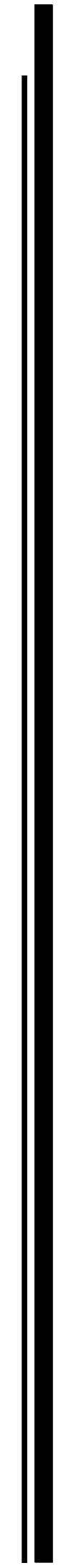


O verdadeiro espírito científico, então, deveria tornar-nos modestos e bondosos. Nós realmente sabemos muito pouco e somos todos falíveis ao enfrentar as imensas dificuldades apresentadas na investigação dos fenômenos naturais. A melhor coisa para fazer, então, é unir nossos esforços, ao invés de dividilos e anulá-los em disputas pessoais.

(Introdução ao Estudo da Medicina Experimental, 1865)

Claude Bernard 
Esta tese está de acordo com:

Referências: adaptado de International Committee of Medical Journals Editors (Vancouver).

Universidade de São Paulo. Faculdade de Medicina. Serviço de Biblioteca e Documentação. Guia de apresentação de dissertações, teses e monografias. Elaborado por Anneliese Carneiro da Cunha, Maria Julia de A. L. Freddi, Maria F. Crestana, Marinalva de Souza Aragão, Suely Campos Cardoso, Valéria Vilhena. São Paulo: Serviço de Biblioteca e Documentação; 2004.

Abreviaturas dos títulos dos periódicos de acordo com List of Journals Indexed in Index Medicus. 


$$
\text { I }
$$




\section{SUMÁRIO}

\section{LISTA DE FIGURAS}

LISTA DE TABELAS

RESUMO

SUMMARY

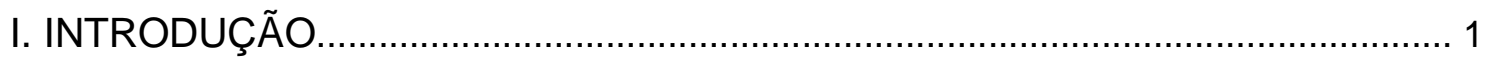

I.1. Rinite alérgica

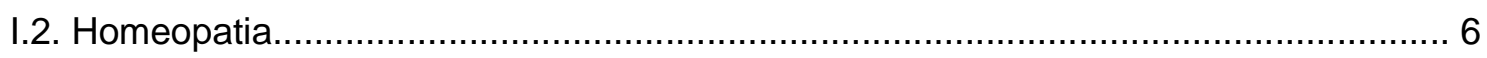

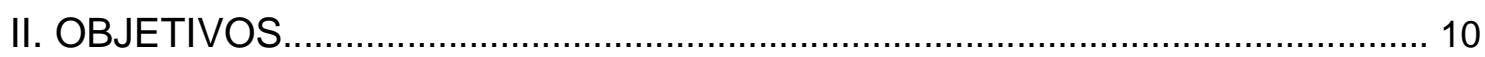

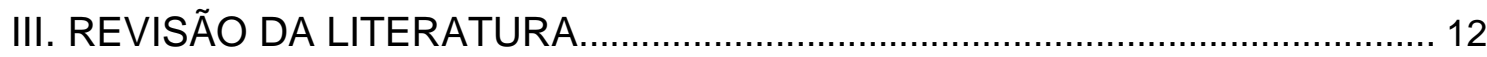

III.1. Racionalidade científica do modelo homeopático ................................................ 13

III.2. Importância do efeito placebo na pesquisa clínica.................................................... 31

III.3. Contribuições da pesquisa clínica em imunoterapia ao desenho de

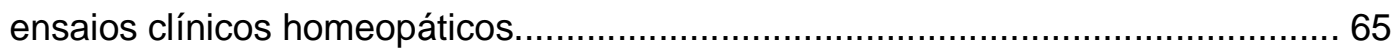

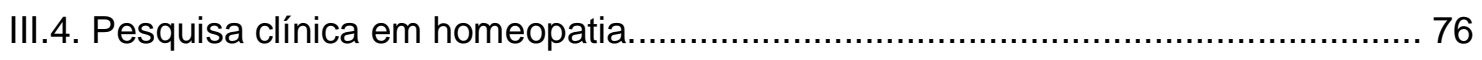

IV. METODOLOGIA

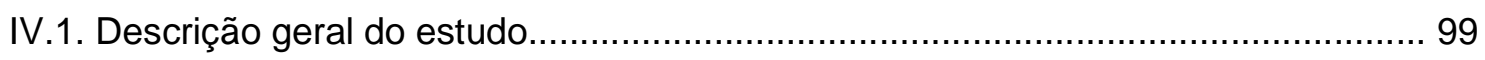

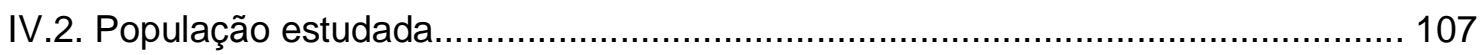

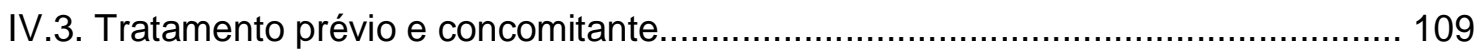

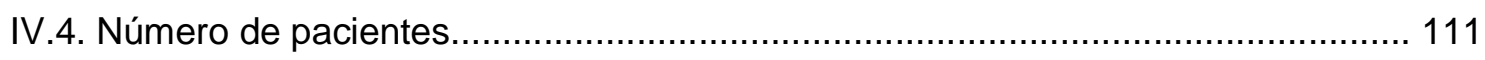

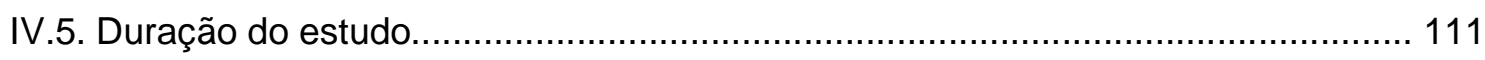

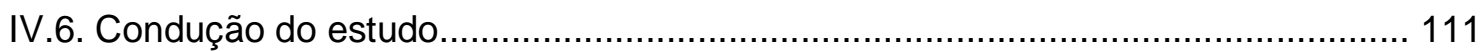




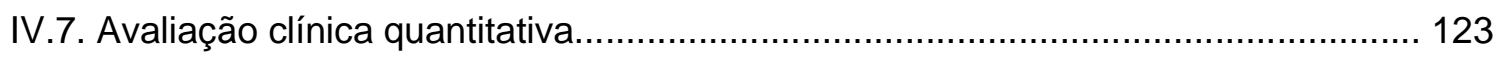

IV.8. Freqüência de utilização de drogas de resgate.................................................. 126

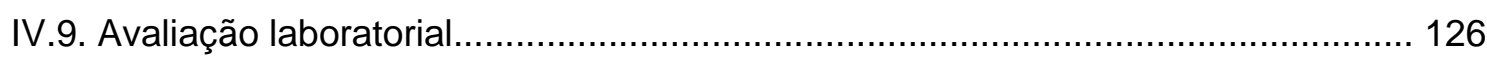

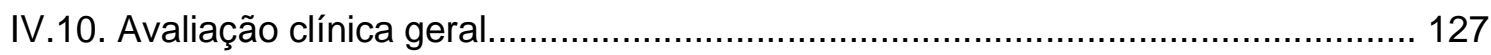

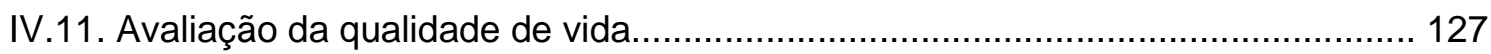

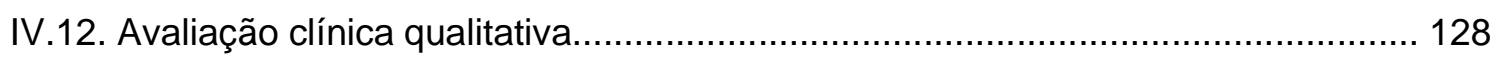

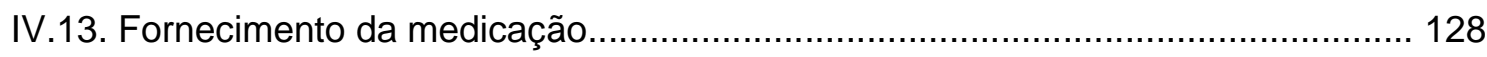

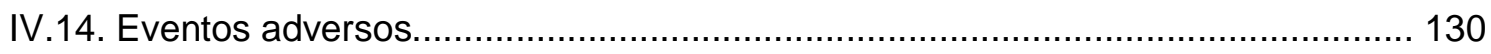

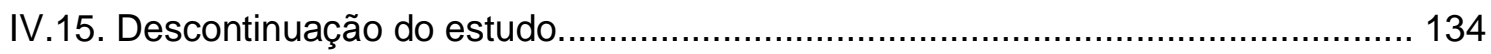

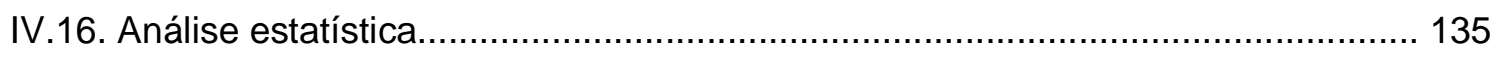

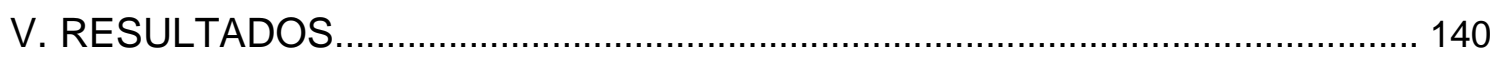

V.1. Análise quantitativa dos grupos de pacientes................................................. 141

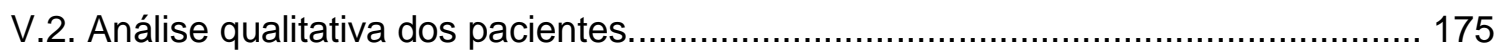

VI. DISCUSSÃO

VI.1. Fase 1 (estudo fechado com a duração de 6 meses de acompanhamento)........... 208

VI.2. Fase 2 (estudo aberto com a duração de 6-36 meses de tratamento).................... 214

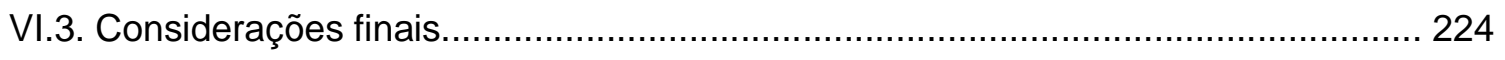

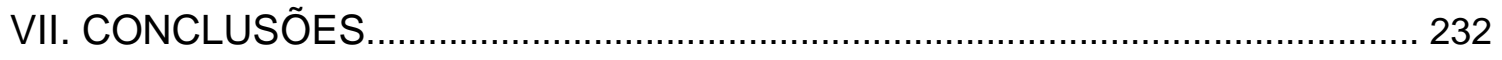

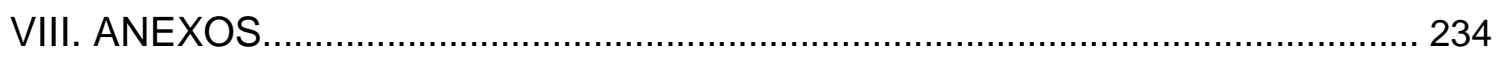

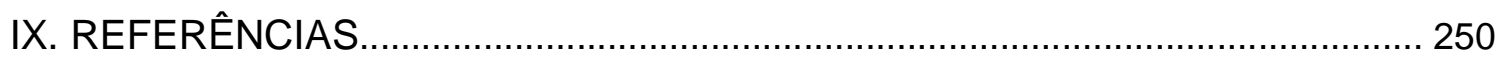

\section{APÊNDICES}




$$
\text { . }
$$




\section{LISTA DE FIGURAS}

Figura 1. Esboço do estudo duplo-cego e placebo-controlado (Fase 1)...................... 101

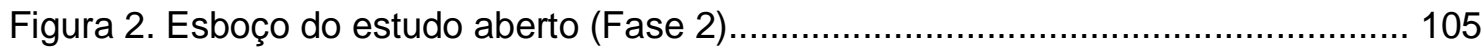

Figura 3. Planejamento do estudo (Fase 1) ....................................................... 142

Figura 4. Escore dos sinais e sintomas específicos da rinite dos grupos placebo e ativo (tempos basal e 6 meses) ................................................ 150

Figura 5. Escore dos sintomas alérgicos gerais dos grupos placebo e ativo (tempos basal e 6 meses)

Figura 6. Escore dos fatores agravantes e precipitantes da rinite dos grupos placebo e ativo (tempos basal e 6 meses). 153

Figura 7. Títulos de lgE total dos grupos placebo e ativo (tempos basal e 6 meses).

Figura 8. Escore dos aspectos da qualidade de vida dos grupos placebo e ativo (tempos basal e 6 meses) 156

Figura 9. Planejamento do estudo (Fase 2). 160

Figura 10. Porcentagem de melhora do escore dos sinais e sintomas específicos da rinite nas Fases 1 e 2

Figura 11. Porcentagem de melhora do escore dos sintomas alérgicos gerais nas Fases 1 e 2 .

Figura 12. Escore dos sinais e sintomas específicos da rinite dos pacientes do grupo ativo ao longo da fase inicial 176

Figura 13. Escore dos sinais e sintomas específicos da rinite dos pacientes do grupo placebo ao longo da fase inicial. 
Figura 14. Escore dos sinais e sintomas específicos da rinite dos pacientes do grupo placebo inicial que completaram 6 meses de tratamento

Figura 15. Escore dos sinais e sintomas específicos da rinite dos pacientes do grupo placebo inicial que completaram 12 meses de tratamento. 180

Figura 16. Escore dos sinais e sintomas específicos da rinite dos pacientes do grupo ativo inicial que completaram 12 meses de tratamento.

Figura 17. Escore dos sinais e sintomas específicos da rinite dos pacientes do grupo placebo inicial que completaram 24 meses de tratamento 182

Figura 18. Escore dos sinais e sintomas específicos da rinite dos pacientes do grupo ativo inicial que completaram 24 meses de tratamento. 183

Figura 19. Escore dos sinais e sintomas específicos da rinite dos pacientes que completaram 36 meses de tratamento.

Figura 20. Evolução clínica dos pacientes que atingiram escore dos sinais e sintomas específicos da rinite $\leq 6$ pontos ao longo do estudo. 185 


\section{LISTA DE TABELAS}

Tabela 1. Medicamentos excludentes e período de wash-out..................................... 108

Tabela 2. Seqüência de avaliações dos pacientes ao longo do estudo......................... 114

Tabela 3. Quadro clínico-alérgico específico............................................................. 125

Tabela 4. Quadro clínico-alérgico geral............................................................ 125

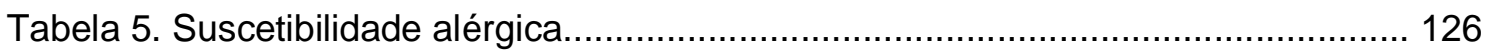

Tabela 6. Gravidade ou intensidade da rinite........................................................... 126

Tabela 7. Classificação quanto à gravidade dos eventos adversos............................. 133

Tabela 8. Relação do medicamento com os eventos adversos................................. 133

Tabela 9. Características descritivas da amostra (Fase 1) ........................................ 144

Tabela 10. Valor basal do escore dos parâmetros clínico-alérgicos, da qualidade de vida e laboratoriais.

Tabela 11. Porcentagem de variação da melhora clínico-alérgica dos grupos placebo e ativo ao final da Fase 1

Tabela 12. Motivos da descontinuação dos pacientes na Fase 2............................... 160

Tabela 13. Comparação entre as características descritivas dos pacientes da Fase 1 com os pacientes que permaneceram na Fase 2.

Tabela 14. Comparação entre as características descritivas dos pacientes da Fase 1 com os pacientes que descontinuaram na Fase 2 .

Tabela 15. Comparação entre as características descritivas dos pacientes que permaneceram com os que descontinuaram na Fase 2. 163

Tabela 16. Porcentagem de melhora clínico-alérgica do subgrupo placebo inicial entre os períodos 0-6 e 0-12 meses de acompanhamento. 165 
Tabela 17. Porcentagem de melhora clínico-alérgica dos grupo ativo e subgrupo placebo iniciais após 6 meses de tratamento. 165

Tabela 18. Porcentagem de melhora clínico-alérgica dos subgrupos ativo e placebo iniciais após 12 meses de tratamento. 166

Tabela 19. Comparação da porcentagem de melhora clínico-alérgica entre as fases inicial e 12 meses de tratamento. 168

Tabela 20. Comparação da porcentagem de melhora clínico-alérgica entre as fases inicial e 24 meses de tratamento.

Tabela 21. Comparação da porcentagem de melhora clínico-alérgica entre as fases inicial e 36 meses de tratamento.

Tabela 22. Comparação da porcentagem de melhora dos subgrupos placebo e ativo iniciais nos períodos de 12, 24 e 36 meses de tratamento. 172

Tabela 23. Magnitude da melhora clínico-alérgica ao longo dos períodos de 12,24 e 36 meses de tratamento. 173

Tabela 24. Pacientes que atingiram escore dos sinais e sintomas específicos da rinite $\leq 3$ pontos ao final dos 36 meses de tratamento 187

Tabela 25. Pacientes que atingiram escore dos sinais e sintomas específicos da rinite entre 4-6 pontos ao final dos 36 meses de tratamento. 193

Tabela 26. Pacientes que atingiram escore dos sinais e sintomas específicos da rinite $>6$ pontos ao final dos 36 meses de tratamento 197 
RESUMO

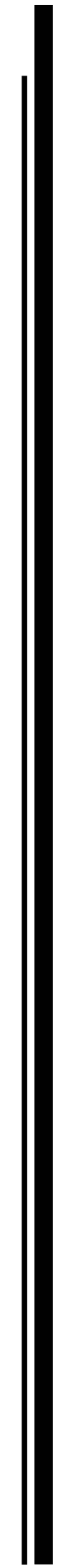


Teixeira, MZ. Ensaio clínico quali-quantitativo para avaliar a eficácia e a efetividade do tratamento homeopático individualizado na rinite alérgica perene [Tese]. São Paulo: Faculdade de Medicina, Universidade de São Paulo; 2008.

INTRODUÇÃO: A rinite alérgica é uma condição clínica comum que apresenta sintomas diversos num significante número de pacientes, deteriorando a qualidade de vida daqueles refratários aos tratamentos usuais (anti-histamínicos e corticosteróides nasais tópicos). Apresentando princípios curativos similares, a imunoterapia sublingual e a homeopatia podem reduzir os sintomas e a necessidade de medicamentos na rinite alérgica, embora a eficácia e a efetividade de ambas terapêuticas não sejam ainda suficientemente conhecidas. OBJETIVOS: O objetivo deste estudo foi avaliar a efetividade clínica do tratamento homeopático individualizado prolongado, comparativamente ao placebo, em adultos portadores de rinite alérgica perene. MÉTODOS: Um total de 41 pacientes com rinite alérgica perene foi alocado numa primeira fase duplo-cego e placebo-controlada durante seis meses, sendo tratada com doses sublinguais semanais de medicamentos homeopáticos individualizados ou placebo. Após esta fase inicial fechada, todos os pacientes foram convidados a participar de uma segunda fase controlada aberta, em que receberiam tratamento homeopático pelo período máximo de 36 meses, e os resultados foram comparados com a melhora da fase inicial. O escore dos sinais e sintomas, a necessidade de medicamentos de resgate e a qualidade de vida foram mensurados por questionários e avaliações clínicas pessoais, aplicadas por um mesmo avaliador independente, antes e após cada fase. As doses dos medicamentos homeopáticos e de resgate utilizados, assim como os efeitos 
colaterais, foram documentados num diário pessoal. Os desfechos clínicos primário e secundários foram, respectivamente, os escores dos sinais e sintomas alérgicos específicos e gerais. Títulos da lgE total foram mensurados antes e após cada fase. RESULTADOS: Após os seis meses da fase placebo-controlada inicial, na análise por protocolo de todos os pacientes incluídos no estudo, não foram observadas diferenças significativas entre os grupos ativo e placebo nos escores clínicos, na utilização de drogas de resgate, na qualidade de vida e nos títulos da IgE total. Entretanto, as análises dos subgrupos da segunda fase mostraram uma crescente e significativa melhora nos desfechos clínicos primário e secundários após 12 meses de tratamento homeopático individualizado, comparativamente à variação de melhora dos mesmos pacientes na fase inicial fechada. Diferença significativa na qualidade de vida foi observada apenas após o segundo ano de tratamento homeopático. CONCLUSÃO: Neste estudo, o tratamento homeopático foi acompanhado de um significante efeito placebo. A efetividade da homeopatia pôde ser observada após 12 meses da terapêutica, apresentando efeito preventivo de longa duração após 36 meses de tratamento homeopático individualizado.

Descritores: homeopatia; alergia e imunologia; rinite; ensaio clínico controlado; ensaio clínico controlado aleatório; projetos de pesquisa; efeito placebo. 


$$
\text { I }
$$


Teixeira, MZ. Quali-quantitative clinical trial to evaluate the efficacy and the effectiveness of individualized homeopathic treatment in perennial allergic rhinitis [Thesis]. São Paulo: School of Medicine, University of São Paulo; 2008.

INTRODUCTION: Allergic rhinitis is a common clinical condition which presented several symptoms in a significant number of patients, deteriorating the quality of life in those resistant to the usual treatments (antihistamines and topical nasal corticosteroids). Presenting similar curative principles, sublingual immunotherapy and homeopathy can reduce symptoms and medication requirements in allergic rhinitis, although the efficacy and effectiveness of both therapeutics are not still sufficiently known. OBJECTIVES: The objective of this study was to evaluate clinical effectiveness of prolonged individualized homeopathic treatment, compared with placebo, in adults with perennial allergic rhinitis. METHODS: A total of 41 adults with perennial allergic rhinitis were enrolled in a first double-blind placebo-controlled phase for six months, and treated on a weekly basis with sublingual doses of single individualized homeopathic medicines or placebo. After this closed initial phase, all patients were invited to participate in an open label controlled phase, in that they would receive homeopathic treatment for the maximum period of 36 months, and the results were compared with the improvement of the initial phase. Signs and symptoms scores, rescue medication requirements and quality of life were assessed by questionnaires and personal clinical evaluation by a same independent researcher, before and after each phase. Applied homeopathic and rescue drugs dosage, and side effects were documented by diary cards. Primary and secondary clinical outcome were, respectively, specific and general allergic signs and symptoms 
scores. Total IgE titles were performed before and after each phase. RESULTS: After six months of placebo-controlled phase, analyzing all patients included in the study per protocol, we observed no significant difference between treatment and placebo groups in primary and secondary clinical outcomes, use of rescue drugs, quality of life and total $\lg \mathrm{E}$. However, second phase subgroups analysis showed a significant and growing improvement of clinical symptoms after 12 months of individualized homeopathic treatment, comparatively to the same patients' variation in closed initial phase. Significant difference in quality of life score were observed only after second homeopathic treatment year. CONCLUSION: In this study, homeopathic treatment was accompanied by a significant placebo effect. Effectiveness of homeopathy could be seen after 12 months of therapy, presenting preventive effect of long duration after 36 months of individualized homeopathic treatment.

Key words: homeopathy; allergy and immunology; rhinitis; controlled clinical trial; randomized controlled trial; research design; placebo effect. 
I. INTRODUÇÃO 


\section{INTRODUÇÃO}

\section{I.1. Rinite alérgica}

A rinite alérgica é uma doença crônica inflamatória que afeta a mucosa nasal, mediada pela IgE após exposição a alérgenos. Seus principais sintomas clínicos são rinorréia, espirros, prurido, obstrução nasal e/ou secreção retronasal, podendo vir acompanhados por prurido ocular, da orofaringe ou do conduto auditivo. Segundo a periodicidade de manifestação dos sintomas, pode ser classificada em intermitente ou persistente; baseada no tempo de exposição aos alérgenos pode ser classificada em sazonal ou perene. A rinite alérgica perene (persistente) é caracterizada pela presença de sintomatologia durante todo o ano, sendo desencadeada por aeroalérgenos ambientais tais como poeira domiciliar, ácaros, pêlo de animais domésticos, restos de insetos, fungos, pólen de gramíneas etc.

Considerada como a doença alérgica respiratória crônica de maior prevalência no mundo, acomete cerca de $10 \%$ a $25 \%$ da população, comprometendo a qualidade de vida, o aprendizado escolar e o rendimento profissional dos portadores. Segundo a primeira análise do International Study on Asthma and Allergies in Childhood (ISAAC) (Asher et al., 2006), a prevalência dos sintomas associados a rinoconjuntivite alérgica varia de $2,2 \%$ a $14,6 \%$ entre crianças (6-7 anos) e de $4,5 \%$ a 45,5\% entre adolescentes (13-14 anos). Numa segunda análise, envolvendo 54.178 crianças (8-12 anos) de 30 centros de estudo em 22 países, o ISAAC mostrou que a prevalência de rinoconjuntivite varia de $1,5 \%$ a $24,5 \%$, enquanto a rinite 
isoladamente varia de $1,4 \%$ a $45,2 \%$ (Weinmayr et al., 2008). No Brasil, a realização do ISAAC mostrou que a prevalência média dos sintomas relacionados à rinite alérgica é de 25,7\% entre escolares e de 29,6\% entre adolescentes (Solé et al., 2006). Na população adulta, o questionário European Community Respiratory Health Survey (Bauchau e Durham, 2004) evidenciou a prevalência média de sintomas de rinite em $23 \%$ da população européia.

Negligenciada por pacientes e profissionais da saúde, que a confundem com um resfriado repetitivo, a rinite alérgica encontra-se entre os dez motivos mais freqüentes de procura ao atendimento primário em saúde, apresentando inúmeros distúrbios concomitantes (fadiga, cefaléia, dificuldade de atenção e aprendizagem, apnéia do sono etc.), sendo considerado um problema de saúde pública mundial (International Consensus Report, 1994).

Apesar da desvalorização do quadro clínico em si, sua ocorrência assume relevância em virtude da correlação direta com a asma, sendo estimada como fator de risco para o desenvolvimento de asma em cerca de $20 \%$ a $38 \%$ dos casos (Grossman, 1997), com avaliações indicando que 60\% a 78\% dos asmáticos são portadores de rinite alérgica (Bousquet et al., 2001; Passalacqua et al., 2001; Koh e Kim, 2003). O ISAAC revelou que a co-morbidade entre asma e rinite pode alcançar $80 \%$ e que pacientes com asma apresentam, freqüentemente, sintomas nasais de difícil controle (Strachan et al., 1997). Recentes revisões reiteram estes dados (Cruz et al., 2007; Bousquet et al., 2008).

Um complexo mecanismo fisiopatológico envolve esta síndrome, composta por uma fase imediata e outra tardia (Castro, 1998). Na fase imediata, após a mucosa nasal entrar em contato com os antígenos (alérgenos), estes são captados e 
processados, sendo apresentados pelas células de Langherans aos linfócitos Th0 (linfócito T auxiliar tipo 0). Provavelmente por fatores genéticos, os linfócitos Th0 diferenciam-se em linfócitos Th2, ao invés de Th1. Nos seres humanos, estes dois tipos de linfócitos secretam interleucinas (IL-2, IL-3, IL-10, IL-13 etc.) e o fator estimulante de colônia granulocítica macrofágica (GM-CSF). Além destas substâncias, os linfócitos Th2 produzem IL-4, IL-5 e IL-9, ao passo que os linfócitos Th1 produzem interferon gama (INF- $\gamma$ ) e fator de necrose tumoral beta (TNF- $\beta$ ). A IL4 atua sobre os linfócitos B transformando-os em células de memória e plasmócitos produtores de $\lg \mathrm{E}$. A ligação entre duas moléculas de $\lg \mathrm{E}$ fixas na parede dos mastócitos com os antígenos gera uma série de processos bioquímicos, que resultam na liberação de grânulos citoplasmáticos contendo determinados mediadores químicos pré-formados (histamina, leucotrienos, triptases, cininas etc.).

A histamina possui vários efeitos no organismo, especificamente na mucosa nasal, como aumento da permeabilidade vascular (quimiotaxia e inflamação), vasodilatação (congestão ou obstrução nasal), aumento da produção de muco (rinorréia), além de estimular terminações nervosas, gerando espirros e prurido. Os mastócitos liberam ainda outras substâncias chamadas neoformadas, que são responsáveis por uma fase tardia de sintomas; neste momento, ocorre o comprometimento da barreira mucociliar, favorecendo a penetração e o contato dos antígenos com as terminações nervosas, levando à hiperreatividade do Sistema Nervoso Autônomo, com predomínio parassimpático.

As células envolvidas na fase tardia são, principalmente, os eosinófilos e os basófilos. A penetração destas células na mucosa nasal depende de sua adesão a 
determinados receptores que serão expressos no endotélio dos vasos. Estes receptores são denominados moléculas de adesão (pertencentes à superfamília das imunoglobulinas) como, por exemplo, as selectinas (E-selectinas e P-selectinas), o ICAM-1 (molécula de adesão intercelular) e o VCAM-1 (molécula de adesão da célula vascular). A histamina e os leucotrienos (LTC4 e LTD4) liberados na fase imediata são indutores de algumas selectinas no endotélio dos vasos nasais como, por exemplo, a P-selectina. Os eosinófilos ligam-se a ela pela selectina SLe-X (antígeno Sialyl Lewis X) e começa seu processo de rolagem sobre este endotélio. Esta ligação não é muito forte e, caso não encontrem outras moléculas de adesão como VCAM-1 e ICAM-1, voltam a circular pelo organismo. A expressão de VCAM-1 está aumentada na inflamação alérgica, provavelmente por ação da IL-4, liberada por linfócitos Th2 e mastócitos, que é um potente indutor desta molécula de adesão. Os eosinófilos, durante sua rolagem sobre o endotélio, irão aderir-se ao VCAM-1 e ao ICAM-1 das células endoteliais pelo VLA-4 e LFA-1, respectivamente. Estas ligações são mais fortes que a ligação com as selectinas, fazendo com que sua fixação no endotélio desencadeie o processo de diapedese e quimiotaxia.

O tratamento convencional da rinite alérgica limita-se a três tipos de condutas: evitar o contato com os alérgenos (higiene ambiental), hipossensibilização (imunoterapia) e terapia medicamentosa (anti-histamínicos, corticosteróides nasais etc.). Em vista da dificuldade na higienização ambiental, dos eventos adversos e da baixa persistência dos efeitos benéficos após a suspensão da terapia medicamentosa clássica, a imunoterapia vem assumindo magnitude no tratamento da rinite alérgica, propiciando, em longo prazo, uma mudança no curso natural da doença. 
A imunoterapia sublingual (ITSL), que não apresenta os inconvenientes e as limitações da administração subcutânea, tem sido considerada alternativa eficaz e efetiva, com incremento nas pesquisas clínicas modernas. Pela semelhança entre os paradigmas da imunoterapia sublingual e do tratamento homeopático, a homeopatia também mostra eficácia e efetividade no tratamento da rinite alérgica, assim como os desenhos de ensaios clínicos com ITSL podem contribuir na elaboração de modelos na pesquisa clínica homeopática.

\section{I.2. Homeopatia}

Criada em 1796 pelo médico alemão Samuel Hahnemann, a homeopatia é um método terapêutico que se propõe a tratar as diversas enfermidades humanas segundo uma metodologia própria, incorporando os conhecimentos da fisiopatologia e dos métodos de diagnóstico modernos na ampliação do entendimento dos fatores etiológicos das doenças.

O modelo homeopático é fundamentalmente experimental, tendo surgido como fruto da observação cuidadosa do efeito das drogas no organismo humano, utilizando como metodologia científica o principio terapêutico pela similitude e a experimentação das substâncias medicinais em indivíduos sadios. A utilização de substâncias em doses infinitesimais (medicamentos dinamizados) surgiu em momento posterior, para evitar as agravações e as intoxicações observadas no emprego de doses ponderais dos medicamentos segundo o princípio da semelhança curativa. 
O tratamento segundo a lei da semelhança baseia-se na resposta homeostática do organismo a qualquer estímulo externo, em vista de que os sistemas fisiológicos, no sentido de manter a constância do meio interno, apresentam a capacidade automática e instintiva de reagir às alterações internas promovidas pelas drogas, produzindo manifestações psico-neuro-imuno-endócrino-metabólicas opostas: "toda droga causa certa alteração no estado de saúde humano pela sua ação primária; a esta ação primária do medicamento, o organismo opõe sua força de conservação, chamada ação secundária ou reação vital, no sentido de neutralizar o distúrbio inicial" (Hahnemann, 1995).

Observando que esta ação secundária poderia ser empregada como reação curativa, desde que direcionada no sentido correto, Hahnemann propôs um modelo terapêutico que utiliza substâncias medicamentosas que provocam, em sua ação primária no organismo, uma doença artificial com sintomas semelhantes à doença natural. Daí surgiu o princípio da semelhança curativa: todo medicamento capaz de despertar determinados sintomas nos indivíduos sadios pode ser utilizado para curar sintomas semelhantes nos indivíduos doentes.

Assim fundamentado, Hahnemann passou a experimentar uma série de substâncias em indivíduos sadios, anotando os sintomas primários de qualquer ordem despertados nos experimentadores (mentais, gerais e particulares), confeccionando com isto a Matéria Médica Homeopática. À medida que defrontava pacientes com sintomas semelhantes às drogas experimentadas, administrava-as a estes enfermos, com o intuito de despertar uma reação homeostática e curativa do organismo. 
Se, por um lado, as doses ponderais das substâncias com poder patogenético forte e semelhante causam agravações dos sintomas nos pacientes, por outro, as doses ultradiluídas, em vista do tênue poder patogenético que apresentam, conseguem despertar reações curativas apenas nos indivíduos com extrema suscetibilidade à substância medicamentosa. Em vista disto, Hahnemann valorizou as particularidades da individualidade enferma, traduzidas na totalidade dos sintomas característicos, para escolher o medicamento homeopático mais adequado, instituindo uma ampla semiologia, com anamneses e exames clínicos minuciosos, a fim de evidenciar as peculiaridades idiossincrásicas que permitissem selecionar o medicamento individualizado perante as diversas opções terapêuticas.

Desta premissa incondicional, inerente ao modelo homeopático de tratamento das doenças, provém a dificuldade em se encontrar um medicamento eficaz no despertar da reação homeostática do organismo num curto espaço de tempo, necessitando-se um período médio-longo de acompanhamento dos pacientes para se atingir o medicamento corretamente individualizado, tanto no tratamento cotidiano quanto nos modelos de pesquisa clínica homeopática epistemologicamente corretos. Desenhos de estudos clínicos que desprezaram estas premissas não conseguiram demonstrar a eficácia e a efetividade do tratamento homeopático perante o efeito placebo.

Ao longo deste trabalho, estaremos discorrendo detalhadamente sobre a racionalidade que envolve os pressupostos e a terapêutica homeopática, elaborando, aplicando e discutindo um desenho de pesquisa clínica que satisfaça a metodologia científica clássica e respeite a episteme homeopática. No modelo proposto, procuramos reproduzir de maneira fiel a prática clínica homeopática cotidiana, 
aplicando a abordagem semiológica globalizante, a prescrição de medicamentos individualizados, as avaliações e os ajustes periódicos das diversas opções terapêuticas, o tempo de acompanhamento satisfatório etc., a fim de que pudéssemos avaliar a efetividade (validade externa) do tratamento homeopático individualizado no médio-longo prazo. 
II. OBJETIVOS 


\section{OBJETIVOS}

Desenvolver metodologia para a elaboração de ensaios clínicos homeopáticos controlados que respeitem as premissas da racionalidade científica homeopática e reproduzam a prática clínica cotidiana, ou seja, apresentem validade externa.

Aplicar a metodologia proposta em ensaio clínico quali-quantitativo, para avaliar a eficácia e a efetividade do tratamento homeopático individualizado na rinite alérgica perene. 


\section{REVISÃO DA LITERATURA}




\section{REVISÃO DA LITERATURA}

\section{III.1. Racionalidade científica do modelo homeopático}

\section{III.1.1. Introdução}

A homeopatia, fundamentada em 1796 pelo médico alemão Samuel Hahnemann, é um modelo terapêutico empregado mundialmente que vem despertando nas últimas décadas, juntamente com outras práticas nãoconvencionais, o interesse crescente de usuários, estudantes de medicina e médicos (Teixeira et al., 2004), por propiciar uma prática segura e eficiente, propondo-se a compreender e tratar o binômio doente-doença segundo uma abordagem antropológica globalizante e humanística (Teixeira, 2007a), valorizando os diversos aspectos da individualidade enferma.

Reconhecida como especialidade médica pelo Conselho Federal de Medicina (CFM) desde 1980, com título de especialista conferido pela Associação Médica Brasileira (AMB) desde 1990, desenvolve suas atividades de forma paralela ao movimento científico hegemônico, divulgando sua racionalidade teórico-prática em cursos de pós-graduação lato senso (extensão universitária; carga-horária de 1.200 horas-aula) oferecidos por entidades formadoras vinculadas à Associação Médica Homeopática Brasileira (AMHB). Em 2004, começou a ser oferecida no programa de residência médica da Universidade Federal do Estado do Rio de Janeiro (UNIRIO, Hospital Universitário Gaffrée e Guinle, 1-2 vagas anuais) como opção de treinamento em serviço (Universidade Federal do Estado do Rio de Janeiro, 2004). 
Com a consulta e os procedimentos homeopáticos reembolsados pelos convênios e seguros de saúde atuais, a partir de 1985 passou a ser disponibilizada no serviço público de saúde, contando, no Brasil, com aproximadamente quinze mil médicos praticantes. Apesar da demanda crescente da população pela terapêutica nas últimas décadas, apenas 110 dos mais de 5.000 municípios brasileiros disponibilizam a homeopatia na rede pública, embora no último ano a especialidade tenha respondido por mais de 300 mil consultas no Serviço Único de Saúde (SUS), que corresponde a $10 \%$ das consultas de atenção básica do período, segundo dados do Ministério da Saúde (Leite, 2008).

Iniciativas na educação médica mundial começam a viabilizar o ensino dos pressupostos homeopáticos nas faculdades de medicina, incorporando disciplinas eletivas ao currículo fundamental, permitindo que a informação respaldada pelas evidências científicas e pelas práticas vivenciais possa dissolver o preconceito arraigado à cultura médica (Teixeira et al., 2005; Teixeira, 2007b).

Apesar de empregada como opção terapêutica há mais de dois séculos em diversos países, a homeopatia permanece marginalizada perante a racionalidade científica moderna, por estar fundamentada em conceitos pouco ortodoxos (princípio da similitude, experimentação no indivíduo sadio e medicamento dinamizado) que desafiam o pensamento cartesiano dominante. O modelo de tratamento homeopático emprega o princípio de cura pela similitude, administrando doses infinitesimais de substâncias que, ao terem sido experimentadas previamente em indivíduos sadios, apresentaram sintomas semelhantes aos dos indivíduos enfermos. Para se tornar um medicamento homeopático, a substância deve ser submetida a protocolos de experimentação patogenética específicos em indivíduos humanos e ter seus efeitos 
primários (mentais, gerais e particulares) descritos na Matéria Médica Homeopática $(\mathrm{MMH})$.

Considerando o ser humano como uma entidade complexa, a concepção filosófico-antropológica do modelo homeopático atribui ao corpo biológico uma natureza dinâmica físico-vital, na qual os pensamentos e os sentimentos interagem com os sistemas orgânicos e suas funções fisiológicas, tornando a individualidade mais ou menos suscetível aos diversos agentes patogênicos. Resultante desta concepção holística do processo de adoecimento humano, a semiologia homeopática valoriza os múltiplos aspectos do indivíduo enfermo, compondo um quadro sintomático que englobe as características peculiares das diversas esferas humanas (biológica, psíquica, social e espiritual) para realizar o diagnóstico medicamentoso individualizado.

Visando restabelecer este equilíbrio dinâmico, a arte de curar homeopática deve ser capaz de identificar as suscetibilidades mórbidas individuais, reconhecidas através da totalidade dos sintomas característicos manifestos no enfermo, a fim de escolher um medicamento que despertou um conjunto de sintomas semelhantes nos experimentadores sadios.

Em vista de o modelo homeopático valorizar os sintomas emocionais e psíquicos como aspectos de alta hierarquia no conjunto das características humanas, seja na experimentação patogenética homeopática ou na compreensão da etiopatogenia dos distúrbios orgânicos de qualquer natureza, estas classes de manifestações fazem parte do ideal de cura do médico homeopata. Medicamentos que suprimam as manifestações clínicas indesejáveis sem propiciarem melhoras 
emocionais e psíquicas proporcionais não satisfazem a concepção globalizante do processo curativo homeopático.

Assim sendo, todo tratamento homeopático individualizado e bem conduzido deve atuar, de forma integrada, tanto nos distúrbios emocionais e psíquicos quanto nos distúrbios gerais e orgânicos, visando propiciar um estado dinâmico completo de bem-estar físico, mental, espiritual e social, e não meramente a ausência de sintomas. Considerado com certo preconceito pela classe científica, o aspecto espiritual assume importância crescente na abordagem dos conceitos relacionados à qualidade de vida e à saúde humana, com a incorporação de instrumentos específicos de avaliação em diversos protocolos de pesquisa modernos (Panzini et al., 2007).

Com o intuito de fundamentar os pilares da homeopatia (princípio da similitude, experimentação no indivíduo sadio e medicamento dinamizado) no conhecimento científico moderno, iremos citar algumas linhas de pesquisa contemporâneas que endossam os pressupostos homeopáticos citados, descritos mais detalhadamente em revisões anteriores (Teixeira, 2001a, 2004, 2006b, 2008b). Pelas dificuldades encontradas no desenho e na condução destes protocolos de pesquisa, inerentes a um modelo que aplica princípios distintos dos usualmente investigados, um número limitado de estudos de qualidade são identificados na literatura.

\section{III.1.2. Princípio da similitude}

Embasado no estudo das propriedades farmacológicas de dezenas de substâncias medicamentosas de sua época, nas quais observou uma reação 
secundária (efeito indireto) do organismo após a ação primária (efeito direto) de drogas das mais diversas classes, Hahnemann enunciou um aforismo para a ação dos medicamentos na constituição humana:

Toda força que atua sobre a vida, todo medicamento afeta, em maior ou menor escala a força vital, causando certa alteração no estado de saúde do Homem por um período de tempo maior ou menor. A isso se chama ação primária. [...] A essa ação, nossa força vital se esforça para opor sua própria energia. Tal ação oposta faz parte de nossa força de conservação, constituindo uma atividade automática da mesma, chamada ação secundária ou reação. (Organon, §63) (Hahnemann, 1995)

llustrando este fenômeno ou lei natural, descreve a ação primária dos medicamentos de sua época, promotora de alterações nos diversos sistemas orgânicos, e a conseqüente ação secundária do organismo (reação vital ou força de manutenção ou conservação) que se manifesta no sentido de neutralizar os distúrbios primários promovidos pelos fármacos, na tentativa de retornar ao equilíbrio do meio interno anterior à intervenção terapêutica:

[...] À ingestão de café forte, segue-se uma superexcitação (ação primária); porém, um grande relaxamento e sonolência (reação, ação secundária) permanecem por algum tempo se não continuar a ser suprimido através de mais café (paliativo, de curta duração). Após o sono profundo e entorpecedor produzido pelo ópio (ação primária), a noite seguinte será tanto mais insone (reação, ação secundária). Depois da constipação produzida pelo ópio (ação primária), segue-se a diarréia (ação secundária) e, após purgativos que irritam os intestinos (ação primária), sobrevêm obstrução e constipação por vários dias (ação secundária). Assim, por toda parte, após a ação primária de uma potência capaz de, em grandes doses, transformar profundamente o estado de saúde do organismo sadio, é justamente o oposto que sempre ocorre na ação secundária, através de nossa força vital. (Organon, §65) (Hahnemann, 1995)

Administrando aos indivíduos enfermos as substâncias que despertam sintomas semelhantes nos experimentadores sadios (similia similibus curentur), o princípio da 
similitude terapêutica tem como objetivo estimular uma reação homeostática curativa contra a enfermidade, induzindo o organismo a reagir contra os seus próprios distúrbios. Descrito em 1860 pelo fisiologista da Sorbonne, Claude Bernard, como "fixité du milieu intérieur", o termo "homeostase" foi cunhado em 1929 pelo fisiologista de Harvard, Walter Bradford Cannon, significando, em ambos momentos, a tendência ou a habilidade dos organismos vivos em manter a constância do meio interno, através de auto-ajustes nos processos fisiológicos.

Citado por Hipócrates e outros expoentes ao longo da história da medicina, o princípio da similitude (reação vital ou homeostática) encontra fundamentação científica no efeito rebote das drogas ou reação paradoxal do organismo, sendo descrito após a suspensão ou a alteração das doses de inúmeras classes de fármacos modernos que atuam de forma contrária (antagônica, antipática, oposta, paliativa ou enantiopática ${ }^{1}$ ) aos sintomas das doenças, e confirmado em estudos da farmacologia experimental (Teixeira, 1998, 1999).

Ilustrando o anteriormente citado, medicamentos utilizados classicamente para o tratamento da angina pectoris (beta-bloqueadores, bloqueadores dos canais de cálcio, nitratos etc.), que promovem melhora da angina como efeito primário (antianginosos), podem despertar exacerbações na freqüência e na intensidade da dor torácica como efeito secundário do organismo após a suspensão ou a descontinuação das doses, em alguns casos não responsivos a qualquer terapêutica. Drogas utilizadas no controle da hipertensão arterial (agonistas alfa-2 adrenérgicos, beta-bloqueadores, inibidores da ECA, inibidores da MAO, nitratos, nitroprussiato de

\footnotetext{
${ }^{1}$ Enantiopático. Adj. 1. Relativo a enantiopatia. 2. Diz-se do agente que atua opostamente à doença (anti-), anulando ou suprimindo, primariamente, os sintomas incomodativos da mesma.
} 
sódio, hidralazina etc.) podem provocar uma hipertensão arterial rebote, como reação paradoxal do organismo ao estímulo primário. Medicamentos antiarrítmicos (adenosina, amiodarona, beta-bloqueadores, bloqueadores dos canais de cálcio, disopiramida, flecainida, lidocaína, mexiletina, moricizina, procainamida, quinidina, digitálicos etc.) podem despertar, após a interrupção do tratamento, exacerbação rebote das arritmias ventriculares basais. Drogas anticoagulantes (argatroban, bezafibrato, heparina, salicilatos, warfarin, clopridogel etc.), empregadas por seu efeito primário na profilaxia da trombose sangüínea, podem promover complicações trombóticas como efeito secundário ou rebote do organismo. No emprego de drogas psiquiátricas como os ansiolíticos (barbitúricos, benzodiazepinas, carbamatos etc.), sedativos-hipnóticos (barbitúricos, bendodiazepinas, morfina, prometazina, zopiclone etc.), estimulantes do SNC (anfetaminas, cafeína, cocaína, mazindol, metilfenidato etc.), antidepressivos (tricíclicos, inibidores da MAO, inibidores da recaptação de serotonina etc.) ou antipsicóticos (clozapina, fenotiazínicos, haloperidol, pimozida etc.) pode-se observar uma reação paradoxal do organismo no sentido de manter a homeostase orgânica, promovendo sintomas contrários aos esperados na sua utilização terapêutica primária, agravando ainda mais o quadro inicial. Drogas com ação primária antiinflamatória (corticosteróides, ibuprofeno, indometacina, paracetamol, salicilatos etc.) podem desencadear respostas secundárias do organismo, aumentando a inflamação e a concentração plasmática dos seus mediadores. Fármacos com ação primária analgésica (cafeína, bloqueadores dos canais de cálcio, clonidina, ergotamina, metisergida, opióides, salicilatos etc.) podem apresentar importante hiperalgesia como efeito rebote. Diuréticos (furosemida, torasemida, trianterene etc.), utilizados enantiopaticamente para diminuir a volemia 
(edema, hipertensão arterial, ICC etc.) podem causar retenção rebote de sódio e potássio, aumentando a volemia basal. Medicamentos utilizados primariamente como antidispépticos (antiácidos, antagonistas do receptor $\mathrm{H}_{2}$, misoprostol, sucralfato etc.) no tratamento das gastrites e úlceras gastroduodenais, podem promover, após uma diminuição primária da acidez, aumento rebote na produção gástrica de ácido clorídrico, chegando a causar perfuração de úlceras gastroduodenais crônicas. Broncodilatores (broncodilatores adrenérgicos, cromoglicato dissódico, epinefrina, ipatropio, nedocromil, salmeterol, formoterol etc.) utilizados no tratamento da asma brônquica, podem promover piora da broncoconstrição como resposta secundária do organismo à suspensão ou descontinuidade do tratamento. Etc.

Apesar do caráter idiossincrásico do efeito rebote, que se manifesta numa pequena proporção dos indivíduos, evidências científicas atuais alertam para a ocorrência de eventos iatrogênicos graves e fatais em decorrência desta reação paradoxal do organismo, após a administração de algumas classes de drogas enantiopáticas modernas (Teixeira, 2006a): antiinflamatórios seletivos e nãoseletivos da COX-2 ocasionando tromboses fatais (IAM, AVE), secundariamente ao seu efeito primário anticoagulante (Teixeira, 2007c); broncodilatadores de longa duração causando broncoespasmos irreversíveis (Teixeira, 2007d); antidepressivos inibidores da recaptação de serotonina exacerbando ideações suicidas (Teixeira, 2009a) etc.

De forma análoga aos medicamentos homeopáticos, o efeito rebote dos fármacos modernos com ação contrária aos sintomas incomodativos (medicamentos enantiopáticos ou anti-) poderia ser empregado de forma curativa, estimulando reações orgânicas favoráveis (Ex: anticoncepcionais promovendo ovulação e 
concepção rebote em mulheres com esterilidade funcional; imunossupressores despertando imunoestimulação paradoxal em indivíduos imunossuprimidos etc.) (Teixeira, 2003, 2005).

Estudos no campo da pesquisa básica evidenciam a ação das ultradiluições na indução desta resposta terapêutica homeostática, testando os efeitos protetores ou curativos das preparações homeopáticas de diversas toxinas (arsênico, mercúrio, cobre, chumbo etc.) em modelos laboratoriais (animais, vegetais, cultura de células etc.) submetidos à intoxicação experimental com as mesmas substâncias (Linde et al., 1994). Em outras áreas do conhecimento científico moderno, utilizando-se a terminologia "hormesis", a reversão da ação tóxica de inúmeros agentes (inclusive irradiações) é observada no emprego terapêutico destes mesmos agentes em doses infinitesimais, com o intuito de despertar o fenômeno de compensação orgânica ou homeostática (Calabrese e Brain, 2005).

\section{III.1.3. Experimentação patogenética homeopática}

Para adquirir o conhecimento das propriedades curativas das substâncias que permitam a aplicação do princípio da similitude, a homeopatia utiliza a experimentação patogenética homeopática (experimentação no indivíduo sadio) como modelo de pesquisa clínica farmacológica (semelhante aos modernos ensaios pré-clínicos fase 1), valorizando todas as classes de manifestações sintomáticas despertadas pelas substâncias medicinais nos indivíduos humanos (mentais, gerais e físicas), em doses ponderais ou infinitesimais, denominados pela farmacologia moderna como efeitos terapêuticos, adversos ou colaterais das drogas: 
Todos os efeitos patogenéticos de cada medicamento precisam ser conhecidos, isto é, todos os sintomas e alterações mórbidas da saúde que cada um deles é especialmente capaz de provocar no homem sadio devem ser primeiramente observados antes de se poder esperar encontrar e escolher, entre eles, o meio de cura homeopático adequado para a maioria das doenças naturais. (Organon, §106) (Hahnemann, 1995)

Seguindo as premissas estipuladas por Hahnemann (Organon, §105-145), inúmeras substâncias foram experimentadas em todo o mundo segundo protocolos diversos de experimentação patogenética homeopática (Dantas et al., 2007; Teixeira, 2007e), para se adquirir o "conhecimento dos instrumentos destinados à cura das doenças naturais", averiguando-se o "poder patogenético dos medicamentos, a fim de que, quando precisar curar, possa-se escolher, entre eles, um cujas manifestações sintomáticas possam constituir uma doença artificial tão semelhante quanto possível à totalidade dos sintomas principais da doença natural a ser curada".

Todos os sintomas observados nas diversas experimentações patogenéticas dos medicamentos homeopáticos são compilados para a Matéria Médica Homeopática (MMH), seguindo uma sistematização anatômico-funcional (Mental, Cabeça, Olho, Ouvido, Nariz, Face, Boca, Garganta, Estômago, Abdome etc.). Na prática clínica, o médico homeopata utiliza também o Repertório de Sintomas Homeopáticos (RSH), no qual todos os medicamentos homeopáticos que despertaram o mesmo sintoma nas experimentações são agrupados numa mesma rubrica, facilitando a seleção do medicamento homeopático que englobe a totalidade de sintomas característicos do paciente.

\section{III.1.4. Medicamento dinamizado}


Contrariando o modelo farmacológico bioquímico e dose-dependente, causa surpresa no meio científico o fato de que de substâncias ultradiluídas (dinamizadas), em concentrações inferiores ao Número de Avogadro $\left(10^{-24} \mathrm{M}\right)$, possam despertar alguma resposta em sistemas biológicos ou seres vivos, sendo este o principal alvo das críticas ao modelo homeopático.

Com o objetivo inicial de evitar as intoxicações e as agravações que as substâncias aplicadas segundo o princípio da similitude poderiam causar, Hahnemann propôs um método farmacotécnico para a preparação dos medicamentos homeopáticos denominado "dinamização", no qual as substâncias eram diluídas e agitadas sucessivamente com 0 intuito de diminuir o efeito patogenético primário, observando que estas preparações infinitesimais e imponderáveis mobilizavam atividade biológica nas diversas esferas da individualidade humana.

A arte de curar homeopática, mediante um procedimento que lhe é próprio e nunca antes tentado, desenvolve, para seus fins específicos, os poderes medicamentosos internos e não materiais das substâncias em estado cru, em um grau até então jamais observado, pelo qual todas elas se tornam incomensuravelmente "penetrantemente" - eficazes e benéficas, mesmo aquelas que no estado cru não demonstram a menor ação medicamentosa sobre o organismo humano. Essa notável mudança nas qualidades dos corpos naturais, mediante ação mecânica em suas menores partes por atrito e sucussão (partes estas que, por sua vez, são separadas umas das outras, através de uma substância indiferente seca ou líquida), desenvolve as forças dinâmicas latentes e, até então, despercebidas, ocultas, como que adormecidas, que afetam especialmente o princípio vital, influenciando o bem-estar da vida animal. Esse preparo, por conseguinte, chamado dinamizar, potencializar (desenvolvimento da força medicamentosa) e os produtos são dinamizações ou potências em diferentes graus. (Organon, §269) (Hahnemann, 1995) 
De forma simplificada, o método farmacotécnico da dinamização (centesimal Hahnemanniana ou $\mathrm{cH}$ ) consiste em diluições centesimais e sucessivas da substância matriz, acompanhadas de 100 agitações vigorosas (sucussões) por passagem:

1 parte da substância matriz (reinos vegetal, animal ou mineral) + 99 partes de água $\Rightarrow 100$ sucussões $\Rightarrow 1 \mathrm{cH}\left(10^{-2} \mathrm{~mol}\right)$;

1 parte da $1 \mathrm{cH}+99$ partes de água $\Rightarrow 100$ sucussões $\Rightarrow 2 \mathrm{CH}\left(10^{-4} \mathrm{~mol}\right)$;

1 parte da $2 \mathrm{cH}+99$ partes de água $\Rightarrow 100$ sucussões $\Rightarrow 3 \mathrm{CH}\left(10^{-6} \mathrm{~mol}\right)$;

1 parte da $3 \mathrm{cH}+99$ partes de água $\Rightarrow 100$ sucussões $\Rightarrow 4 \mathrm{CH}\left(10^{-8} \mathrm{~mol}\right)$;

Etc.

$>12 \mathrm{cH} \Rightarrow 10^{-24} \mathrm{~mol}$ da substância matriz (Número de Avogadro: 6,02 x 10-23 mol $=1$ molécula-grama) $\Rightarrow$ ausência de matéria ("imponderável”).

Na prática clínica homeopática secular, estas preparações infinitesimais são administradas, freqüentemente, em potências $30 \mathrm{cH}, 200 \mathrm{cH}$ e $1000 \mathrm{cH}$, em doses mínimas de 1-5 glóbulos (impregnados pela solução) ou gotas da solução e aplicados debaixo da língua (sublingual), em vista da rápida absorção local.

A capacidade destas informações medicamentosas, contidas nas doses infinitesimais de substâncias ultradiluídas, em promover alterações nos sistemas orgânicos, de forma análoga às doses ponderais (independente da sua utilização segundo o princípio da similitude terapêutica), tem sido estudada em trabalhos científicos, sejam em modelos físico-químicos ou biológicos de pesquisa.

\section{III.1.4.1. Modelos físico-químicos de pesquisa}


Algumas hipóteses fundamentadas em modelos experimentais físico-químicos buscam uma explicação científica para o fenômeno da transmissão da informação dos efeitos primários das substâncias através destas doses infinitesimais. Dentre elas, citamos as pesquisas que estudam as modificações de natureza eletromagnética da água segundo a eletrodinâmica quântica, na qual a matéria não representaria um aglomerado inerte de moléculas e sim um meio dinâmico, capaz de selecionar e catalisar as reações moleculares de acordo com os diversos campos eletromagnéticos que ocorrem em seu interior. Através de modelos matemáticos e experimentais, especula-se que o campo eletromagnético de um soluto pode gerar certos "domínios de coerência estável" no solvente (com estruturas e vibrações específicas), produzindo aglomerados ou "clusters" de moléculas de água (com tamanhos e geometrias próprios), como uma assinatura eletromagnética da substância na água. Assim sendo, a organização da água seria um processo coerente, reprodutível, e associado a interações eletromagnéticas de longo alcance e baixíssima intensidade, transmitindo repetitivamente a informação eletromagnética do soluto inicialmente diluído e sucussionado pelo processo da dinamização. (Del Giudice et al., 1988; Lo et al., 1996; Lo et al., 2000; Rey, 2003; Chaplin, 2007)

\section{III.1.4.2. Modelos biológicos de pesquisa}

Em 1988, o grupo liderado pelo pesquisador Jacques Benveniste publicou na revista Nature um estudo in vitro que mostrou o efeito das ultradiluições de anticorpos anti-lgE na degranulação de basófilos (Davenas et al., 1988). Este experimento, após sua publicação, foi duramente criticado nas considerações teóricas, na dificuldade de reprodução dos resultados e na metodologia insuficiente, 
segundo uma inspeção organizada pela própria revista no laboratório de Benveniste (Maddox et al., 1988). Num segundo momento, Benveniste et al. (1991a, 1991b) repetiram o ensaio utilizando metodologia e avaliação estatística mais aperfeiçoada, concluindo pela existência do efeito das ultradiluições. Na contraprova, dois outros trabalhos tentaram repetir o estudo inicial, sem obter os resultados anteriores, e os autores concluíram que se tratava de um modelo de difícil reprodução (Ovelgome et al., 1992; Hirst et al., 1993).

Dando continuidade a experimentos prévios (Sainte-Laudy, 1987; Sainte-Laudy e Belon, 1996, 1997), estudos multicêntricos recentes, sob a coordenação de pesquisadores ortodoxos, encontraram resultados semelhantes aos de Benveniste, observando que ultradiluições de histamina inibiram significativamente a degranulação de basófilos induzida por anti-lgE (Belon et al., 1999, 2005; SainteLaudy, 2000; Brown e Ennis, 2001; Guggisberg et al., 2005; Sainte-Laudy e Belon, 2006).

Reproduzindo o modelo de Endler et al. (1994, 1995), que evidenciou, numa série de quatro experimentos, a ação das ultradiluições de tiroxina no retardo da metamorfose e do desenvolvimento de girinos, Guedes et al. (2004) realizaram ensaio semelhante no Departamento de Patologia da Faculdade de Medicina da Universidade de São Paulo, confirmando os dados iniciais.

\section{III.1.5. Individualização do medicamento homeopático}

Segundo Hahnemann, o médico que se intitule um "legítimo artista da cura" deve ser capaz de reconhecer o que deva ser curado em cada caso individualmente 
e compreender o elemento curativo dos medicamentos, adequando-os em qualidade e quantidade às necessidades do enfermo, segundo o princípio da similitude.

Encarando o processo de adoecimento como um enfraquecimento dos mecanismos fisiológicos normais de adaptação e compensação, Hahnemann correlacionou qualquer desequilíbrio interior às diversas manifestações sintomáticas individuais, utilizando esta "totalidade dos sintomas" como o principal e único referencial para diagnosticar o "padecimento da força vital" (predisposição individual, suscetibilidade mórbida ou desequilíbrio homeostático) e para prescrever os medicamentos homeopáticos mais semelhantes à individualidade enferma:

[...] a totalidade de seus sintomas, esse quadro do ser interior da doença que se reflete no exterior, isto é, do padecimento da força vital, deve ser o principal ou o único através do qual a doença dá a conhecer o meio de cura de que ela necessita, o único que pode determinar a escolha do meio de auxílio adequado - em suma, a totalidade dos sintomas deve ser, para o artista da cura, a coisa principal, senão a única que ele, em cada caso de doença, necessita conhecer e afastar através de sua arte, a fim de que a doença seja curada e transformada em saúde. (Organon, §7) (Hahnemann, 1995)

No conjunto dos sinais e sintomas manifestos, a semiologia homeopática seleciona "os mais evidentes, singulares, incomuns e característicos" a cada caso, desprezando os sintomas comuns, gerais e indefinidos pela inerente ausência de poder individualizante nos mesmos:

Nessa procura do meio de cura homeopático específico, isto é, nessa confrontação do conjunto característico dos sinais da doença natural contra a série de sintomas dos medicamentos existentes a fim de encontrar um cujas potências mórbidas artificiais correspondam, por semelhança, ao mal a ser curado, deve-se, seguramente, atentar especialmente e quase que exclusivamente para os sinais e sintomas mais evidentes, singulares, incomuns e próprios (característicos) do caso de doença, pois na série de sintomas produzidos pelo medicamento escolhido, é principalmente a estes que devem corresponder 
sintomas muito semelhantes, a fim de que seja mais conveniente à cura. Os sintomas mais gerais e indefinidos: falta de apetite, dor de cabeça, debilidade, sono inquieto, mal-estar etc., merecem pouca atenção devido ao seu caráter vago, se não puderem ser descritos com mais precisão, pois algo assim geral pode ser observado em quase todas as doenças e medicamentos. (Organon, §7) (Hahnemann, 1995)

Dentre esta totalidade de sintomas característicos e peculiares, classifica as "alterações mentais e psíquicas" como aspectos de alta hierarquia na escolha do medicamento, reiterando a importância e a complexidade da individualização no êxito do tratamento homeopático para qualquer tipo de doença:

Por conseguinte, jamais se poderá curar de acordo com a natureza, isto é, homeopaticamente, se não se observar, simultaneamente, em cada caso individual de doença, mesmo nos casos de doenças agudas, o sintoma das alterações mentais e psíquicas, e se não se escolher, para alívio do doente, entre os medicamentos, uma tal potência morbífica que, a par da semelhança de seus outros sintomas com os da doença, também seja capaz de produzir por si um estado psíquico ou mental semelhante. (Organon, §213) (Hahnemann, 1995)

Associando a individualização medicamentosa à prescrição de "uma única substância medicamentosa simples" por vez, Hahnemann se coloca terminantemente contrário ao uso de mais de um medicamento homeopático simultaneamente, fundamentado na experimentação patogenética homeopática que foi realizada com substâncias simples e únicas, criticando o emprego de meios compostos (mistura de medicamentos ou complexos homeopáticos) sem experimentação patogenética prévia:

Em nenhum caso de tratamento é necessário e, por conseguinte, não é admissível administrar a um doente mais do que uma única e simples substância medicamentosa de cada vez. E inconcebível que possa existir a menor dúvida acerca do que está mais de acordo com a natureza e é mais racional: prescrever uma única substância medicamentosa simples e bem conhecida num caso de doença ou misturar várias diferentes. Na única, 
verdadeira, simples e natural arte de curar, a homeopatia, não é absolutamente permitido dar ao doente duas substâncias medicamentosas diferentes de uma só vez. (Organon, §273) (Hahnemann, 1995)

Como o verdadeiro artista da cura encontra nos medicamentos simples administrados separadamente e sem mistura tudo o que por ventura possa desejar [...], conforme reza o sábio provérbio que diz ser um erro empregar meios compostos quando os simples são suficientes, jamais lhe ocorrerá dar como medicamento mais do que uma substância medicamentosa simples de cada vez e também por ter em vista que, embora os medicamentos simples tivessem sido completamente experimentados quanto a seus efeitos puros peculiares no estado de saúde dos Homens, é impossível prever como duas ou mais substâncias medicamentosas compostas podem mutuamente alterar e obstar a ação da outra sobre o organismo humano [...]. (Organon, §274) (Hahnemann, 1995)

Desta forma, a eficácia e a efetividade de um medicamento homeopático único e individualizado numa determinada condição clínica estão diretamente relacionadas ao seu poder de agir, de forma concomitante, nos distúrbios psíquico-emocionais e clínicos da individualidade enferma (Teixeira, 2008a), assim como em outros aspectos gerais não relacionadas diretamente ao distúrbio orgânico específico.

Resumindo, o tratamento homeopático adequado deve priorizar a individualização do medicamento único segundo os sinais e sintomas mais peculiares e característicos do paciente em seus diversos aspectos constitucionais (mentais, gerais e particulares), permitindo que para uma mesma doença cada indivíduo possa vir a receber medicamentos únicos distintos em momentos distintos, conforme as próprias suscetibilidades físicas, psíquicas, emocionais, alimentares, climáticas etc.

Vale ressaltar que este processo de individualização medicamentosa necessita de um período de acompanhamento regular e variável, em que as respostas às diversas hipóteses medicamentosas (medicamentos únicos 
individualizados) são avaliadas sucessivamente, ajustando-se os medicamentos, as doses e as potências homeopáticas aos diversos aspectos idiossincrásicos do paciente. Até que se atinja o medicamento ideal (simillimum), a substituição das drogas alo-enantiopáticas em uso, desde que imprescindíveis ao equilíbrio das funções vitais orgânicas, deve ser realizada segundo critérios éticos e seguros, evitando-se as iatrogenias conseqüentes à ausência da ação terapêutica homeopática (Teixeira, 2007f). 


\section{III.2. Importância do efeito placebo na pesquisa clínica}

\section{III.2.1. Introdução}

Em qualquer tratamento farmacológico, os efeitos terapêuticos relacionam-se a dois tipos de fatores: específicos (dose, duração, via de administração, farmacodinâmica, farmacocinética, interações medicamentosas etc.) e inespecíficos (história e evolução natural da doença, regressão à média, aspectos sócio-ambientais, variabilidade inter e intra-individual, desejo de melhora, expectativas e crenças no tratamento, relação médico-paciente, características não-farmacológicas do medicamento etc). O fenômeno placebo-nocebo faz parte destes últimos.

Etimologicamente, o termo placebo se origina do latim placeo, placere, que significa agradar, enquanto o termo nocebo se origina do latim nocere, que significa infligir dano. Como um dos precursores dos estudos científicos na área, Shapiro (1964) define placebo como "qualquer procedimento terapêutico que desperta um efeito em um paciente, sintoma, síndrome ou doença, mas que é objetivamente isento de atividade específica para a condição que está sendo tratada".

Apesar dos termos efeito placebo e resposta placebo serem usados indistintamente, alguns autores insistem na diferenciação existente entre eles: enquanto o efeito placebo é atribuído a qualquer melhoria significativa na condição de um grupo de sujeitos que recebeu determinado tratamento placebo (comparativamente à ausência de tratamento), a resposta placebo relaciona-se à mudança individual causada pela intervenção placebo (Hoffman et al., 2005). 
De forma generalizada, entende-se efeito ou resposta placebo como a melhoria dos sintomas e/ou funções fisiológicas do organismo em resposta a fatores supostamente inespecíficos e aparentemente inertes (sugestão verbal ou visual, comprimidos de lactose, injeção de soro fisiológico, cirurgia fictícia etc.), sendo atribuível, comumente, ao significado simbólico que o tratamento exerce na expectativa positiva do paciente (Brody, 2000). Efeito ou resposta nocebo é um fenômeno oposto ao placebo, em que a antecipação e a expectativa por um resultado negativo podem conduzir à agravação de um sintoma ou doença. Exemplos naturais deste fenômeno podem ser observados no impacto de diagnósticos negativos e na desconfiança do paciente pela equipe médica ou por um determinado tratamento (Flaten et al., 1999; Barsky et al., 2002), tendo seus mecanismos neurofisiológicos estudados experimentalmente de forma análoga ao fenômeno placebo (Benedetti et al., 2007).

Segundo De Craen et al. (1999), desde a realização do primeiro ensaio clínico placebo-controlado em 1799, o efeito placebo já trazia importantes ensinamentos para a ciência médica, demonstrando "a maravilhosa e poderosa influência das paixões da mente sobre o estado e os distúrbios do corpo". Com a introdução sistemática dos ensaios clínicos randomizados, duplo-cegos e placebos-controlados, considerados o padrão ouro para avaliar a eficácia dos diversos tratamentos, os relatos freqüentes de mudanças clínicas significativas nos grupos placebo conduziram à difusão de que a intervenção placebo pode apresentar efeitos poderosos em diversas condições clínicas (Kaptchuk, 1998; Quitkin, 1999).

O primeiro estudo importante mostrando os efeitos clínicos positivos do efeito placebo surgiu na década de 50 com Beecher (1955), no qual foram analisados 
numerosos ensaios clínicos com pacientes randomizados e submetidos às intervenções placebos, observando um incremento de melhora numa gama considerável de condições clínicas. Em 1997, Kienle e Kiene evidenciaram os vieses daquela análise inicial, constatando a ausência de grupo controle (pacientes sem tratamento) na grande maioria dos estudos citados, impedindo, dentre outros aspectos, as diferenciações entre efeito placebo, melhoria espontânea ou flutuação dos sintomas (variação temporo-sazonal do padrão de intensidade ou regressão à média).

Exemplificando a regressão à média nos distúrbios dolorosos, observa-se que os indivíduos tendem a experimentar um nível elevado de intensidade dolorosa na abordagem inicial, com diminuição nas abordagens subseqüentes, confundindo este fenômeno estatístico com o verdadeiro efeito placebo. Este viés de interpretação é superado com a presença do grupo controle "sem tratamento" nos ensaios clínicos, parâmetro de avaliação da história natural da doença (Price et al., 2007a).

Dentre os aspectos psicológicos, sociais, ambientais e metodológicos que interagem num ensaio clínico, outros fatores inespecíficos de confusão na estimativa do efeito placebo devem ser considerados, tais como: efeito hawthorne (melhoria que deriva do simples fato do indivíduo ser submetido à observação clínica); efeitos benéficos de tratamento adicional ou da atenção médica aumentada durante o estudo; respostas de delicadeza ou subordinação experimental (sabendo a resposta desejada pelo avaliador, o participante pode reportar benefícios quando estes não ocorrem); viés de escala na medição de resultados subjetivos (escalas diferentes para melhoria e piora da condição) etc. Estes mesmos fatores, quando atuam em sentido oposto, podem induzir o efeito nocebo (Benedetti et al., 2007). 
Pesquisa que avaliou os componentes do efeito placebo da acupuntura na síndrome do intestino irritável pelo período de 3 e 6 semanas (Kaptchuk et al., 2008) mostrou que $28 \%$ dos pacientes na "lista de espera" (efeito hawthorne + evolução natural da doença + regressão à média), 44\% dos pacientes submetidos apenas à intervenção placebo das agulhas e $62 \%$ dos pacientes que receberam a intervenção placebo das agulhas associada à relação médico-paciente diferenciada apresentaram melhoras significativas dos sintomas.

Enquanto algumas revisões estudaram o fenômeno placebo-nocebo em sistemas fisiológicos específicos [imunológico (Pacheco-López et al., 2006), cardiovascular (Olshansky, 2007) etc.], outras metanálises analisaram a resposta placebo em doenças isoladas, utilizando ensaios clínicos controlados (ECC) e constatando sua influência em asma (33 ECC, 1243 pacientes; Joyce et al., 2000), câncer (37 ECC, 1237 pacientes; Chvetzoff e Tannock, 2003), doença de Crohn (32 ECC, 1047 pacientes; Su et al., 2004), síndrome da fadiga crônica (29 ECC, 1016 pacientes; Cho et al., 2005), úlcera duodenal (79 ECC, 3325 pacientes; de Craen et al., 1999), síndrome do intestino irritável (45 ECC, 3193 pacientes; Patel et al., 2005), esclerose múltipla (1 ECC, 953 pacientes; La Mantia et al., 1996), colite ulcerativa (38 ECC; Inycyj et al., 1997), depressão maior (75 ECC; Walsh et al., 2002), mania (20 ECC; Sysko e Walsh, 2007), enxaqueca (32 ECC; Macedo et al., 2008) etc.

Em 2001, Hrobjartsson e Gotzche publicaram uma primeira revisão sistemática com 114 ensaios clínicos randomizados que compararam pacientes tratados e não tratados por placebo, não encontrando evidências generalizadas de que a intervenção placebo poderia causar melhoras clínicas significativas, relatando um possível efeito quando o próprio paciente respondeu a modelos de avaliação 
contínua dos desfechos clínicos (escala analógica visual ou escala de padrão numérico), ao contrário dos modelos de avaliação binária dos resultados.

Acrescentando 52 novos ensaios clínicos randomizados à análise anterior (perfazendo um total de 156 ensaios, com 11.737 pacientes), os mesmos autores publicaram uma segunda revisão sistemática em 2004 (Hrobjartsson e Gotzsche, 2004a, 2004b), encontrando desfechos clínicos semelhantes à análise inicial: das dez condições clínicas investigadas em três ou mais ensaios (dor, obesidade, asma, hipertensão, insônia, náusea, depressão, ansiedade, fobia e tabagismo), a intervenção placebo mostrou melhora significativa apenas nos tratamentos da dor e da fobia, quando avaliadas pelos próprios pacientes através de escalas de avaliação contínua dos desfechos. Por outro lado, não mostrou diferenças significativas em relação ao tamanho da amostra, ao tipo de intervenção placebo (física, psicológica ou farmacológica), ao emprego de escalas de avaliação binária dos desfechos ou ao relato de mudanças por avaliadores externos. Entretanto, no processo de agrupar ensaios heterogêneos, os autores assumiram a responsabilidade de terem excluído grupos respondentes à intervenção placebo.

Estas revisões têm sido questionadas, porque, como os próprios autores admitem, o aspecto da heterogeneidade dos estudos não foi suficientemente valorizada, permitindo a seleção de ensaios clínicos que minimizavam a relação médico-paciente (Spiegel et al., 2001), aspecto fundamental na contextualização da dinâmica do efeito placebo (Slingsby, 2001; Stefano et al., 2001; Kaptchuk et al., 2008). Valorizando esta heterogeneidade como importante viés de análise, Price et al. (2007a) discorreram sobre a limitação destas metanálises em relacionarem, de 
forma sistemática, os determinantes psico-sócio-ambientais à magnitude do efeito placebo.

Numa re-análise qualitativa destas revisões, Wampold et al. (2005) mostraram que, quando as doenças são suscetíveis ao placebo e o desenho dos estudos é adequado para detectar seus efeitos, o efeito placebo foi robusto. Considerando as ambigüidades das distintas análises citadas, Hunsley e Westmacott (2007) concluem pela existência do fenômeno placebo nos ensaios clínicos e que "ele não pode ser simples e sumariamente descartado como sem importância ou irrelevante", apesar de considerarem ocorrer num grupo reduzido de condições clínicas.

Partindo da hipótese questionável de que o efeito placebo somente pode ser constatado através de parâmetros físicos e subjetivos de análise, Meissner et al. (2007) conduziram uma meta-análise com um subgrupo dos ensaios clínicos levantados por Hrobjartsson e Gotzche (2004a, 2004b), selecionando 26 trabalhos que avaliaram o efeito placebo segundo parâmetros de análise físicos conscientes e bioquímicos inconscientes. Apesar da grande heterogeneidade entre os estudos, a intervenção placebo mostrou um incremento positivo significativo nos parâmetros físicos de algumas condições clínicas quando comparada à ausência de intervenção (hipertensão, edema pós-operatório, asma, hiperplasia prostática, resfriado etc.), ao contrário dos parâmetros bioquímicos que mostraram incremento negativo em outras manifestações clínicas (anemia hemorrágica, hipercolesterolemia, hiperprolactinemia, hiperglicemia etc.). Como veremos adiante, a ausência do condicionamento operante inconsciente nestas intervenções placebo foi responsável pela não-observância das alterações nos parâmetros bioquímicos. 
Os diversos fatores envolvidos na relação médico-paciente, do acolhimento ao teor específico das declarações feitas pelo médico, influenciando a expectativa do paciente por uma melhora ou piora do quadro clínico, podem desencadear efeitos significativos no desfecho clínico de qualquer tratamento, alterando a atividade de determinadas regiões cerebrais e a liberação de neurotransmissores específicos. Exemplificando o modus operandi da fisiologia integrativa no processo saúdedoença, estudos experimentais têm sido elaborados com o intuito de mapear e entender o fenômeno placebo-nocebo segundo parâmetros psiconeurofisiológicos.

\section{III.2.2. Mecanismos psíquicos moduladores do fenômeno placebo-nocebo}

\section{III.2.2.1. Condicionamento clássico ou operante inconsciente}

Dentre os mecanismos moduladores do efeito placebo, o condicionamento clássico reivindica que a resposta placebo surge após a exposição repetida do indivíduo a associações de sugestões sensórias neurais (forma e cor dos comprimidos, ambiente do consultório médico etc.) com intervenções de tratamento efetivas (ex. morfina no tratamento da dor). Este modelo não emprega a consciência do fato em si, supondo que após uma repetição de tais associações, segundo um paradigma estritamente behaviorista (pavloviano), as sugestões sensórias neurais possam extrair de forma automática e isolada, após a intervenção placebo, uma resposta semelhante ao tratamento real. Deste modo, o condicionamento estaria relacionado ao fato de que os pacientes são capazes de monitorar rapidamente as flutuações no estado dos órgãos internos pelo feedback sensorial, através da 
percepção visceral ou somática, e o grau de abrangência desta percepção teria influência proporcional na resposta placebo. De forma análoga, o efeito nocebo seria conseqüência do condicionamento operante inconsciente prévio por experiências terapêuticas negativas (Geers et al., 2006; Meissner et al., 2007).

Durante o tratamento placebo, a convicção do paciente em estar sendo tratado (conseqüente a uma experiência prévia positiva) pode resultar em atenção seletiva para a melhora do sintoma (Allan e Siegel, 2002) que, por sua vez, age como recompensa e reforço positivo, precedendo mudanças na função autonômica. Assim sendo, pode ocorrer uma aprendizagem visceral secundária a um mecanismo similar ao condicionamento operante inconsciente (Miller, 1969), em que a recompensa é interiormente providenciada (de la Fuente-Fernandez et al., 2004). O rápido feedback neural dos órgãos internos para centros cerebrais corticais envolvidos no controle autonômico anularia o processo de adoecimento físico ajustado idealmente para este tipo de modificação central (Cechetto e Saper, 1987).

Contrariando a análise de Meissner et al. (2007) citada inicialmente, o condicionamento operante inconsciente é capaz de mediar a resposta placebo em diversas funções fisiológicas inconscientes de diversos sistemas (inclusive nos parâmetros bioquímicos).

Estudando o condicionamento operante no sistema imunológico, McKenzie (1896) mostrou que algumas pessoas alérgicas a pólen de flores apresentavam reações alérgicas em contato com flores artificiais. Ader e Cohen (1982), após o condicionamento de ratos com solução de sacarina contendo drogas imunossupressoras (ciclofosfamida), observaram imunossupressão placebo dos animais após a administração da solução isolada. Repetindo este modelo em 
humanos, Olness e Ader (1992) condicionaram crianças portadoras de lupus eritematoso sistêmico com a administração de ciclofosfamida associada a estímulos gustativos e olfativos, observando imunossupressão placebo durante o curso de doze meses da administração isolada dos mesmos estimulantes do paladar e do olfato. A imunossupressão placebo (leucopenia periférica) foi observada em pacientes com esclerose múltipla, após a administração isolada de xarope de aniz, utilizado no pré-condicionamento em associação com ciclofosfamida (Giang et al., 1996). Após a indução de imunossupressão condicionada por solução de sacarina com ciclosporina A, observou-se imunossupressão placebo (alterações na IL-2 e INF- $\gamma$ ) após a administração isolada da solução de sacarina (Goebel et al., 2002).

Em relação ao sistema cardiovascular, Benedetti et al. $(1998,1999 a)$ mostraram que o condicionamento prévio pela repetição de doses analgésicas de buprenorfina, indutoras de hipoventilação moderada como efeito colateral, permitiu que a posterior analgesia placebo mimetizasse a mesma depressão respiratória. Esta resposta respiratória colateral placebo foi totalmente bloqueada pela naloxona (antagonista opióide), indicando ter sido mediada pelos mesmos opióides endógenos da resposta placebo analgésica principal. Pollo et al. (2003), após observarem que a analgesia placebo em voluntários sadios foi acompanhada pela redução dos batimentos cardíacos, constataram que ambos os fenômenos placebo foram revertidos pela naloxona, enquanto o propranolol (beta-bloqueador) antagonizou apenas a bradicardia.

No sistema endócrino, após o pré-condicionamento com sumatripan, um agonista serotoninérgico que estimula a secreção do hormônio do crescimento $(\mathrm{GH})$ e inibe a 
secreção do cortisol, a administração do placebo estimulou os mesmos efeitos da droga ativa (Benedetti et al., 2003).

\section{III.2.2.2. Expectativa consciente}

Um importante mecanismo psicológico modulador do efeito placebo é a expectativa consciente dos pacientes nas perspectivas de melhoras clínicas, que pode ser incrementada pelas sugestões verbais que acompanham a administração do placebo.

Estudos experimentais mostraram que a expectativa consciente sugestionada pela intervenção placebo pode afetar parâmetros físicos de órgãos periféricos, como funções gástricas e pulmonares (Leigh et al., 2003; Meissner et al., 2005; Levine et al., 2006).

Um modelo experimental peculiar tem avaliado o impacto clínico das expectativas positiva e negativa isoladamente, revelando ou ocultando ao paciente a administração ou a suspensão do tratamento melhor escolhido (open-hidden paradigm). Diversos estudos têm mostrado que um mesmo tratamento mostra-se mais efetivo quando é revelado (open) do que quando é ocultado (hidden) ao paciente, indicando que a expectativa positiva (efeito psicológico) desempenha um papel crucial no desfecho do tratamento (Levine et al., 1981; Amanzio et al., 2001; Colloca et al., 2004). Considerando que o desfecho clínico secundário a um tratamento não revelado (hidden) representa o efeito específico do tratamento em si, livre de qualquer contaminação psicológica, o resultado de um tratamento revelado (open) representa a somatória dos efeitos específicos e psicológicos. A diferença entre os efeitos dos tratamentos revelados e ocultados tem sido considerada como a 
representação do componente placebo, embora nenhum placebo tenha sido administrado (Amanzio et al., 2001; Price, 2001; Colloca et al., 2004). De forma análoga, a expectativa negativa foi avaliada com a revelação ou a ocultação da suspensão do tratamento indicado (Colloca et al., 2004), mostrando que o grupo que sabia da interrupção apresentou piora dos sintomas de forma mais intensa e antecipada ao outro grupo. A diferença entre os efeitos da suspensão do tratamento nos dois grupos representaria o efeito nocebo.

Em estudo duplo-cego com um ano de acompanhamento, McRae et al. (2004) compararam a resposta de pacientes submetidos ao transplante de mesencéfalo fetal (tratamento experimental para doença de Parkinson) com pacientes submetidos à cirurgia placebo, observando melhoras clínicas e psicológicas semelhantes em todos os pacientes que acreditavam estarem recebendo intervenção efetiva (expectativa positiva), independente do grupo. Pacientes que perceberam estarem alocados no grupo ativo (tratamento revelado) apresentaram um incremento no resultado global, que se manteve por todo o período de estudo.

Em dois estudos semelhantes, o efeito da acupuntura verdadeira foi comparado com a acupuntura placebo em diferentes condições dolorosas (enxaqueca, lombalgia crônica e osteoartirte), juntamente com o efeito da expectativa dos pacientes pelos desfechos terapêuticos. Pacientes que acreditavam terem sido alocados no grupo ativo apresentaram melhoras clínicas superiores àqueles que acreditavam pertencer ao grupo placebo (Bausell et al., 2005). Pacientes com elevada expectativa pelos efeitos da acupuntura apresentaram maiores benefícios clínicos do que aqueles descrentes com o tratamento, independente do grupo (Linde et al., 2005). 


\section{III.2.2.3. Expectativa consciente + Condicionamento operante inconsciente}

Apesar dos defensores incondicionais de um ou outro mecanismo, expectativa consciente e condicionamento operante inconsciente são complementares. Estudos indicam que ambos os mecanismos são coadjuvantes na modulação da analgesia placebo, um amplificando a resposta do outro (Amanzio e Benedetti, 1999; Price et al., 1999; De Pascalis et al., 2002; Benedetti et al., 2003).

Em pacientes com doença de Parkinson, tem-se demonstrado que a expectativa e a experiência vivencial de benefícios clínicos durante a intervenção placebo (condicionamento) ativam o circuito de recompensa cerebral (de la FuenteFernandez e Stoessl, 2002b; de la Fuente-Fernandez et al., 2004), reiterando a hipótese de que ambos mecanismos estão envolvidos na mediação do efeito placebo.

Amanzio e Benedetti (1999) estudaram a interação entre estes mecanismos em indivíduos no pós-operatório de cirurgia odontológica, segundo quatro tipos de intervenções: "expectativa" (infusão salina com sugestão verbal de que era um "poderoso analgésico"), "condicionamento" (dois dias de condicionamento em que morfina foi associada com infusão salina, dizendo aos sujeitos que era um "antibiótico para limpar o sangue"), "expectativa + condicionamento" (associando os dois aspectos anteriores) e "nenhum tratamento" (controle). Comparados ao grupo controle, os grupos "expectativa" e "condicionamento" mostraram cada qual um pequeno mas significativo aumento na tolerância à dor, enquanto o grupo que recebeu "expectativa + condicionamento" apresentou tolerância à dor duas vezes maior que os grupos das intervenções isoladas. 
Buscando comparar as respostas placebo analgésicas do condicionamento com diferentes tipos de sugestão, Pollo et al. (2001) administraram a pacientes no pósoperatório de cirurgias odontológicas, após pré-condicionamento com bupremorfina por três dias consecutivos, solução salina placebo pelo mesmo período, em associação com três tipos de sugestão verbal: nenhuma sugestão (controle), sugestão incerta de que a solução poderia ou não ter um potente analgésico (administração duplo-cega ou expectativa incerta) e sugestão de que a solução era um potente analgésico (expectativa positiva). O efeito placebo foi mensurado pela necessidade de bupremorfina nos três dias de tratamento placebo. Em comparação ao grupo controle (condicionamento apenas), a necessidade de bupremorfina diminuiu em 20,8\% na administração duplo-cega (condicionamento + expectativa incerta) e em 33,8\% no grupo da sugestão verbal positiva (condicionamento + expectativa positiva).

Com o propósito de delinear as contribuições da expectativa e do condicionamento na resposta placebo, sugestões verbais positivas e negativas foram usadas em estudo clínico para testar os efeitos placebo e nocebo, respectivamente, em três modelos experimentais distintos: placebo ou ketorolac intravenosos num modelo experimental de dor isquêmica do braço; diferentes formas de intervenção placebo em distúrbios motores de pacientes portadores de doença de Parkinson; e expectativa e/ou condicionamento na secreção hormonal. Os pesquisadores observaram que expectativas positivas ou negativas induzidas verbalmente foram efetivas nas mudanças correspondentes em processos fisiológicos conscientes de ambos os modelos [sugestões verbais positivas promovendo analgesia e melhora 
motora (efeito placebo) e sugestões verbais negativas gerando hiperalgesia e piora motora (efeito nocebo)] (Benedetti et al., 2003).

Enquanto a sugestão verbal isolada não foi efetiva na modulação das secreções de hormônio do crescimento e cortisol (processos fisiológicos inconscientes), o précondicionamento com sumatripan permitiu que a posterior administração do placebo reproduzisse os efeitos da droga, mesmo com sugestões verbais contrárias. Os autores concluíram que as respostas placebo de funções fisiológicas inconscientes (secreção hormonal) são mediadas pelo condicionamento operante, ao passo que a expectativa interfere em processos fisiológicos conscientes (dor e função motora), associada ou não ao condicionamento (Benedetti et al., 2003).

$\mathrm{Na}$ proposta de um modelo que adiciona o desejo à expectativa consciente (modelo desejo-expectativa), estudos sugerem que a resposta placebo seria codeterminada por metas, desejos, expectativas e os respectivos sentimentos emocionais que as acompanham (Verne et al., 2003; Vase et al., 2003, 2005; Geers et al., 2005). Acrescentando o condicionamento operante a este modelo, experimentos mostraram que a percepção somática das mudanças internas facilita a retro-alimentação destes fatores ao longo do tempo, selecionando sentimentos emocionais mais positivos (ou menos negativos) na perspectiva de evitar experiências aversivas ou propiciar experiências desejáveis (Geers et al., 2006). De forma análoga, uma dinâmica mental negativista atuaria em sentido oposto, estimulando a resposta nocebo. 


\section{III.2.3. Mecanismos neurofisiológicos mediadores do fenômeno placebo-nocebo}

\section{III.2.3.1. Fenômenos dolorosos}

A resposta placebo analgésica teria como mediadores principais os peptídeos opiódes endógenos cerebrais (endorfinas), que atuariam nos mesmos sítios dos receptores dos analgésicos opióides exógenos (morfina) distribuídos em regiões cerebrais específicas (tronco encefálico, tálamo e medula espinhal), atingindo grandes concentrações no líquido espinhal. Esta hipótese foi confirmada por uma série de experimentos que evidenciaram o bloqueio da resposta analgésica placebo pela infusão de naloxona, antagonista dos receptores opióides (Levine et al., 1978; Lipman et al., 1990; Benedetti, 1996; Amanzio e Benedetti, 1999; Benedetti et al., 1999b, Amanzio et al., 2001; Sauro e Greenberg, 2005).

Dentre os mecanismos moduladores da analgesia placebo, postula-se que a expectativa pela diminuição da dor deve estimular os opióides endógenos, enquanto o condicionamento operante deve ativar subsistemas específicos insensíveis a naloxona (Amanzio e Benedetti, 1999). O efeito placebo analgésico ainda pode ser mediado pela estimulação dos circuitos dopaminérgicos (de la Fuente-Fernandez e Stoessl, 2002b), e pela inibição dos circuitos prostaglandina-dependentes (Amanzio e Benedetti, 1999) e colecistoquinase-dependentes (Benedetti et al., 1995; Benedetti, 1996, 1997).

Segundo a visão neuroquímica do fenômeno placebo-nocebo, expectativas ou sugestões verbais positivas estimulariam o sistema dos opióides endógenos responsável pelo efeito placebo analgésico, enquanto expectativas ou sugestões 
verbais negativas diminuiriam a atividade deste sistema e estimulariam o sistema das colecistoquinases (CCK), responsáveis pelo efeito nocebo hiperálgico.

Utilizando um modelo experimental de dor induzida pelo calor (Petrovic et al., 2002), os efeitos neurofisiológicos das analgesias opióide e placebo foram estudados em nove voluntários sadios através de tomografia por emissão de positrons (PET), comparando-se as áreas cerebrais ativadas. Tanto o placebo quanto o agonista opióide (remifentanil) ativaram áreas cerebrais específicas, sugerindo uma relação direta entre ambos os tipos de analgesia: córtex pré-frontal medial (córtex cingular anterior ou cíngulo anterior), córtex pré-frontal orbitofrontal (córtex somatosensorial) e sistema opióide do tronco encefálico (substância cinzenta periaquedutal, SCP ou PAG). No grupo da analgesia placebo, o aumento da atividade no cíngulo anterior ocorreu somente nos pacientes classificados independentemente como placebosrespondedores.

Em dois experimentos com ressonância nuclear magnética funcional (RNMF), Wager et al. (2004) observaram diminuição da dor com a aplicação de um creme placebo nos braços de pacientes submetidos a choques elétricos, coincidente ao aumento da atividade cerebral no córtex pré-frontal orbitofrontal, córtex pré-frontal dorsolateral, córtex pré-frontal medial e SCP (regiões relacionadas à modulação emocional da expectativa e da antecipação do fenômeno doloroso), e diminuição da atividade cerebral no tálamo, córtex insular anterior e córtex cingular anterior (regiões relacionadas à dor).

De forma análoga, Price et al. (2007b) mapearam a atividade cerebral (RNMF) logo após a administração de analgesia placebo em pacientes com síndrome do intestino irritável, observando o efeito da sugestão verbal (expectativa positiva) na 
diminuição da atividade neural das áreas cerebrais relacionadas à dor (tálamo, insula e córtex cingular anterior), acompanhada pelo aumento da atividade cerebral nas áreas responsáveis pela modulação emocional da dor (córtex cingular anterior, amígdala lateral e SCP).

Aprofundando o entendimento do circuito neural da analgesia placebo, Fricchione e Stefano (2005) salientam que caberia ao córtex pré-frontal dorsolateral a propriedade de manter e refinar representações internas das expectativas, ativando posteriormente as demais regiões cerebrais. Expectativas positivas relacionadas à analgesia estimulariam então o córtex pré-frontal dorsolateral que ativaria simultaneamente o córtex pré-frontal medial, o córtex pré-frontal orbitofrontal e o sistema opióide do tronco encefálico (SCP), áreas responsáveis pela modulação da dor emocional, desencadeando a analgesia placebo.

Associando ambas as expectativas num mesmo estudo eletroencefalográfico, Koyama et al. (2005) observaram aumento da atividade cerebral nas regiões do tálamo, insula e córtex cingular anterior com a expectativa negativa hiperálgica, enquanto que a expectativa positiva analgésica diminuiu a atividade nas regiões cerebrais do córtex somatosensorial, córtex insular anterior e córtex cingular anterior.

Aplicando um modelo experimental de dor isquêmica em membros a voluntários sadios, Benedetti et al. (2006) executaram um detalhado estudo neurofarmacológico do efeito nocebo hiperalgésico, encontrando que a administração oral de uma substância inerte, juntamente com a sugestão verbal de aumento da dor (expectativa negativa), induziu hiperalgesia e hiperatividade no eixo hipotálamo-pituitária-adrenal (HPA), mensurada através das concentrações plasmáticas dos hormônios adrenocorticotrófico (ACTH) e cortisol. Como ambos os efeitos foram bloqueados pelo 
diazepan (ansiolítico), os autores sugerem que a ansiedade tem um papel importante nos mesmos. Em contraste, a administração da proglumida (Benedetti et al., 1997), um antagonista da CCK que não é antagonizado pela naloxona, bloqueou completamente a hiperalgesia nocebo, sem atuar no eixo HPA, sugerindo um envolvimento específico da CCK no componente hiperalgésico do efeito nocebo, sem relação com o componente ansiolítico. Vale ressaltar que proglumida e diazepan não mostraram propriedades analgésicas em estados dolorosos comuns, atuando somente na hiperalgesia nocebo. Estes dados sugerem que a CCK transforma a ansiedade em dor e que os antagonistas da CCK previnem este efeito, potencializando o efeito placebo analgésico sem atuar no sistema dos opióides endógenos. Similarmente, estes efeitos também foram observados em modelos experimentais com animais (Andre et al., 2005; Hebb et al., 2005).

Em relação ao efeito nocebo hiperálgico, outros estudos experimentais tem demonstrado que a percepção da intensidade do estímulo doloroso é amplificada após uma expectativa (sugestão verbal) negativa de aumento da dor (Koyama et al., 1998; Price, 2000; Dannecker et al., 2003) e que diversas regiões cerebrais (córtex préfrontal orbitofrontal, córtex cingular anterior e córtex insular anterior) apresentam atividade aumentada durante a antecipação da dor (Chua et al., 1999; Hsieh et al., 1999; Ploghaus et al., 1999; Porro et al., 2002; Porro et al., 2003; Koyama et al., 2005; Lorenz et al., 2005; Keltner et al., 2006). Estas alterações cerebrais mostraram-se opostas às encontradas durante a indução de uma expectativa positiva de diminuição da dor.

Keltner et al. (2006) observaram que o nível de intensidade da expectativa dolorosa térmica (efeito nocebo hiperálgico) altera a intensidade da percepção da 
dor, juntamente com a ativação de regiões do cérebro visualizadas na RNMF: expectativa negativa secundária a um estímulo visual nocivo de alta intensidade ativou distintas regiões do cérebro (tálamo, córtex insular anterior, córtex cingular anterior, córtex somatosensorial, amígdala, estriado ventral e os núcleos cuneiformes no tronco encefálico) em intensidade superior a um estímulo visual nocivo de baixa intensidade.

\section{III.2.3.2. Doença de Parkinson}

Em 2002, Pollo et al. estudaram a influência das expectativas positiva e negativa na melhora motora em pacientes portadores de doença de Parkinson que tinham implantado eletrodos no núcleo subtalâmico (NST) para estimulação cerebral profunda, tratamento paliativo para os sintomas motores da doença (tremor, rigidez muscular e lentificação dos movimentos). Empregando um analisador de movimentos, avaliaram o efeito da estimulação subtalâmica sobre a velocidade do movimento da mão direita, observando maior rapidez dos movimentos quando a estimulação foi acompanhada de expectativa positiva de melhora (efeito placebo) e lentificação com expectativa negativa (efeito nocebo). Vale ressaltar que estes efeitos opostos ocorreram em minutos, indicando que a expectativa induz mudanças neurais rapidamente. Confirmando estes resultados, outros estudos indicaram que, dentre os sintomas motores, a bradicinesia é mais sensível à sugestão verbal do que o tremor e a rigidez, desconhecendo-se seu mecanismo neurofisiológico (Benedetti et al., 2003, 2007; Mercado et al., 2006).

Em modelo experimental semelhante, Benedetti et al. (2004) investigaram a relação do efeito placebo com a atividade elétrica intranuclear de neurônios únicos 
do NST, em vista da sua importância no funcionamento dos núcleos da base (estriado ventral). A atividade elétrica dos neurônios foi medida pré e pós-placebo, mostrando que os pacientes que tiveram resposta clínica ao placebo (diminuição da rigidez muscular) apresentaram atividade elétrica neuronal reduzida em comparação ao estado pré-placebo. Os autores inferiram que esta melhora estaria relacionada à diminuição da atividade neuronal no NST, que coincide com o aumento da dopamina estriatal dorsal. Desta forma, o efeito placebo induziria a secreção de dopamina (DA) no estriado dorsal, inibindo a atividade do NST e propiciando a melhora motora perceptível. Neste contexto, a expectativa positiva do paciente teria papel importante no desencadeamento do processo (Pollo et al., 2002).

Utilizando PET com $\left({ }^{11} \mathrm{C}\right)$ raclopride, um antagonista dos receptores dopaminérgicos, de la Fuente-Fernandez et al. (2001) estudaram o efeito da intervenção placebo em seis pacientes portadores de doença de Parkinson. Em resposta às injeções subcutâneas de solução salina, foram liberadas quantidades significativas de DA endógena, presumivelmente de sinapses dos núcleos caudado e putamen (estriado dorsal), desalojando o raclopride marcado dos receptores dopaminérgicos da região. Esta liberação de DA foi maior em pacientes que perceberam melhoras com o placebo (placebos-respondedores) do que naqueles que não perceberam. $\mathrm{O}$ aumento de DA endógena liberada no estriado dorsal sugere que o efeito placebo em doença de Parkinson é mediado pela ativação dos depósitos de DA nigrostriatal com subseqüentes efeitos sinápticos, embora este sistema esteja danificado no Parkinson. O placebo induziu uma mudança na concentração do antagonista raclopride comparável ao de doses terapêuticas de levodopa. Os autores acreditam que a expectativa relacionada à antecipação do benefício terapêutico e 
acompanhada pela liberação de DA endógena pode ser um fenômeno comum ao efeito placebo, em qualquer distúrbio clínico placebo-responsivo.

Como predito em estudo prévio (de la Fuente-Fernandez et al., 2002a), mudanças na PET relacionadas ao placebo foram encontradas também nos núcleos da base (estriado ventral) com um declínio da ligação do raclopride aos receptores dopaminérgicos em proporção similar ao observado nos núcleos caudado e putamen (estriado dorsal) (de la Fuente-Fernandez et al., 2004). Porém, neste novo estudo ocorreu uma diferença singular: ao contrário do que aconteceu no estriado dorsal, os investigadores encontraram que ambos os pacientes, tanto os que referiram melhora clínica com o placebo quanto os que não referiram, mostraram aumentos semelhantes nos níveis de DA no estriado ventral. Desta forma, inferiram que a DA liberada no estriado ventral em resposta ao placebo reflete apenas a expectativa de recompensa clínica em lugar da recompensa em si, que é a própria percepção do benefício clínico. Isto pode ser explicado em vista do estriado ventral estar menos relacionado, comparativamente ao estriado dorsal, ao desempenho motor como um resultado de benefício clínico ou recompensa, e mais relacionado à expectativa de recompensa. Expectativas podem influenciar os sistemas nigrostriatal e mesolímbico de formas distintas. Segundo de la Fuente-Fernandez e Stoessl (2002b), os sistemas mesolímbico e estriado ventral podem ser mais propensos para "ligar-desligar" respostas dopaminérgicas, enquanto o sistema nigrostriatal do estriado dorsal pode ser mais propenso na responsividade dopaminérgica, como no ajuste de movimentos finos. 


\section{III.2.3.3. Depressão}

Estima-se que $25 \%$ a $60 \%$ dos pacientes depressivos tratados com placebo apresentam redução dos sintomas (Greenberg et al., 1992; Quitkin, 1999).

Em metanálise que avaliou a eficácia dos antidepressivos versus placebos no tratamento da depressão, Kirsch e Sapirstein (1998) concluíram que $25 \%$ do efeito terapêutico dos antidepressivos são devidos à substância ativa, 50\% ao efeito placebo e os restantes $25 \%$ a fatores inespecíficos. Desta forma, $75 \%$ da eficácia dos antidepressivos estariam relacionados a fatores inespecíficos.

Em estudo semelhante, a magnitude da resposta placebo no tratamento da depressão maior foi avaliada em revisão sistemática de 75 estudos placeboscontrolados (Walsh et al., 2002), mostrando que o grupo placebo apresentou um efeito terapêutico médio de $29,7 \%$ e o grupo ativo de $50,1 \%$. Chegando a valores semelhantes, Sysko e Walsh (2007) avaliaram o efeito placebo no tratamento da mania bipolar (lítio e risperidona), encontrando uma resposta terapêutica média de $31,2 \%$ no grupo placebo e de $55,9 \%$ no grupo ativo.

Com o intuito de distinguir as mudanças na atividade cerebral que o tratamento placebo produziria em pacientes depressivos, Leuchter et al. (2002) conduziram um ensaio clínico com 51 indivíduos portadores de depressão maior que receberam antidepressivos (fluoxetina ou venlafaxina) ou placebo durante nove semanas, sendo então classificados como "respondedores ao medicamento", "respondedores ao placebo", "não-respondedores ao medicamento" e "não-respondedores ao placebo". Utilizando a eletroencefalografia quantitativa (EEGQ) como marcador da atividade cerebral pré e pós-tratamentos, observaram que enquanto o grupo pré-tratamento não apresentou diferenças eletroencefalográficas quantitativas, os "respondedores 
ao placebo" mostraram um aumento significativo da cordance no córtex pré-frontal, que é uma medida da atividade eletroencefalográfica que apresenta forte correlação com a perfusão cerebral quantificada pela PET. Esta alteração foi observada precocemente no curso do tratamento e não foi vista no grupo dos "nãorespondedores" nem no grupo dos "respondedores ao medicamento", que mostrou diminuição da cordance pré-frontal.

Mayberg et al. (2002), empregando PET no estudo da resposta placebo no metabolismo regional da glicose cerebral em 17 pacientes masculinos com depressão maior, conduziram um ensaio clínico duplo-cego e placebo-controlado em que os efeitos tomográficos da fluoxetina foram comparados aos do placebo. A remissão dos sintomas foi observada em oito (quatro de cada grupo) dos 15 indivíduos que completaram o estudo. A resposta placebo mostrou estar associada ao aumento no metabolismo da glicose no córtex pré-frontal, cíngulo anterior, córtex parietal, insula posterior e cíngulo posterior, além da diminuição do metabolismo no cíngulo subgenual, para-hipocampo e tálamo. Os que responderam à fluoxetina mostraram um padrão metabólico similar, sugerindo um possível envolvimento da serotonina nos efeitos antidepressivos da indução placebo (Benedetti et al., 2005). Petrovic et al. (2002), em estudo anteriormente citado, observaram mudanças semelhantes no metabolismo da glicose cerebral.

\section{III.2.3.4. Efeito placebo e resposta ao estresse}

Induzindo convicção e expectativa consciente, o placebo prepara um campo receptivo para o consolo que acompanha o sentimento de segurança transmitido por um profissional solidário. O resultado é o alívio da dor angustiante e uma redução na 
resposta ao estresse, como conseqüência de uma modulação promotora da saúde pelo sistema nervoso amigdaliano-hipotalâmico-simpático e pelos sistemas de resposta ao estresse límbico-hipotalâmico-pituitário-adrenal. O efeito placebo poderia então beneficiar o funcionamento do órgão-alvo e a saúde global do indivíduo pelo poder curativo da convicção e da expectativa consciente positiva (Fricchione e Stefano, 2005).

\section{III.2.4. Integração dos mecanismos psiconeurofisiológicos no fenômeno placebo-nocebo}

Segundo Benedetti et al. (2007), existem evidências suficientes para afirmar que a expectativa positiva ativa os opióides endógenos e as interconexões moduladoras da dor, diminuindo a transmissão nos trajetos dolorosos, induzindo a liberação de dopamina no estriado e afetando a atividade de neurônios únicos no núcleo subtalâmico. Na depressão, existe alguma evidência experimental que diferentes regiões cerebrais relacionadas à serotonina estariam envolvidas na resposta placebo. Por outro lado, evidências experimentais recentes indicam que sugestões verbais negativas induzem ansiedade antecipatória sobre o provável aumento da dor, ativando o sistema colecistoquinérgico facilitador da transmissão dolorosa e diminuindo a atividade dos opióides endógenos, promovendo hiperalgesia nocebo. $\mathrm{O}$ efeito nocebo também mostrou afetar experimentalmente outras condições clínicas, como a doença de Parkinson.

Baseados no fato de que a expectativa pode estar estritamente relacionada a uma ativação tônica dos neurônios dopaminérgicos que se projetam para os estriado 
dorsal, estriado ventral e córtex pré-frontal, de la Fuente-Fernandez et al. (2004) propuseram o seguinte mecanismo psiconeurofisiológico para explicar o efeito placebo: quando qualquer tipo de intervenção placebo cria uma expectativa positiva de recompensa, neurônios do córtex pré-frontal são ativados pela probabilidade de ocorrência da mesma; estas células, por sua vez, enviam impulsos glutamatérgicos excitatórios diretos e impulsos gabaérgicos inibitórios indiretos aos neurônios dopaminérgicos distribuídos ao longo do corpo, estando na combinação destes sinais o requisito para sua ativação tônica. Além disso, neurônios do córtex pré-frontal, estriado dorsal e estriado ventral podem exibir ativações tônicas durante a expectativa de recompensa. Existe também a ativação dopaminérgica fásica que acontece após a recompensa efetiva, sendo muito forte quando esta surge inesperadamente. Desta forma, a incerteza parece aumentar a expectativa neste circuito de recompensa cerebral.

Unindo ambos os mecanismos, Fricchione e Stefano (2005) propõem que a convicção em uma expectativa positiva pode afetar uma mudança na atividade do córtex pré-frontal, cuja retro-alimentação estimula o fluxo de dopamina do fascículo medial para o tegumento ventral. Receptores no estriado dorsal (núcleos caudado e putamen), no estriado ventral (núcleos da base) e nos córtex pré-frontal medial, orbitofrontal e dorsolateral registrarão esta mudança tônica de dopamina. Ao mesmo tempo, a ativação do córtex pré-frontal por expectativa positiva pode estimular também o sistema opióide do tronco cerebral (SCP).

Acrescentando a reação ao estresse e o óxido nítrico (NO) ao mecanismo de resposta placebo, os autores explicam-na através do seguinte modelo psiconeurofisiológico: iniciando pela convicção de melhora gerada no córtex pré- 
frontal pelo estímulo sensório talâmico, a mensagem de expectativa positiva é transmitida por tratos córtico-límbico-estriatais para os núcleos da base, por onde vários mediadores podem trabalhar via NO para liberar o fluxo de dopamina para o movimento, a recompensa e os circuitos de motivação. Desta forma, o poder da convicção e da expectativa consciente positiva ao qual o efeito placebo está relacionado alteraria o padrão neuroquímico em áreas chaves do cérebro responsáveis pelo movimento (corpo estriado), prazer (núcleos da base) e dor física ou psicológica (cíngulo anterior), desencadeando uma resposta placebo evidente na doença de Parkinson, nos transtornos depressivos e nos distúrbios dolorosos, respectivamente. Entretanto, o sistema dopaminérgico mesolímbico-mesocortical também sofre controle superior dos eixos de resposta ao estresse (hipotálamopituitária-adrenal e amígdala lateral hipotalâmica-locus coeruleus). Desta forma, sugerem que convicção e expectativa positiva podem modificar a resposta ao estresse e conduzir o efeito placebo para muitos distúrbios psicossomáticos como hipertensão, angina, doença intestinal inflamatória e asma, dentre outras (Fricchione e Stefano, 2005).

\section{III.2.5. Probabilidade e sensibilidade individual ao efeito placebo}

Com o intuito de mensurar a probabilidade de resposta ao placebo, alguns estudos experimentais controlados (grupo controle "sem tratamento") têm sido desenvolvidos principalmente no campo da analgesia placebo. Em ensaio clínico para dor secundária a procedimentos odontológicos, Levine et al. (1979) observaram resposta placebo analgésica em $39 \%$ dos indivíduos tratados. Em estudo que utilizou 
um modelo de dor isquêmica aplicada a voluntários sadios, Benedetti (1996) encontrou que $26,9 \%$ dos sujeitos responderam a analgesia placebo, quando comparados a extenso grupo controle de indivíduos não-tratados e não-responsivos. Estudo envolvendo dor cutânea por aquecimento em mão mostrou que $56 \%$ dos indivíduos responderam ao tratamento placebo, com 10\% de melhora em relação à dor inicial (Petrovic et al., 2002).

Desde o início dos estudos, os autores assumem que há "respondedores" e "não-respondedores" ao placebo, e que os respondedores representam a minoria dos indivíduos. Estudos experimentais têm demonstrado que um pequeno subgrupo exibe uma resposta placebo de grande magnitude. Em todo grupo placebo também tende a existir um subgrupo de indivíduos que não mostra nenhuma resposta evidente à intervenção placebo, ou seja, que não apresenta melhora estatisticamente significativa em relação aos indivíduos do grupo sem tratamento (Levine et al., 1979; Benedetti, 1996; Leuchter et al., 2002).

Em pacientes portadores de depressão maior, Leuchter et al. (2004) constataram que, comparativamente aos "não-respondedores", os "respondedores" ao placebo apresentavam diminuição na atividade do córtex fronto-central, aumento na rapidez do processamento cognitivo e menor incidência de insônia tardia, sugerindo um conjunto de características clínicas, neurofisiológicas e cognitivas para identificar os indivíduos sensíveis à resposta placebo.

$\mathrm{Na}$ busca pelos traços da personalidade que definiriam um indivíduo como responsivo ou não-responsivo ao efeito placebo, algumas características psicológicas como sugestionabilidade, aquiescência, ansiedade e hipnotizabilidade foram pesquisadas no passado, sem resultados experimentais consistentes. Estudo 
recente com grupo controle encontrou uma relação positiva entre sugestionabilidade e magnitude da analgesia placebo (De Pascalis et al., 2002).

Segundo o paradoxo que indivíduos responsivos ao placebo num determinado tipo de estudo podem não ser responsivos em outros semelhantes, Hoffman et al. (2005) enfatizam que não existem dados suficientes para concluir que a responsividade à intervenção placebo se relaciona às características ou traços fixos da personalidade, propondo que outros tipos de estudo serão necessários para determinar se e quais aspectos da personalidade apresentam relação direta com a sensibilidade ao efeito placebo.

\section{III.2.6. Magnitude do efeito placebo}

Alguns estudos evidenciam que a magnitude da resposta relaciona-se ao tipo de intervenção placebo, por afetar a expectativa do paciente. Em virtude da magnitude dos efeitos colaterais que apresentam, placebos "ativos" (drogas clássicas sem atuação no sistema fisiológico em estudo) são mais eficazes que os "inertes” (pílulas de açúcar), enquanto a resposta placebo é proporcional à conhecida eficácia do fármaco com o qual está sendo comparado (Kirsch e Sapirstein, 1998). Pacientes submetidos a cirurgias placebo, que acreditavam estar recebendo intervenções ativas, apresentaram melhoras semelhantes aos submetidos a cirurgias reais (McRae et al., 2004). Deste fato, poderíamos inferir que a terapia pluralista (polifarmácia) estimularia efeito placebo mais poderoso do que a monoterapia, assim como um tratamento não-convencional, considerado popularmente como "fraco" e 
"de longo prazo", deveria estimular um efeito placebo menos intenso do que um tratamento alo-enantiopático "forte" e "rápido".

Empregando grupos controle, diversos estudos encontraram que a magnitude média do efeito placebo analgésico para os indivíduos está em torno de 2/10 unidades na escala analógica visual (EAV) ou na escala de padrão numérico, ou seja, 20\% de variação de melhora placebo (Gracely et al., 1983; Levine e Gordon, 1984; Benedetti et al., 1995, 1998; Amanzio et al., 2001; Price, 2001).

Utilizando injeção subcutânea de capsaicina como indutora da dor, Benedetti et al. (1999b) encontraram que a aplicação de um creme placebo causou uma redução média na dor de $46 \%$ a $57 \%$, em comparação ao grupo controle. Metanálise realizada para investigar a analgesia placebo (Sauro e Greenberg, 2005) evidenciou que a administração de uma substância placebo acompanhada da sugestão verbal positiva de que poderia aliviar a dor produziu redução significativa na dor experimentalmente induzida (injeção subcutânea de capsaicina ou isquemia local) ou pós-operatória (procedimento odontológico). A média do grupo tratado com placebo foi $81 \%$ melhor do que no grupo não tratado.

$\mathrm{Na}$ fase de expectativa pela recompensa, antes da recompensa ou benefício clínico em si, há incerteza, e isto é refletido em ativação contínua do sistema dopaminérgico, que pode ser maximizada quando a probabilidade de recompensa for estimada em 5\%. Com esta probabilidade de recompensa, 29\% das células dopaminérgicas são ativadas tonicamente (Fiorillo et al., 2003).

As distintas revisões sistemáticas que avaliaram o efeito placebo em condições clínicas específicas encontraram diferentes porcentagens de resposta, com uma média em torno de 25\%: asma (6\%; Joyce et al., 2000), câncer ( $9 \%$ na dor, 20\% no 
apetite e 2,4\% na diminuição do tumor; Chvetzoff e Tannock, 2003), doença de Crohn (19\%; Su et al., 2004), síndrome da fadiga crônica (19,6\%; Cho et al., 2005), úlcera duodenal (36,2 a 44,2\%; de Craen et al., 1999), síndrome do intestino irritável (40\%; Patel et al., 2005), colite ulcerativa (26,7\%; Inycyj et al., 1997), depressão maior (29,7\%; Walsh et al., 2002), mania (31,2\%; Sysko e Walsh, 2007), enxaqueca (21\%; Macedo et al., 2008) etc.

\section{III.2.7. Sensibilidade individual versus Magnitude do efeito placebo}

Buscando relacionar as variáveis "sensibilidade individual" e "magnitude da resposta" frente ao placebo, Benedetti (1996) concentrou seus estudos no subgrupo dos sensíveis ou respondedores à analgesia placebo, encontrando um efeito placebo médio de 5/10 unidades na escala de padrão numérico, ou seja, 50\% de variação de melhora placebo. Este resultado foi semelhante aos de Levine et al. (1979) que, num estudo não controlado com dor odontológica pós-operatória, encontraram 3,3/10 cm de melhora média na escala analógica visual de dor dos respondedores ao placebo em comparação aos não-respondedores (33\% de variação de melhora placebo). Apesar da ausência de grupo controle, este mesmo estudo mostrou que o grupo dos não-respondedores apresentou níveis de dor idênticos ao grupo que não recebeu tratamento (controle). 


\section{III.2.8. Efeito placebo versus Gravidade do sintoma}

Comumente, relaciona-se a resposta analgésica placebo a casos de dor moderada, questionando sua eficácia em dores de intensidade grave; no entanto, evidências experimentais sugerem justamente o oposto. Em estudo com dor pósoperatória, Levine et al. (1979) encontraram uma forte e significante correlação positiva entre a gravidade da dor pré-tratamento e a resposta ao tratamento placebo. Outros estudos apontam para esta correlação, evidenciando que a intervenção placebo apresentou um efeito analgésico significativo em casos clínicos severos, como as dores pós-operatórias odontológicas e de toracotomia (Gracely et al., 1983; Benedetti et al., 1995, 1998). Buscando uma explicação fisiológica para este paradoxo, Hoffman (2005) sugere que o estresse relacionado às dores severas é um fator independente que incrementa a resposta analgésica placebo, como citado anteriormente.

\section{III.2.9. Duração da intervenção versus Duração e/ou Magnitude do efeito placebo}

Praticamente, os estudos citados não investigaram a relação entre a duração da intervenção placebo e a duração e/ou magnitude da resposta placebo, aspecto fundamental na abordagem dos ensaios clínico placebos-controlados de longa duração, necessários para a avaliação dos diversos tratamentos empregados em doenças crônicas.

Em vista deste hiato experimental, muitos questionamentos precisam ser respondidos, a fim de que possamos distinguir os efeitos específicos dos 
inespecíficos: Qual a duração do fenômeno placebo-nocebo após uma intervenção isolada? O efeito placebo-nocebo é diretamente proporcional à duração da respectiva intervenção? Qual a relação do fenômeno placebo-nocebo com mudanças psico-sócio-ambientais cotidianas? Como o fenômeno placebo-nocebo interfere na evolução a médio-longo prazo das doenças crônicas?

No presente trabalho, buscou-se responder alguns destes quesitos segundo a abordagem semiológico-terapêutica homeopática e o desenho de estudo empregado.

\section{III.2.10. Mensuração do fenômeno placebo-nocebo na pesquisa clínica}

Para que se possa diferenciar e mensurar os diversos aspectos envolvidos no fenômeno placebo-nocebo, de caráter multifatorial e com grande heterogeneidade, os ensaios clínicos desenhados para este propósito deveriam incorporar avaliações sobre perspectivas diversas, a fim de que as interpretações do fenômeno sejam mais seguras e menos sujeitas a vieses de análise e interpretação (Price et al., 2007).

Na tentativa de avaliar a influência de um possível condicionamento operante inconsciente nos resultados, importaria levantar a experiência prévia dos pacientes em procedimentos semelhantes. Perguntas simples sobre as expectativas conscientes dos pacientes nos desfechos clínicos de qualquer tratamento deveriam ser incorporadas aos protocolos clínicos, tais como: o que você espera do tratamento? em qual grupo (ativo ou placebo) você acredita que foi alocado? 
Sugestões verbais às quais o paciente esteja submetido (familiares, amigos, colegas, médicos etc.), também podem alterar a expectativa quanto ao tratamento e deveriam ser investigadas.

O desenho dos estudos clínicos segundo o paradigma open-hidden, que descarta a influência dos aspectos psicológicos (expectativa + sugestão verbal) nos desfechos clínicos, permite que os efeitos específicos do tratamento possam ser diferenciados destes.

Na ausência de um grupo controle (história natural; sem tratamento), outros aspectos inespecíficos que possam influenciar o fenômeno placebo-nocebo também deverão ser investigados, tais como: mudanças sazonais; regressão à média; efeito hawthorne; efeitos benéficos de tratamento adicional ou da atenção médica; respostas de delicadeza ou subordinação ao médico; viés de escala na medição de resultados subjetivos etc.

\section{III.2.11. Aspectos éticos da pesquisa humana com placebo}

Com o propósito de defender os interesses éticos de pacientes submetidos a pesquisas clínicas (WHO, 1993), desrespeitados em situações tais como nos estudos placebos-controlados com pacientes HIV positivos na África e na Ásia na década de 1990 (Lurie e Wolfe, 1997; Whalen et al., 1997; Wawer et al., 1999), a World Medical Association (WMA), em outubro de 2000, aprovou uma revisão da Declaração de Helsinque (WMA, 2000), em que novos fármacos deveriam ser testados frente aos melhores tratamentos disponíveis, restringindo o uso do placebo 
apenas a situações em que não existissem outras terapêuticas disponíveis para comparar com o procedimento em estudo.

Pelas restrições limitativas ao emprego do placebo, esta revisão gerou polêmicas e críticas (Temple e Ellenberg, 2000), fazendo com que a Food and Drug Administration (FDA), em março de 2001, publicasse um guia para a aceitação de ensaios clínicos em que declarava não incorporar as referidas mudanças nos seus regulamentos (FDA, 2001).

Em vista destas pressões, provavelmente associadas às publicações das pesquisas que evidenciam a existência do efeito placebo, a Assembléia Geral da WMA, reunida em Washington em 2002, adicionou a seguinte nota de esclarecimento ao polêmico artigo 29 da Declaração de Helsinque (WMA, 2002):

A WMA reafirma aqui a sua posição, em que deve ser tomado extremo cuidado no uso de ensaios controlados com placebo e que, em geral, esta metodologia deve ser usada unicamente na ausência de existência de terapêutica comprovada. Contudo, um ensaio controlado com placebo pode ser eticamente aceitável, mesmo havendo terapêutica comprovada disponível, nas seguintes circunstâncias:

- quando, por razões metodológicas, o seu uso seja necessário para determinar a eficácia ou a segurança de um método profilático ou terapêutico; ou,

- quando um método profilático, diagnóstico ou terapêutico estiver investigando uma situação clínica menos grave e os doentes que recebam placebo não fiquem sujeitos a qualquer risco adicional de dano grave ou irreversível.

Todas as outras provisões da Declaração de Helsinque devem ser atendidas, especialmente a necessidade para uma revisão ética e científica apropriada.

De forma análoga, o Conselho para Assuntos Éticos e Jurídicos da American Medical Association (AMA) estabeleceu recomendações para o uso de cirurgiasplacebo em estudos que visam avaliar a eficácia de procedimentos cirúrgicos (Tenery et al., 2002). 


\section{III.3. Contribuições da pesquisa clínica em imunoterapia}

\section{ao desenho de ensaios clínicos homeopáticos}

\section{III.3.1. Imunoterapia e rinite alérgica}

Como citado inicialmente, a rinite alérgica (perene e sazonal) apresenta largo espectro de manifestações clínicas, interferindo na qualidade de vida e no desempenho profissional dos portadores, com um número significante de quadros graves resistentes aos tratamentos farmacológicos convencionais. Nestes casos, a imunoterapia mostra-se efetiva na melhora dos sintomas clínicos e na redução da utilização de medicamentos concomitantes, com a persistência dos efeitos benéficos após a suspensão do tratamento.

A imunoterapia subcutânea (ITSC) emprega injeções semanais com doses crescentes de extratos de alérgenos até atingir uma dose de manutenção, que passa a ser administrada mensalmente, por um período de 2-3 anos. Com este tratamento em longo prazo, observam-se alterações nos títulos dos anticorpos séricos, redução na sensibilidade cutânea e nasal aos alérgenos, e alteração nas subpopulações dos linfócitos $T(T h 2 \Rightarrow$ Th1), sugerindo uma modulação na resposta imune local alergênica. Ao contrário dos tratamentos farmacológicos, a imunoterapia apresenta o potencial de modificar o processo e o curso natural das doenças alérgicas, representando uma opção terapêutica "curativa" (Durham et al., 1999; Möller et al., 2002; Passalacqua e Canonica, 2002).

No entanto, os eventos adversos locais e sistêmicos (incluindo ocasionais fatalidades) são um fator limitante ao emprego generalizado da imunoterapia 
subcutânea, estando sua aplicação restrita aos centros especializados, com a recomendação de observação dos pacientes durante uma hora após a injeção, a fim de monitorar e reverter possíveis iatrogenias graves. Estas medidas preventivas tornam o tratamento dispendioso, incentivando o estudo de outras vias de administração dos alérgenos segundo o princípio da identidade curativa (aequalia aequalibus curentur).

Enquanto a administração oral mostrou-se ineficaz (presumivelmente pela baixa absorção dos alérgenos), a efetividade da administração nasal foi descartada perante a magnitude dos efeitos colaterais locais (rinorréia, obstrução nasal e espirros). Segundo os modernos consensos (van Cauwenberge et al., 2000; Alvares et al., 2006; Scading et al., 2008), a via de administração sublingual tem-se mostrado como uma alternativa à imunoterapia subcutânea, em vista da satisfatória absorção dos alérgenos pela mucosa sublingual (eficácia terapêutica) e da ausência de efeitos colaterais locais e sistêmicos (segurança clínica).

O paradigma do modelo de tratamento imunoterápico apresenta inúmeras analogias com os pressupostos do modelo de tratamento homeopático, dentre eles a utilização do princípio de cura pela identidade terapêutica (aequalia aequalibus curentur), que busca estimular uma reação homeostática específica do sistema imunológico a fatores alergênicos individualizados através da administração repetida e prolongada de ultradiluições destes mesmos agentes (doses homeopáticas), os quais, em doses fortes, despertam os mesmos sintomas da doença em indivíduos sadios (experimentação no indivíduo sadio). Acrescentemos a via sublingual de administração do estímulo terapêutico, com o intuito de minimizar as reações adversas locais e sistêmicas (patogenesia e agravação homeopática) observadas na 
administração de doses pela via nasal e subcutânea (com maior poder antigênico primário), e teremos elementos suficientes para inferir uma enorme semelhança entre ambas terapêuticas.

Pela ausência de referências na literatura sobre o tratamento homeopático individualizado na rinite alérgica perene e pela semelhança entre os paradigmas citados, buscaremos subsídios nos recentes estudos clínicos placebos-controlados que empregaram a imunoterapia subcutânea e, principalmente, a imunoterapia sublingual (ITSL) no tratamento da rinite alérgica, para fundamentar algumas das premissas estipuladas na elaboração do desenho e na análise estatística deste ensaio clínico homeopático placebo-controlado de longa duração.

\section{III.3.2. Imunoterapia sublingual no tratamento da rinite alérgica}

Para avaliar a eficácia da imunoterapia sublingual (ITSL) no tratamento da rinite alérgica, Wilson et al. (Wilson et al., 2003, 2005) conduziram revisão sistemática dos ensaios clínicos randomizados e placebos-controlados publicados entre 1966-2002, selecionando 22 estudos (484 intervenções ativas versus 475 intervenções placebos; média de 44 participantes/estudo) para metanálise, comparando as reduções nos escores de sintomas e nos requerimentos de medicamentos antialérgicos nos grupos ativos e placebos, assim como as alterações nos marcadores imunológicos e nos testes de sensibilidade. Os ensaios também foram agrupados e analisados segundo características específicas: rinite perene versus sazonal; crianças versus adultos; doses dos alérgenos (< $5 \mathrm{mcg}$ versus $5-20$ mcg versus > 20mcg); duração da imunoterapia (< 6 meses versus $6-12$ meses versus $>12$ meses). Nas análises 
globais, incluindo os 22 ensaios clínicos, a diferença média padronizada (DMP) do grupo ativo para os escores dos sintomas (DMP $-0,42$; IC $95 \%-0,69$ a $-0,15 ; P=$ 0,002) e para os requerimentos de antialérgicos (DMP -0,43; IC 95\%-0,63 a -0,23; $P$ $=0,00003)$ foi significativamente maior do que no grupo placebo; dos marcadores imunológicos, observou-se aumento consistente da IgG4 alérgeno-específica no grupo ativo; não foi possível avaliar os testes de sensibilidade da pele devido à variabilidade na metodologia. Nas avaliações específicas, a imunoterapia sublingual mostrou efeitos semelhantes na rinite perene e sazonal; efeitos benéficos consistentes e significativos em adultos, e não significativos em crianças; quatro tratamentos com duração superior a 12 meses mostraram tendência a aumentar o efeito terapêutico $(P=0,07)$, com a média de 53 participantes/estudo e taxa de abandono chegando a 50\% após dois anos de tratamento (Guez et al., 2000). Em dois estudos que compararam os efeitos da imunoterapia subcutânea e sublingual, as respostas foram similares (Quirino et al., 1996; Mungan et al., 1999). Ao contrário dos estudos com ITSC, nenhum dos estudos reportou efeitos colaterais significantes durante a ITSL.

Limitando a análise a pacientes entre 3-18 anos, que não mostraram resposta significativa na metanálise anterior, Penagos et al. (2006) realizaram um estudo sistemático dos ensaios clínicos randomizados e placebos-controlados publicados entre 1966-2006, que empregaram ITSL no tratamento da rinite alérgica em crianças, selecionando 10 estudos para metanálise, comparando a DMP do escore de sintomas e da utilização de medicamentos de resgate nos grupos ativos e placebos. Dos 577 pacientes incluídos inicialmente nos estudos, 484 terminaram os mesmos e puderam ser avaliados (245 ITSL versus 239 placebo). Apesar da relevante 
heterogeneidade dos estudos, observou-se redução significativa no escore dos sintomas (DMP -0,59; IC 95\% 0,10 a 1,01; $P=0,02$ ) e na utilização das drogas (DMP -0,76; IC 95\% 0,06 a 1,46; $P=0,03$ ) após a imunoterapia. Numa subanálise, a ITSL mostrou-se significativamente efetiva com período de tratamento superior a 18 meses.

A eficácia clínica da ITSL no tratamento da asma, associada ou não a outras doenças alérgicas, foi avaliada numa revisão sistemática de 119 ensaios clínicos placebos-controlados, com posterior metanálise de 25 estudos (1706 pacientes) (Calamita et al., 2006). Em nove estudos (303 pacientes), os sintomas asmáticos foram analisados separadamente de outros sintomas alérgicos (rinite e conjuntivite), mostrando que ITSL não diminuiu o escore de sintomas significativamente (DMP 0,38; IC $95 \%-0,79$ a 0,03 ). Dez estudos (360 pacientes) analisaram os sintomas asmáticos em associação com outros sintomas alérgicos, mostrando uma redução significativa nos sintomas alérgicos (DMP -1,18; IC 95\% -1,93 a -0,43). O uso de medicamentos para sintomas alérgicos associados (asma + rinite + conjuntivite) foi analisado em 10 estudos (488 pacientes), mostrando redução significativa no consumo (DMP -0,82; IC 95\% -1,25 a -0,39), enquanto seis estudos (254 pacientes) não mostraram redução significativa no consumo de medicamentos exclusivos para asma (DMP -0.91; IC 95\% -1,94 a 0,12). A associação do escore de sintomas alérgicos (asma + rinite + conjuntivite) com a necessidade de medicamentos antialérgicos foi avaliada em sete estudos (724 pacientes), mostrando diminuição significativa (DMP -0.79; IC 95\% -1,34 a -0,24). Os testes de função respiratória mostraram melhora significativa em seis estudos (186 pacientes). A análise combinada de todos os parâmetros (sintomas asmáticos, testes de função 
respiratória, consumo de medicamentos etc.) sugere que a ITSL reduz a expressão da asma.

Atendo-nos à relação entre o período de tratamento da rinite alérgica com ITSL e a melhora clínica significativa (escore de sintomas e emprego de medicamentos antialérgicos), ensaios clínicos randomizados e placebos-controlados recentes ampliam a base de evidências.

Em ensaio clínico randomizado e placebo-controlado com dois anos de duração, Tonnel et al. (2004) estudaram a eficácia da ITSL na rinite alérgica perene por ácaro doméstico (Dermatophagoides pteronyssinus e D. farinae) em 32 pacientes (9-38 anos; 15 ITLS versus 17 placebo) com a média do escore de sintomas iniciais maior do que $60 \%$ da pontuação máxima (100/168). Com a permanência de 18 pacientes (10 ITSL versus 8 placebo) até o término do estudo (44\% de abandono), foram observadas melhoras significativas no grupo ativo após o primeiro ano de tratamento no escore total de sintomas $(P<0.03)$, na obstrução $(P<0.01)$ e no prurido nasal $(P$ < 0.01) em relação ao escore basal, com manutenção da melhora ao final do segundo ano.

Estudo multicêntrico alemão, com interessante desenho misto (estudo placebocontrolado seguido por estudo aberto) que permite aumentar o tempo de tratamento com diminuição das taxas de abandono, foi desenvolvido por Bufe et al. (2004), aplicando ITSL em crianças portadoras de rinite alérgica sazonal. Numa fase inicial (fechada), um total de 161 crianças (82 ITSL versus 79 placebo) com rinoconjuntivite sazonal, das quais 68 também apresentavam sintomas de asma, foram alocadas num ensaio clínico duplo-cego e placebo-controlado com um ano de duração e administração de doses diárias de ITSL ou placebo; após este período, numa fase 
secundária (aberta), todas as crianças continuaram recebendo ITSL até completarem três anos de tratamento imunoterápico (tratamento adicional de 2 anos para o grupo ativo e de 3 anos para o grupo placebo iniciais). Como desfecho primário, o índice clínico (combinação entre o escore de sintomas e o requerimento de medicamentos antialérgicos) foi medido durante as estações de pólen (maio-setembro); mensurações dos testes de sensibilidade dermatológica (prick test ou teste cutâneo) e anticorpos específicos também foram realizados anualmente. Nos pacientes que receberam ITSL, observou-se uma resposta do sistema imune semelhante à ITSC, com aumento significativo de $\lg E$ alérgenos-específicas e subclasses de $\lg$ ( $\lg$ G-4 e lgG-1); não foram observadas mudanças significativas no teste cutâneo. Cento e trinta e duas crianças (68 ITSL versus 64 placebo; 18\% de abandono) completaram a primeira fase do estudo (ensaio clínico placebo-controlado, com um ano de duração), não sendo observadas mudanças significativas no índice clínico entre os grupos ativo e placebo. Na segunda fase do estudo (estudo aberto até completar três anos de tratamento imunoterápico dos pacientes), a análise dos subgrupos dos pacientes segundo o modelo de medidas repetidas mostrou melhoras clínicas significativas apenas nos pacientes com rinite severa ao final dos três anos de tratamento (103 pacientes, 36\% de abandono; $30 \%$ de melhora com três anos de ITSL versus 10\% de melhora com um ano de placebo).

Outro desenho de estudo peculiar com imunoterapia avaliou a eficácia da ITSL e da ITSC na rinoconjuntivite sazonal em adultos, segundo o modelo randomizado, placebo-controlado, duplo-cego e duplo-simulado (Khinchi et al., 2004). Após um ano de acompanhamento basal (com monitoramento pré-tratamento dos escores basais de sintomas e de emprego de antialérgicos durante uma estação de pólen), setenta e 
um pacientes adultos foram alocados em três grupos de tratamento pelo período de dois anos: grupo ITSL (recebendo ITSL em gotas + injeção placebo), grupo ITSC (ITSC + gotas placebo) e grupo placebo (injeção placebo + gotas placebo). Todos os pacientes tinham acesso livre a anti-histamínico de resgate. Questionário de qualidade de vida (SF-36) foi respondido após cada uma das três estações de pólen consecutivas. Comparativamente aos escores basais, a eficácia clínica dos tratamentos foi mensurada separadamente segundo os escores de sintomas e do requerimento de drogas de resgate após cada estação de pólen, com um fator de ajuste proporcional à quantidade de pólen de cada estação. Dos 71 pacientes randomizados inicialmente, 58 foram avaliados durante a primeira estação de pólen (21 ITSC, 18 ITSL e 19 placebo; 18\% de abandono) e 48 durante a segunda estação (19 ITSC, 14 ITSL e 15 placebo; 32\% de abandono), sem diferença significativa de abandono entre os três grupos. A avaliação da eficácia foi realizada apenas após o primeiro ano de tratamento, em vista da escassez de pólen na segunda estação de tratamento (pacientes apresentaram poucos sintomas e utilizaram poucas drogas de resgate). O grupo ITSL apresentou melhora no escore de sintomas (DMP 0,78; IC 95\% 0,6 a 1,06; $P<0,01$ ) e no requerimento de drogas de escape (DMP 1,03; IC $95 \% 0,77$ a 1,$75 ; P<0,05)$, com metade da gravidade da doença do grupo placebo. O grupo ITSC apresentou melhora no escore de sintomas (DMP 0,48; IC 95\% 0,28 a 1,02; $P<0,001$ ) e no requerimento de drogas de escape (DMP 0,78; IC 95\% 0,3 a 2,0; $P<0,002$ ), com $1 / 3$ da gravidade da doença do grupo placebo. Não foram encontradas diferenças significativas entre os tipos de imunoterapia. No questionário de qualidade de vida, não foram encontradas diferenças significativas entre as 
diversas fases do estudo (pré-tratamento, um e dois anos de tratamento) em nenhum dos domínios do SF-36, nos três grupos de tratamento.

\section{III.3.3. Pressupostos dos ensaios clínicos placebos-controlados com imunoterapia}

A recente recomendação da Organização Mundial de Alergia (WAO) para padronizar os ensaios clínicos controlados com imunoterapia em alergias respiratórias (Canonica et al., 2007) estipula determinados parâmetros que podem ser estendidos aos desenhos de ensaios clínicos homeopáticos, em vista das semelhanças epistemológicas dos referidos modelos. Como premissas básicas, teríamos:

- Ensaios clínicos randomizados, duplo-cegos e placebos-controlados (em vista das variabilidades na suscetibilidade alérgica e nas manifestações clínicas individuais, assim como na subjetividade da natureza dos sintomas);

- Número elevado de pacientes;

- Pela especificidade da resposta imunológica aos diversos alérgenos, os estudos ideais devem avaliar a eficácia da imunoterapia monoantigênica em pacientes sensibilizados por um único alérgeno;

- O tempo de duração do estudo deve ser proporcional à intensidade dos sintomas e a cronicidade da doença (eficácia é proporcional à duração do tratamento), sugerindo-se um período de acompanhamento de 3-6 anos para que os efeitos preventivos possam ser apropriadamente avaliados; 
- A avaliação da resposta específica ao tratamento deve basear-se no escore dos sintomas locais da doença alérgica (desfecho primário) e no escore dos sintomas sistêmicos da síndrome alérgica (desfecho secundário); os sintomas podem ser avaliados continuamente pelo próprio paciente através de uma escala analógica visual (EAV) e anotado num diário;

- Medicamento de resgate será fornecido por todo o período de análise e a necessidade de utilização será outro desfecho primário na avaliação da eficácia do tratamento, juntamente com os sintomas específicos da doença;

- Em vista de a alergia ser uma doença sistêmica (síndrome alérgica), com sintomas subjetivos e inespecíficos, questionário de qualidade de vida deve ser incorporado à avaliação global do tratamento (desfecho secundário);

- Nenhum exame subsidiário ou parâmetro paraclínico (teste cutâneo ou de provocação específica, fluxo expiratório máximo, espirometria, rinoscopia, parâmetros imunológicos etc.) poderá substituir os desfechos primários citados anteriormente, podendo ser utilizados apenas como desfechos secundários;

- O relato dos eventos adversos ou efeitos colaterais devem constar em todos os protocolos;

- A análise de subgrupos pode ser executada após a análise principal, com a finalidade de confirmar parâmetros exploratórios em desenhos de estudos específicos;

- A análise dos resultados deve mostrar a significância estatística (IC 95\% e $P<0,05)$ juntamente com a diferença entre a variação média dos grupos (\% de variação ou magnitude da resposta); 
- Por ser um tratamento de longa duração, observa-se um grande índice de desistências e desligamentos (abandono), tornando inviável a análise estatística "por intenção de tratamento" (intention-to-treat) e viabilizando a análise "por protocolo";

- A magnitude da resposta ao tratamento deve se relacionar à redução dos escores de sintomas dos grupos placebo e ativo (em comparação aos valores basais), aceitando-se uma eficácia clínica mínima do grupo ativo de $20 \%$ acima da resposta do grupo placebo (semelhante aos antihistamínicos). 


\section{III.4. Pesquisa clínica em homeopatia}

\section{III.4.1. Panorama geral}

Em vista dos aspectos singulares do modelo homeopático, que fazem da homeopatia uma prática terapêutica individualizante por excelência, pode-se vislumbrar as dificuldades encontradas na elaboração de desenhos de ensaios clínicos que contemplem as premissas da metodologia científica clássica (Teixeira, 2001b, 2004, 2006, 2008b).

Numa primeira metanálise realizada em 1991, Kleijnen et al. (1991) analisaram a qualidade metodológica de 107 ensaios clínicos homeopáticos placeboscontrolados, concluindo que apenas 22 trabalhos (20\%) foram considerados de qualidade metodológica satisfatória (escore mínimo de 55/100 pontos). Dentre estes 22 trabalhos, 15 (68\%) mostraram eficácia do tratamento homeopático frente ao placebo. Em vista destes resultados, concluíram haver evidência positiva, mas não suficiente para se tirarem conclusões definitivas.

De forma análoga, Linde et al. (1997) realizaram uma revisão sistemática de 89 ensaios clínicos homeopáticos placebos-controlados, concluindo que os resultados observados no tratamento homeopático não eram efeitos-placebo (resultados 2,45 vezes superior da homeopatia frente ao placebo). Devido à quantidade insuficiente de ensaios clínicos de uma mesma entidade nosológica para que metanálises específicas fossem realizadas, os autores agruparam todos os tipos de trabalhos homeopáticos na sua revisão, sendo criticados por terem adotado esta metodologia. 
Conforme discutimos anteriormente, algumas premissas devem ser seguidas para que atinjamos os resultados desejados no tratamento homeopático, estando na individualização do medicamento segundo a totalidade de sintomas característicos do paciente uma condição sine qua non ao desenho de estudos epistemologicamente corretos. Desta forma, para uma mesma doença, cada indivíduo enfermo poderá receber medicamentos homeopáticos distintos, não existindo medicamentos particulares para condições clínicas específicas (Kleijnen, 2000; Oberbaum et al., 2003).

Diversos ensaios clínicos que desrespeitaram esta individualização do tratamento, administrando o mesmo medicamento para diversos indivíduos portadores de uma mesma doença, não mostraram resultados significativos (exemplificado no emprego indiscriminado da Arnica montana para processos inflamatórios) (Ernst et al., 1998), ferindo a racionalidade científica do modelo homeopático. Buscando avaliar a eficácia da homeopatia em estudos que priorizam a individualização do tratamento como padrão-ouro da epidemiologia clínica homeopática, uma metanálise foi realizada com 32 ensaios clínicos placeboscontrolados, de qualidades metodológicas variáveis, sugerindo que o tratamento homeopático individualizado é mais efetivo que o placebo (Linde e Melchart, 1998).

Revisando os ensaios clínicos controlados homeopáticos, Jonas et al. (2003) relataram que os estudos clínicos e laboratoriais demonstram resultados que contestam a racionalidade contemporânea da medicina. Destacaram as três revisões sistemáticas citadas anteriormente (Kleijnen et al., 1991; Linde et al., 1997; Linde e Melchart, 1998) como as que utilizaram métodos de avaliação condizentes com a homeopatia, reportando efeitos superiores do tratamento homeopático frente ao 
placebo. Descartando as metanálises com metodologia questionável ou que menosprezaram as peculiaridades intrínsecas ao modelo (Walach, 1997; Cucherat et al., 2000; Egger et al., 2001), realçaram as evidências científicas da eficácia do tratamento homeopático na influenza (Vickers e Smith, 2000), nas alergias (Wiesenauer e Lüdtke, 1996; Taylor et al., 2000) e na diarréia infantil (Jacobs et al., 2003), não encontrando respostas satisfatórias nos ensaios clínicos que avaliaram a resposta homeopática frente à prevenção da cefaléia (Ernst, 1999) e da influenza (Vickers e Smith, 2000). Discorrendo sobre a falta de evidências conclusivas para avaliar o tratamento homeopático em outras condições clínicas, defendem que a homeopatia merece "uma oportunidade isenta de preconceitos para demonstrar o seu valor, utilizando princípios baseados em evidências".

Ensaios clínicos placebos-controlados isolados evidenciaram a eficácia do tratamento homeopático individualizado na enxaqueca (Straumshein et al., 2000), na fibromialgia (Bell et al., 2004), no transtorno do déficit de atenção e hiperatividade (Frei et al., 2005, 2007), e na prevenção das infecções do trato respiratório superior (Steinsbekk et al., 2005).

Como proposta terapêutica individualizada e globalizante, a homeopatia pode acrescentar eficiência e segurança à medicina convencional atuando de forma curativa e preventiva, diminuindo as manifestações sintomáticas e a predisposição ao adoecer, com baixo custo e efeitos colaterais mínimos (Buxton, 2000; van Haselen, 2000; Jain, 2003; Trichard et al., 2003, 2005; Guthlin, 2005).

Importa ressaltar que a semiologia homeopática clássica busca diagnosticar as diversas suscetibilidades do enfermo (biológicas, climáticas, alimentares, psíquicas, emocionais etc.) com o principal objetivo de evidenciar sintomas característicos que 
contribuam à seleção do medicamento homeopático individualizado. No entanto, permitindo ao paciente expor suas idiossincrasias de forma detalhada, mobiliza aspectos interiores inespecíficos que, por si sós, podem trazer alívio para muitas manifestações sintomáticas.

Associado ao efeito placebo descrito anteriormente, o adicional de melhora deste efeito consulta (rapport effect) pode dificultar a observação do efeito específico do medicamento homeopático no curto prazo, favorecendo o incremento de resultados falso-positivos de acordo às características influenciáveis da amostra e se o tempo de tratamento não for suficiente para que a reação homeopática atinja sua plenitude.

Os desenhos de ensaios clínicos placebos-controlados convencionais encontram nestas particularidades obstáculos suficientes para evidenciar a superioridade do tratamento homeopático frente ao placebo (Kaptchuk, 1998, 2002), exigindo a incorporação de critérios epidemiológicos condizentes com os aspectos epistemológicos do modelo em questão.

\section{III.4.2. Importância da individualização terapêutica na eficácia clínica homeopática}

A eficácia e a efetividade do tratamento homeopático estão diretamente relacionadas ao grau de similitude entre a totalidade dos sintomas característicos do paciente e os sintomas despertados pelos medicamentos nas experimentações patogenéticas. Em vista de a terapêutica homeopática empregar substâncias simples ultradiluídas com potência de ação primária infinitesimal, ao contrário das doses 
ponderais com potente ação patogenética e efeitos colaterais da terapêutica convencional, os sintomas do medicamento único corretamente selecionado devem apresentar grande similaridade com as características mais peculiares e idiossincrásicas do paciente, a fim de que o imponderável efeito primário do medicamento dinamizado consiga despertar uma reação vital ou homeostática através do princípio da similitude terapêutica.

Apesar de diminuir os efeitos nefastos das agravações e intoxicações das doses ponderais, a sutil freqüência do medicamento dinamizado somente conseguirá entrar em ressonância com a freqüência dos sistemas orgânicos que apresentarem alto grau de semelhança vital ou freqüencial, traduzidos na semiologia homeopática pelos sinais e sintomas peculiares e característicos da individualidade enferma:

Todo módulo oscilante, quando for estimulado por freqüências especificamente definidas, ressoará produzindo ondas estacionárias. Apenas nestas freqüências individuais o agente receptor absorverá eficientemente a vibração dispensada pelo agente externo, ou seja, durante a ressonância a energia flui inteiramente do estimulador para o receptor. (Teixeira, 1995)

Por estes e outros aspectos que Hahnemann e todos os seus seguidores enfatizaram a individualização medicamentosa e o emprego de substâncias únicas e simples (medicamento único individualizado) na prática clínica homeopática, aplicando o princípio da similitude entre a totalidade de sintomas característicos do binômio doente-doença e as manifestações patogenéticas das substâncias únicas e simples que foram experimentadas em indivíduos humanos, criticando o emprego de meios compostos (mistura de medicamentos ou complexos homeopáticos) sem a experimentação patogenética prévia. 
Alegando o intuito explícito de estudar a relação dos efeitos clínicos do tratamento homeopático com o efeito placebo, Shang et al. (2005) desenvolveram um estudo comparativo entre ensaios clínicos homeopáticos e alopáticos placeboscontrolados. Pareando 110 ensaios homeopáticos com 110 ensaios alopáticos segundo as mesmas doenças e os mesmos tipos de resultados (efeitos específicos), os autores classificaram os estudos segundo critérios de qualidade metodológicos clássicos (número de participantes envolvidos, método de randomização, aplicação do método duplo-cego, tipo de publicação, cálculo do odds ratio etc.), utilizando a meta-regressão como método de análise estatística, avaliando como os vícios ou erros sistemáticos (vieses) na condução e na descrição dos estudos poderiam interferir na interpretação final dos resultados.

Numa primeira análise geral de todos os ensaios clínicos levantados, a maioria de baixa qualidade metodológica segundo os critérios clássicos anteriormente citados, os autores observaram que tanto a homeopatia quanto a alopatia mostraram-se efetivas (de forma análoga aos resultados da metanálise publicada no The Lancet em 1997; Linde et al., 1997). Entretanto, quando os erros sistemáticos foram valorizados, selecionando para análise apenas os estudos com alta qualidade metodológica segundo o critério específico do número de participantes envolvidos (oito ensaios clínicos homeopáticos versus seis ensaios clínicos convencionais), os resultados mostraram fraca evidência para um efeito específico dos medicamentos homeopáticos $(\mathrm{OR}=0,88 ;$ IC $95 \% \quad 0,65$ a 1,19) e forte evidência para efeitos específicos de intervenções convencionais (OR = 0,58; IC 95\% 0,39 a 0,85). Partindo da premissa que os efeitos específicos das ultradiluições homeopáticas são "implausíveis", pela dificuldade de explicá-los segundo os parâmetros da pesquisa 
farmacológica dose-dependente, os autores concluíram que os efeitos clínicos da homeopatia são efeitos placebo.

Como rege a epidemiologia clínica, em estudos que visem comparar a eficácia de racionalidades médicas distintas como a homeopatia e a alopatia, os critérios de qualidade metodológica específica a cada modelo devem constar como premissas fundamentais na descrição e condução dos mesmos, a fim de que se reproduza na pesquisa a realidade clínica (efetividade ou validade externa). Desta forma, os ensaios clínicos homeopáticos deveriam priorizar como critérios de alta qualidade metodológica as seguintes premissas: individualização na escolha do medicamento, das doses e das potências homeopáticas; período de estudo suficiente para ajustar o medicamento à complexidade da individualidade enferma; avaliação da resposta global e dinâmica ao tratamento com a aplicação de instrumentos específicos (análise qualitativa, questionários de qualidade de vida etc.) etc.

Nesta metanálise publicada no The Lancet, estes critérios homeopáticos de alta qualidade metodológica não foram valorizados, pois apenas $16 \%$ dos ensaios clínicos homeopáticos selecionados inicialmente (e nenhum dos oito estudos de melhor qualidade metodológica clássica incluídos na segunda análise) respeitavam a individualização na escolha do medicamento, principal premissa do modelo, constituindo um viés ou erro sistemático de grande magnitude para a episteme homeopática. A grande maioria dos ensaios clínicos homeopáticos selecionados apresentava desenhos impróprios à clínica da individualidade, empregando um mesmo medicamento (44\%) ou uma mesma mistura de medicamentos (32\%) para uma queixa clínica comum a todos os pacientes. 
Buscando descaracterizar a premissa da individualização do medicamento homeopático (que requer estudos clínicos com longo tempo de acompanhamento dos pacientes), estado-da-arte da epidemiologia clínica homeopática, os autores da recente metanálise admitiram que "addressed these points in additional analyses but found no strong evidence in support of these hypotheses": "found no strong evidence" é diferente de "there was weak evidence" citado na conclusão final do estudo.

Segundo as premissas apresentadas, torna-se evidente que tanto esta publicação enviesada quanto o editorial da mesma ("The end of homoeopathy"), assim como outras duas matérias críticas publicadas na mesma edição do The Lancet (Vandenbroucke, 2005; McCarthy, 2005), apresentaram o intuito implícito de desacreditar a homeopatia perante a classe científica (Teixeira, 2006c).

Com este exemplo, frisamos a importância que deve ser dispensada ao desenho dos protocolos clínicos homeopáticos, a fim de que satisfaçam a racionalidade científica do modelo e possam ser avaliadas as verdadeiras possibilidades e limitações de sua aplicação no tratamento das diversas enfermidades humanas.

\section{III.4.3. Protocolo para pesquisa clínica em homeopatia}

Com o intuito de aprimorar o desenho dos ensaios clínicos homeopáticos controlados elaborados nas últimas décadas, estamos propondo uma conciliação entre as premissas epistemológicas do modelo científico convencional (epidemiologia clínica) e as premissas epistemológicas do modelo científico homeopático (epidemiologia clínica homeopática), buscando suplantar a cristalização dogmática, 
estimular a criatividade e aproximar os horizontes destas racionalidades científicas (Teixeira, 2001b, 2008b).

\section{III.4.3.1. Premissas epistemológicas do modelo científico convencional}

Como citado anteriormente, a primeira avaliação da qualidade metodológica e científica dos ensaios clínicos homeopáticos placebos-controlados foi realizada no início da década de 1990 (Kleijnen et al., 1991), evidenciando falhas metodológicas fundamentais que inviabilizavam a maioria dos estudos perante as premissas da epidemiologia clínica. De um total de 107 estudos analisados, apenas 22 (20,6\%) mostraram qualidade científica satisfatória, superando o escore de 55/100 pontos. Nesta metanálise, os ensaios clínicos homeopáticos foram analisados segundo sete critérios fundamentais, sinalizando as falhas existentes e as premissas que deveriam ser incorporadas em estudos futuros:

1) Descrição adequada das características dos pacientes (sintomas homeopáticos utilizados corretamente descritos): 10 pontos; 2) Número de pacientes envolvidos no estudo: $25-49$ pacientes $=10$ pontos, 50-99 pacientes $=20$ pontos, >100 pacientes = 30 pontos; 3) Ensaio duplo-cego e placebo-controlado: corretamente descrito e executado $=20$ pontos, apenas mencionado $=10$ pontos; 4 ) Randomização: corretamente descrita e executada = 20 pontos; incorretamente descrita ou executada $=10$ pontos; 5) Conduta medicamentosa corretamente descrita = 5 pontos; 6) Avaliação dos resultados: efeito significante e corretamente descrito $=10$ pontos; 7) Apresentação dos resultados corretamente descrita $=5$ pontos. 
Numa segunda metanálise, dentre 119 ensaios clínicos levantados, Linde et al. (1997) selecionaram 89 que preenchiam quatro premissas básicas de qualidade metodológica:

1) Randomização corretamente descrita e executada; 2) Alocação e mascaramento dos grupos ativo e placebo corretamente descritos e executados; 3) Relatório escrito, publicado ou não; 4) Apresentação dos resultados corretamente descrita, a fim de se avaliar a eficácia do tratamento homeopático frente ao placebo.

Deste modo, segundo o ponto de vista da metodologia da pesquisa, os ensaios clínicos homeopáticos deveriam seguir alguns critérios mínimos e fundamentais para serem aceitos pela racionalidade científica contemporânea:

1) Ensaio duplo-cego, randomizado, placebo-controlado corretamente descrito e executado; 2) Número de indivíduos superior a 50; 3) Descrição adequada das características dos pacientes, possibilitando relacionar os sintomas homeopáticos escolhidos com o medicamento administrado; 4) Tanto a escolha quanto qualquer mudança na medicação deverá ser justificada, segundo uma corrente terapêutica específica; 5) Os efeitos observados devem estar claramente descritos no estudo, permitindo que os resultados sejam analisados corretamente.

\section{III.4.3.2. Premissas epistemológicas do modelo científico homeopático}

Ao contrário do que muitos homeopatas afirmam dogmaticamente, a possibilidade de adaptação dos protocolos de pesquisa clínica convencional ao modelo homeopático é viável, desde que sejam respeitados os pressupostos do princípio da similitude curativa quando empregamos doses infinitesimais de substâncias medicinais. 
III.4.3.2.1. Individualização do tratamento homeopático

Independente do diagnóstico clínico, a homeopatia utiliza as premissas da totalidade sintomática e da individualização medicamentosa na escolha da sua conduta terapêutica. Assim sendo, indivíduos que apresentem uma mesma enfermidade, via de regra, poderão receber medicamentos homeopáticos únicos distintos, conforme o conjunto de suas manifestações peculiares (sintomas mentais, gerais e particulares). Fundamentados numa concepção comum e imprescindível de totalidade sintomática característica, os diversos autores descrevem suas técnicas de valorização e hierarquização dos sinais e sintomas, priorizando os aspectos mentais (imaginativos, oníricos, emocionais, intelectivos etc.), gerais (climáticos, alimentares, temperatura corporal, transpiração, sono etc.) ou particulares (sistemas orgânicos).

Apesar das diversas correntes terapêuticas homeopáticas privilegiarem uma ou outra categoria de manifestação sintomática, a noção de terapêutica individualizada e selecionada segundo o conjunto de sintomas característicos da individualidade enferma não pode estar ausente de qualquer tratamento ou ensaio clínico homeopático, que deve propiciar, de forma imperiosa e concomitante, melhoras mentais, gerais e particulares aos pacientes.

Esta noção de individualização terapêutica, aplicando medicamentos únicos e distintos aos diversos pacientes, esbarra no método clássico de avaliação metodológica da eficácia dos fármacos modernos, que emprega uma mesma intervenção terapêutica para pacientes portadores da mesma doença, buscando evidenciar a eficácia clínica frente à intervenção placebo. Segundo a dinâmica individualizadora, estaremos avaliando a melhora clínica de uma mesma abordagem 
terapêutica (segundo condutas padronizadas e devidamente especificadas para efeitos de comparação e reprodutibilidade posterior) perante uma abordagem placebo. Desta forma, atingiremos um denominador epistemológico comum para ambas as metodologias científicas, pemitindo a avaliação do tratamento homeopático individualizado segundo os parâmetros científicos vigentes.

A dificuldade de adaptação da terapêutica homeopática individualizante frente à terapêutica comum empregada nos ensaios clínicos convencionais levou à realização de diversos ensaios clínicos homeopáticos que não valorizaram a totalidade sintomática característica dos enfermos, não apresentando melhora significativa perante o placebo (Shipley et al., 1983; Bignamini et al., 1987; Labrecque et al., 1992; Ernst et al., 1998), ao contrário dos estudos citados anteriormente que priorizaram a individualização medicamentosa.

Na tentativa de encontrar uma abordagem metodológica comum, aplicando a individualização e administrando a todos os pacientes o mesmo medicamento, Bignamini et al. (1987) selecionaram numa grande população de pacientes com uma mesma doença aqueles indivíduos que apresentavam sintomas característicos do medicamento específico que se desejava avaliar, os quais foram randomizados posteriormente nos grupos ativo e placebo. Pacientes que foram alocados no grupo ativo apresentaram resultados significativamente superiores aos do grupo placebo.

Alguns ensaios realizados sem a individualização do medicamento perante o binômio doente-doença apresentaram resultados significativos frente ao placebo, estando geralmente relacionados a transtornos secundários a traumas diversos (íleo, hematoma e dor pós-cirúrgicos) (Barnes et al., 1997; Wolf et al., 2003; Robertson et al., 2007), caracterizados como intercorrências passageiras sem a gravidade de 
doenças crônicas instaladas, ou seja, sem a importância miasmática da concepção prognóstica homeopática.

Dentro da similitude etiológica, bastante utilizada por algumas correntes homeopáticas seculares nos tratamentos isoterápicos (imunoterapia homeopática) das doenças alérgicas, que empregam o mesmo princípio da identidade curativa (aequalia aequalibus curentur) incorporado pela imunoterapia clássica citada anteriormente, os ensaios clínicos que utilizaram preparados homeopáticos com os antígenos individualizados para cada paciente (selecionados através dos mesmos aspectos individualizantes da imunoterapia convencional: história clínica, antecedentes alérgicos, lgE específica etc.) também mostraram diferenças significativas entre os grupos ativo e placebo (Reilly e Taylor, 1985; Reilly et al., 1986, 1994; Taylor et al., 2000).

III.4.3.2.2. Descrição do método de seleção dos sintomas homeopáticos

A escolha dos medicamentos homeopáticos únicos e individualizados (totalidade sintomática característica) deverá ser padronizada segundo uma determinada técnica de valorização (hierarquização) e repertorização dos sintomas (mentais, gerais e particulares), dentre as diversas abordagens terapêuticas homeopáticas existentes, a fim de uniformizar o ensaio clínico num dos aspectos mais subjetivo e difícil de ser reproduzido.

Dentro desta postura objetiva de análise e conduta, seriam favoráveis que o mesmo pesquisador realizasse a anamnese homeopática (coleta dos sintomas característicos) e a escolha do medicamento único individualizado (hierarquização e repertorização dos sintomas) para todos os pacientes do ensaio, ou para um grupo representativo dos mesmos. 
$\mathrm{Na}$ realidade, em cada ensaio clínico homeopático individualizado estaremos avaliando a eficácia de determinada "abordagem terapêutica homeopática", que deve ser estipulada segundo condutas semiológicas e terapêuticas devidamente padronizadas.

\section{III.4.3.2.3. Abordagens terapêuticas homeopáticas}

$\mathrm{Na}$ escolha do medicamento homeopático único e individualizado, podemos simplificar as abordagens terapêuticas existentes segundo duas categorias de valorização e repertorização dos sintomas característicos e peculiares:

a) medicamento único crônico (constitucional ou miasmático), selecionado segundo a hierarquização e a repertorização dos sintomas mentais, gerais e particulares característicos da doença crônica (totalidade sintomática característica permanente e antiga);

b) medicamento único agudo (local ou sintomático), escolhido segundo a hierarquização e a repertorização dos sintomas mentais, gerais e particulares característicos do momento ou doença aguda (totalidade sintomática característica recente), dando-se ênfase aos aspectos atuais, objetivos e clínicos (Teixeira, 2002a; Teixeira et al., 2008).

Na concepção homeopática, se observa que a prescrição de um medicamento crônico ou constitucional, selecionado segundo a repertorização da sintomatologia permanente e antiga, deverá atingir a suscetibilidade mórbida prevalente, com resultados mais profundos e duradouros nas doenças crônicas, após um período de ação prolongado. Com os medicamentos agudos ou locais, escolhidos segundo a repertorização dos sintomas particulares recentes, teremos ação mais imediata nas 
queixas clínicas agudas, geralmente com resultados mais superficiais e menos duradouros nas doenças crônicas.

III.4.3.2.4. Doses e potências homeopáticas

Buscando uma uniformização de critérios (Teixeira, 1995), apoiados na observação clínica consensual de que o medicamento homeopático único corretamente individualizado deve despertar algum tipo de resposta, propomos a prescrição inicial do medicamento único crônico (constitucional ou miasmático) na potência $30 \mathrm{cH}\left(10^{-60} \mathrm{~mol}\right)$, em doses únicas (3-5 glóbulos ou gotas sublinguais) semanais, quinzenais, mensais ou bimensais, segundo o tipo de patologia analisada e a suscetibilidade do enfermo.

Para o medicamento único agudo (local ou sintomático), propomos a prescrição inicial do mesmo na potência $6 \mathrm{cH}\left(10^{-12} \mathrm{~mol}\right)$, em doses repetidas (3-5 glóbulos ou gotas sublinguais, 3 ou mais vezes ao dia) durante as crises agudas; sempre que possível, a forma líquida é a mais apropriada, por permitir variações mínimas na potência medicamentosa entre as ingestas (através de agitações vigorosas ou sucussões), minimizando as possíveis agravações homeopáticas (piora inicial dos sintomas após a administração de doses excessivas).

Estes esquemas poderão ser alterados ao longo do tratamento, conforme as respostas individuais dos pacientes, devendo ser avaliados a cada retorno mensal ou bimensal.

III.4.3.2.5. Tempo de consulta e duração do tratamento homeopático

Como prerrogativa essencial, o tempo de consulta deve seguir o padrão ao qual o pesquisador está acostumado, segundo uma determinada abordagem semiológicoterapêutica que propõe aplicar. 
Quanto à duração do tratamento, supomos que o tempo mínimo para a avaliação de um ensaio clínico homeopático individualizado em qualquer tipo de doença crônica deva se situar em torno de 6-12 meses, com avaliações clínicas e ajustes na prescrição mensais. Além da necessidade de um tempo maior de acompanhamento para se atingir a individualização do medicamento segundo a totalidade sintomática característica do enfermo, a duração do tratamento homeopático também deverá ser proporcional ao grau de cronicidade e à gravidade da doença, em vista da amplitude e magnitude dos desequilíbrios homeostáticos instalados na fisiologia humana.

Como descrito anteriormente, ao contrário dos tratamentos convencionais em que se observa o retorno dos sintomas de uma doença crônica após a suspensão da medicação supressora, muitas vezes em intensidade superior aos níveis iniciais (efeito rebote), a recente imunoterapia sublingual tem-se mostrado um tratamento seguro para as alergias respiratórias (rinite e asma), com mudanças efetivas no curso natural destas doenças, apresentando resposta significativa frente ao placebo após um período mínimo de doze meses de tratamento (Wilson et al., 2005; Penagos et al., 2006; Calamita et al., 2006).

Pelas analogias existentes entre os pressupostos terapêuticos da imunoterapia sublingual e da homeopatia individualizada, podemos inferir que os parâmetros de eficácia e de efetividade (tempo de tratamento, magnitude e duração da resposta) de ambas terapêuticas devam se aproximar. Dentro deste raciocínio lógico, situaríamos em torno de doze meses a duração mínima do tratamento homeopático individualizado para as alergias respiratórias, a fim de que possamos evidenciar uma diferença estatística na resposta perante o placebo. 
Para minimizar os abandonos inerentes aos estudos placebos-controlados por tempo prolongado, o desenho de "ensaio clínico misto" citado na revisão sobre imunoterapia (Bufe et al., 2004), que associa um estudo placebo-controlado inicial ao estudo aberto de longo prazo [open label extension study ou follow-on randomised controlled trial (FORCT)], se mostra como uma alternativa a ser incorporada nos desenhos de ensaios clínicos homeopáticos controlados, desde que na análise dos resultados seja valorizado o possível viés de seleção dos pacientes ao longo do estudo (Hemming et al., 2008; Maquire et al., 2008).

Toda conduta terapêutica homeopática deverá ser avaliada regularmente, com a possibilidade de alteração mensal ou bimensal dos medicamentos, das doses e/ou das potências, ajustando-se gradativamente as diversas hipóteses medicamentosas à individualidade enferma, viabilizando a aproximação da similitude ideal (medicamento simillimum) no menor período de tratamento.

III.4.3.26. Eventos adversos do tratamento homeopático

Em vista de seu mecanismo de ação reacional, podemos observar como eventos adversos do tratamento homeopático a piora inicial dos sintomas da enfermidade (agravação primária ou homeopática propriamente dita), o surgimento posterior de sintomas acessórios nos órgãos e sistemas afetados (agravação secundária ou de cura), o retorno de sintomas antigos e o surgimento de sintomas novos. Todos estes eventos deverão ser anotados pelos pacientes num diário e relatados ao investigador nos retornos ou relatórios mensais, pois orienta o médico na conduta terapêutica segundo as observações prognósticas homeopáticas (Teixeira, 1997). 
Como principal evento adverso, o surgimento da agravação homeopática propriamente dita, fruto da administração inadequada das doses ou das potências homeopáticas, produzindo um efeito primário muito forte, indicará ao médico homeopata sua conduta frente à posologia empregada.

Tanto o retorno de sintomas antigos quanto a agravação de cura indicarão um bom prognóstico, trazendo ao investigador o indício de que o medicamento está sendo efetivo e que uma melhora evidente ocorrerá. No caso de sintomas novos incomodativos que evidencia uma evolução indesejada, o medicamento deverá ser suspenso e antidotado com outro melhor selecionado.

III.4.3.2.7. Avaliação dos resultados do tratamento

A relação médico-paciente diferenciada do modelo homeopático, que visa captar a totalidade de sintomas característicos do indivíduo enfermo, pode trazer um incremento de melhora clínica inicial devido a efeitos subjetivos e inespecíficos (efeito placebo-consulta), distintos dos efeitos objetivos e específicos do medicamento homeopático (princípio da similitude curativa). Em muitos ensaios clínicos homeopáticos, a ausência de diferenças estatísticas significativas na comparação entre os grupos placebo e ativo foi causada por esta melhora subjetiva (falsos-positivos), assumindo maior relevância quando empregamos um período de observação e tratamento curtos, insuficientes para se atingir a individualização medicamentosa desejável.

Além do aumento no período de tratamento, a utilização de um segundo grupo controle "sem tratamento" ou um período de observação inicial mediano (wash-out de 1-2 meses) após a anamnese homeopática e antes da administração da terapêutica, permitirá diferenciar a ocorrência de melhora clínica imputada a alguns dos fatores 
inespecíficos (regressão à média, efeito hawthorne, relação médico-paciente etc.) da abordagem homeopática.

Desde que tenhamos exames subsidiários com grande especificidade às alterações clínicas de determinada enfermidade, estes métodos objetivos de análise deverão ser incorporados ao protocolo.

A evolução da dinâmica global (miasmática) do paciente, valorizada no modelo homeopático segundo os aspectos psíquicos, emocionais, sociais, ambientais e existenciais do indivíduo enfermo, pode ser avaliada quantitativamente através de questionários de qualidade de vida, aplicados em todas as fases do estudo (Teixeira, 2002b). Dentre os inúmeros instrumentos de avaliação da qualidade de vida existentes, resta-nos escolher um que melhor se adapte à enfermidade estudada e à dimensão globalizante valorizada na evolução do tratamento homeopático. Outras abordagens qualitativas poderão ampliar a avaliação desta dinâmica global.

III.4.3.2.8. Utilização concomitante de medicamentos convencionais

Segundo a Declaração de Helsinque, dependendo da gravidade da enfermidade analisada e do tempo de duração do estudo, nenhum ensaio clínico placebocontrolado será aprovado pelas Comissões de Ética em Pesquisa se não for incluído um fármaco com atuação comprovada no alívio dos sintomas dos pacientes do grupo placebo ou do grupo ativo sem resposta efetiva ao tratamento proposto. Com estas drogas de resgate, podemos prolongar os períodos de duração dos ensaios clínicos homeopáticos, prerrogativa essencial para que tenhamos maiores possibilidades de selecionar o medicamento individualizado e observar a efetividade do tratamento.

$\mathrm{Na}$ literatura, encontramos a citação da utilização de anti-histamínicos como drogas de resgate em ensaios clínicos homeopáticos em doenças alérgicas (Reilly e 
Taylor, 1985; Reilly et al., 1986, 1994; Taylor et al., 2000), sem influírem na resposta ao tratamento em curto prazo, empregando-se a freqüência de utilização dos mesmos como fator de eficácia do tratamento homeopático frente ao placebo (de forma análoga aos estudos com imunoterapia). No entanto, os corticosteróides ou imunossupressores deveriam ser evitados nos protocolos clínicos homeopáticos, por contrariarem a terapêutica pela similitude, que se baseia na reação do organismo à enfermidade (reação vital ou homeostática).

III.4.3.2.9. Análise estatística

Pelas analogias citadas entre os modelos terapêuticos da imunoterapia sublingual e da homeopatia individualizada, a análise estatística dos ensaios clínicos homeopáticos individualizados também deveria seguir os mesmos critérios do consenso da Organização Mundial de Alergia (WAO) para padronização dos ensaios clínicos com imunoterapia em alergias respiratórias (Canonica et al., 2007): a) a análise dos resultados deve mostrar a significância estatística (IC 95\% e $P<0,05$ ) juntamente com a diferença entre a variação média dos grupos (\% de variação ou magnitude da resposta); b) por ser um tratamento de longa duração, observa-se um grande índice de desistências e desligamentos, tornando inviável a análise estatística "por intenção de tratamento" (intention-to-treat); c) a magnitude da resposta ao tratamento deve estar relacionada com a redução dos escores de sintomas entre os grupos placebo e ativo, aceitando-se uma eficácia clínica mínima de $20 \%$ acima da resposta placebo.

III.4.3.2.10. Proposta de desenho de ensaio clínico homeopático individualizado

Em vista do exposto anteriormente, sugerimos a incorporação de algumas premissas básicas ao desenho de ensaios clínicos homeopáticos: 
- Ensaio duplo-cego, randomizado, placebo-controlado inicial, com seguimento posterior de todos os pacientes interessados em estudo aberto (open label study) por um período superior a doze meses de tratamento homeopático;

- Número de pacientes superior a 50;

- Tratamento homeopático individualizado e selecionado segundo a totalidade sintomática característica;

- Disponibilidade de drogas de resgate durante todo o período de estudo;

- Duração mínima do estudo de seis meses (fase controlada), com avaliações mensais da resposta ao tratamento segundo parâmetros clínicos de análise (observações prognósticas homeopáticas, sinais e sintomas clínicos, utilização de drogas de resgate etc.), com a possibilidade de mudanças na conduta terapêutica (medicamentos, doses e potências homeopáticas) de acordo à suscetibilidade individual;

- Após o término da fase controlada inicial (Fase 1), permanência optativa dos pacientes num estudo aberto durante período mínimo semelhante (Fase 2), com o intuito de propiciar o tratamento homeopático ao grupo placebo e quantificar a melhora objetiva e subjetiva de todos os pacientes num período maior de tratamento homeopático;

- Avaliações periódicas da eficácia e da efetividade do tratamento homeopático por avaliador independente, segundo parâmetros de análise objetivos (escore de sinais e sintomas, uso de drogas de resgate, exames subsidiários etc.) e subjetivos (questionário de qualidade de vida);

- Análise estatística dos resultados "por protocolo", associando a significância estatística (IC 95\% e $P<0,05)$ com a diferença entre as variações médias 
dos grupos, aceitando-se uma eficácia clínica mínima de $20 \%$ acima da resposta placebo. 
IV. METODOLOGIA 


\section{METODOLOGIA}

\section{IV.1. Descrição geral do estudo}

Com o intuito de aumentar a duração do tratamento homeopático e diminuir as taxas de abandono e desligamento, este estudo adotou um desenho de ensaio clínico misto (estudo randomizado, duplo-cego e placebo-controlado inicial, seguido por estudo aberto), semelhante ao modelo de estudo com imunoterapia de Bufe et al. (2004), dividido nas seguintes etapas:

- Fase 1 (fechada), composta por um estudo clínico randomizado, duplo-cego e placebo-controlado com a duração de seis meses, visando determinar a eficácia do tratamento homeopático individualizado frente ao placebo no curto prazo;

- Fase 2 (aberta), que se propôs avaliar a efetividade da terapêutica homeopática individualizada no médio-longo prazo (máximo de 36 meses de tratamento), aspecto imprescindível ao ajuste do medicamento à complexidade da individualidade enferma. (Sinopse do Estudo - Anexo 1)

Pela ausência de estudos semelhantes realizados anteriormente (ausência de estudo-piloto), não foi possível calcular o tamanho ideal da amostra. Foi inferido um número em torno de 50 pacientes baseado nos padrões mínimos estipulados na revisão sistemática que avaliou a qualidade metodológica dos ensaios clínicos homeopáticos placebos-controlados (Kleijnen et al., 1991). 
O estudo foi aprovado pela Comissão de Ética para Análise de Projetos de Pesquisa - CAPPesq da Diretoria Clínica do Hospital das Clínicas e da Faculdade de Medicina da Universidade de São Paulo (Documentação aprovada pela CAPPesq Apêndice 1).

\section{IV.1.1. Fase 1 (estudo clínico randomizado, duplo-cego e placebo- controlado, com a duração equivalente a seis meses de acompanhamento)}

Para facilitar a locomoção e a aderência dos pacientes, o processo de recrutamento foi realizado através de cartazes distribuídos no Hospital das Clínicas da Faculdade de Medicina da Universidade de São Paulo (HCFMUSP) e em instituições e agremiações próximas [FMUSP, Faculdade de Saúde Pública da USP (FSPUSP), Associação dos Servidores do HCFMUSP, Centro de Saúde Geraldo de Paula Souza, Fundacentro, Farmácias Homeopáticas etc.], resenhas publicadas em jornais (Folha de S.Paulo, Jornal da USP etc.) e páginas eletrônicas da USP e da FSPUSP. Todos os pacientes interessados foram esclarecidos por telefone a respeito do cronograma do estudo e dos principais critérios de seleção.

Cinqüenta e cinco pacientes voluntários foram selecionados segundo os critérios de inclusão e exclusão definidos no protocolo. Estes pacientes foram separados aleatoriamente (randomização) em dois grupos terapêuticos, recebendo medicamentos ativo (G1) e placebo (G2), permanecendo cada participante no mesmo grupo inicialmente randomizado até o final desta fase inicial. Profissionais 
sem vínculo com o estudo foram escolhidos para realizar a randomização dos grupos e a distribuição das substâncias ativas ou placebos para cada paciente.

Nesta primeira fase, correspondente a sete visitas mensais, tanto os pacientes quanto os profissionais vinculados ao estudo não tiveram conhecimento da randomização dos grupos (duplo cegamento ou mascaramento). Tanto nesta quanto na fase seguinte, todos os pacientes foram avaliados pelos seguintes investigadores:

- Dra Patrícia Vieira Barreto, médica alergo-imunologista indicada pelo Serviço de Alergia e Imunologia Clínica do HCFMUSP, que realizou as avaliações clínico-alérgicas e a coleta dos exames complementares (teste cutâneo, hemograma completo, imunoglobulinas séricas etc.) de forma independente e desconhecedora dos demais passos do estudo, nos períodos iniciais e finais de cada fase citada;

- Dr Marcus Zulian Teixeira, médico homeopata do Serviço de Clínica Médica Geral do HCFMUSP e pesquisador responsável pelo projeto, que acompanhou os pacientes durante todo o período do estudo realizando as avaliações clínicas gerais e as avaliações e prescrições homeopáticas mensais. (Figura 1)

\section{Fase 1 - Estudo Fechado}

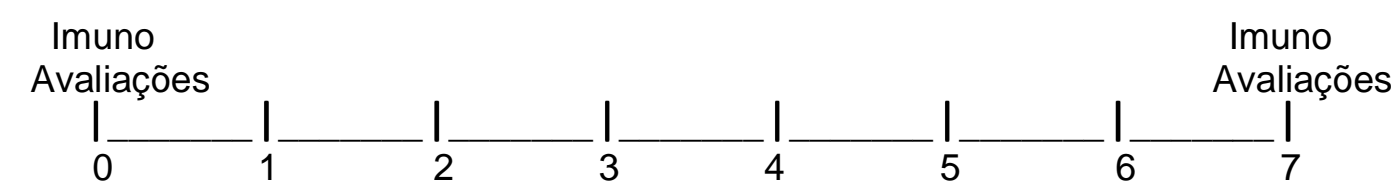

Visitas Mensais

Figura 1 - Esboço do estudo duplo-cego e placebo-controlado (Fase 1) 
$\mathrm{Na}$ visita 0 (semana -1), para serem incluídos no protocolo, todos os pacientes voluntários apresentaram pelo menos um ano de história de rinite alérgica perene com sinais e sintomas ativos da doença: escore basal dos sinais e sintomas específicos da rinite alérgica maior do que 6 (escore $>6$ ), tanto na visita 0 quanto na visita 1 (vide item IV.7.2). Os pacientes realizaram as avaliações clínico-alérgicas e a coleta dos exames complementares no Ambulatório de Rinite Alérgica do Serviço de Alergia e Imunologia Clínica do HCFMUSP. Cumprindo os pré-requisitos para participarem do estudo, todos os pacientes leram e assinaram o Consentimento Livre e Esclarecido (Consentimento Livre e Esclarecido - Fase 1 - Apêndice 2). Após esta visita, os pacientes cumpriram período de uma semana sem medicação (wash-out), sendo avaliados pelo médico homeopata e iniciando o tratamento na semana seguinte.

Na visita 1 (semana 0), os pacientes possuíam teste cutâneo positivo para pelo menos um aeroalérgeno (segundo o padrão determinado no protocolo) e continuavam preenchendo os critérios de inclusão e exclusão citados. Nesta visita e em todas as posteriores, foram acompanhados pelo médico homeopata no Ambulatório CMG 4402 do Serviço de Clínica Médica Geral do HCFMUSP, que realizou a semiologia clínico-homeopática periódica com o objetivo de avaliar a totalidade sintomática característica e selecionar o(s) medicamento(s) homeopático(s) individualizado(s) mais indicado(s) para cada indivíduo. Para este mister, utilizou-se a repertorização mecânica (sem escolha de sintoma diretor) e computadorizada (Ribeiro Filho, 1998) dos sintomas homeopáticos característicos mentais, gerais e particulares identificados (Modelo de Repertorização Mecânica Computadorizada dos Sintomas Homeopáticos - Anexo 2), com concomitante 
análise diferencial das hipóteses medicamentosas através de consulta à Matéria Médica Homeopática. Optou-se por este método de repertorização e hierarquização dos sintomas em vista da simplicidade de execução.

O medicamento único constitucional individualizado, que buscou englobar a totalidade dos sintomas característicos do paciente, foi administrado logo após a visita 1 para todos os pacientes do grupo ativo (G1) na potência $30 \mathrm{cH}$, em doses únicas semanais (3 gotas, 1 vez por semana); a posologia (doses e potências) foi alterada ao longo do estudo, sendo aumentada em situações de resposta ineficiente (melhora pequena, curta ou interrompida) ou diminuída nos casos em que eventos adversos evidenciassem uma super-dosagem (agravação homeopática). O medicamento único individualizado foi substituído ao longo do estudo por outras hipóteses medicamentosas, no caso de prescrição incorreta (ineficácia terapêutica ou surgimento de sintomas novos incomodativos). O grupo placebo (G2) recebeu substância inerte segundo a mesma posologia e conduta.

Na visita 2 (semana 4), após a avaliação da resposta terapêutica, foi disponibilizado anti-histamínico de resgate a todos os indivíduos que não apresentaram melhora clínica evidente, de ambos os grupos (G1 e G2). A necessidade de utilização do anti-histamínico, segundo a posologia recomendada, ficou a critério do paciente e foi utilizada como fator de avaliação da eficácia do tratamento homeopático, sendo relatada pelo mesmo em caderneta de anotações fornecida a todos participantes.

Tanto nesta visita quanto em todas as visitas mensais posteriores (visitas 3, 4, 5, 6 e 7), a medicação homeopática foi reavaliada e ajustada a cada paciente individualmente, sendo alterada segundo os critérios homeopáticos na qualidade 
(mudança de medicamento único individualizado no caso de falha terapêtica ou sintomas novos incomodativos) e na quantidade (mudança de dose ou potência no caso de resposta terapêutica insuficiente ou exagerada). Caso fosse optado pela mudança de medicamento, o critério de seleção, pedido e distribuição dos medicamentos seguiu os moldes da visita 1 (vide item IV.13).

Em todas as visitas mensais, o médico homeopata avaliou os aspectos clínicos gerais (doenças concomitantes, eventos adversos, exame clínico etc.), os aspectos homeopáticos (psiquismo, emoções, disposição, sono, alimentação etc.), a condição geral da rinite e a resposta terapêutica, adequadamente relatados no prontuário e na "Ficha Clínica Homeopática” (Anexo 3).

Avaliações clínicas gerais (Ficha Clínica Geral - Anexo 4), avaliações clínicoalérgicas (escores dos sinais e sintomas específicos da rinite alérgica, dos sintomas da síndrome alérgica, e dos fatores agravantes e/ou precipitantes da rinite alérgica) (Ficha de Rinite Alérgica - Anexo 5) e avaliações laboratoriais (teste cutâneo, hemograma completo e imunoglobulinas séricas) (Exames Complementares - Anexo 6) foram aplicadas em todos os pacientes nas visitas iniciais (0 ou 1) e final (7), sendo descritas em fichas específicas.

Avaliações da qualidade de vida (Questionário de Qualidade de Vida FACIT-Sp12 - Anexo 7) foram aplicadas em todos os pacientes nas visitas 1 e 7.

\section{IV.1.2. Fase 2 (estudo aberto prospectivo, com a duração equivalente a 6-36 meses de tratamento homeopático)}


Após o término da primeira fase placebo-controlada (visita 7 ou semana 24), todos os pacientes foram convidados a permanecer nesta segunda fase, correspondente a um estudo aberto em que receberam tratamento homeopático por um período máximo de 36 visitas mensais, da seguinte forma: os pacientes alocados inicialmente no grupo ativo (G1), que já vinham recebendo o tratamento homeopático pelo período equivalente a seis visitas mensais, continuaram recebendo tratamento por mais 30 visitas mensais, perfazendo um período de tratamento homeopático máximo correspondente a aproximadamente trinta e seis meses (3 anos); os pacientes alocados inicialmente no grupo placebo (G2) passaram a receber tratamento homeopático pelo período equivalente a 36 visitas mensais, perfazendo o mesmo período máximo de três anos de tratamento. (Figura 2)

Imuno
Figura 2 - Esboço do estudo aberto (Fase 2)

No início desta segunda fase, a randomização foi revelada aos pacientes e ao médico homeopata responsável pelo acompanhamento mensal, a fim de que pudesse avaliar a resposta terapêutica dos medicamentos anteriormente prescritos e continuar selecionando a medicação individualizada para cada paciente. A médica alergo-imunologista, responsável pelas avaliações clínicas e alérgicas da rinite e pela 
coleta dos exames complementares ao final de cada período de 6-12 meses de tratamento homeopático, permaneceu desconhecendo o grupo a que cada paciente foi alocado inicialmente até o término do estudo.

Todos os pacientes que optaram por permanecer nesta segunda fase assinaram novos consentimentos livres e esclarecidos para cada período subseqüente de 6-12 meses de tratamento homeopático (Consentimento Livre e Esclarecido - Fase 2 Apêndice 3), abandonando o estudo à hora que desejassem, sem qualquer prejuízo para seu acompanhamento no HCFMUSP.

Nas visitas mensais 8-37 para o grupo ativo inicial (G1) e nas visitas mensais 843 para o grupo placebo inicial (G2), todos os pacientes continuaram a ser atendidos conforme descrito na primeira fase, com a medicação homeopática sendo avaliada e ajustada mensalmente de acordo à evolução clínica e global observada no período.

A fim de que a efetividade do tratamento homeopático pudesse ser avaliada por um período maior de acompanhamento (12-36 meses), premissa necessária e imprescindível para selecionar dentre as centenas de medicamentos homeopáticos aqueles melhor adaptados à totalidade sintomática característica dos enfermos, avaliações clínicas gerais (Ficha Clínica Geral - Anexo 4), clínico-alérgicas (Ficha de Rinite Alérgica - Anexo 5), laboratoriais (teste cutâneo, hemograma completo e imunoglobulinas séricas - Anexo 6) e da qualidade de vida (FACIT-Sp-12 - Anexo 7) foram aplicadas a todos os pacientes periodicamente, segundo o seguinte esquema:

- Pacientes do grupo ativo inicial (G1) que permaneceram no estudo foram avaliados nas visitas mensais 13, 25 e 37, correspondentes aos períodos aproximados de 12, 24 e 36 meses de tratamento homeopático; 
- Pacientes do grupo placebo inicial (G2) que permaneceram no estudo foram avaliados nas visitas mensais 13, 19, 31 e 43, correspondentes aos períodos aproximados de 6, 12, 24 e 36 meses de tratamento homeopático.

\section{IV.2. População estudada}

\section{IV.2.1. Critérios de inclusão}

- pacientes que após orientação adequada sobre o estudo clínico a ser realizado pelo investigador preencheram corretamente o consentimento livre e esclarecido e receberam uma cópia do documento;

- pacientes acima de 18 anos de idade, de ambos os sexos e qualquer raça;

- pacientes com pelo menos um ano de história de rinite alérgica perene e que apresentavam sintomas segundo critério de escore definido: escore basal de sinais e sintomas clínicos específicos da rinite $>6$ nas visitas 0 e 1 ;

- pacientes com teste cutâneo (prick test) positivo para aeroalérgenos;

- pacientes capacitados e habilitados a seguirem e aderirem ao esquema de visitas e à terapêutica instituída.

\section{IV.2.2. Critérios de exclusão}

- pacientes que participaram de estudo clínico prévio num prazo $<30$ dias;

- pacientes grávidas ou lactantes;

- pacientes com histórias recorrentes e/ou significativas de infecções das vias aéreas superiores; 
- pacientes com história alérgica a fármacos empregados nos tratamentos de doenças alérgicas e/ou imunológicas;

- pacientes com doença significativa que pudesse interferir no estudo, segundo avaliação clínica e subsidiária (laboratorial, radiológica etc.);

- pacientes com problema intelectual ou emocional que pudesse limitar a validade do consentimento para a participação no estudo;

- pacientes com rinite medicamentosa ou candidíase nasal significante;

- pacientes que estivessem utilizando medicamentos que pudessem levar a um quadro de rinite vasomotora (ex. vasoconstritor tópico);

- pacientes que fizeram imunoterapia num prazo $<12$ meses;

- pacientes que estivessem fazendo uso crônico de outra medicação (além das abaixo referidas) por um período $\geq 4$ semanas;

- pacientes que houvessem utilizado alguma das medicações abaixo, em tempo menor ao citado. (Tabela 1 - Medicamentos excludentes e período de wash-out)

Tabela 1 - Medicamentos excludentes e período de wash-out

\begin{tabular}{|c|c|}
\hline Medicamentos excludentes & Período de wash-out \\
\hline corticosteróide - nasal, otológico ou ocular & 2 semanas \\
\hline corticosteróide - inalatório, oral, intravenoso ou retal & 1 mês \\
\hline corticosteróide - intramuscular ou intra-articular & 3 meses \\
\hline corticosteróide tópico de uso na pele & 1 mês \\
\hline anti-histamínico via oral, exceto Astemizol & 7 dias \\
\hline cetotifeno, azelastina ou levocabastina & 2 semanas \\
\hline astemizol & 3 meses \\
\hline descongestionante ou antiinflamatório nasal, oral ou ocular & 3 dias \\
\hline atropina nasal ou brometo de Ipratrópio & 1 semana \\
\hline antibiótico sistêmico (qualquer forma) & 15 dias \\
\hline cromoglicato de sódio ou nedocromil & 2 semanas \\
\hline
\end{tabular}




\section{IV.2.3. Restrições observadas}

- nenhum paciente foi envolvido nas fases do estudo mais de uma vez;

- nenhuma pessoa envolvida diretamente com a administração do fármaco participou do estudo como paciente;

- pacientes com consentimento livre e esclarecido considerado incompleto não iniciaram o estudo;

- o estudo foi conduzido pelos mesmos investigadores acordados previamente no protocolo.

\section{IV.3. Tratamento prévio e concomitante}

\section{IV.3.1. Considerações gerais}

- nenhum paciente do estudo recebeu, concomitantemente, qualquer medicação que não estivesse acordada e registrada em protocolo;

- nenhum paciente do estudo recebeu, concomitantemente, qualquer medicação associada a uma incidência comprovada, clínica e laboratorialmente de hepatotoxicidade ou aumento das enzimas hepáticas;

- todas as medicações prévias ou concomitantes utilizadas um mês antes do início do estudo, incluindo qualquer produto OTC (produto farmacêutico de venda livre), bem como sua posologia, via de administração, duração do tratamento e as razões para seu uso foram registradas;

- conforme descrito no protocolo, ao longo do tratamento foram feitas alterações tanto na escolha como na posologia dos medicamentos homeopáticos, buscando-se 
uma melhor adaptação dos mesmos a cada paciente (individualização do medicamento, das doses e das potências), segundo as observações prognósticas homeopáticas;

- pacientes que utilizaram qualquer medicação que pudesse afetar o curso da doença foram excluídos do estudo.

\section{IV.3.2. Medicações restritas e proibidas após visita 1 e durante todo o estudo}

- corticosteróide sistêmico (oral, intravenoso, intramuscular ou intra-articular);

- corticosteróide tópico de uso na pele;

- corticosteróide tópico inalatório, nasal, ocular ou otológico;

- cromoglicato de sódio ou Nedocromil (qualquer forma);

- anti-histamínico (com exceção do anti-histamínico de resgate);

- descongestionante oral e nasal;

- antibiótico sistêmico;

- imunoterapia e outros produtos da farmacopéia homeopática além dos estabelecidos neste protocolo.

[Obs: Os pacientes que utilizaram algum medicamento com as características acima durante o protocolo puderam ser re-incluídos no estudo após afastamento por um período de wash-out correspondente ao citado no item IV.2.2. (Tabela 1 Medicamentos excludentes e período de wash-out)] 


\section{IV.4. Número de pacientes}

$\mathrm{Na}$ Fase 1, todos os pacientes voluntários que preencheram os critérios estipulados no protocolo (inclusão/exclusão) foram randomizados em dois grupos aleatórios, recebendo medicamento ativo (G1) e placebo (G2) pelo período correspondente a seis visitas mensais. Um total de 55 pacientes foi incluído nesta fase, segundo os critérios mínimos estipulados inicialmente (> 50 pacientes).

$\mathrm{Na}$ Fase 2, todos os pacientes remanescentes da fase inicial que desejaram permanecer no estudo, sem número mínimo ou \% de abandono estipulada, foram acompanhados por um período máximo de 36 meses de tratamento homeopático.

\section{IV.5. Duração do estudo}

O estudo foi dividido em duas fases:

- Fase 1: estudo clínico randomizado, duplo-cego e placebo-controlado com acompanhamento dos pacientes pelo período equivalente a seis visitas mensais (aproximadamente seis meses).

- Fase 2: estudo aberto com tratamento homeopático dos pacientes pelo período máximo equivalente a trinta e seis visitas mensais (aproximadamente trinta e seis meses).

\section{IV.6. Condução do estudo}


Em sua fase inicial (Fase 1), este estudo foi prospectivo, randomizado, duplocego, avaliando a eficácia do tratamento homeopático individualizado da rinite alérgica perene frente ao uso do placebo, por um período aproximado de seis meses.

Os pacientes foram incluídos consecutivamente e a substituição dos pacientes foi feita usando-se a seqüência disponível, não havendo alteração na ordem da seqüência estabelecida (ordem de entrada no protocolo ou de atendimento inicial). Os pacientes foram distribuídos aleatoriamente em dois grupos: um que recebeu medicamento(s) homeopático(s) (G1) e outro que recebeu placebo (G2).

Um profissional sem vínculo com o estudo, uma farmacêutica do Serviço de Clínica Médica Geral do HCFMUSP, realizou a randomização (método do sorteio), distribuindo prévia e aleatoriamente os pacientes nos grupos G1 e G2 conforme a ordem de entrada no protocolo $(01,02,03,04,05$ etc.). Após a conclusão da escala de randomização, relacionando o número de atendimento inicial do paciente (ordem de entrada no protocolo) aos grupos ativo (G1) e placebo (G2), esta farmacêutica entrou em contato com a farmacêutica responsável pela Farmácia HNCristiano (fornecedora dos medicamentos homeopáticos ao protocolo), repassando a lista de alocação dos pacientes nos referidos grupos.

Após cada consulta, o paciente se dirigia à respectiva farmácia (Rua Cristiano Viana $n^{\circ} 67$, próxima ao HCFMUSP), com a receita em que constava o respectivo número de atendimento $(01,02,03,04,05$ etc.), cabendo à farmacêutica responsável distribuir o medicamento ativo ou o placebo conforme a lista de randomização previamente estipulada. A profissional se comprometeu a manter sigilo absoluto sobre a escala de randomização, procurando tão somente a farmacêutica do Serviço de Clínica Médica Geral do HCFMUSP em caso de dúvidas, a qual se 
reportaria aos pesquisadores envolvidos, buscando solucionar as questões (vide item IV.13).

Os frascos dos medicamentos homeopáticos e placebos eram idênticos, tendo a capacidade de $20 \mathrm{ml}$, com conta-gotas próprio, sendo suficientes para o período de estudo programado. Caso ocorresse algum acidente com o medicamento, que desperdiçasse ou inutilizasse o seu conteúdo, o paciente deveria notificar imediatamente o pesquisador, para que novo frasco fosse providenciado, evitando-se a descontinuação do tratamento.

Os medicamentos foram fornecidos gratuitamente, após cada consulta, pela Farmácia HNCristiano.

Os pacientes e seus representantes foram orientados pelo investigador quanto à forma de administração do(s) medicamento(s) homeopático(s), posologia, freqüência e horários estabelecidos: o medicamento constitucional individualizado foi utilizado pelo paciente na posologia de três (3) gotas, em jejum, ao despertar, uma vez por semana, com a possibilidade de ajuste na posologia ao longo do estudo. Um folheto de orientação sobre a utilização dos medicamentos foi devidamente confeccionado e fornecido aos pacientes na visita 1 (Utilização dos Medicamentos - Instruções ao Paciente - Anexo 8).

Em relação ao uso de medicações concomitantes, os pacientes foram corretamente orientados segundo as especificações do protocolo.

Todos os pacientes foram acompanhados no Ambulatório CMG 4402 (Serviço de Clínica Médica Geral do HCFMUSP) e no Ambulatório de Rinite Alérgica 035 (Serviço de Alergia e Imunologia Clínica do HCFMUSP). 
Após a avaliação inicial da médica alergo-imunologista (visita 0), os pacientes foram acompanhados em retornos mensais pelo médico homeopata (Fase 1: visitas 1-7; Fase 2: visitas 8-42), sendo novamente avaliados no Ambulatório de Rinite Alérgica ao final do período equivalente a seis retornos mensais na Fase 1 (visita 7) e ao final dos períodos equivalentes a seis ou doze retornos mensais na Fase 2, conforme a alocação inicial nos grupos ativo ou placebo e a permanência no estudo [grupo ativo inicial (G1): visitas 13, 25 e 37, correspondentes aos períodos aproximados de 12, 24 e 36 meses de tratamento homeopático; grupo placebo inicial (G2): visitas 13, 19, 31 e 43, correspondentes aos períodos aproximados de 6, 12, 24 e 36 meses de tratamento homeopático]. (Tabela 2)

Tabela 2 - Seqüência de avaliações dos pacientes ao longo do estudo

\begin{tabular}{|c|c|c|c|c|}
\hline \multicolumn{2}{|c|}{$\begin{array}{l}\text { Ambulatório de Rinite Alérgica } \\
\text { (035) }\end{array}$} & \multicolumn{3}{|c|}{$\begin{array}{l}\text { Ambulatório da Clínica Médica Geral } \\
\text { (CMG4402) }\end{array}$} \\
\hline $\begin{array}{c}\text { Avaliação } \\
\text { clínico-alérgica }\end{array}$ & $\begin{array}{c}\text { Avaliação } \\
\text { laboratorial }\end{array}$ & $\begin{array}{l}\text { Avaliação } \\
\text { clínica geral }\end{array}$ & $\begin{array}{c}\text { Avaliação } \\
\text { homeopática }\end{array}$ & $\begin{array}{c}\text { Avaliação } \\
\text { qualidade de } \\
\text { vida }\end{array}$ \\
\hline $\begin{array}{l}\text { (Ficha de rinite } \\
\text { alérgica) }\end{array}$ & $\begin{array}{c}\text { (Teste cutâneo, } \\
\text { hemograma, } \\
\text { imunoglobulinas) }\end{array}$ & $\begin{array}{l}\text { (Ficha clínica } \\
\text { geral) }\end{array}$ & $\begin{array}{l}\text { (Ficha clínica } \\
\text { homeopática) }\end{array}$ & (FACIT-Sp-12) \\
\hline $\begin{array}{l}\text { Visitas 0, 7, 13, } \\
19,25,31,37 \text { } \\
43\end{array}$ & $\begin{array}{l}\text { Visitas } 0,7,13 \text {, } \\
19,25,31,37 \text { e } \\
43\end{array}$ & $\begin{array}{l}\text { Visitas 1, 7, 13, } \\
19,25,31,37 \text { e } \\
43\end{array}$ & Visitas 1 a 43 & $\begin{array}{l}\text { Visitas } 1,7,13 \\
19,25,31,37 \text {, } \\
43\end{array}$ \\
\hline
\end{tabular}

\section{IV.6.1. Instruções gerais}

- o protocolo do estudo, assim como a ficha clínica para documentação dos casos e os formulários para obtenção dos consentimentos livres e esclarecidos 
utilizados no estudo foram aprovados pela Comissão de Ética em Pesquisa do HCFMUSP;

- os investigadores informaram os pacientes quanto aos métodos, possíveis riscos e sobre o direito do paciente em abandonar o estudo a qualquer momento, na presença de testemunhas. Os formulários dos consentimentos livres e esclarecidos foram anexados e mantidos no prontuário do paciente;

- a história e o exame clínico foram checados paralelamente com os critérios de inclusão e exclusão para garantir a adequação do paciente ao estudo. Uma cópia do consentimento livre e esclarecido e assinada pelo paciente foi obtida antes do início do estudo, após explicação clara e objetiva sobre o estudo clínico. Uma cópia do consentimento ficou em propriedade do paciente;

- o medicamento em estudo foi retirado, posteriormente à consulta, diretamente na farmácia homeopática indicada (HNCristiano) e as instruções sobre a sua utilização foram fornecidas aos pacientes diretamente pelo pesquisador;

- para que ocorresse um mínimo de variabilidade, todas as avaliações foram realizadas pelos mesmos investigadores;

- durante o estudo, a aderência ao protocolo foi constantemente checada (uso correto e revisão da medicação), procurando-se evitar qualquer problema que pudesse prejudicar o adequado desenvolvimento do projeto;

- qualquer evento adverso foi anotado e especificado pelo paciente em um diário pessoal (caderneta fornecida ao paciente), sendo notificado em formulário próprio (Formulário de Eventos Adversos - Anexo 9) na próxima visita. 


\section{IV.6.2. Esquema de visitação}

\section{$>$ Visita 0 (Semana -1$)$}

Um consentimento livre e esclarecido foi obtido, após explicação ao paciente sobre os objetivos e riscos do estudo, assim como as alternativas terapêuticas para o tratamento de sua condição clínica; uma cópia assinada do termo retornou ao paciente. Os critérios de inclusão e exclusão foram preenchidos.

Procedimentos: 1) Identificação; 2) História médica; 3) Avaliação Clínico-alérgica ("Ficha de Rinite Alérgica"); 4) O paciente foi questionado sobre o uso de medicações concomitantes; 5) Sinais vitais; 6) Exame clínico geral; 7) Exame nasal; 8) Exames complementares (teste cutâneo, hemograma completo, imunoglobulinas séricas).

\section{$>$ Visita 1 (Semana 0)}

As visitas 0 e 1 ocorreram num intervalo de 7-30 dias.

Procedimentos: 1) História médica homeopática; 2) O paciente foi questionado sobre doenças concomitantes; 3) Revisão da condição geral da rinite; 4) Revisão de medicações concomitantes; 5) Sinais vitais; 6) Exame clínico geral; 7) Preenchimento da "Ficha Clínica Geral"; 8) Aplicação do "Questionário de Qualidade de Vida"; 9) Hierarquização e repertorização dos sintomas homeopáticos característicos; 10) Seleção dos possíveis medicamentos homeopáticos e conduta terapêutica; 11) Preenchimento da "Ficha Clínica Homeopática".

Alocação dos pacientes nos grupos:

- o paciente continuou reunindo todos os critérios para esta visita, em ordem de qualificação, e mostrou-se suficientemente sintomático para ser incluído no estudo; 
- estando o paciente de acordo com os critérios previamente estipulados (inclusão/exclusão), o mesmo recebeu uma numeração (01, 02, 03, 04, 05 etc.) conforme sua entrada seqüencial no estudo, sendo este número utilizado para alocar os pacientes segundo a escala de randomização nos grupos ativo (G1) ou placebo (G2);

- após esta visita, de posse da receita com o número de entrada seqüencial no protocolo $(01,02,03,04,05$ etc.), o paciente se dirigiu à Farmácia HNCristiano, retirando gratuitamente o medicamento homeopático individualizado na forma ativa (G1) ou placebo (G2), conforme a aleatorização inicialmente realizada e em posse da farmacêutica responsável;

- até a visita sete, o paciente procedeu de forma semelhante, permanecendo no mesmo grupo alocado inicialmente.

Instruções aos pacientes:

- os pacientes foram instruídos quanto às medicações restritas;

- os pacientes foram instruídos quanto à correta utilização dos medicamentos homeopáticos;

- qualquer evento adverso deveria ser anotado e especificado pelo paciente em um diário pessoal (caderneta fornecida ao paciente), devendo ser notificado em formulário próprio (Formulário de Eventos Adversos - Anexo 9) na próxima visita;

- o paciente deveria trazer na próxima visita as anotações de eventos adversos e o frasco do medicamento em uso.

\section{$>$ Visita 2 (Semana 4)}

Esta visita ocorreu um mês após a visita anterior (visita 1), quando se iniciou o tratamento homeopático na forma ativa (G1) ou placebo (G2). 
Caso houvesse alguma anormalidade nos exames complementares colhidos na visita inicial (visita 0), o paciente permaneceria no estudo somente se esta anormalidade:

- fosse esperada no curso da doença e não ocasionasse riscos;

- fosse clinicamente insignificante e não interferisse na condução do estudo.

O paciente foi excluído do estudo caso existisse anormalidade significativa.

Procedimentos: 1) História médica homeopática; 2) O paciente foi questionado sobre eventos adversos; 3) O paciente foi questionado sobre doenças concomitantes; 4) Revisão da condição geral da rinite; 5) A resposta terapêutica foi avaliada em comparação à visita anterior; 6) Nesta e em todas as visitas subseqüentes, o paciente foi questionado sobre a correta utilização da medicação (forma de administração, quantidade de gotas, freqüência de ingesta). Caso o paciente não estivesse de acordo com as recomendações protocolares, o tratamento poderia ser interrompido, invalidando-se este período ou a participação no estudo; 7) Revisão de medicações concomitantes; 8) Sinais vitais; 9) Exame clínico geral; 10) Conduta terapêutica; 11) Preenchimento da "Ficha Clínica Homeopática".

Associando a avaliação geral da rinite (resposta terapêutica na rinite) com a avaliação clínico-homeopática geral do indivíduo (resposta terapêutica global), o investigador optou pelas seguintes condutas terapêuticas:

A. Em caso de melhora evidente da sintomatologia anterior:

A.1. Manutenção do medicamento homeopático individualizado aumentando, diminuindo ou mantendo a posologia anterior;

A.2. Suspensão da medicação anteriormente utilizada. 
B. Em caso de permanência da sintomatologia anterior, sem melhoras ou com piora do quadro:

B.1. Substituição da medicação homeopática anteriormente utilizada por outra melhor adaptada às condições do doente, segundo o método de hierarquização e repertorização dos sintomas;

B.2. Oferecimento do anti-histamínico de resgate, concomitante à mudança da medicação homeopática.

Instruções aos pacientes:

- a forma correta de utilização do anti-histamínico de resgate foi orientada ao paciente, que o recebeu gratuitamente do HCFMUSP;

- o paciente deveria anotar num diário pessoal (caderneta) a freqüência com que fizesse uso do anti-histamínico, conforme a gravidade dos sintomas exigissem. Este fator seria utilizado como parâmetro de avaliação da eficácia do tratamento homeopático;

- o paciente foi instruído quanto à forma correta de utilização dos medicamentos homeopáticos, conforme o folheto anteriormente distribuído;

- qualquer evento adverso deveria ser especificado pelo paciente em um diário pessoal, devendo ser notificado em formulário próprio na próxima visita;

- o paciente deveria trazer, na próxima visita, as anotações de eventos adversos e o frasco do medicamento homeopático em uso.

$>$ Visitas 3 a 6 (semanas $8,12,16$ e 20 respectivamente)

Estas visitas ocorreram aproximadamente em períodos mensais.

Procedimentos e Instruções semelhantes à visita 2.

$>$ Visita 7 (semana 24) 
Nesta visita, foi concluída a Fase 1 do ensaio clínico (estudo duplo-cego, randomizado, placebo-controlado com a duração aproximada de seis meses).

Procedimentos: 1) História médica homeopática; 2) O paciente foi questionado sobre eventos adversos; 3) O paciente foi questionado sobre doenças concomitantes; 4) Revisão da condição geral da rinite; 5) A resposta terapêutica foi avaliada em comparação à visita anterior; 6) Nesta e em todas as visitas subseqüentes, o paciente foi questionado sobre a correta utilização da medicação (forma de administração, quantidade de gotas, freqüência de ingesta). Caso o paciente não houvesse seguido as recomendações protocolares, o tratamento poderia ser interrompido, invalidando-se este período de estudo; 7) Revisão de medicações concomitantes; 8) Sinais vitais; 9) Exame clínico geral; 10) Exame nasal; 11) Preenchimento da "Ficha de Rinite Alérgica"; 12) Preenchimento da "Ficha Clínica Geral"; 13) Preenchimento da "Ficha Clínica Homeopática"; 14) Preenchimento do "Questionário de Qualidade de Vida"; 15) Coleta de exames complementares (teste cutâneo, hemograma completo, imunoglobulinas séricas); 16) Preenchimento da "Ficha de Registro Final" (Ficha de Registro Final - Anexo 10).

Instruções aos pacientes:

- os medicamentos em estudo foram descontinuados; todos os frascos da medicação em teste foram coletados e armazenados;

- após o conhecimento da escala de randomização, todos os pacientes foram convidados a participar da segunda fase do estudo (estudo aberto), em que passariam a receber tratamento homeopático pelo período máximo aproximado de 36 meses; 
- caso não concordasse em participar da fase aberta e se alguma anormalidade ou evento adverso fosse observado, o paciente deveria retornar periodicamente até a resolução completa do mesmo;

- caso concordasse em participar da fase subseqüente, novo consentimento livre e esclarecido foi assinado;

- neste caso, nova conduta terapêutica foi efetuada, seguindo o modelo da visita 2 para os pacientes alocados inicialmente no grupo ativo (G1), e iniciando o tratamento homeopático com as hipóteses medicamentosas levantadas nas visitas anteriores para os pacientes alocados inicialmente no grupo placebo (G2);

- os pacientes continuaram retirando, gratuitamente, o(s) medicamento(s) homeopático(s) na Farmácia HNCristiano, assim como continuaram recebendo o anti-histamínico de resgate para utilizarem conforme suas necessidades.

$>$ Visitas 8 a 12 (semanas 28, 32, 36, 40 e 44 respectivamente)

Estas visitas ocorreram aproximadamente em períodos mensais.

Procedimentos e Instrucõos semelhantes à visita 2.

$>$ Visita 13 (semana 48)

Nesta visita, foram concluídas as primeiras seis visitas mensais (seis meses aproximadamente) de acompanhamento da Fase 2 do ensaio clínico.

Procedimentos e Instruções semelhantes à visita 7.

Visitas 14 a 18 (semanas 52, 56, 60, 64 e 68 respectivamente)

Estas visitas ocorreram aproximadamente em períodos mensais.

Procedimentos e Instruções semelhantes à visita 2.

> Visita 19 (semana 72) 
Nesta visita, foram concluídas as 12 visitas mensais (12 meses aproximadamente) de acompanhamento da Fase 2 do ensaio clínico.

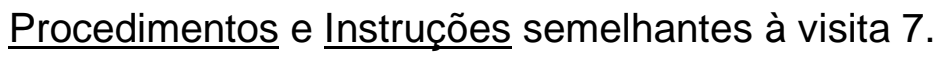

> Visitas 20 a 24 (semanas 76, 80, 84, 88 e 92 respectivamente)

Estas visitas ocorreram aproximadamente em períodos mensais.

Procedimentos e Instruções semelhantes à visita 2.

$>$ Visita 25 (semana 96)

Nesta visita, foram concluídas as 18 visitas mensais (18 meses aproximadamente) de acompanhamento da Fase 2 do ensaio clínico.

Procedimentos e Instruções semelhantes à visita 7.

$>$ Visitas 26 a 30 (semanas 100, 104, 108, 112 e 116 respectivamente)

Estas visitas ocorreram aproximadamente em períodos mensais.

Procedimentos e Instruções semelhantes à visita 2.

$>$ Visita 31 (semana 120)

Nesta visita, foram concluídas as 24 visitas mensais (24 meses aproximadamente) de acompanhamento da Fase 2 do ensaio clínico.

Procedimentos e Instruções semelhantes à visita 7.

Visitas 32 a 36 (semanas 124, 128, 132, 136 e 140 respectivamente)

Estas visitas ocorreram aproximadamente em períodos mensais.

Procedimentos e Instruções semelhantes à visita 2.

$>$ Visita 37 (semana 144)

Nesta visita, foram concluídas as 30 visitas mensais (30 meses aproximadamente) de acompanhamento da Fase 2 do ensaio clínico.

Procedimentos e Instruções semelhantes à visita 7. 
$>$ Visitas 38 a 42 (semanas 148, 152, 156, 160 e 164 respectivamente)

Estas visitas ocorreram aproximadamente em períodos mensais.

Procedimentos e Instruções semelhantes à visita 2.

$>$ Visita 43 (semana 168)

Nesta visita, foram concluídas as 36 visitas mensais (36 meses aproximadamente) de acompanhamento da Fase 2 do ensaio clínico.

Procedimentos e Instruções semelhantes à visita 7.

\section{IV.7. Avaliação clínica quantitativa}

\section{IV.7.1. Avaliação homeopática}

Em todas as visitas mensais, foram avaliados pelo médico homeopata os aspectos clínicos gerais (doenças concomitantes, eventos adversos, exame clínico etc.), os aspectos homeopáticos (psiquismo, emoções, disposição, sono, etc.), a condição geral da rinite e as respostas terapêuticas, adequadamente descritas no prontuário e na "Ficha Clínica Homeopática" (Anexo 3).

A avaliação alérgica (melhora ou piora da rinorréia, espirros, prurido, secreção retronasal e congestão) no período compreendido desde a última visita, juntamente com a avaliação homeopática do indivíduo (sintomas mentais, gerais e particulares), orientou o investigador na conduta terapêutica a seguir:

A. Em caso de melhora evidente da sintomatologia anterior:

A.1. Manutenção do medicamento homeopático individualizado aumentando, diminuindo ou mantendo a posologia anterior; 

A.2. Suspensão da medicação anteriormente utilizada.
B. Em caso de permanência da sintomatologia anterior, sem melhoras ou com piora do quadro:
B.1. Substituição da medicação homeopática anteriormente utilizada por outra melhor adaptada às condições do doente, segundo o método de hierarquização e repertorização dos sintomas;
B.2. Oferecimento do anti-histamínico de resgate, concomitante à mudança da medicação homeopática.

\section{IV.7.2. Avaliação clínico-alérgica específica e geral}

As avaliações clínico-alérgicas da rinite e da síndrome alérgica foram realizadas nas visitas mensais $0,7,13,19,25,31,37$ e 43 pela médica alergo-imunologista, seguindo o modelo da "Ficha de Rinite Alérgica" (Anexo 5) utilizada nos Serviços de Otorrinolaringologia \& Alergia e Imunologia do HCFMUSP, na qual foram quantificados através de pontuações, dentre outros aspectos, o quadro clínicoalérgico específico (Tabela 3), o quadro clínico-alérgico geral (Tabela 4) e a suscetibilidade alérgica (Tabela 5), para que a eficácia e a efetividade do tratamento homeopático individualizado pudesse ser avaliada.

Ao final da "Ficha de Rinite Alérgica", a gravidade ou intensidade da doença foi classificada segundo a pontuação do escore dos sinais e sintomas específicos da rinite alérgica (Tabela 3) em quatro graus (I, II, III e IV) e seus respectivos tratamentos (Tabela 6). Isto indica a importância deste grupo de sinais e sintomas na avaliação clínico-alérgica. 
Tabela 3 - Quadro clínico-alérgico específico (sinais e sintomas específicos da rinite)

\begin{tabular}{|c|c|c|c|}
\hline \multirow{2}{*}{\multicolumn{2}{|c|}{$\begin{array}{l}\text { Sintomas } \\
\text { Rinorréia }\end{array}$}} & \multirow{3}{*}{$\begin{array}{c}\text { Escore } \\
0\end{array}$} & \multirow{2}{*}{$\begin{array}{c}\text { Sinais } \\
\text { Cornetos (coloração) }\end{array}$} \\
\hline & & & \\
\hline 0 & Ausente & & Róseo \\
\hline 1 & Limpeza 1-4 vezes ao dia & 1 & Avermelhado/ rosa pálido \\
\hline 2 & Limpeza 5-10 vezes ao dia & 2 & Vermelho/ pálido \\
\hline 3 & Limpeza constante & 3 & Anêmico/ azulado \\
\hline & Espirros/ prurido & & Rinorréia \\
\hline 0 & Ausente & 0 & Ausente \\
\hline 1 & 1-4 por dia/ prurido ocasional & 1 & Mucosa aparece úmida \\
\hline 2 & $\begin{array}{l}5-10 \text { por dia/ prurido esporádico por } \\
30 \text { minutos }\end{array}$ & 2 & $\begin{array}{l}\text { Secreção visível em cornetos ou } \\
\text { assoalho da fossa nasal }\end{array}$ \\
\hline 3 & $\begin{array}{l}11 \text { ou mais/ interfere com } \\
\text { atividades }\end{array}$ & 3 & Profusa/ drenando \\
\hline & Secreção retronasal & & Inflamação faríngea \\
\hline 0 & Ausente & 0 & Ausente \\
\hline 1 & Sensação de secreção na garganta & 1 & Orofaringe discretamente vermelha \\
\hline 2 & Limpeza freqüente da garganta & 2 & $\begin{array}{l}\text { Orofaringe vermelha e folículos } \\
\text { linfóides aparentes }\end{array}$ \\
\hline 3 & Tosse e incomoda para falar & 3 & $\begin{array}{l}\text { Muco visível na parede posterior da } \\
\text { orofaringe }\end{array}$ \\
\hline & Congestão / Obstrução Nasal & & Edema \\
\hline 0 & Ausente & 0 & Ausente \\
\hline 1 & Pequena e não atrapalha & 1 & $\begin{array}{l}\text { Hipertrofia de corneto inferior ou } \\
\text { médio com pequeno bloqueio nasal }\end{array}$ \\
\hline 2 & $\begin{array}{l}\text { Respiração bucal na maior parte do } \\
\text { dia }\end{array}$ & 2 & $\begin{array}{l}\text { Congestão comprometendo a } \\
\text { respiração em uma ou ambas as } \\
\text { narinas }\end{array}$ \\
\hline 3 & $\begin{array}{l}\text { Não respira pelo nariz/ interfere no } \\
\text { sono, olfato ou voz }\end{array}$ & 3 & $\begin{array}{l}\text { Congestão impedindo a respiração } \\
\text { em uma ou ambas as narinas }\end{array}$ \\
\hline
\end{tabular}

FONTE: Tabela de escores utilizada no Serviço de Alergia e Imunologia Clínica e na Clínica de Otorrinolaringologia do HCFMUSP. E.O. Meltzer, 1988, validada e adaptada por J.F. Mello Jr. (Meltzer et al., 1988; Castro, 1998; Mello Júnior et al., 2002; Balbani et al., 2002; Lemos et al., 2007)

Tabela 4 - Quadro clínico-alérgico geral (sintomas alérgicos gerais ou síndrome alérgica)

Quadro clínico $(0 /+++)$

Sintomas pulmonares

Sintomas cutâneos

Sintomas sinusais

Sintomas oculares

Espirros/prurido

Coriza

Obstrução nasal

Secreção retronasal

Epistaxe

Sintomas auriculares

Outros (respiração oral, roncos ou pigarro) 
Tabela 5 - Suscetibilidade alérgica (fatores agravantes e/ou precipitantes da rinite)

Fatores agravantes e/ou precipitantes $(0 /+++)$

Inalantes: poeira, fungos, paina, piretro, lã, penas e pelos

Irritantes específicos: alterações meteorológicas, exercícios, estresse emocional, ciclo menstrual, drogas e alimentos

Tabela 6 - Gravidade ou intensidade da rinite (escore de sinais e sintomas da rinite)

\begin{tabular}{c|c|l}
\hline Escore & Grau & Tratamento \\
\hline $1-6$ & I & Cuidados gerais + anti-histamínico (tópico ou oral) \\
\hline $7-12$ & II & Item I + corticosteróide tópico + imunoterapia (s.n.) \\
\hline $13-18$ & III & Item I + corticosteróide tópico + imunoterapia (s.n.) \\
\hline $19-24$ & IV & Item III + corticosteróide sistêmico + imunoterapia \\
\hline
\end{tabular}

Vale ressaltar que para a inclusão do paciente no estudo, o mesmo deveria apresentar um escore $>6$ para o total de sinais e sintomas específicos da rinite (escore $\geq 7$ ou grau de gravidade $\geq 2$ ), nas visitas 0 e 1 .

\section{IV.8. Freqüência de utilização de drogas de resgate}

Os pacientes que precisaram utilizar o anti-histamínico de resgate, em vista da ausência de melhora significativa pelo tratamento administrado, foram avaliados nas visitas $0,7,13,19,25,31,37$ e 43 quanto à freqüência total de consumo do mesmo. De forma análoga aos estudos com imunoterapia citados anteriormente, estes dados poderiam ser indicativos da eficácia e da efetividade do tratamento proposto.

\section{IV.9. Avaliação laboratorial}


Os pacientes foram avaliados nas visitas $0,7,13,19,25,31,37$ e 43 por exames complementares empregados no acompanhamento da rinite alérgica perene (Anexo 6): hemograma completo, teste cutâneo (dupla fita) e imunoglobulinas séricas.

\section{IV.10. Avaliação clínica geral}

Os pacientes foram avaliados nas visitas $1,7,13,19,25,31,37$ e 43 segundo uma "Ficha Clínica Geral" (Anexo 4), em que as doenças concomitantes foram descritas, a fim de que se avaliasse a melhora clínica global (totalidade sintomática) propiciada pelo tratamento homeopático individualizado.

\section{IV.11. Avaliação da qualidade de vida}

Os pacientes preencheram um questionário de avaliação da qualidade de vida auto-aplicável (FACIT-Sp-12 - Anexo 7) nas visitas 1, 7, 13, 19, 25, 31, 37 e 43, a fim de que se avaliasse a evolução de aspectos subjetivos ao longo do tratamento homeopático individualizado.

O instrumento de avaliação da qualidade de vida utilizado (FACIT-Sp-12) é originário do FACT-G, que teve sua tradução transcultural para o português revalidada em nosso país (Furia, 2006). Tanto a tradução quanto a autorização para uso neste estudo foram concedidas pela FACIT (Functional Assessment Chronic Illness) (FACIT, 2008). 


\section{IV.12. Avaliação clínica qualitativa}

A evolução dos pacientes pertencentes a cada grupo inicial (ativo e placebo) foi analisada de forma qualitativa e individual ao longo das diversas fases do ensaio. Os efeitos preventivos ou residuais do tratamento homeopático individualizado foram constatados na narrativa fenomenológica dos pacientes (relatório por e-mail) após o encerramento do protocolo.

\section{IV.13. Fornecimento da medicação}

Conforme citado anteriormente, uma farmacêutica do Serviço de Clínica Médica Geral do HCFMUSP, sem vínculo com o estudo, realizou a distribuição prévia e aleatória dos pacientes nos grupos G1 e G2, conforme a ordem de entrada no protocolo $(01,02,03,04,05$ etc. $)$.

O fornecimento gratuito dos medicamentos homeopáticos foi assumido pela Farmácia HNCristiano, situada à Rua Cristiano Viana ${ }^{\circ} 67$.

Nas visitas mensais da fase inicial (visitas 1 a 7), a farmácia aviou as receitas dos medicamentos homeopáticos prescritos (identificadas pelo código da seqüência de entrada do paciente no estudo: 01, 02, 03, 04, 05 etc.), fornecendo substâncias ativa $(A)$ ou placebo $(P)$ segundo a escala randômica previamente recebida (por exemplo, 01-A, 02-P, 03-P, 04-A, 05-P etc.), que não se modificou ao longo desta fase inicial (Fase 1), sendo retirados pelo paciente junto à mesma. 
Após a visita 7, os pacientes passaram a receber tratamento homeopático (Fase 2), retirando os medicamentos ativos prescritos nas receitas sem o "código da randomização". No lugar do "código", constou a assertiva "Fase 2".

Havendo necessidade de substituir ou repor alguma medicação homeopática em uso para um paciente envolvido no estudo, o fornecimento e a distribuição seguiram os procedimentos acima descritos.

Toda medicação fornecida foi estocada pelo paciente em local apropriado, evitando-se a umidade, o calor e a incidência de luz direta.

(Obs: Assim como nas receitas, constaram no rótulo dos frascos os nomes dos pacientes, os nomes dos medicamentos homeopáticos e o respectivo código de randomização ou a fase do projeto).

As preparações medicamentosas utilizadas no estudo foram as seguintes:

A. Medicamento homeopático individualizado: medicamento homeopático na forma líquida, em solução hidroalcoólica a 20\%, acondicionado num frasco de $20 \mathrm{ml}$ com conta-gotas individual, aviado segundo as especificações da Farmacopéia Homeopática Brasileira (Farmacopéia Homeopática Brasileira, 2002) na potência inicial $30 \mathrm{cH}$ (diluição de $1 / 10^{60} \mathrm{~mol}$ ). Tanto o medicamento quanto a potência foram alteradas ao longo do estudo para se adaptar aos ajustes individuais necessários.

B. Anti-histamínico de resgate: foi utilizada a Dexclorfeniramina (4 mg/cp), na dosagem de 1 comprimido a cada 12 horas.

Toda medicação foi checada a cada visita, sendo o paciente orientado a trazer o frasco do medicamento, a cartela de anti-histamínicos e a caderneta de anotações em todas as visitas. 


\section{IV.14. Eventos adversos}

\section{IV.14.1. Potenciais eventos adversos do tratamento homeopático}

Em vista do tratamento homeopático utilizar o princípio terapêutico da similitude, com o intuito de estimular uma reação curativa do organismo através da administração de uma substância que causou nos indivíduos sadios sintomas semelhantes aos dos indivíduos doentes, algumas alterações específicas podem ser observadas nos pacientes após a ingesta do medicamento, descritas nas observações prognósticas homeopáticas (Teixeira, 1997).

\section{IV.14.1.1. Agravação homeopática}

Como principal evento adverso, totalmente relacionado ao tratamento homeopático, a agravação homeopática propriamente dita pode ocorrer como fruto da administração do medicamento corretamente escolhido em doses ou potências inadequadas: ação primária do medicamento intensa, induzindo uma exacerbada doença medicamentosa (apesar de semelhante à doença natural). Nestes casos, os sintomas da doença natural aumentam inicialmente, dando a falsa impressão de que o paciente está piorando. Geralmente, após um breve período desta agravação homeopática, instala-se uma melhora generalizada que reitera um prognóstico e uma evolução favorável.

Quando esta agravação homeopática ocorre, ela é observada nas primeiras semanas após a administração do medicamento que apresenta sintomas semelhantes aos da enfermidade que se deseja tratar. Daí o uso cuidadoso do medicamento constitucional em potências médias $(30 \mathrm{cH})$ e doses únicas semanais (mensais ou bimensais), aguardando-se quatro semanas para avaliar o efeito do 
mesmo. Em caso de piora dos sintomas, deve-se observar se o episódio apresentou alguma relação com a repetição excessiva das doses (super-dosagem); neste caso, basta suspender a administração do medicamento para que o desconforto desapareça.

\section{IV.14.1.2. Retorno de sintomas antigos}

O retorno de sintomas antigos (RSA), que desapareceram há algum tempo por outro tipo de tratamento, indica um bom prognóstico, esperando-se uma melhora evidente dos sintomas da doença após o surgimento destes. Segundo as observações prognósticas homeopáticas, isto indica que a reação do organismo está ocorrendo de uma forma satisfatória (segundo as leis de cura homeopáticas). Assim como na agravação homeopática, caso este evento adverso ocorra ao longo do tratamento, juntamente com uma melhora clínica dos sintomas tratados, importa esclarecer ao paciente que ele não está piorando, pensamento imediato de quem não entende as reações despertadas pelo tratamento homeopático.

\section{IV.14.1.3. Exonerações}

Estimulando a reação do organismo, em busca do equilíbrio das sensações e funções vitais, o medicamento homeopático pode promover uma ativação dos emunctórios naturais do organismo, aumentando as secreções e excreções fisiológicas naturais (transpiração, coriza, leucorréia, urina, fezes etc.). Observada como bom prognóstico, apresenta curta duração, sem causar maiores incômodos.

\section{IV.14.1.4. Sintomas novos}

O surgimento de sintomas novos após o medicamento homeopático, desde que incomodativos e incomuns, pode indicar que o mesmo não apresenta uma similitude ideal, causando uma doença artificial dessemelhante ao conjunto de sintomas 
apresentados. No entanto, estas características individuais despertadas pelo medicamento homeopático pouco semelhante podem auxiliar na escolha de um outro medicamento mais bem adaptado ao caso. Como conduta padrão, estes sintomas novos devem ser incorporados aos antigos, e uma nova repertorização com todos os sintomas deve indicar um novo medicamento.

\section{IV.14.2. Notificação dos eventos adversos}

Um evento adverso é qualquer ocorrência indesejável, não tendo necessariamente relação causal com o tratamento em estudo. Isto inclui quaisquer alterações psíquicas ou físicas apresentadas pelo indivíduo, relacionadas ou não ao uso do fármaco em estudo.

Todos os eventos adversos que surgiram ao longo do estudo foram registrados no prontuário e descritos no "Formulário de Eventos Adversos" (Anexo 9). Para cada evento adverso foram registrados: datas de início e término, duração, relação e efeito sobre a administração do medicamento em estudo (ex. interrupção ou descontinuidade da ingesta), utilização de qualquer outro fármaco para tratar este efeito, assim como a ocorrência de acontecimentos ou mudanças marcantes na vida ou na rotina do indivíduo. A gravidade do evento adverso e a relação com o medicamento em estudo foram avaliadas individualmente, recebendo orientações específicas em cada caso.

Os indivíduos foram questionados e/ou examinados pelo pesquisador em relação à evidência de eventos adversos. O questionamento sobre eventos adversos específicos do modelo homeopático foi realizado levando-se em conta a agravação 
homeopática, o retorno de sintomas antigos, as exonerações e o surgimento de sintomas novos, registrados no prontuário e descritos na "Ficha Clínica Homeopática" (Anexo 3).

\section{IV.14.3. Classificação de eventos adversos quanto à gravidade e à relação com o medicamento}

A gravidade dos eventos adversos foi classificada usando as definições abaixo.

(Tabela 7)

Tabela 7 - Classificação quanto à gravidade dos eventos adversos

\begin{tabular}{l|l}
\hline Grau 1 - Leve & $\begin{array}{l}\text { Sinal, sintoma ou evento perceptível, mas facilmente } \\
\text { tolerado. }\end{array}$ \\
\hline Grau 2 - Moderado & $\begin{array}{l}\text { Desconforto suficiente para provocar interferência na } \\
\text { atividade habitual podendo merecer intervenção. }\end{array}$ \\
\hline Grau 3 - Grave & $\begin{array}{l}\text { Provoca limitação, com incapacidade de realizar } \\
\text { atividades habituais ou afeta significativamente o estado } \\
\text { clínico e merece intervenção. }\end{array}$ \\
\hline Grau 4 - Potencialmente Fatal & Risco de morte imediato. \\
\hline
\end{tabular}

O pesquisador também avaliou a relação de qualquer evento adverso com o uso do medicamento em estudo, seguindo as orientações abaixo. (Tabela 8)

Tabela 8 - Relação do medicamento com os eventos adversos

\begin{tabular}{l|l}
\hline 0 - Não relacionado & $\begin{array}{l}\text { Sem associação temporal, ou a causa do evento foi } \\
\text { identificada, ou o medicamento não pode ser implicado } \\
\text { com base nas informações disponíveis. }\end{array}$ \\
\hline 1 - Possivelmente relacionado & $\begin{array}{l}\text { Associação temporal, mas outras etiologias são a causa } \\
\text { provável. No entanto, o envolvimento do medicamento } \\
\text { não pode ser excluído. }\end{array}$ \\
\hline 2 - Provavelmente relacionado & $\begin{array}{l}\text { Associação temporal; outras etiologias são possíveis, } \\
\text { mas improváveis. }\end{array}$ \\
\hline 3 - Relacionado & $\begin{array}{l}\text { Associação temporal estabelecida ou o caso não é } \\
\text { razoavelmente explicado pelo estado clínico conhecido } \\
\text { do paciente ou qualquer outro fator. }\end{array}$ \\
\hline
\end{tabular}




\section{IV.14.4. Monitorização dos eventos adversos}

Os indivíduos que apresentaram eventos adversos foram acompanhados com avaliações clínicas e laboratoriais determinadas pelo pesquisador.

Todos os eventos adversos foram observados até a resolução satisfatória ou estabilização do paciente. Quaisquer ações adotadas e seus resultados foram registrados no prontuário e na ficha clínica do paciente. Para todos os eventos adversos que exigiram o afastamento do indivíduo do estudo, as avaliações clínicas e os exames complementares pertinentes foram repetidos, até a resolução final ou estabilização dos eventos.

\section{IV.14.5. Orientações para o tratamento de eventos adversos}

Pacientes que apresentaram evento adverso Grau 3 ou 4 durante o estudo, foram excluídos do estudo e o medicamento foi suspenso imediatamente.

No caso de agravação homeopática por repetição excessiva das doses do medicamento, a suspensão das mesmas foi suficiente para interromper o processo, observando-se melhora significativa dos sintomas após este incidente.

No caso de sintomas novos incomodativos, o efeito do medicamento homeopático que causou estes incômodos foi antidotado com um novo medicamento selecionado segundo o conjunto de todos os sintomas.

\section{IV.15. Descontinuação do estudo}


Os pacientes foram descontinuados do estudo em decorrência de um evento adverso significativo ou pela não-aderência ao protocolo. Pacientes afastados do estudo tiveram a razão adequadamente relatada no protocolo.

Em caso de descontinuação do estudo, foram realizados todos os exames complementares e avaliações delineadas para a visita final. Todos os testes laboratoriais feitos na visita inicial foram repetidos. Em caso de algum resultado anormal, desde que clinicamente significante, o paciente foi monitorado até o completo retorno da normalidade clínica e laboratorial. O registro final foi preenchido pelo investigador (Ficha de Registro Final - Anexo 10). Eventos adversos foram acompanhados até a sua resolução.

\section{IV.16. Análise estatística}

Este ensaio clínico foi composto por duas fases: uma fase inicial fechada e randomizada (Fase 1) que visou determinar a eficácia do tratamento homeopático individualizado frente ao uso de placebo num período de seis meses; e uma segunda fase aberta (Fase 2), com a participação voluntária dos pacientes da fase inicial, que se propôs a avaliar a efetividade do tratamento homeopático individualizado a médiolongo prazo, imprescindível ao ajuste do medicamento à complexidade da individualidade enferma.

Nesta segunda fase do ensaio (Fase 2), a efetividade clínica de períodos maiores de tratamento homeopático (12-36 meses) foi analisada estatisticamente frente à melhora do mesmo grupo de pacientes na fase controlada (Fase 1). 
Pelas analogias citadas anteriormente entre os modelos terapêuticos da imunoterapia sublingual e da homeopatia individualizada, a análise estatística seguiu os mesmos critérios do consenso da Organização Mundial de Alergia (WAO) para padronização dos ensaios clínicos com imunoterapia em alergias respiratórias (Canonica et al., 2007):

- Por ser um estudo de longa duração, dever-se-ia esperar um grande índice de desistências e desligamentos, tornando inviável a análise estatística "por intenção de tratamento" (intention-to-treat);

- A análise dos resultados mostrou a significância estatística (IC 95\% e $P<$ 0,05) juntamente com a diferença entre a variação média dos grupos (\% de variação ou magnitude da resposta);

- A magnitude da resposta (\% de variação) ao tratamento se relacionou à redução dos escores de pontuação das diversas variáveis entre os grupos placebo e ativo nos seis meses iniciais (Fase 1); e à redução dos escores de pontuação das diversas variáveis entre a fase controlada (6 meses iniciais) e as demais fases semestrais ou anuais posteriores (Fase 2), aceitando-se uma eficácia clínica mínima de $20 \%$ acima da resposta do mesmo grupo de pacientes ao término da fase inicial.

Desta forma, os resultados foram analisados "por protocolo", tendo sido incluídos no estudo apenas os subgrupos de pacientes que concluíram as diversas fases, considerando-se nível de significância de $0,05(\alpha=5 \%)$, ou seja, significância estatística para níveis descritivos inferiores a esse valor $(P<0,05)$. A normalidade foi testada e os valores extremos não foram desprezados. 
As variáveis quantitativas e paramétricas (normalidade estatística) foram expressas através da distribuição $t$ de Student por média e erro-padrão (médiatep) e representados por gráficos de barra. Decidiu-se pela utilização do erro padrão (ep), em vista das análises estatísticas serem realizadas entre populações com tamanhos amostrais problemáticos (pequenos e/ou diferentes), pois "o erro padrão da média de uma amostra é uma estimativa do desvio padrão da distribuição das médias de amostras com o mesmo tamanho e obtidas da mesma população", e "o erro padrão da estimativa diminui com o aumento do tamanho da amostra" (Lunet et al., 2006).

Para variáveis quantitativas não-paramétricas, utilizou-se a mediana e percentil 25-75 (mediana, 25-75\%) pelo teste $U$ de Wilcoxon-Mann-Whitney; neste caso, os gráficos utilizados foram do tipo Box Plot. Em todas as análises estatísticas foi empregado o programa SigmaStat (versão 2.03) e para a confecção dos gráficos o programa SigmaPlot (versão 2.01).

\section{IV.16.1. Análise descritiva das populações em estudo}

Os pacientes foram analisados, antes e após as diversas fases do tratamento, segundo as seguintes variáveis: gênero, idade, tempo da doença, tempo proporcional de doença, características específicas do quadro alérgico ("Ficha de Rinite Alérgica": escores dos sinais e sintomas específicos da rinite, dos sintomas alérgicos gerais e dos fatores agravantes e/ou precipitantes da rinite), exames complementares (teste cutâneo e imunoglobulinas séricas), utilização de antihistamínico de resgate, doenças concomitantes e parâmetros de avaliação da qualidade de vida. Estas variáveis foram agrupadas onde se fizeram necessárias. 


\section{IV.16.2. Análise quantitativa dos grupos de pacientes}

As variáveis quantitativas de eficácia e efetividade foram analisadas em todas as fases do ensaio, buscando caracterizar a evolução dos grupos iniciais ativo e placebo ao longo dos diversos períodos de tratamento homeopático:

- A primeira variável foram os parâmetros clínico-alérgicos (escores dos sinais e sintomas específicos da rinite, dos sintomas alérgicos gerais e dos fatores agravantes e/ou precipitantes da rinite), avaliados durante as duas fases do estudo, em períodos de avaliação relativos a seis visitas mensais, conforme definido anteriormente (vide item IV.7.2 - Avaliação específica da rinite e da síndrome alérgica - Tabelas 3, 4, 5 e 6; Ficha de rinite alérgica - Anexo 5). Em concordância à recomendação da Organização Mundial de Alergia (WAO), utilizamos o escore dos sinais e sintomas específicos da rinite (escore dos sintomas locais da doença alérgica) e o escore dos sintomas alérgicos gerais (escore dos sintomas sistêmicos da síndrome alérgica) como desfechos primário e secundário respectivamente, na avaliação da resposta específica ao tratamento homeopático.

- A segunda variável foi a freqüência da utilização de anti-histamínico de resgate, conforme definido anteriormente (vide item IV.8 - Freqüência de utilização de drogas de resgate). Segundo a recomendação da WAO, a utilização de drogas de resgate é considerada como desfecho primário juntamente com o escore dos sinais e sintomas específicos da rinite. 
- A terceira variável foram os exames complementares ou parâmetros paraclínicos (teste cutâneo e imunoglobulinas séricas), conforme definido anteriormente (vide item IV.9 - Avaliação laboratorial - Anexo 6). Vale ressaltar que a WAO estipula que nenhum parâmetro paraclínico poderá substituir os desfechos clínicos primários, sugerindo sua utilização apenas como desfecho secundário.

- A quarta variável foi a evolução das doenças concomitantes presentes no início do estudo (vide item IV.10 - Avaliação clínica geral - Anexo 4).

- A quinta variável foram os parâmetros de qualidade de vida, segundo o instrumento definido anteriormente (vide item IV.11 - Avaliação da qualidade de vida - FACIT-Sp-12 - Anexo 7).

\section{IV.16.3. Análise qualitativa e individual dos pacientes}

Com o intuito de ampliar o entendimento dos resultados encontrados na análise quantitativa dos grupos, acrescentou-se o estudo qualitativo da evolução dos pacientes nas diversas fases do ensaio, analisando o significado individual dos fenômenos observados na população em estudo.

Associando as informações do estudo aprofundado das individualidades com os dados da pesquisa quantitativa, buscou-se desenvolver um raciocínio lógico indutivo que validasse os pressupostos teóricos do modelo homeopático em relação ao efeito terapêutico e/ou preventivo do medicamento homeopático corretamente individualizado. (Turato, 2005). 
V. RESULTADOS 


\section{RESULTADOS}

Os resultados das duas fases deste ensaio clínico misto, segundo as variáveis de eficácia e efetividade propostas, serão descritos sobre dois aspectos:

- Análise quantitativa dos grupos placebo e ativo iniciais (Fase 1) e dos grupos de tratamento homeopático ao longo do tempo (Fase 2);

- Análise qualitativa e individual dos pacientes.

\section{V.1. Análise quantitativa dos grupos de pacientes}

\section{V.1.1. Fase 1 (estudo fechado com a duração de 6 meses de acompanhamento)}

\section{V.1.1.1. Amostra analisada}

Conforme os critérios de inclusão e exclusão estabelecidos no protocolo, 59 pacientes foram avaliados, dos quais quatro foram excluídos (dois por teste cutâneo negativo e dois por uso intermitente de corticosteróide sistêmico).

Dos 55 voluntários incluídos inicialmente no estudo (Fase 1), 28 foram randomizados no grupo ativo (G1) e 27 no grupo placebo (G2). Nesta fase inicial de aproximadamente seis meses de duração, 14 pacientes $(25 \%$ ou $14 / 55)$ descontinuaram o estudo: sete pacientes abandonaram voluntariamente o estudo 
antes de completar o primeiro mês de acompanhamento e receber intervenção (visita 2), e três antes de completar o sexto mês (visita 7); duas pacientes foram descontinuadas por gestação e duas por eventos secundários graves (cirurgia ortopédica e broncopneumonia de repetição). Desta forma, 41 pacientes concluíram a primeira fase, com 21 pacientes alocados no grupo ativo (G1) e 20 pacientes alocados no grupo placebo (G2). (Figura 3)

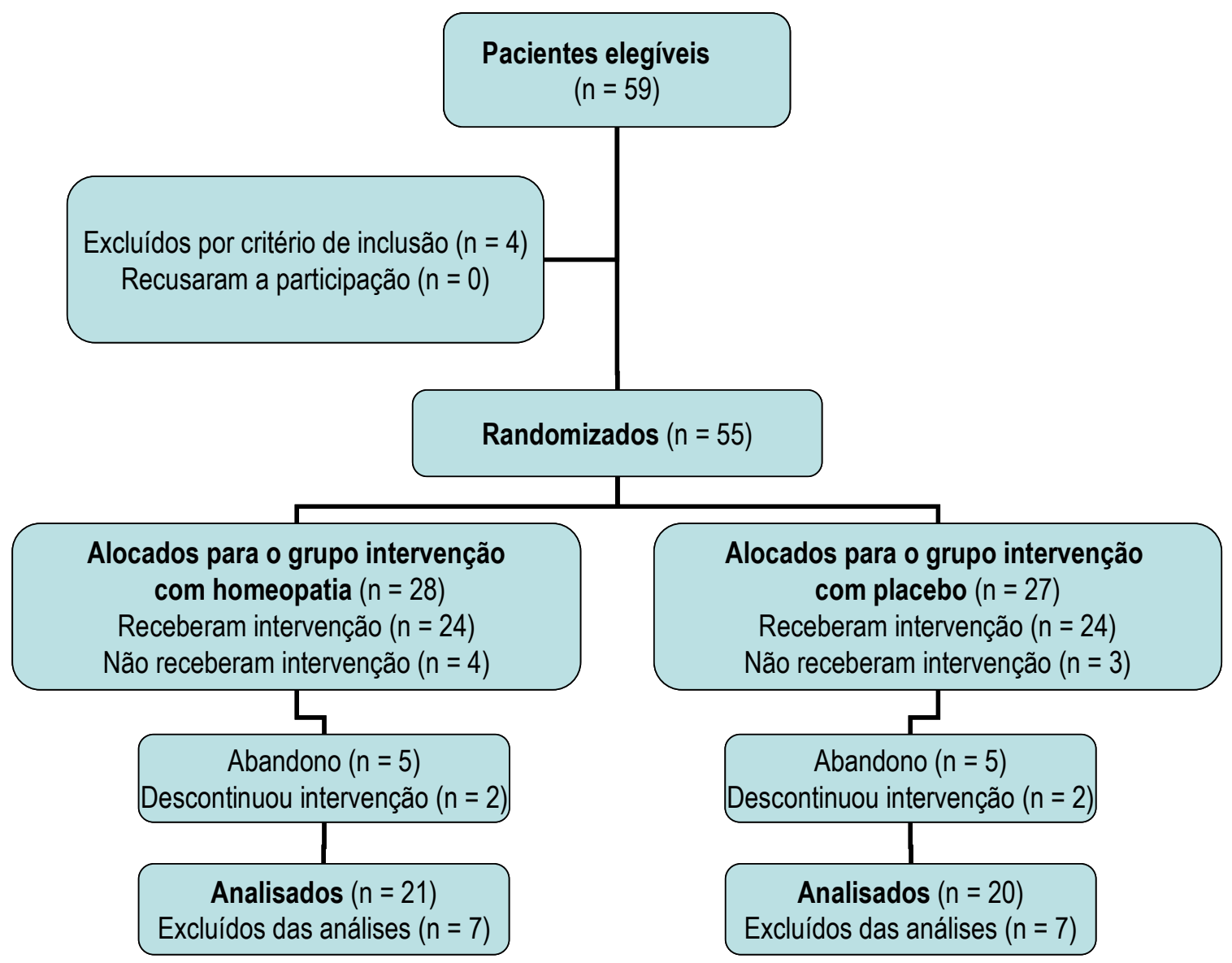

Figura 3 - Planejamento do estudo (Fase1) 


\section{V.1.1.1.2. Características da amostra}

Não foram encontradas diferenças estatisticamente significativas entre os grupos ativo (G1) e placebo (G2) em relação às seguintes características: gênero; tempo proporcional de doença; aspectos clínicos e alérgicos da rinite (escores dos sinais e sintomas específicos da rinite, sintomas alérgicos gerais, e fatores agravantes e/ou precipitantes da rinite); parâmetros laboratoriais; e aspectos da qualidade de vida. Encontrou-se diferença estatisticamente significativa em relação à idade e ao tempo de doença.

\section{V.1.1.1.3. Características descritivas da amostra em estudo (Tabela 9)}

Em relação ao gênero, o grupo placebo foi composto por 17 pacientes do gênero feminino e 3 do masculino, enquanto o grupo ativo foi composto por 15 e 6 , respectivamente.

Em relação à idade, o grupo placebo apresentou média de 26,65 anos e o grupo ativo de 33,05 anos, com diferença estatisticamente significativa $(P=0,030)$.

Em relação ao tempo de doença, o grupo placebo apresentou média de 10,25 anos e o grupo ativo de 16,90 anos, com diferença estatisticamente significativa $(P=$ 0,020).

Em relação ao tempo proporcional de doença (tempo de doença/idade), o grupo placebo apresentou média de $37,90 \%$ e o grupo ativo de $49,47 \%$, sem diferença estatisticamente significativa $(P=0,094)$.

Em relação à gravidade ou intensidade da doença (escore de sinais e sintomas específicos da rinite), desfecho primário na análise da eficácia do tratamento, o grupo placebo apresentou média do escore total basal de 14,80 pontos e o grupo ativo de 
15,38 pontos, ambos no grau III de gravidade da doença, sem diferença estatisticamente significativa $(P=0,554)$.

Em vista destes resultados, apesar do grupo ativo apresentar idade e tempo de doença (cronicidade da doença) significativamente maior do que o grupo placebo, aspectos que poderiam dificultar a capacidade de reação vital curativa daquelas constituições, ambos os grupos não apresentaram diferenças significativas em relação ao tempo proporcional de doença e ao escore dos sinais e sintomas específicos da rinite (gravidade da rinite), tornando os grupos homogêneos perante a principal variável de avaliação da resposta ao tratamento homeopático.

Tabela 9 - Características descritivas da amostra (Fase 1)

\begin{tabular}{|c|c|c|c|}
\hline & $\begin{array}{c}\text { Grupo placebo } \\
(n=20)\end{array}$ & $\begin{array}{l}\text { Grupo ativo } \\
(\mathrm{n}=21)\end{array}$ \\
\hline \multirow[t]{2}{*}{ Gênero } & Feminino & 17 & 15 \\
\hline & Masculino & 3 & 6 \\
\hline \multirow{2}{*}{\multicolumn{2}{|c|}{$\begin{array}{l}\text { Idade (anos) } \\
\text { (média } \pm \text { ep) }\end{array}$}} & $26,65 \pm 1,3$ & $33,05 \pm 2,5$ \\
\hline & & \multicolumn{2}{|c|}{$P=0,030$} \\
\hline \multirow{2}{*}{\multicolumn{2}{|c|}{$\begin{array}{l}\text { Tempo de doença (anos) } \\
\text { (média } \pm \text { ep) }\end{array}$}} & $10,25 \pm 1,3$ & $16,90 \pm 2,3$ \\
\hline & & \multicolumn{2}{|c|}{$P=0,020$} \\
\hline \multirow{2}{*}{\multicolumn{2}{|c|}{$\begin{array}{l}\text { Tempo proporcional de doença } \\
\text { (idade/tempo doença \%) } \\
\text { (médiatep) }\end{array}$}} & $37,90 \pm 4,0$ & $49,47 \pm 2,5$ \\
\hline & & \multicolumn{2}{|c|}{$P=0,094$} \\
\hline \multirow{2}{*}{\multicolumn{2}{|c|}{$\begin{array}{l}\text { Gravidade ou intensidade da doença } \\
\text { (escore dos sinais e sintomas da rinite) } \\
\text { (média } \pm \text { ep) }\end{array}$}} & $14,80 \pm 0,6$ & $15,38 \pm 0,7$ \\
\hline & & \multicolumn{2}{|c|}{$P=0,554$} \\
\hline
\end{tabular}

V.1.1.2. Avaliação clínico-alérgica basal da rinite (tempo 0)

V.1.1.2.1. Quadro clínico-alérgico específico (escore dos sinais e sintomas específicos da rinite alérgica ou desfecho primário) 
Em relação à variável quadro clínico-alérgico específico, que avaliou a condição clínica da rinite alérgica através de quatro modalidades de sintomas subjetivos específicos (rinorréia, espirros/prurido, secreção retronasal e congestão ou obstrução nasal) e quatro modalidades de sinais objetivos específicos (rinorréia, inflamação faríngea, coloração e edema dos cornetos), empregando um escore descritivo e detalhado com valor máximo de 24 pontos (0-3 pontos/modalidade) (vide item IV.7.2, Tabela 3; Ficha de rinite alérgica - Anexo 5), o grupo placebo apresentou média de 14,80 pontos no escore total basal e o grupo ativo de 15,38 pontos, sem diferença estatisticamente significativa entre os grupos $(P=0,554)$. (Tabela 10)

Esta normalidade foi reiterada quando desmembramos a média do escore total basal na média dos escores parciais basais dos sinais objetivos (grupo placebo = 6,80 versus grupo ativo $=6,67 ; P=0,761$ ) e dos sintomas subjetivos (grupo placebo $=8,00$ versus grupo ativo $=8,71 ; P=0,266$ ) específicos da rinite.

$\mathrm{Na}$ classificação de intensidade ou gravidade da doença (graus I a IV), estipulada ao final da "Ficha de Rinite Alérgica" como parâmetro de indicação específica do tratamento convencional (Tabela 6; Anexo 5), a média dos escores basais dos sinais e sintomas clínicos específicos da rinite dos grupos placebo e ativo corresponderam ao grau III (13-18 pontos), tendo como terapêutica proposta “cuidados gerais + anti-histamínico + corticosteróide tópico + imunoterapia (s.n.)”.

A média do escore total basal dos grupos placebo e ativo corresponderam, respectivamente, a $62 \%$ e $64 \%$ do escore máximo de gravidade da rinite.

Pela especificidade da avaliação dos sinais e sintomas específicos da rinite e em concordância com a recomendação da Organização Mundial de Alergia (WAO) (Canonica et al., 2007), esta variável foi considerada como a de maior importância 
para a avaliação clínico-alérgica da doença (desfecho primário). Assim sendo, a fim de simplificar a exposição dos dados, priorizaremos esta variável em análises secundárias ("efeito placebo ao longo do acompanhamento homeopático", "análise separada dos grupos ativo e placebo iniciais ao longo dos períodos de tratamento homeopático", "análise qualitativa individual dos pacientes" etc.).

V.1.1.2.2. Quadro clínico-alérgico geral (sintomas alérgicos gerais ou sistêmicos, síndrome alérgica ou desfecho secundário)

Em relação à variável quadro clínico-alérgico geral, que avaliou a síndrome alérgica através de onze modalidades de sintomas alérgicos gerais ou sistêmicos [pulmonares, cutâneos, sinusais, oculares, auriculares, espirros/prurido, coriza, obstrução nasal, secreção retronasal, epistaxe e outros (respiração oral, roncos ou pigarro)], empregando um escore com valor máximo de 33 pontos (0-3 pontos/modalidade) (vide item IV.7.2, Tabela 4; Ficha de rinite alérgica - Anexo 5), o grupo placebo apresentou média de 14,90 pontos no escore basal e o grupo ativo de 16,86 pontos, sem diferença estatisticamente significativa $(P=0,203)$. (Tabela 10)

As médias do escore basal dos grupos placebo e ativo corresponderam, respectivamente, a $45 \%$ e $51 \%$ do escore máximo de gravidade da alergia geral.

Seguindo o consenso da Organização Mundial de Alergia (WAO) (Canonica et al., 2007), esta variável foi considerada como a segunda em importância (desfecho secundário) para a avaliação clínico-alérgica da rinite ao longo do estudo, por agrupar sintomas alérgicos de outros sistemas orgânicos e sintomas nasais específicos.

V.1.1.2.3. Suscetibilidade alérgica (fatores agravantes e/ou precipitantes da rinite alérgica) 
Em relação à variável suscetibilidade alérgica, que avaliou os fatores agravantes e/ou precipitantes da rinite alérgica através de sete modalidades de inalantes específicos (poeira, fungos, paina, piretro, lã, penas e pelos) e seis modalidades de irritantes específicos (alterações meteorológicas, exercícios, estresse emocional, ciclo menstrual, drogas e alimentos), empregando um escore com valor máximo de 39 pontos (0-3 pontos/modalidade) (vide item IV.7.2, Tabela 5; Ficha de rinite alérgica - Anexo 5), o grupo placebo apresentou mediana de 11,50 pontos no escore basal e o grupo ativo apresentou mediana de 11,00 pontos, sem diferença estatisticamente significativa $(P=0,754)$. (Tabela 10)

As médias do escore basal dos grupos placebo e ativo corresponderam, respectivamente, a $29 \%$ e $28 \%$ do escore máximo de gravidade da suscetibilidade alérgica, com uma aparente menor especificidade para a avaliação clínico-alérgica da rinite em comparação aos parâmetros anteriores.

Mudanças ambientais ocupacionais e domésticas não foram incorporadas à análise, pois foram mantidas inalteradas pelos pacientes ao longo do estudo, conforme solicitação e avaliação periódica (Ficha de Rinite Alérgica - Anexo 5).

\section{V.1.1.3. Avaliação laboratorial basal (tempo 0)}

O teste cutâneo para aeroalérgenos ( $\lg \mathrm{E}$ específica in vivo) foi utilizado como fator de inclusão dos pacientes no estudo. Assim sendo, todos os pacientes apresentaram reação cutânea positiva a pelo menos um aeroalérgeno.

A dosagem de $\lg E$ específica no sangue periférico (RAST) foi realizada inicialmente, conforme acordado entre os Serviços de Clínica Médica Geral e de 
Alergia e Imunologia Clínica do HCFMUSP. No entanto, a partir do vigésimo paciente, ela foi interrompida devido ao custo financeiro de manutenção exigido.

A dosagem de $\lg E$ total no sangue periférico foi realizada nas duas fases do estudo, excluindo três pacientes em que as amostras iniciais extraviaram $(n=38)$. Em relação a esta variável, cujo valor de referência é abaixo de $100 \mathrm{Ul} / \mathrm{ml}$, o subgrupo placebo $(n=19)$ apresentou mediana de 120,00 pontos no valor basal e o subgrupo ativo ( $n=19$ ) apresentou mediana de 233,00 pontos, sem diferença estatisticamente significativa $(P=0,793)$. (Tabela 10)

\section{V.1.1.4. Avaliação basal da qualidade de vida (tempo 0)}

Em relação à variável qualidade de vida, que avaliou a individualidade enferma através de cinco modalidades de aspectos subjetivos gerais [bem-estar físico (7 perguntas), bem-estar social-familiar (7 perguntas), bem-estar emocional (6 perguntas), bem-estar funcional (7 perguntas) e preocupações adicionais ou existenciais (12 perguntas)], empregando um escore com valor máximo de 156 pontos (0-4 pontos/pergunta) (Questionário de Qualidade de Vida FACIT-Sp-12 Anexo 7), o grupo placebo apresentou média de 120,05 pontos no escore basal e o grupo ativo de 114,43 pontos, sem diferença estatisticamente significativa $(P=$ 0,345). (Tabela 10)

Vale ressaltar que as médias dos escores basais dos grupos placebo e ativo corresponderam, respectivamente, a $77 \%$ e $73 \%$ do escore máximo de melhora na qualidade de vida, denotando uma baixa especificidade deste instrumento para a avaliação da qualidade de vida nos pacientes com rinite alérgica. 
Tabela 10 - Valor basal do escore dos parâmetros clínico-alérgicos, da qualidade de vida e laboratoriais

\begin{tabular}{|c|c|c|}
\hline & $\begin{array}{c}\text { Grupo placebo } \\
(n=20)\end{array}$ & $\begin{array}{c}\text { Grupo ativo } \\
(\mathrm{n}=21)\end{array}$ \\
\hline \multirow{2}{*}{$\begin{array}{l}\text { Quadro clínico-alérgico específico } \\
\text { (média } \pm \text { ep) }\end{array}$} & $14,80 \pm 0,6$ & $15,38 \pm 0,7$ \\
\hline & \multicolumn{2}{|c|}{$P=0,554$} \\
\hline \multirow{2}{*}{ 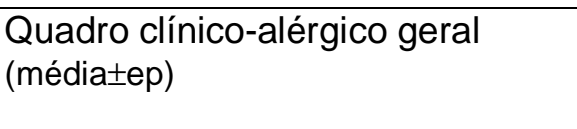 } & $14,90 \pm 1,1$ & $16,86 \pm 1,0$ \\
\hline & \multicolumn{2}{|c|}{$P=0,203$} \\
\hline \multirow[t]{2}{*}{$\begin{array}{l}\text { Suscetibilidade alérgica } \\
\text { [mediana }(25-75 \%)]\end{array}$} & $\begin{array}{c}11,50 \\
(10,5-15,5)\end{array}$ & $\begin{array}{c}11,00 \\
(10,0-15,2)\end{array}$ \\
\hline & \multicolumn{2}{|c|}{$P=0,754$} \\
\hline \multirow{2}{*}{$\begin{array}{l}\text { Qualidade de vida } \\
\text { (média } \pm \text { ep) }\end{array}$} & $120,05 \pm 4,1$ & $114,43 \pm 4,1$ \\
\hline & \multicolumn{2}{|c|}{$P=0,345$} \\
\hline \multirow{3}{*}{$\begin{array}{l}\text { IgE total }(\mathrm{Ul} / \mathrm{ml}) \\
\text { [mediana }(25-75 \%)]\end{array}$} & $(n=19)$ & $(n=19)$ \\
\hline & $\begin{array}{c}120,00 \\
(94,5-455,2)\end{array}$ & $\begin{array}{c}233,00 \\
(63,7-303,0)\end{array}$ \\
\hline & \multicolumn{2}{|c|}{$P=0,793$} \\
\hline
\end{tabular}

\section{V.1.1.5. Avaliação clínico-alérgica final da rinite (tempo $6 \mathrm{~m}$ )}

Após os seis meses iniciais de intervenção, não encontramos diferenças estatisticamente significativas entre os grupos placebo e ativo em relação aos parâmetros de avaliação clínico-alérgica (quadro clínico-alérgico específico, quadro clínico-alérgico geral e suscetibilidade alérgica).

V.1.1.5.1. Quadro clínico-alérgico específico

Após os seis meses iniciais de intervenção, o grupo placebo apresentou média de $10,55 \pm 0,66$ pontos no escore total dos sinais e sintomas específicos da rinite, denotando melhora clínico-alérgica estatisticamente significativa em relação à média de $14,80 \pm 0,64$ pontos do escore total basal, com diferença média padronizada (DMP) de 4,25 pontos (DMP 4,25; IC 95\% 2,39 a 6,1; $P<0,001$ ). O grupo ativo apresentou mediana de $11,00(8,75-14,25)$ pontos, com melhora estatisticamente significativa em relação à mediana de $16,00(14,75-18,00)$ pontos do escore total basal $(P=0,002)$. 
A variação de melhora dos grupos placebo e ativo corresponderam, respectivamente, a $25,86 \%$ e $21,89 \%$ de diminuição do escore total basal dos sinais e sintomas específicos da rinite, sem diferença estatisticamente significativa entre os grupos $(P=0,678)$. (Figura 4$)$

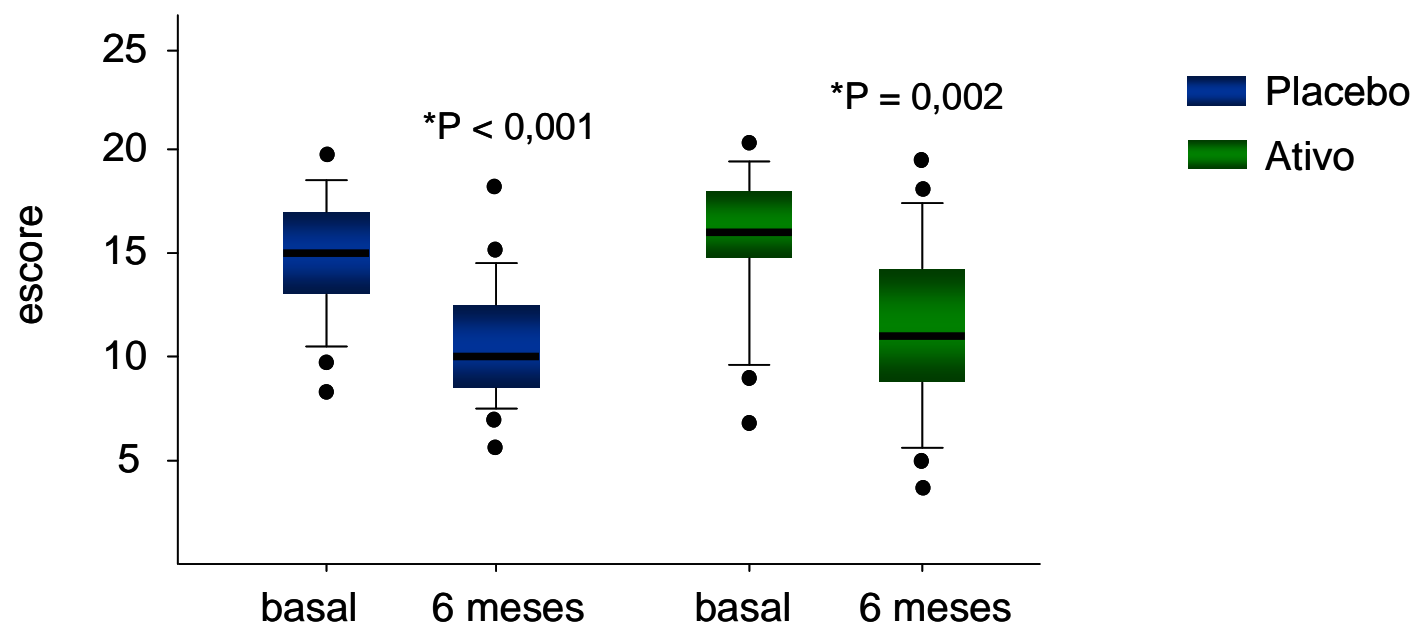

Figura 4 - Box Plot ilustrando as medianas dos escores de sinais e sintomas específicos da rinite dos grupos placebo e ativo, nos tempos basal e 6 meses. A barra (negra) representa a mediana, a base inferior da caixa está situada na altura do percentil $25 \%$ e a superior na do percentil $75 \%$. Não houve diferença estatisticamente significativa entre os grupos.

Numa análise secundária, esta normalidade de resposta foi reiterada quando desmembramos o escore total nos escores parciais dos sinais e dos sintomas específicos da rinite. Após os seis meses iniciais de intervenção, o grupo placebo apresentou média de $5,30 \pm 0,30$ pontos no escore parcial de sinais, com melhora estatisticamente significativa em relação à média de $6,80 \pm 0,25$ pontos do escore parcial basal (DMP 1,5; IC 95\% 0,71 a 2,29; $P<0,001$ ), e média de 5,25 $\pm 0,48$ pontos no escore parcial de sintomas, com melhora estatisticamente significativa em relação

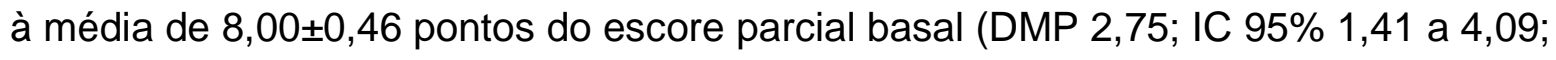


$P<0,001)$. O grupo ativo apresentou média de 5,52 $\pm 0,43$ pontos no escore parcial de sinais, com melhora significativa em relação à média de $6,67 \pm 0,35$ pontos do escore parcial basal (DMP 1,15; IC 95\% 0,02 a 2,27; $P<0,046$ ), e média de $5,86 \pm 0,51$ pontos no escore parcial de sintomas, com melhora significativa em relação à média de $8,71 \pm 0,44$ pontos do escore parcial basal (DMP 2,85; IC 95\% $1,50$ a 4,$21 ; P<0,001)$. Não foram observadas diferenças estatisticamente significativas entre os grupos, na melhora dos escores parciais de sinais $(P=0,566)$ e sintomas $(P=0,776)$ específicos da rinite.

$\mathrm{Na}$ classificação de gravidade ou intensidade da doença (graus I a IV), as médias dos escores totais dos sinais e sintomas específicos da rinite dos grupos placebo e ativo corresponderam ao grau II (7-12 pontos), tendo como terapêutica convencional proposta "cuidados gerais + anti-histamínico + corticosteróide tópico + imunoterapia (s.n.)" (Tabela 6). Esta diminuição de um grau na gravidade da rinite corresponde a uma melhora de $25 \%(1 / 4)$.

\section{V.1.1.5.2. Quadro clínico-alérgico geral}

Após os seis meses iniciais de intervenção, o grupo placebo apresentou média de $10,55 \pm 1,10$ pontos no escore dos sintomas alérgicos gerais, com melhora clínicoalérgica estatisticamente significativa em relação à média de $14,90 \pm 1,12$ pontos do escore basal (DMP 4,35; IC 95\% 1,16 a 7,53; $P=0,009$ ). $O$ grupo ativo apresentou média de $12,57 \pm 1,17$ pontos, com melhora estatisticamente significativa em relação à média de 16,86 $\pm 1,02$ pontos do escore basal (DMP 4,29; IC 95\% 1,17 a 7,40; $P=$ $0,008)$. 
A variação de melhora dos grupos placebo e ativo corresponderam, respectivamente, a $25,51 \%$ e $21,25 \%$ de diminuição do escore basal da síndrome alérgica, sem diferença estatisticamente significativa $(P=0,672)$. (Figura 5)

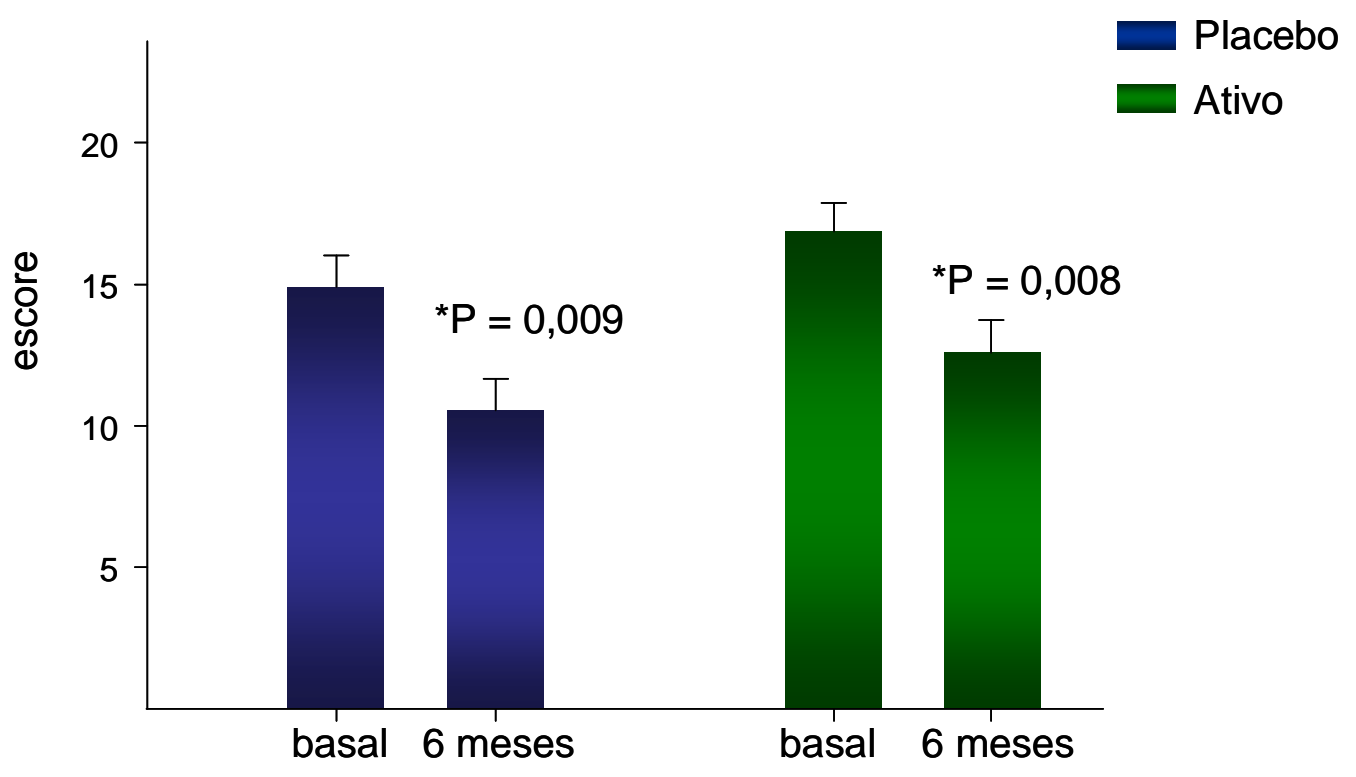

Figura 5 - Gráfico de barras ilustrando as médias dos escores dos sintomas alérgicos gerais dos grupos placebo e ativo, nos tempos basal e 6 meses. Não houve diferença estatisticamente significativa entre os grupos.

\section{V.1.1.5.3. Suscetibilidade alérgica}

Após os seis meses iniciais de intervenção, o grupo placebo apresentou média de $9,95 \pm 0,97$ pontos no escore dos fatores agravantes e/ou precipitantes da rinite alérgica, denotando melhora alérgica com forte tendência à significância estatística em relação à média de 12,55 $\pm 0,88$ pontos do escore basal (DMP 2,60; IC 95\% -0,04 a 5,24; $P=0,053)$. O grupo ativo apresentou média de $10,00 \pm 1,01$ pontos, com forte tendência à significância estatística em relação à média de $12,52 \pm 0,79$ pontos do escore basal (DMP 2,52; IC 95\% -0,08 a 5,12; $P=0,057)$. 
A variação de melhora dos grupos placebo e ativo $(0-6 \mathrm{~m})$ corresponderam, respectivamente, a 20,84\% e $20,18 \%$ de diminuição do escore basal dos fatores agravantes e/ou precipitantes da rinite alérgica, sem diferença estatisticamente significativa $(P=0,948)$. (Figura 6$)$

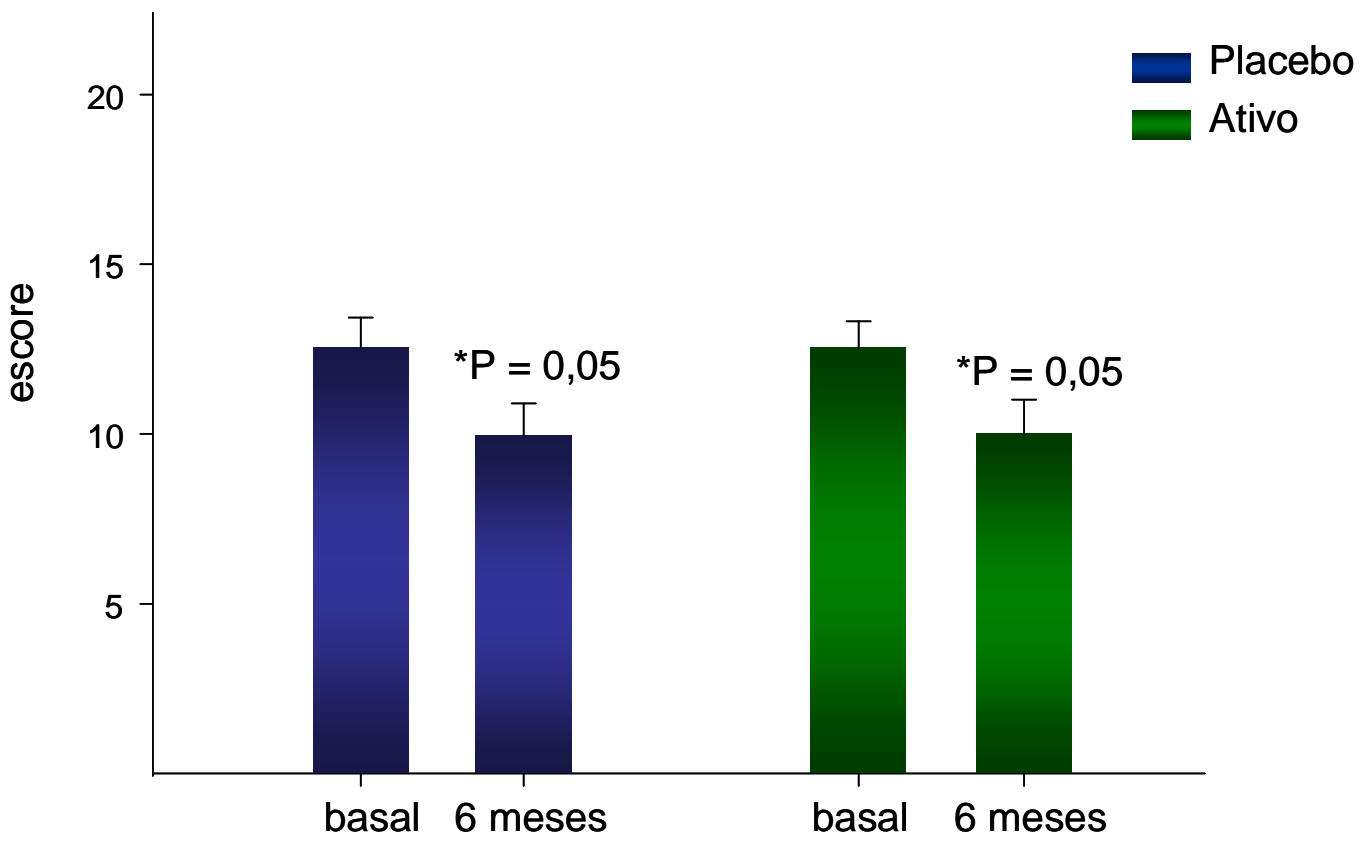

Figura 6 - Gráfico de barras ilustrando as médias dos escores dos fatores agravantes e/ou precipitantes da rinite dos grupos placebo e ativo, nos tempos basal e 6 meses. Não houve diferença estatisticamente significativa entre os grupos.

\section{V.1.1.6. Avaliação laboratorial final (tempo 6m)}

Os kits do teste cutâneo para aeroalérgenos ( $\lg \mathrm{E}$ específica in vivo) apresentaram grandes variações ao longo do período de acompanhamento dos pacientes, tanto no grupo de inalantes testados quanto na procedência dos mesmos (falta de padronização dos alérgenos), impossibilitando o emprego deste parâmetro como variável de avaliação da eficácia do tratamento. 
Em relação à variável IgE total, após os seis meses iniciais de tratamento, o grupo placebo $(n=19)$ apresentou mediana de $148,00 \mathrm{UI} / \mathrm{ml}$ no valor final, sem variação estatisticamente significativa em relação à mediana de $120,00 \mathrm{Ul} / \mathrm{ml}$ do valor basal $(P=0,661)$. O grupo ativo $(\mathrm{n}=19)$ apresentou mediana de $203,00 \mathrm{UI} / \mathrm{ml}$ no valor final, sem variação estatisticamente significativa em relação à mediana de 233,00 Ul/ml do valor basal $(P=0,511)$.

Ao final da fase inicial, o grupo placebo apresentou aumento de 9,60\% na mediana do valor basal da $\lg E$ total, enquanto o grupo ativo apresentou diminuição de $12,90 \%$ na mediana do valor basal da IgE total, sem diferença estatisticamente significativa entre os grupos $(P=0,609)$. (Figura 7$)$

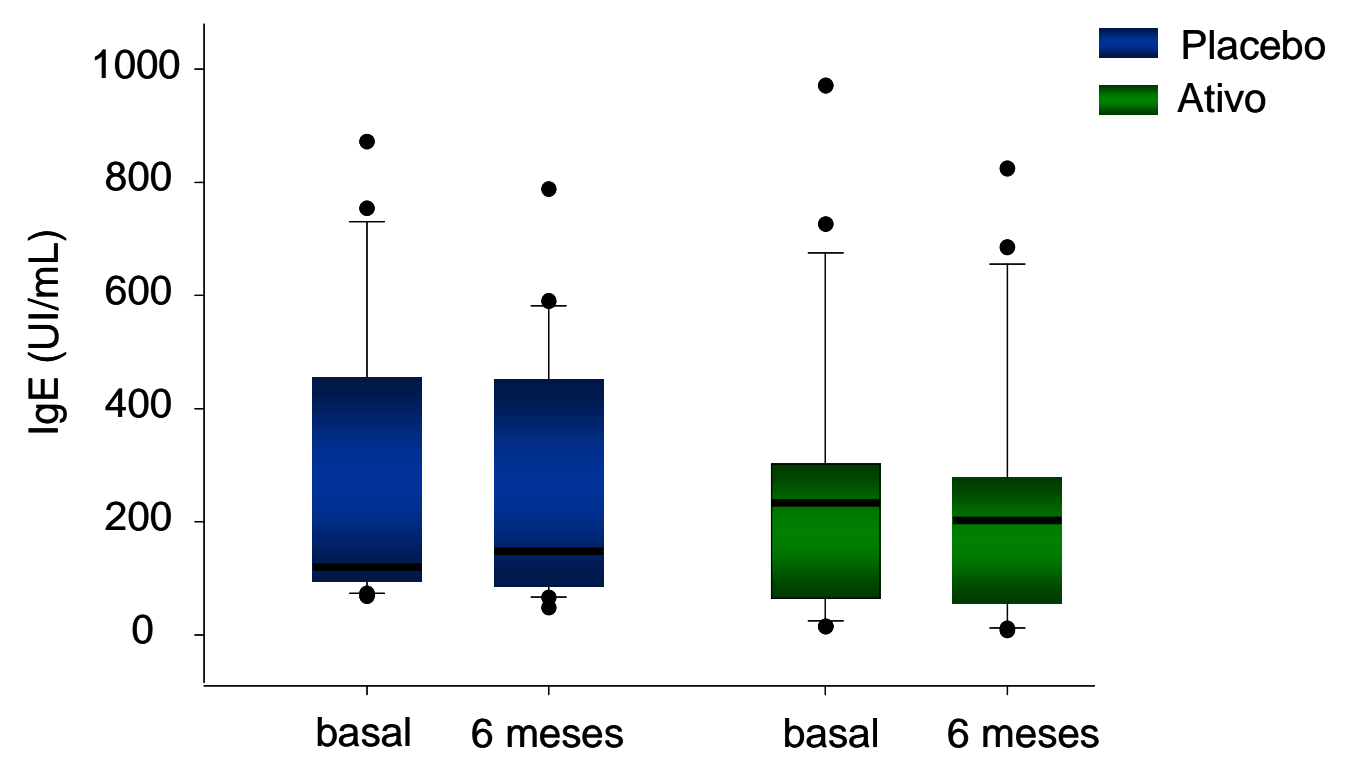

Figura 7 - Box Plot ilustrando as medianas dos valores de IgE total dos grupos placebo e ativo, nos tempos basal e 6 meses. A barra (negra) representa a mediana, a base inferior da caixa está situada na altura do percentil $25 \%$ e a superior na do percentil $75 \%$. Não houve diferença estatisticamente significativa entre os grupos. 
V.1.1.7. Avaliação da freqüência de utilização de anti-histamínico (tempo $6 m)$

A utilização de anti-histamínico pelos pacientes foi desprezível (apenas quatro pacientes utilizaram o máximo de quatro comprimidos na fase inicial), impossibilitando o emprego deste parâmetro como variável de avaliação da eficácia do tratamento.

\section{V.1.1.8. Avaliação da evolução das doenças concomitantes à rinite alérgica} (tempo 6m)

Em vista desta avaliação ter sido realizada pelo pesquisador principal, sem a colaboração de um avaliador independente, estes dados não foram analisados estatisticamente e não foram incluídos no estudo.

\section{V.1.1.9. Avaliação final da qualidade de vida (tempo $6 \mathrm{~m}$ )}

Em relação à variável qualidade de vida, após os seis meses iniciais de tratamento, o grupo placebo apresentou média de 124,55 pontos no escore, sem diferença estatisticamente significativa em relação à média de 120,05 do escore basal $(P=0,405)$. O grupo ativo apresentou média de 122,90 pontos, sem diferença estatisticamente significativa em relação à média de 114,42 do escore basal $(P=$ 0,184). (Figura 8) 


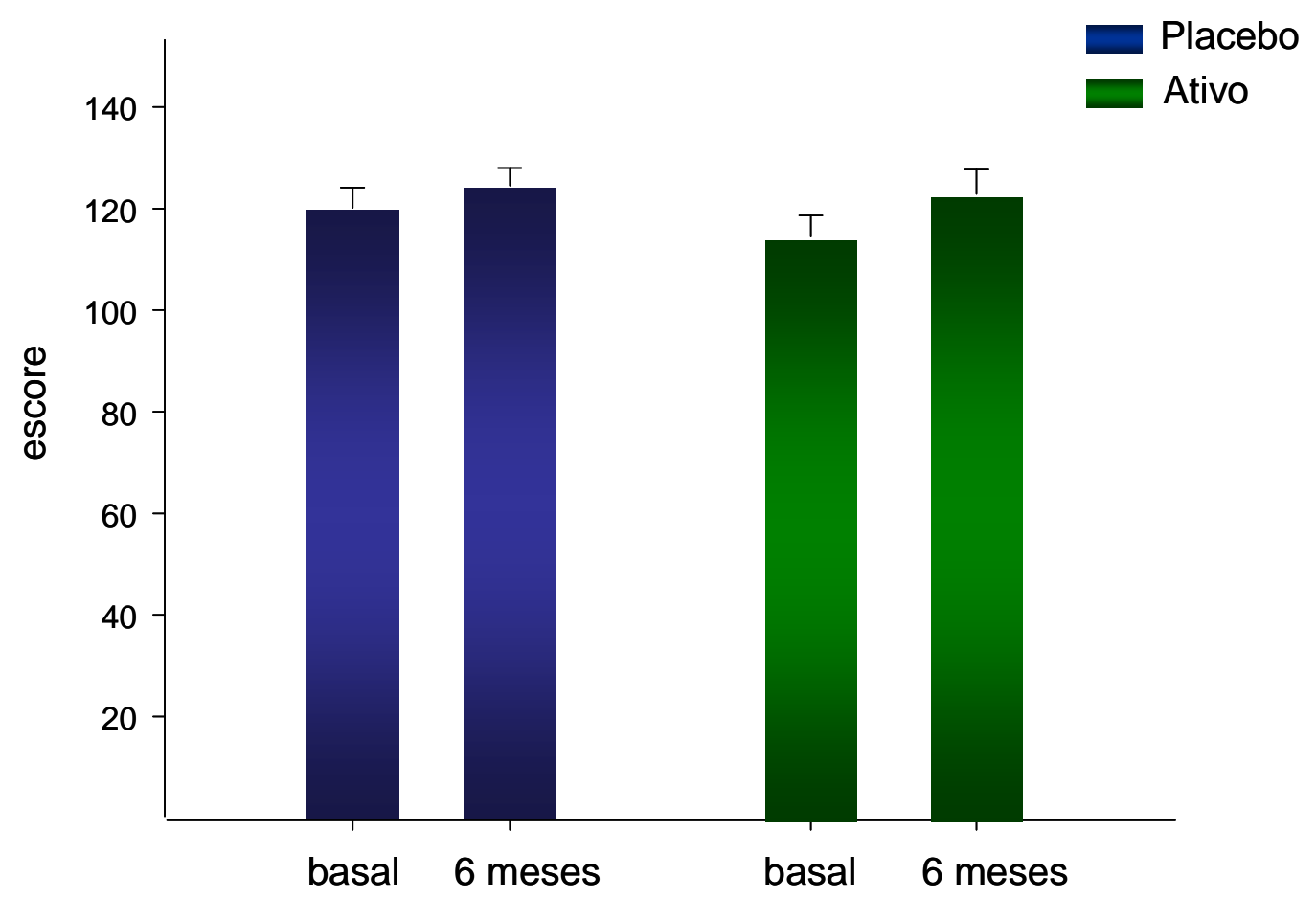

Figura 8 - Gráfico de barras ilustrando as médias dos escores dos aspectos da qualidade de vida dos grupos placebo e ativo, nos tempos basal e 6 meses. Não houve diferença estatisticamente significativa entre os grupos.

Em resumo, após completar a fase inicial do estudo, em que os grupos placebo e ativo foram submetidos a seis meses das respectivas intervenções, observaram-se melhoras significativas de ambos os grupos nos parâmetros clínico-alérgicos da rinite, sem diferença estatisticamente significativa entre eles. (Tabela 11)

Tabela 11 - Porcentagem de variação da melhora clínico-alérgica ao final da Fase 1

\begin{tabular}{|c|c|c|}
\hline & $\begin{array}{c}\text { Grupo placebo } \\
(n=20)\end{array}$ & $\begin{array}{l}\text { Grupo ativo } \\
(\mathrm{n}=21)\end{array}$ \\
\hline \multirow{2}{*}{$\begin{array}{l}\text { Quadro clínico-alérgico específico } \\
\text { (média } \pm \text { ep) }\end{array}$} & $25,86 \pm 5,8$ & $21,89 \pm 7,5$ \\
\hline & \multicolumn{2}{|c|}{$P=0,678$} \\
\hline \multirow{2}{*}{$\begin{array}{l}\text { Quadro clínico-alérgico geral } \\
\text { (média } \pm \text { ep) }\end{array}$} & $25,51 \pm 7,2$ & $21,25 \pm 6,9$ \\
\hline & \multicolumn{2}{|c|}{$P=0,672$} \\
\hline \multirow{2}{*}{$\begin{array}{l}\text { Suscetibilidade alérgica } \\
\text { (médiatep) }\end{array}$} & $20,84 \pm 5,8$ & $20,18 \pm 7,8$ \\
\hline & \multicolumn{2}{|c|}{$P=0,948$} \\
\hline
\end{tabular}




\section{V.1.1.10. Avaliação da ocorrência de eventos adversos (tempo 0-6 m)}

Apesar dos eventos adversos homeopáticos (agravação homeopática, retorno de sintomas antigos, exonerações e surgimento de sintomas novos) terem sido registrados e empregados na tomada de decisão terapêutica de acordo aos prognósticos homeopáticos (Teixeira, 1997), as análises das ocorrências e as correlações com a evolução clínica dos pacientes não foram incluídas neste estudo. Vale ressaltar que estes eventos adversos homeopáticos não ultrapassaram o grau 1-2 de gravidade (leve-moderado) (item IV.14.3, Tabela 7), melhorando, geralmente, após a suspensão do medicamento e/ou a prescrição de um novo medicamento mais bem individualizado (antídoto homeopático).

Quanto aos eventos adversos clássicos, ocorreram seis ocorrências nesta primeira fase do estudo: duas gestações e dois eventos adversos graves (cirurgia ortopédica e broncopneumonia de repetição), que desligaram os pacientes do estudo; uma faringite e uma broncopneumonia, com o uso de antibióticos pelos pacientes, os quais retornaram ao estudo após o cumprimento do período correspondente de wash-out. De forma análoga, na segunda fase, uma paciente apresentou abscesso dentário e utilizou antibiótico após drenagem do mesmo, retornando ao estudo após respectivo período de wash-out.

\section{V.1.2. Fase 2 (estudo aberto com a duração de 6-36 meses de tratamento homeopático)}


Com o intuito de analisar o resultado do tratamento homeopático na rinite alérgica perene a médio-longo prazo, evitando-se a administração de placebo por um período superior a seis meses (minimizando os aspectos antiéticos e o abandono dos pacientes), foi proposto para este ensaio clínico um desenho de estudo misto, em que fosse possível utilizar os valores de eficácia clínica relativos à fase inicial (estudo placebo-controlado com 6 meses de duração) como parâmetro de comparação na avaliação da efetividade clínica de períodos maiores de tratamento homeopático desta segunda fase (estudo aberto e controlado pela melhora dos mesmos pacientes na fase inicial).

O desenho deste estudo apresenta grandes semelhanças com o estudo misto multicêntrico proposto por Bufe et al. (2004), que avaliou a efetividade da imunoterapia sublingual no tratamento da rinite sazonal durante o período de três anos, empregando a melhora clínica de $10 \%$ do grupo placebo na fase inicial (estudo placebo-controlado com 12 meses de duração), que também não mostrou diferenças estatisticamente significativas em relação ao grupo ativo, como padrão de referência para avaliar as possíveis melhoras nas fases subseqüentes do estudo aberto (dois e três anos de tratamento imunoterápico).

\section{V.1.2.1. Amostra analisada (Fase 2)}

Apesar de todos os pacientes terem sido convocados ao término da fase inicial a permanecerem na fase aberta recebendo tratamento homeopático, muitos descontinuaram o estudo. Dos 41 pacientes que terminaram a fase inicial $(25 \%$ ou 14/55 de descontinuação do grupo randomizado inicialmente), 27 pacientes permaneceram nesta segunda fase completando doze meses de tratamento $(34 \%$ ou 
14/41 de descontinuação; $71 \%$ do grupo placebo inicial versus $29 \%$ do grupo ativo inicial, $P<0,001), 20$ pacientes completando vinte e quatro meses de tratamento (51\% ou $21 / 41$ de descontinuação; $62 \%$ do grupo placebo inicial versus $38 \%$ do grupo ativo inicial, $P=0,003)$, e 13 pacientes completando trinta e seis meses de tratamento ( $68 \%$ ou $28 / 41$ de descontinuação; $54 \%$ do grupo placebo inicial versus $46 \%$ do grupo ativo inicial, $P=0,30)$. O grupo placebo inicial foi responsável pelas maiores taxas de descontinuação nos dois primeiros anos de tratamento, equiparando-se ao grupo ativo inicial apenas no terceiro ano.

Analisando as taxas de abandono ao final de cada período de tratamento homeopático desta fase aberta, constatou-se que 14 pacientes (34\% ou 14/41) não completaram 12 meses de tratamento (10 do grupo placebo e 4 do grupo ativo inicial), 7 pacientes ( $26 \%$ ou $7 / 27$ ) não completaram 24 meses de tratamento ( 3 do grupo placebo e 4 do grupo ativo inicial) e 7 pacientes (35\% ou $7 / 20)$ não completaram 36 meses de tratamento (3 do grupo placebo e 4 do grupo ativo inicial). Vale ressaltar que dos 14 pacientes que não completaram os 12 meses iniciais de tratamento, seis (43\%) que eram do grupo placebo inicial descontinuaram o estudo logo após o término da Fase 1, sem receber qualquer tratamento homeopático, por desinteresse ou impossibilidade em permanecer no estudo (não relacionados à ineficácia terapêutica). (Figura 9)

Os motivos da descontinuação dos pacientes nesta segunda fase foram: abandono com eficácia terapêutica, por mudança de localidade, dificuldade em comparecer nos retornos etc. ( $n=23 ; 82 \%$ do abandono); abandono por ineficácia terapêutica ( $\mathrm{n}=4 ; 14 \%$ do abandono); abandono por motivo desconhecido (paciente não localizado) ( $n=1 ; 4 \%$ do abandono). (Tabela 12; Figura 9) 
Tabela 12 - Motivos da descontinuação dos pacientes na Fase 2

\begin{tabular}{l|c|c|c}
\hline \multirow{2}{*}{} & \multicolumn{2}{|c}{ Descontinuação dos pacientes - Fase 2 } \\
\cline { 2 - 4 } & $\begin{array}{c}\text { Antes de } \\
\text { completar 12m } \\
\text { tratamento } \\
(\mathrm{n}=14)\end{array}$ & $\begin{array}{c}\text { Antes de } \\
\text { completar 24m } \\
\text { tratamento } \\
(\mathrm{n}=7)\end{array}$ & $\begin{array}{c}\text { Antes de } \\
\text { completar 36m } \\
\text { tratamento } \\
(\mathrm{n}=7)\end{array}$ \\
\hline $\begin{array}{l}\text { Abandono com eficácia } \\
\text { terapêutica }\end{array}$ & $\mathrm{n}=12$ & $\mathrm{n}=5$ & $\mathrm{n}=6$ \\
$(8 \mathrm{P}, 3 \mathrm{~A})$ & $\mathrm{n}=2$ & $\mathrm{n}=1 \mathrm{P}, 2 \mathrm{~A})$ & $(3 \mathrm{P}, 4 \mathrm{~A})$ \\
\hline $\begin{array}{l}\text { Abandono por ineficácia } \\
\text { terapêutica }\end{array}$ & $(1 \mathrm{P}, 1 \mathrm{~A})$ & $\mathrm{n}=1(\mathrm{~A})$ \\
\hline $\begin{array}{l}\text { Abandono por motivo } \\
\text { desconhecido }\end{array}$ & $\mathrm{n}=0$ & $\mathrm{n}=1(\mathrm{~A})$ & $\mathrm{n}=0$ \\
\hline
\end{tabular}

NOTA: $\mathrm{P}=$ grupo placebo inicial; $\mathrm{A}=$ grupo ativo inicial.

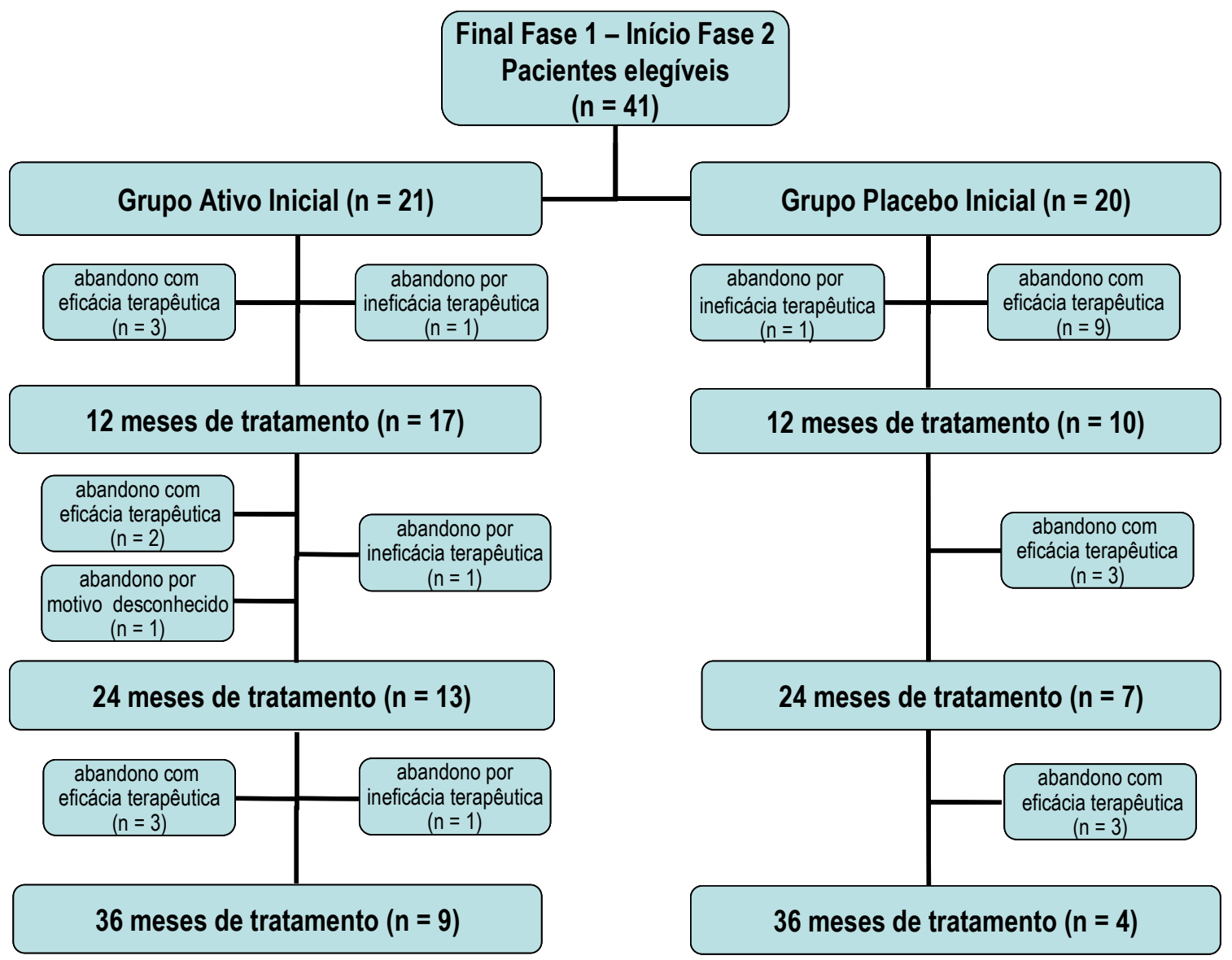

Figura 9 - Planejamento do estudo (Fase 2) 


\section{V.1.2.1.1. Características descritivas das amostras (Fase 2)}

Em relação às características idade, tempo de doença, tempo proporcional de doença e gravidade ou intensidade da doença, os pacientes que permaneceram na segunda fase do estudo (períodos de 12 a 36 meses de tratamento homeopático) não apresentaram diferenças significativas em relação à média dos pacientes da fase inicial, sugerindo que não ocorreu viés de seleção, ou seja, permanência dos pacientes menos graves ao longo da fase aberta. (Tabela 13)

Tabela 13 - Comparação entre as características descritivas dos pacientes da Fase 1 com os pacientes que permaneceram na Fase 2

\begin{tabular}{|c|c|c|c|c|}
\hline & \multirow{2}{*}{$\begin{array}{l}\text { Fase } 1 \\
(n=41)\end{array}$} & \multicolumn{3}{|c|}{ Fase 2} \\
\hline & & $\begin{array}{c}12 \text { meses } \\
\text { tratamento } \\
(n=27)\end{array}$ & $\begin{array}{c}24 \text { meses } \\
\text { tratamento } \\
(n=20)\end{array}$ & $\begin{array}{c}36 \text { meses } \\
\text { tratamento } \\
(n=13)\end{array}$ \\
\hline \multirow[t]{2}{*}{$\begin{array}{l}\text { Idade } \\
\text { (média } \pm \text { ep) }\end{array}$} & \multirow{2}{*}{$29,68 \pm 1,51$} & $32,51 \pm 1,97$ & $32,75 \pm 2,45$ & $34,69 \pm 3,15$ \\
\hline & & $P=0,21$ & $P=0,22$ & $P=0,07$ \\
\hline \multirow[t]{2}{*}{$\begin{array}{l}\text { Tempo de doença } \\
\text { (médiatep) }\end{array}$} & \multirow{2}{*}{$13,63 \pm 1,45$} & $16,48 \pm 1,90$ & $15,05 \pm 2,07$ & $16,76 \pm 2,46$ \\
\hline & & $P=0,22$ & $P=0,52$ & $P=0,22$ \\
\hline \multirow[t]{2}{*}{$\begin{array}{l}\text { Tempo proporcional de } \\
\text { doença } \\
\text { (média } \pm e p \text { ) }\end{array}$} & \multirow{2}{*}{$44,15 \pm 3,45$} & $49,89 \pm 4,46$ & $46,12 \pm 5,20$ & $48,81 \pm 5,74$ \\
\hline & & $P=0,31$ & $P=0,75$ & $P=0,51$ \\
\hline \multirow[t]{2}{*}{$\begin{array}{l}\text { Gravidade da doença } \\
\text { (média } \pm \text { ep) }\end{array}$} & \multirow{2}{*}{$15,09 \pm 0,48$} & $15,11 \pm 0,66$ & $15,60 \pm 0,79$ & $15,53 \pm 1,06$ \\
\hline & & $P=0,82$ & $P=0,57$ & $P=0,67$ \\
\hline
\end{tabular}

NOTA: $O$ valor de $P$ resulta da comparação com a Fase 1.

Em relação a cronicidade da doença (idade e tempo de doença), os pacientes que abandonaram o estudo antes de completar 12 meses de tratamento 
apresentaram características significativamente inferiores à média dos pacientes da fase inicial. Nas demais características e períodos de tratamento (24 e 36 meses), os pacientes que descontinuaram o estudo não apresentaram diferenças estatisticamente significativas em relação à média dos pacientes da fase inicial. Estes dados sugerem que não ocorreu descontinuação dos pacientes mais graves ao longo da fase aberta (viés de seleção). (Tabela 14)

Tabela 14 - Comparação entre as características descritivas dos pacientes da Fase 1 com os pacientes que descontinuaram na Fase 2

\begin{tabular}{|c|c|c|c|c|}
\hline \multirow[t]{2}{*}{ 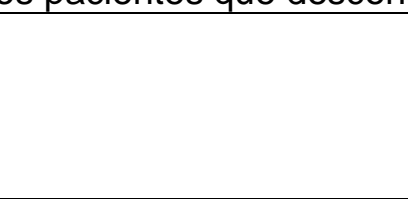 } & \multirow{2}{*}{$\begin{array}{l}\text { Fase } 1 \\
(n=41)\end{array}$} & \multicolumn{3}{|c|}{ Fase 2} \\
\hline & & $\begin{array}{l}12 \text { meses } \\
\text { tratamento } \\
(n=14)\end{array}$ & $\begin{array}{c}24 \text { meses } \\
\text { tratamento } \\
(n=7)\end{array}$ & $\begin{array}{c}36 \text { meses } \\
\text { tratamento } \\
(n=7)\end{array}$ \\
\hline \multirow[t]{2}{*}{$\begin{array}{l}\text { Idade } \\
\text { (média } \pm \text { ep) }\end{array}$} & \multirow{2}{*}{$29,68 \pm 1,51$} & $24,21 \pm 1,48$ & $31,85 \pm 3,24$ & $29,14 \pm 3,75$ \\
\hline & & $P=0,05$ & $P=0,55$ & $P=0,82$ \\
\hline \multirow[t]{2}{*}{$\begin{array}{l}\text { Tempo de doença } \\
\text { (média } \pm \text { ep) }\end{array}$} & \multirow{2}{*}{$13,63 \pm 1,45$} & $8,14 \pm 1,25$ & $20,57 \pm 4,21$ & $11,85 \pm 3,73$ \\
\hline & & $P=0,05$ & $P=0,10$ & $P=0,58$ \\
\hline \multirow[t]{2}{*}{$\begin{array}{l}\text { Tempo proporcional de } \\
\text { doença } \\
\text { (média } \pm \text { ep\%) }\end{array}$} & \multirow{2}{*}{$44,15 \pm 3,45$} & $33,08 \pm 4,04$ & $60,66 \pm 7,88$ & $41,14 \pm 10,80$ \\
\hline & & $P=0,08$ & $P=0,07$ & $P=0,75$ \\
\hline \multirow[t]{2}{*}{$\begin{array}{l}\text { Gravidade da doença } \\
\text { (média } \pm \text { ep) }\end{array}$} & \multirow{2}{*}{$15,09 \pm 0,48$} & $15,07 \pm 0,62$ & $13,71 \pm 1,12$ & $15,71 \pm 1,20$ \\
\hline & & $P=0,72$ & $P=0,28$ & $P=0,63$ \\
\hline
\end{tabular}

NOTA: O valor de $P$ resulta da comparação com a Fase 1.

De forma análoga, em relação aos primeiros 12 meses de tratamento, os pacientes que permaneceram no estudo apresentaram cronicidade da doença (idade, tempo de doença e tempo proporcional de doença) significativamente superior aos que abandonaram o estudo. Nas demais características e períodos de 
tratamento (24 e 36 meses de tratamento), não se observou diferenças significativas. Os dados sugerem que não ocorreu descontinuação dos pacientes mais graves ao longo da fase aberta (viés de seleção). (Tabela 15)

Tabela 15 - Comparação entre as características descritivas dos pacientes que permaneceram com os que descontinuaram na Fase 2

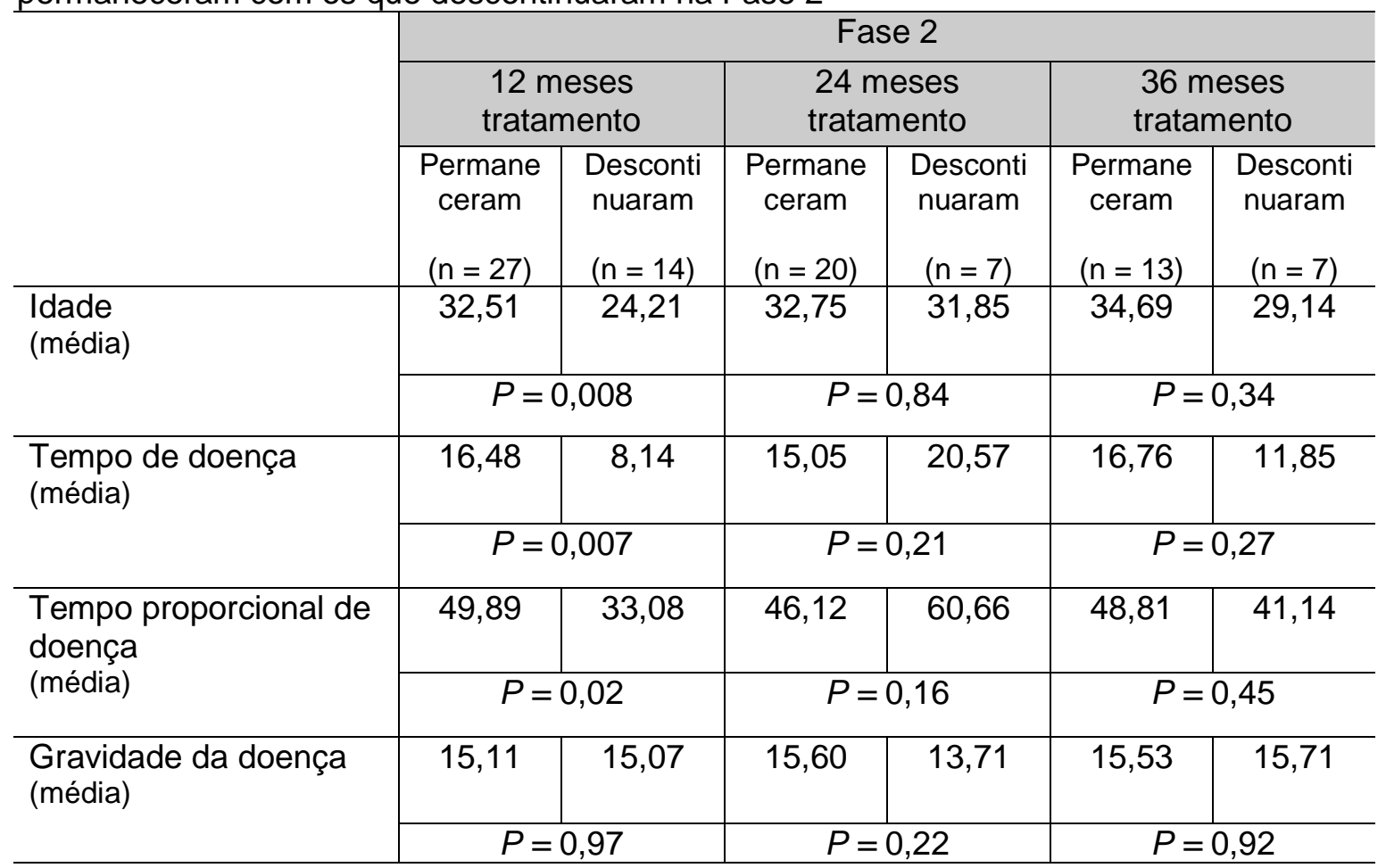

\section{V.1.2.2. Efeito placebo ao longo do acompanhamento homeopático}

Apesar das semelhanças citadas anteriormente entre imunoterapia e homeopatia, a semiologia e a relação médico-paciente da dinâmica homeopática diferem daquelas empregadas pela imunoterapia sublingual, apresentando fatores inespecíficos distintos que podem interferir na magnitude do efeito placebo. Assim sendo, faz-se necessário um estudo mais detalhado da magnitude do efeito placebo 
da abordagem homeopática ao longo do tempo de acompanhamento, para que possamos inferir uma porcentagem média de resposta placebo que sirva de comparação aos fatores específicos do tratamento homeopático na segunda fase do estudo (12-36 meses de tratamento homeopático).

Nos primeiros seis meses de aplicação da dinâmica homeopática, observou-se uma magnitude de $20-26 \%$ de melhora nos parâmetros clínico-alérgicos da rinite nos grupos ativo e placebo, sem diferenças entre eles, e com diferenças estatisticamente significativas perante a avaliação basal. (item V.1.1.5; Tabela 11)

Como o estudo foi aberto após este período inicial, sendo esclarecido aos pacientes o grupo de origem e a nova fase de tratamento homeopático que se iniciaria aos voluntários, não foi possível observar o efeito placebo dos períodos superiores a seis meses de aplicação da dinâmica homeopática exclusiva (relação médico-paciente + intervenção placebo), que permitiria uma estimativa mais abrangente para comparar os períodos de tratamento da segunda fase.

No entanto, nesta segunda fase do ensaio, na avaliação semestral subseqüente do subgrupo de pacientes alocados inicialmente no grupo placebo (12 meses de acompanhamento ou 6 meses de tratamento), não ocorreram diferenças estatisticamente significativas em relação à fase inicial $(6$ meses de acompanhamento dos mesmos pacientes) para os parâmetros clínico-alérgicos específicos e gerais (desfechos primário e secundário, respectivamente). (Tabela 16)

De forma análoga, comparativamente ao grupo ativo da fase inicial (6 meses de intervenção homeopática), o subgrupo placebo também não apresentou diferenças significativas nos primeiros seis meses de intervenção homeopática (12 meses de acompanhamento). (Tabela 17) 
Evidenciando uma relação direta e específica entre a resposta clínica e o período de tratamento homeopático, subgrupos de pacientes alocados na fase inicial nos grupos placebo ou ativo não apresentaram diferenças significativas em relação ao período de doze meses de tratamento homeopático (12 meses de acompanhamento do subgrupo ativo versus 18 meses de acompanhamento do subgrupo placebo), apesar dos seis meses adicionais de efeitos inespecíficos (relação médico-paciente, intervenção placebo etc.) recebidos naturalmente pelo grupo placebo na fase inicial. (Tabela 18)

Tabela 16 - Porcentagem de melhora clínico-alérgica do subgrupo placebo inicial entre os períodos 0-6 e 0-12 meses de acompanhamento

\begin{tabular}{|c|c|c|}
\hline & $\begin{array}{l}\text { Subgrupo placebo inicial } \\
\qquad \begin{array}{c}(0-6 m) \\
(n=14)\end{array}\end{array}$ & $\begin{array}{l}\text { Subgrupo placebo inicial } \\
\qquad \begin{array}{c}(0-12 m) \\
(n=14)\end{array}\end{array}$ \\
\hline \multirow{2}{*}{$\begin{array}{l}\text { Quadro clínico-alérgico específico } \\
\text { (média土ep) }\end{array}$} & $26,45 \pm 7,3$ & $39,21 \pm 8,0$ \\
\hline & \multicolumn{2}{|c|}{$P=0,248$} \\
\hline \multirow{2}{*}{$\begin{array}{l}\text { Quadro clínico-alérgico geral } \\
\text { (média } \pm \text { ep) }\end{array}$} & $24,59 \pm 9,2$ & $37,49 \pm 8,3$ \\
\hline & \multicolumn{2}{|c|}{$P=0,307$} \\
\hline
\end{tabular}

Tabela 17 - Porcentagem de melhora clínico-alérgica do grupo ativo e subgrupo placebo iniciais após 6 meses de tratamento homeopático

\begin{tabular}{|c|c|c|}
\hline & $\begin{array}{c}\text { Grupo ativo } \\
(0-6 m) \\
(n=21)\end{array}$ & $\begin{array}{l}\text { Subgrupo placebo inicial } \\
\qquad \begin{array}{c}(0-12 m) \\
(n=14)\end{array}\end{array}$ \\
\hline \multirow{2}{*}{$\begin{array}{l}\text { Quadro clínico-alérgico específico } \\
\text { (médiatep) }\end{array}$} & $21,89 \pm 7,5$ & $39,21 \pm 8,0$ \\
\hline & \multicolumn{2}{|c|}{$P=0,133$} \\
\hline \multirow{2}{*}{$\begin{array}{l}\text { Quadro clínico-alérgico geral } \\
\text { (média } \pm \text { ep) }\end{array}$} & $21,25 \pm 6,9$ & $37,49 \pm 8,3$ \\
\hline & \multicolumn{2}{|c|}{$P=0,145$} \\
\hline
\end{tabular}


Tabela 18 - Porcentagem de melhora clínico-alérgica dos subgrupos ativo e placebo iniciais após 12 meses de tratamento homeopático

\begin{tabular}{|c|c|c|}
\hline & $\begin{array}{c}\text { Subgrupo ativo inicial } \\
(0-12 \mathrm{~m}) \\
(\mathrm{n}=17)\end{array}$ & $\begin{array}{l}\text { Subgrupo placebo inicial } \\
\qquad(0-18 m) \\
(n=10)\end{array}$ \\
\hline \multirow[t]{2}{*}{$\begin{array}{l}\text { Quadro clínico-alérgico específico } \\
\text { [mediana }(25-75 \%)]\end{array}$} & $\begin{array}{c}50,00 \\
(43,8-57,8)\end{array}$ & $\begin{array}{c}61,10 \\
(35,7-70,0)\end{array}$ \\
\hline & \multicolumn{2}{|c|}{$P=0,238$} \\
\hline \multirow{2}{*}{$\begin{array}{l}\text { Quadro clínico-alérgico geral } \\
\text { (média } \pm \text { ep) }\end{array}$} & $50,27 \pm 4,1$ & $36,93 \pm 15,9$ \\
\hline & \multicolumn{2}{|c|}{$P=0,320$} \\
\hline
\end{tabular}

Segundo estes dados, inferimos que o primeiro período semestral de acompanhamento dos pacientes mobilizou uma resposta inespecífica (efeito placebo) robusta, de magnitude superior aos demais períodos semestrais subseqüentes. Em vista disto, e em conformidade com o desenho de estudo misto proposto por Bufe et al. (2004), estipulamos a melhora clínico-alérgica observada na fase inicial do estudo (nos grupos placebo e ativo iniciais) como padrão de referência dos efeitos inespecíficos inerentes à dinâmica homeopática (relação médico-paciente + intervenção placebo), a fim de compararmos os efeitos específicos do tratamento homeopático na segunda fase.

Nesta fase aberta do ensaio, independente da alocação dos pacientes nos grupos placebo ou ativo iniciais, foram estudados os subgrupos submetidos a 12, 24 e 36 meses de tratamento homeopático, comparando a porcentagem de melhora clínico-alérgica dos subgrupos de pacientes que completaram cada período de tratamento $(0-12 \mathrm{~m}, 0-24 \mathrm{~m}$ e $0-36 \mathrm{~m})$ com a porcentagem de melhora clínicoalérgica dos mesmos subgrupos de pacientes na fase controlada do estudo (0$6 m)$. 
Quanto à variável qualidade de vida, comparamos a média do escore final de cada período de tratamento homeopático à média do escore basal do mesmo subgrupo de pacientes, pois não observamos variação de melhora estatisticamente significativa durante a fase inicial do estudo.

\section{V.1.2.3. Subgrupo submetido a 6 meses de tratamento homeopático}

Excetuando os pacientes do grupo ativo inicial $(n=21)$ submetidos a seis meses de tratamento homeopático e que fizeram parte da análise na Fase 1, os pacientes deste subgrupo corresponderam a quatorze pacientes do grupo placebo inicial que passaram a receber tratamento homeopático (retrocruzamento ou cross-over) e completaram 12 meses de acompanhamento $(6$ meses de intervenção placebo +6 meses de intervenção homeopática), os quais não apresentaram diferenças estatisticamente significativas na porcentagem de variação dos parâmetros clínicoalérgicos quando comparados à fase inicial do estudo (6 meses de intervenção placebo). (Tabela 16)

Em relação à variável $\lg E$ total, também não foram observadas diferenças estatisticamente significativas.

Quanto à qualidade de vida, o subgrupo submetido a seis meses de tratamento homeopático $(n=35)$, composto por vinte e um pacientes do grupo ativo inicial (6 meses de intervenção homeopática) e quatorze pacientes do grupo placebo inicial que completaram 12 meses de acompanhamento ( 6 meses de intervenção placebo + 6 meses de intervenção homeopática), apresentou média de $116,06 \pm 3,2$ pontos no escore basal e média de $125,46 \pm 3,2$ pontos no escore final, com melhora significativa da qualidade de vida (DMP -9,4; IC 95\%-18,46 a -0,33, $P=0,042$ ). 
V.1.2.4. Subgrupo submetido a 12 meses de tratamento homeopático $(n=$ 27)

Este subgrupo foi composto por todos os pacientes submetidos a doze meses de tratamento homeopático $(n=27)$, associando dezessete pacientes do grupo ativo inicial que completaram 12 meses de acompanhamento (12 meses de intervenção homeopática) a dez pacientes do grupo placebo inicial que completaram dezoito meses de acompanhamento (6 meses de intervenção placebo +12 meses de intervenção homeopática), com uma perda total de quatorze pacientes em relação à fase inicial (34\% ou $14 / 41)$.

Em comparação à fase inicial $(0-6 m)$, os pacientes deste subgrupo apresentaram diferenças estatisticamente significativas na porcentagem de variação dos parâmetros clínico-alérgicos. (Tabela 19)

Tabela 19 - Comparação da porcentagem de melhora clínico-alérgica entre as fases inicial e 12 meses de tratamento homeopático

\begin{tabular}{|c|c|c|}
\hline & $\begin{array}{c}\text { Fase } 1 \\
(6 \mathrm{~m} \text { iniciais }) \\
(\mathrm{n}=27)\end{array}$ & $\begin{array}{c}\text { Fase } 2 \\
(12 \mathrm{~m} \text { tratamento }) \\
(\mathrm{n}=27)\end{array}$ \\
\hline \multirow{2}{*}{$\begin{array}{l}\text { Sinais e sintomas específicos da } \\
\text { rinite } \\
\text { [mediana }(25-75 \%)]\end{array}$} & $\begin{array}{c}31,30 \\
(11,3-46,6)\end{array}$ & $\begin{array}{c}50,00 \\
(43,8-54,0)\end{array}$ \\
\hline & \multicolumn{2}{|c|}{$P=0,003$} \\
\hline \multirow{2}{*}{$\begin{array}{l}\text { Sintomas alérgicos gerais } \\
\text { (média } \pm \mathrm{ep} \text { ) }\end{array}$} & $23,62 \pm 6,4$ & $45,33 \pm 6,3$ \\
\hline & \multicolumn{2}{|c|}{ (DMP -21,71; IC 95\% -39,86 a -3,56; $P=0,020)$} \\
\hline \multirow{2}{*}{$\begin{array}{l}\text { Fatores agravantes e/ou } \\
\text { precipitantes } \\
\text { (média } \pm \text { ep) }\end{array}$} & $24,44 \pm 6,9$ & $44,61 \pm 6,3$ \\
\hline & \multicolumn{2}{|c|}{ (DMP -20,17; IC 95\% -38,93 a -1,40; $P=0,036)$} \\
\hline
\end{tabular}

NOTA: DMP = diferença média padronizada. 
Em relação à variável IgE total, não foram observadas diferenças estatisticamente significativas no valor médio entre as fases inicial $(0-6 m)$ e final (12 meses de tratamento homeopático).

Quanto aos parâmetros da qualidade de vida, o subgrupo que foi submetido a 12 meses de tratamento homeopático apresentou média de 117,85 pontos no escore basal e média de 125,30 pontos no escore final, sem melhora estatisticamente significativa $(P=0,164)$.

\section{V.1.2.5. Subgrupo submetido a 24 meses de tratamento homeopático $(n=$} 20)

Este subgrupo foi composto por todos os pacientes submetidos a 24 meses de tratamento homeopático $(n=20)$, associando treze pacientes do grupo ativo inicial que completaram 24 meses de acompanhamento (24 meses de intervenção homeopática) a sete pacientes do grupo placebo inicial que completaram 30 meses de acompanhamento (6 meses de intervenção placebo +24 meses de intervenção homeopática), com uma perda total de sete pacientes em relação à fase anterior (26\% ou $7 / 27)$.

Em comparação à fase inicial $(0-6 \mathrm{~m})$, os pacientes deste subgrupo apresentaram diferenças estatisticamente significativas na porcentagem de variação dos parâmetros clínico-alérgicos. (Tabela 20)

Quanto à qualidade de vida, o subgrupo que foi submetido a 24 meses de tratamento homeopático apresentou média de $115,30 \pm 4,5$ pontos no escore basal e média de $128,20 \pm 3,4$ pontos no escore final, com melhora estatisticamente significativa (DMP -12,90; IC 95\% -24,42 a -1,37, $P=0,029)$. 
Tabela 20 - Comparação da porcentagem de melhora clínico-alérgica entre as fases inicial e 24 meses de tratamento homeopático

\begin{tabular}{|c|c|c|}
\hline & $\begin{array}{c}\text { Fase } 1 \\
(6 \mathrm{~m} \text { iniciais }) \\
(\mathrm{n}=20)\end{array}$ & $\begin{array}{c}\text { Fase } 2 \\
(24 \mathrm{~m} \text { tratamento }) \\
(\mathrm{n}=20)\end{array}$ \\
\hline \multirow{2}{*}{$\begin{array}{l}\text { Sinais e sintomas específicos da } \\
\text { rinite } \\
\text { (média } \pm \text { ep) }\end{array}$} & $33,04 \pm 7,0$ & $64,19 \pm 5,5$ \\
\hline & \multicolumn{2}{|c|}{ (DMP -31,15; IC 95\% -49,10 a -13,19; $P=0,001)$} \\
\hline \multirow{2}{*}{$\begin{array}{l}\text { Sintomas alérgicos gerais } \\
\text { (média } \pm \text { ep) }\end{array}$} & $29,78 \pm 7,6$ & $63,69 \pm 4,1$ \\
\hline & \multicolumn{2}{|c|}{ (DMP -33,91; IC 95\% -51,30 a -16,52; $P<0,001)$} \\
\hline \multirow{2}{*}{$\begin{array}{l}\text { Fatores agravantes e/ou } \\
\text { precipitantes } \\
\text { (média } \pm \text { ep) }\end{array}$} & $24,44 \pm 6,9$ & $54,46 \pm 6,2$ \\
\hline & \multicolumn{2}{|c|}{ (DMP -32,02; IC 95\% -49,56 a -10,46; $P=0,003)$} \\
\hline
\end{tabular}

NOTA: DMP = diferença média padronizada.

V.1.2.6. Subgrupo submetido a 36 meses de tratamento homeopático $(n=$ 13)

Este subgrupo foi composto por todos os pacientes submetidos a 36 meses de tratamento homeopático $(n=13)$, associando oito pacientes do grupo ativo inicial que completaram 36 meses de acompanhamento (36 meses de intervenção homeopática) a cinco pacientes do grupo placebo inicial que completaram 42 meses de acompanhamento ( 6 meses de intervenção placebo +36 meses de intervenção homeopática), com uma perda total de sete pacientes em relação à fase anterior (35\% ou $7 / 20)$.

Em comparação à fase inicial $(0-6 m)$, os pacientes deste subgrupo apresentaram diferenças estatisticamente significativas na porcentagem de variação dos parâmetros clínico-alérgicos. (Tabela 21) 
Tabela 21 - Comparação da porcentagem de melhora clínico-alérgica entre as fases inicial e 36 meses de tratamento homeopático

\begin{tabular}{|c|c|c|}
\hline & $\begin{array}{c}\text { Fase } 1 \\
(6 \mathrm{~m} \text { iniciais }) \\
(\mathrm{n}=13)\end{array}$ & $\begin{array}{c}\text { Fase } 2 \\
\text { (36m tratamento) } \\
(\mathrm{n}=13)\end{array}$ \\
\hline \multirow{2}{*}{$\begin{array}{l}\text { Sinais e sintomas específicos da } \\
\text { rinite } \\
\text { (média } \pm \text { ep) }\end{array}$} & $32,12 \pm 10,3$ & $71,77 \pm 7,1$ \\
\hline & \multicolumn{2}{|c|}{ (DMP -39,65; IC 95\% -65,49 a -13,79; $P=0,004)$} \\
\hline \multirow{2}{*}{$\begin{array}{l}\text { Sintomas alérgicos gerais } \\
\text { (médiatep) }\end{array}$} & $32,71 \pm 9,4$ & $68,76 \pm 6,3$ \\
\hline & \multicolumn{2}{|c|}{ (DMP -36,05; IC 95\% -59,33 a -12,76; $P=0,004)$} \\
\hline \multirow{2}{*}{$\begin{array}{l}\text { Fatores agravantes e/ou } \\
\text { precipitantes } \\
\text { (média } \pm \text { ep) }\end{array}$} & $32,47 \pm 10,8$ & $63,20 \pm 7,8$ \\
\hline & \multicolumn{2}{|c|}{$($ DMP -30,73; IC 95\% -58,28 a -3,17; $P=0,030)$} \\
\hline
\end{tabular}

NOTA: DMP = diferença média padronizada.

$\mathrm{Na}$ qualidade de vida, o subgrupo que foi submetido a 36 meses de tratamento homeopático apresentou média de 114,85 pontos no escore basal e média de 125,84 pontos no escore final, sem melhora estatisticamente significativa $(P=0,211)$.

\section{V.1.2.7. Análise em separado dos subgrupos ativo e placebo iniciais ao longo dos períodos de tratamento homeopático}

$\mathrm{Na}$ análise separada dos subgrupos ativo e placebo inicias ao longo dos períodos de tratamento (Fase 2), em comparação aos 6 meses iniciais de acompanhamento dos mesmos pacientes (Fase 1), o subgrupo placebo apresentou diferenças estatisticamente significativas na porcentagem de variação dos sinais e sintomas específicos da rinite alérgica (desfecho primário) nos períodos de 24 e 36 meses de tratamento homeopático (com tendência à significância no período de 12 meses), e o subgrupo ativo apresentou diferenças estatisticamente significativas nos períodos de 12 e 24 meses de tratamento homeopático. (Tabela 22) 
Tabela 22 - Comparação da porcentagem de melhora dos subgrupos placebo e ativo iniciais ao longo dos períodos de 12, 24 e 36 meses de tratamento

$$
\text { Porcentagem de melhora dos sinais e sintomas específicos da rinite }
$$

[médiatep; mediana (25-75\%)]

\begin{tabular}{|c|c|c|c|}
\hline \multicolumn{2}{|c|}{ Subgrupo placebo inicial } & \multicolumn{2}{|c|}{ Subgrupo ativo inicial } \\
\hline $\begin{array}{c}\text { Fase } 1 \\
\text { (6m iniciais) }\end{array}$ & $\begin{array}{c}\text { Fase } 2 \\
(12 \mathrm{~m} \text { tratamento) }\end{array}$ & $\begin{array}{c}\text { Fase } 1 \\
\text { (6m iniciais) }\end{array}$ & $\begin{array}{c}\text { Fase } 2 \\
(12 \mathrm{~m} \text { tratamento) }\end{array}$ \\
\hline$(n=10)$ & $(n=10)$ & $(n=17)$ & $(n=17)$ \\
\hline $28,57 \pm 10,0$ & $55,04 \pm 9,7$ & $\begin{array}{c}25,00 \\
(5,0-46,9)\end{array}$ & $\begin{array}{c}50,00 \\
(43,8-57,8)\end{array}$ \\
\hline \multicolumn{2}{|c|}{ (DMP -26,47; IC 95\% -55,72 a 2,$78 ; P=0,073$ ) } & \multicolumn{2}{|c|}{$(P=0,027)$} \\
\hline $\begin{array}{c}\text { Fase } 1 \\
(6 \mathrm{~m} \text { iniciais })\end{array}$ & $\begin{array}{c}\text { Fase } 2 \\
(24 \mathrm{~m} \text { tratamento) }\end{array}$ & $\begin{array}{c}\text { Fase } 1 \\
\text { (6m iniciais) }\end{array}$ & $\begin{array}{c}\text { Fase } 2 \\
\text { (24m tratamento) }\end{array}$ \\
\hline$(n=7)$ & $(n=7)$ & $(n=13)$ & $(n=13)$ \\
\hline $39,37 \pm 8,0$ & $73,40 \pm 5,5$ & $29,64 \pm 9,9$ & $59,24 \pm 7,7$ \\
\hline \multicolumn{2}{|c|}{ (DMP -34,03; IC 95\% - 15,18 a $-12,88 ; P=0,004)$} & \multicolumn{2}{|c|}{ (DMP -29,60; IC 95\% $-55,51$ a $-3,69 ; P=0,027$ ) } \\
\hline $\begin{array}{c}\text { Fase } 1 \\
\text { (6m iniciais) }\end{array}$ & $\begin{array}{c}\text { Fase } 2 \\
\text { (36m tratamento) }\end{array}$ & $\begin{array}{c}\text { Fase } 1 \\
(6 \mathrm{~m} \text { iniciais })\end{array}$ & $\begin{array}{c}\text { Fase } 2 \\
\text { (36m tratamento) }\end{array}$ \\
\hline$(n=5)$ & $(n=5)$ & $(n=8)$ & $(\mathrm{n}=8)$ \\
\hline $44,88 \pm 9,1$ & $81,64 \pm 7,9$ & $24,15 \pm 15,6$ & $52,97 \pm 8,7$ \\
\hline (DMP -36,76; IC & $3 \mathrm{a}-8,89, P=0$ & \multicolumn{2}{|c|}{ (DMP -28,83; IC 95\% -67,11 a 9,46; $P=0,129$ ) } \\
\hline
\end{tabular}

\section{V.1.2.8. Magnitude da resposta clínico-alérgica ao longo dos períodos de tratamento homeopático}

O tratamento homeopático a médio-longo prazo mostrou melhoras estatisticamente significativas nos parâmetros de avaliação clínico-alérgicos (sinais e sintomas específicos da rinite, sintomas alérgicos gerais, e fatores agravantes e/ou precipitantes), com magnitudes de respostas (diferença entre a \% média de melhora do tratamento homeopático e a \% média de melhora da fase inicial) crescentes ao longo do período de tratamento. (Tabela 23; Figuras 10 e 11) 
Tabela 23 - Magnitude da melhora clínico-alérgica ao longo dos períodos de 12, 24 e 36 meses de tratamento homeopático

\begin{tabular}{l|c|c|c}
\hline \multirow{2}{*}{} & \multicolumn{3}{|c}{$\begin{array}{c}\text { Magnitude da melhora clínico-alérgica (\% média) } \\
\text { (melhora do tratamento - melhora da fase inicial) }\end{array}$} \\
\cline { 2 - 4 } & $\begin{array}{c}12 \mathrm{~m} \text { de tratamento } \\
(\mathrm{n}=27)\end{array}$ & $\begin{array}{c}24 \mathrm{~m} \text { de tratamento } \\
(\mathrm{n}=20)\end{array}$ & $\begin{array}{c}36 \mathrm{~m} \text { de tratamento } \\
(\mathrm{n}=13)\end{array}$ \\
\hline $\begin{array}{l}\text { Sinais e sintomas } \\
\text { específicos da rinite }\end{array}$ & $\begin{array}{c}31,15 \\
39,65\end{array}$ & $(P=0,004)$ \\
\hline $\begin{array}{l}\text { Sintomas alérgicos } \\
\text { gerais }\end{array}$ & 21,71 & $(P=0,001)$ & 36,05 \\
\hline Fatores agravantes & $(P=0,020)$ & $(P<0,001)$ & $(P=0,004)$ \\
e/ou precipitantes & 20,17 & 30,02 & 30,73 \\
\hline
\end{tabular}

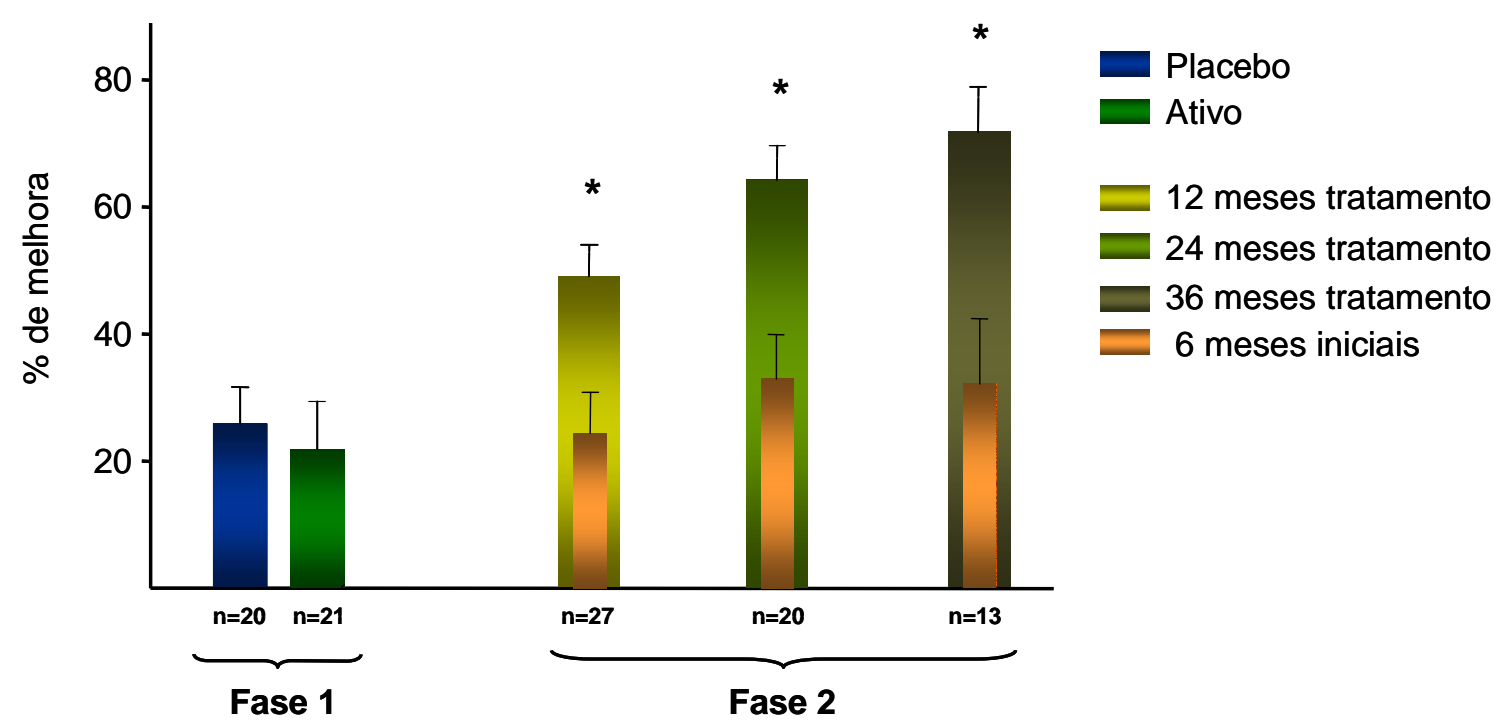

Figura 10 - Gráfico de barras ilustrando a porcentagem média de melhora dos sinais e sintomas específicos da rinite (desfecho primário) nas Fases 1 e 2.

* $P<0,05$ em relação ao respectivo controle [\% média de melhora dos mesmos pacientes ao término dos 6 meses iniciais (Fase 1)]. 


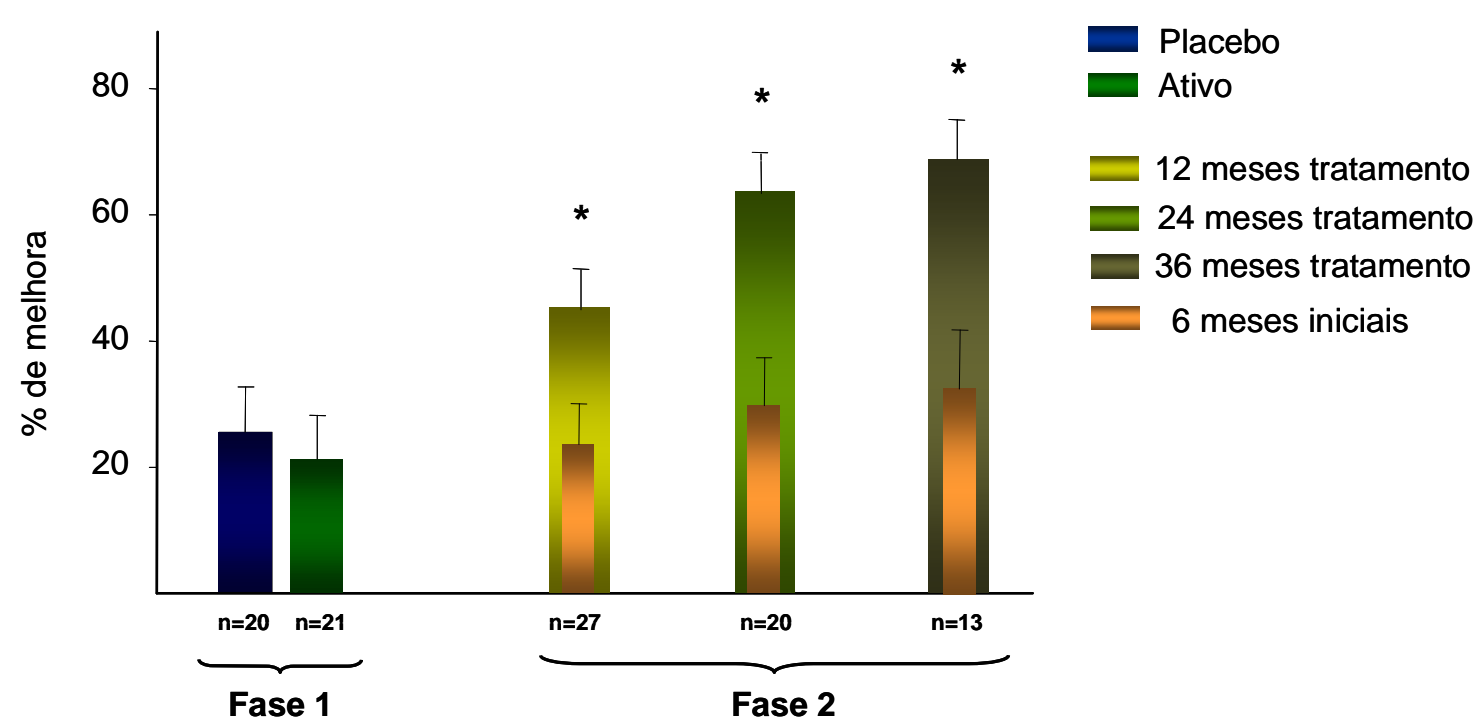

Figura 11 - Gráfico de barras ilustrando a porcentagem média de melhora dos sintomas alérgicos gerais (desfecho secundário) nas Fases 1 e 2.

* $P<0,05$ em relação ao respectivo controle [\% média de melhora dos mesmos pacientes ao término dos 6 meses iniciais (Fase 1)]. 


\section{V.2. Análise qualitativa dos pacientes}

\section{V.2.1. Fase 1 (estudo fechado, com a duração de 6 meses de acompanhamento)}

\section{V.2.1.1. Gravidade da rinite e resposta ao tratamento homeopático}

Ao contrário do estudo de Bufe et al. (2004), que observou melhoras significativas perante o placebo apenas nos pacientes do subgrupo com rinite de intensidade severa, não foi possível comparar a resposta inicial às intervenções ativa e placebo no subgrupo de pacientes com rinite de maior gravidade (grau IV: escore 19-24 pontos), em vista da pequena amostragem dos mesmos (5 pacientes: $2 \mathrm{P}$ e 3A). Pelo mesmo motivo (7 pacientes: 4P e 3A), não foi possível analisar o subgrupo de pacientes com rinite de menor gravidade (grau II: escore 7-12 pontos).

Como a média do escore basal de todos os pacientes incluídos no estudo foi 15,10 pontos $(n=41$ ), inferimos um subgrupo de maior gravidade ao conjunto de pacientes com escore $>15$ pontos e um subgrupo de menor gravidade ao conjunto de pacientes com escore $\leq 15$ pontos. O subgrupo placebo de maior gravidade não apresentou diferenças significativas em relação ao subgrupo ativo de maior gravidade na variação da média dos escores entre os tempos 0 e $6 \mathrm{~m}$ da fase inicial. O mesmo ocorreu para os subgrupos placebo e ativo de menor gravidade.

\section{V.2.1.2. Eficácia clínica das intervenções ativa e placebo individualmente}

Analisando individualmente os pacientes dos grupos placebo $(n=20)$ e ativo $(n$ $=21$ ) iniciais após seis meses das respectivas intervenções, observamos que cinco 
pacientes do grupo ativo e dois pacientes do grupo placebo apresentaram piora em relação ao escore basal $(17 \%$ ou $7 / 41)$. Dos trinta e quatro pacientes que apresentaram melhora (83\%), um paciente do grupo placebo e três pacientes do grupo ativo atingiram escore de sinais e sintomas específicos da rinite $\leq 6$ pontos (grau I: 1-6 pontos), que corresponde a um nível satisfatório de baixa gravidade ou intensidade da doença (critério de inclusão no estudo: escore total basal > 6 pontos; item IV.2.1). (Figuras 12 e 13)

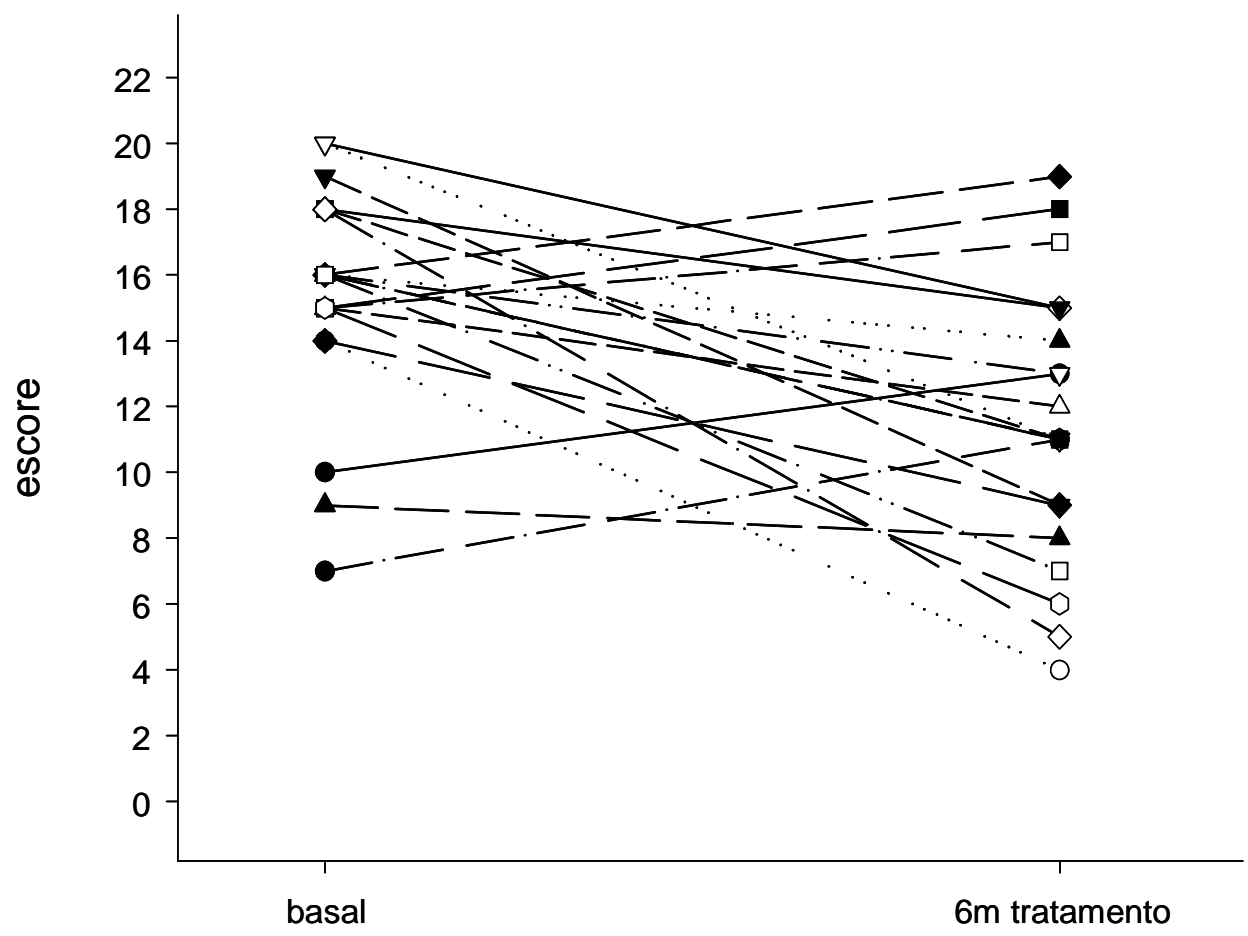

Figura 12 - Variação do escore de sinais e sintomas específicos da rinite dos pacientes do grupo ativo $(n=21)$ ao longo da fase inicial (basal-6m). 


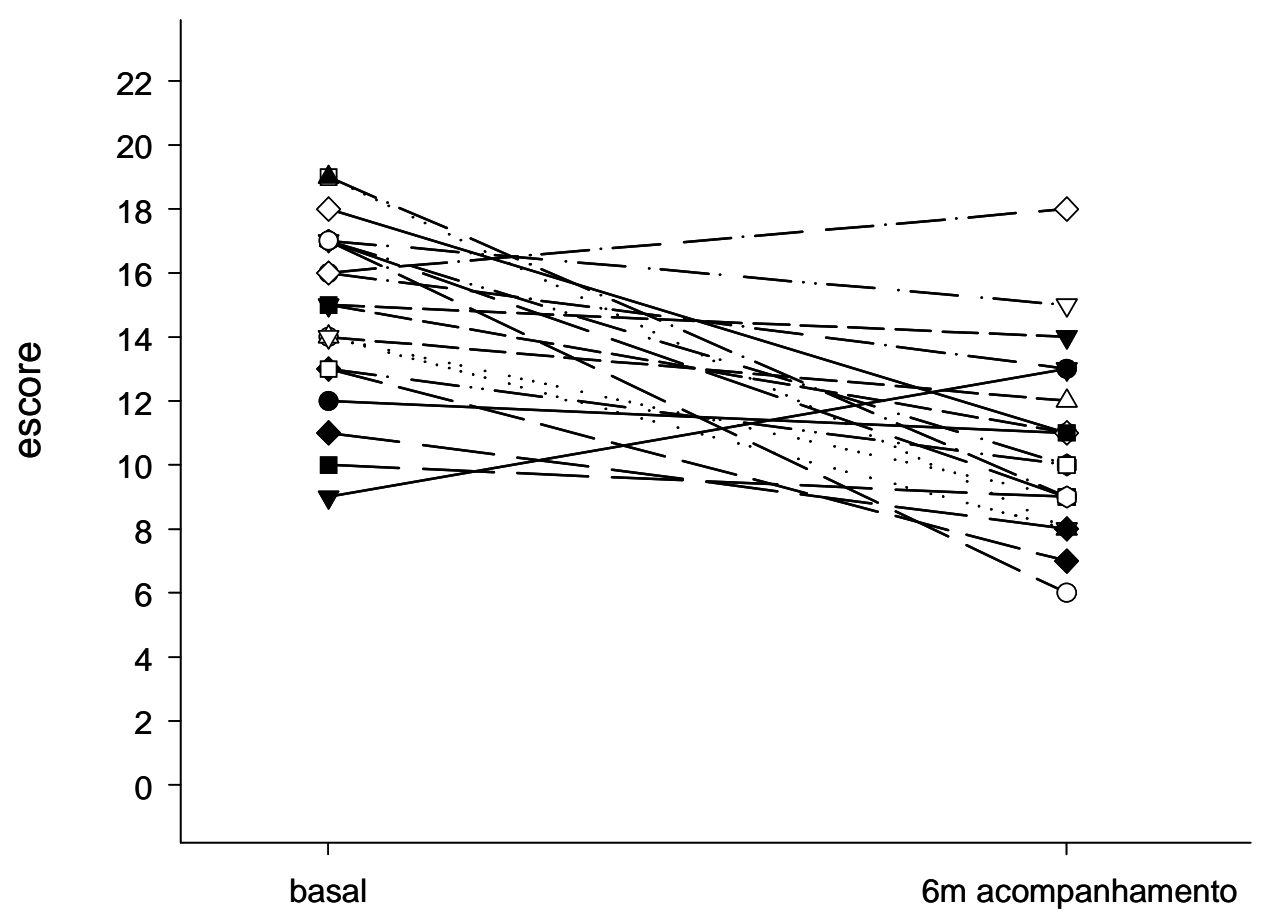

Figura 13 - Variação do escore de sinais e sintomas específicos da rinite dos pacientes do grupo placebo $(n=20)$ ao longo da fase inicial (basal-6m).

Logo após completarem esta fase inicial $(n=41)$, dez pacientes (seis do grupo placebo e quatro do grupo ativo) abandonaram o estudo (24\% ou 10/41), com dois pacientes (um de cada grupo) apresentando piora em relação ao escore basal e nenhum deles atingindo escore final $\leq 6$ pontos.

V.2.2. Fase 2 (estudo aberto com a duração de 6-36 meses de tratamento homeopático)

V.2.2.1. Evolução dos pacientes submetidos a 6 meses de tratamento homeopático 
Dos vinte pacientes incluídos na fase inicial no grupo placebo, quatorze permaneceram nesta segunda fase (30\% de abandono). Destes quatorze pacientes do grupo placebo inicial que foram submetidos a 6 meses de tratamento, dois apresentaram piora em relação ao escore final da fase inicial (6 meses de intervenção placebo). Dos doze pacientes que apresentaram melhora ou quadro inalterado, três atingiram escore $\leq 6$ pontos (grau I: 1-6 pontos) ao final destes 6 meses de tratamento homeopático. (Figura 14)

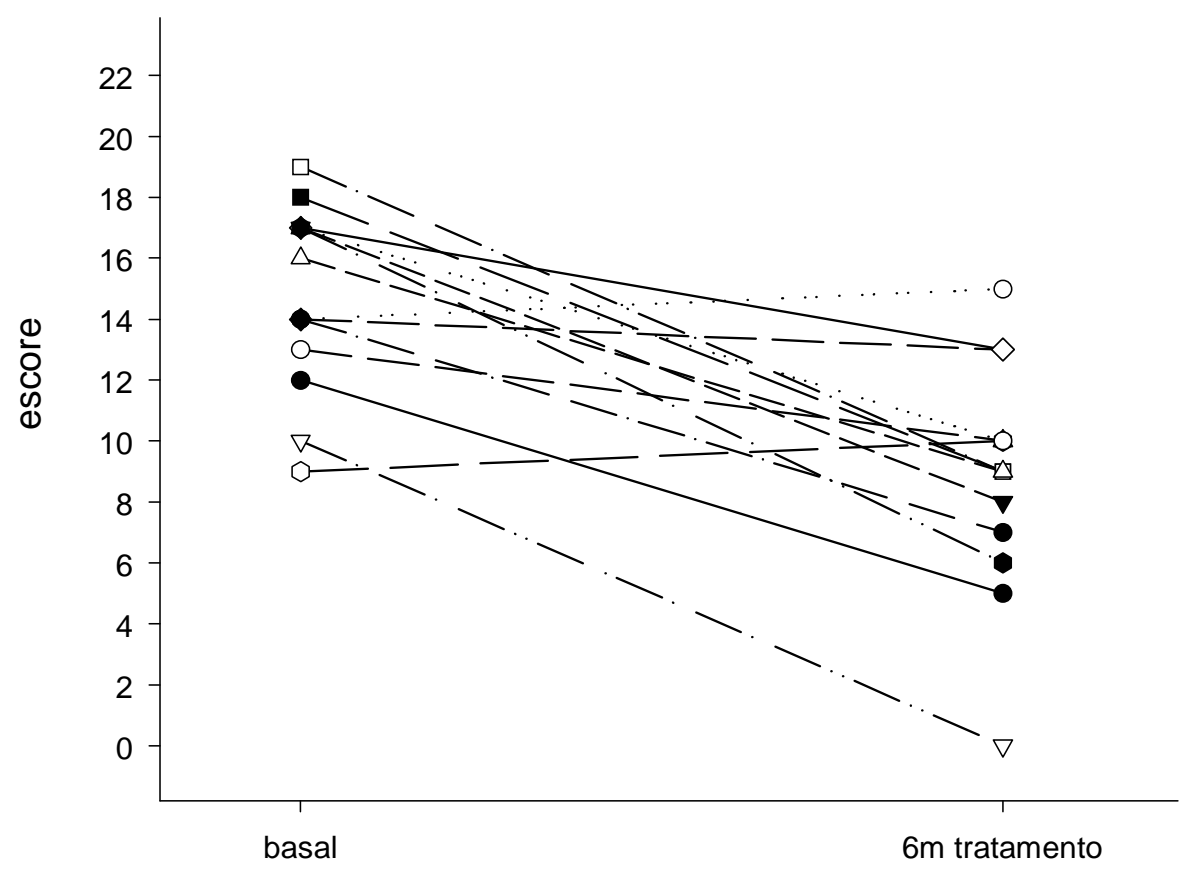

Figura 14 - Variação do escore de sinais e sintomas específicos da rinite dos pacientes do grupo placebo inicial que completaram $6 \mathrm{~m}$ de tratamento ou $12 \mathrm{~m}$ de acompanhamento $(\mathrm{n}=$ 14). 
Associando estes quatorze pacientes do grupo placebo inicial aos vinte e um pacientes do grupo ativo inicial $(n=35)$, seis (três do grupo placebo e três do grupo ativo) ou $17 \%$ do total de pacientes (6/35) atingiram escore $\leq 6$ pontos ao final de 6 meses de tratamento homeopático.

Do total de trinta e cinco pacientes que completaram 6 meses de tratamento homeopático, oito (quatro de cada grupo) abandonaram o estudo ao término do período de 6 meses de tratamento homeopático (23\% ou 8/35), com dois (um de cada grupo) apresentando piora em relação ao escore anterior e um paciente, do grupo placebo inicial, atingindo escore $\leq 6$ pontos.

\section{V.2.2.2. Evolução dos pacientes submetidos a 12 meses de tratamento homeopático $(n=27)$}

Dos trinta e cinco pacientes que receberam 6 meses de tratamento, dez do subgrupo placebo inicial anterior ( $n=14 ; 29 \%$ ou $4 / 14$ de abandono) e dezessete do grupo ativo inicial ( $n=21 ; 19 \%$ ou $4 / 21$ de abandono) permaneceram nesta fase. Destes vinte e sete pacientes submetidos a 12 meses de tratamento, cinco apresentaram piora em relação ao escore final da fase anterior (6 meses de tratamento), sendo três do grupo placebo e dois do grupo ativo iniciais. (Tabela 12; Figuras 15 e 16).

Associado a 12 meses de tratamento homeopático $(n=27)$, nove pacientes (cinco do grupo placebo e quatro do grupo ativo iniciais) ou $33 \%$ do total (9/27) atingiram escore $\leq 6$ pontos, quatro pela primeira vez (três do grupo placebo e um do 
grupo ativo iniciais) e um atingindo escore igual a zero (cura momentânea dos sinais e sintomas específicos da rinite).

Após completarem esta fase $(n=27)$, sete pacientes (três do grupo placebo e quatro do grupo ativo iniciais) abandonaram o estudo (26\% ou $7 / 27)$, com um paciente do grupo ativo inicial apresentando piora em relação ao escore anterior (6 meses de tratamento) e um paciente do grupo placebo inicial atingindo escore final $\leq$ 6 pontos. Estes dados, semelhantes aos dos períodos subseqüentes, reiteram a constatação anterior de que o principal motivo de descontinuação do estudo não foi a ineficácia terapêutica do tratamento.

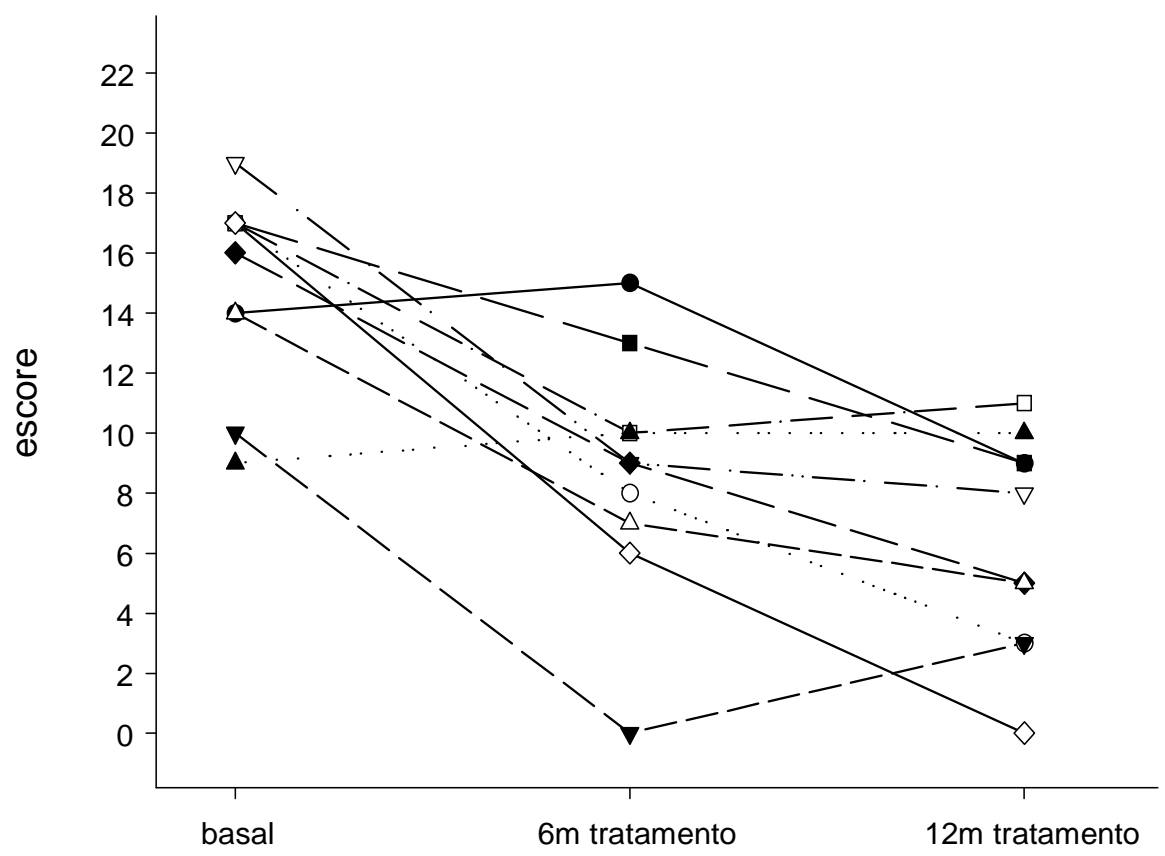

Figura 15 - Variação do escore de sinais e sintomas específicos da rinite dos pacientes do grupo placebo inicial que completaram $12 \mathrm{~m}$ de tratamento ou $18 \mathrm{~m}$ de acompanhamento $(\mathrm{n}=$ 10). 


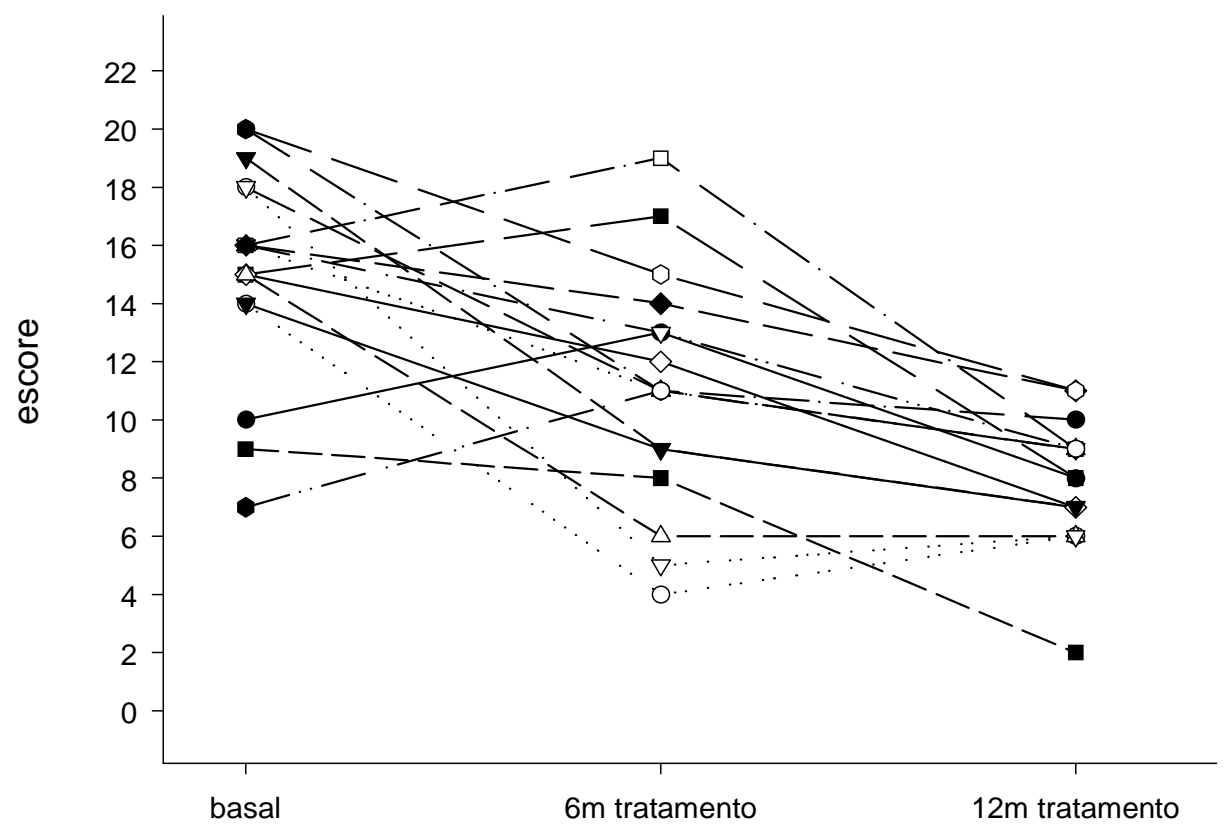

Figura 16 - Variação do escore de sinais e sintomas específicos da rinite dos pacientes do grupo ativo inicial que completaram $12 \mathrm{~m}$ de tratamento $(n=14)$.

\section{V.2.2.3. Evolução dos pacientes submetidos a 24 meses de tratamento homeopático $(n=20)$}

Dos vinte e sete pacientes que receberam 12 meses de tratamento, sete do subgrupo placebo inicial anterior ( $n=10 ; 30 \%$ ou $3 / 10$ de abandono) e treze do subgrupo ativo inicial anterior ( $n=17 ; 23 \%$ ou $4 / 17$ de abandono) permaneceram nesta fase. Destes vinte pacientes submetidos a 24 meses de tratamento, quatro apresentaram piora em relação ao escore final da fase anterior (12 meses de tratamento), sendo um do grupo placebo e três do grupo ativo iniciais. (Figuras 17 e 18) 
Associado a 24 meses de tratamento homeopático $(n=20)$, onze pacientes (cinco do grupo placebo e seis do grupo ativo inicias) ou 55\% do total $(11 / 20)$ atingiram escore $\leq 6$ pontos, quatro pela primeira vez (um do grupo placebo e três do grupo ativo iniciais) e um atingindo escore igual a zero (cura momentânea dos sinais e sintomas específicos da rinite).

Após completarem esta fase $(n=20)$, sete pacientes (três do grupo placebo e quatro do grupo ativo iniciais) abandonaram o estudo (35\% ou $7 / 20)$, com um paciente do grupo ativo inicial apresentando piora em relação ao escore anterior (12 meses de tratamento) e três pacientes (dois do grupo placebo e um do grupo ativo inicial) atingindo escore final $\leq 6$ pontos.

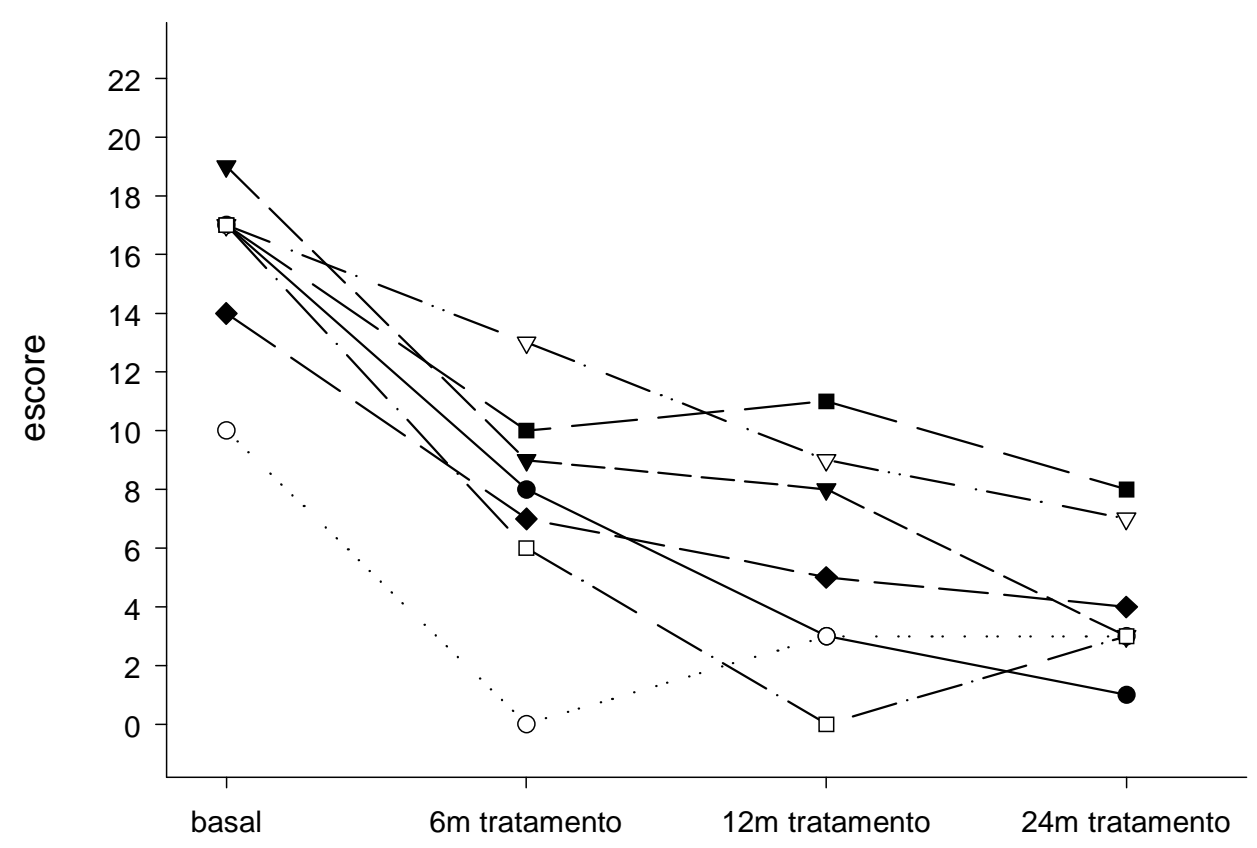

Figura 17 - Variação do escore de sinais e sintomas específicos da rinite dos pacientes do grupo placebo inicial que completaram $24 \mathrm{~m}$ de tratamento ou $30 \mathrm{~m}$ de acompanhamento $(n=$ 7). 


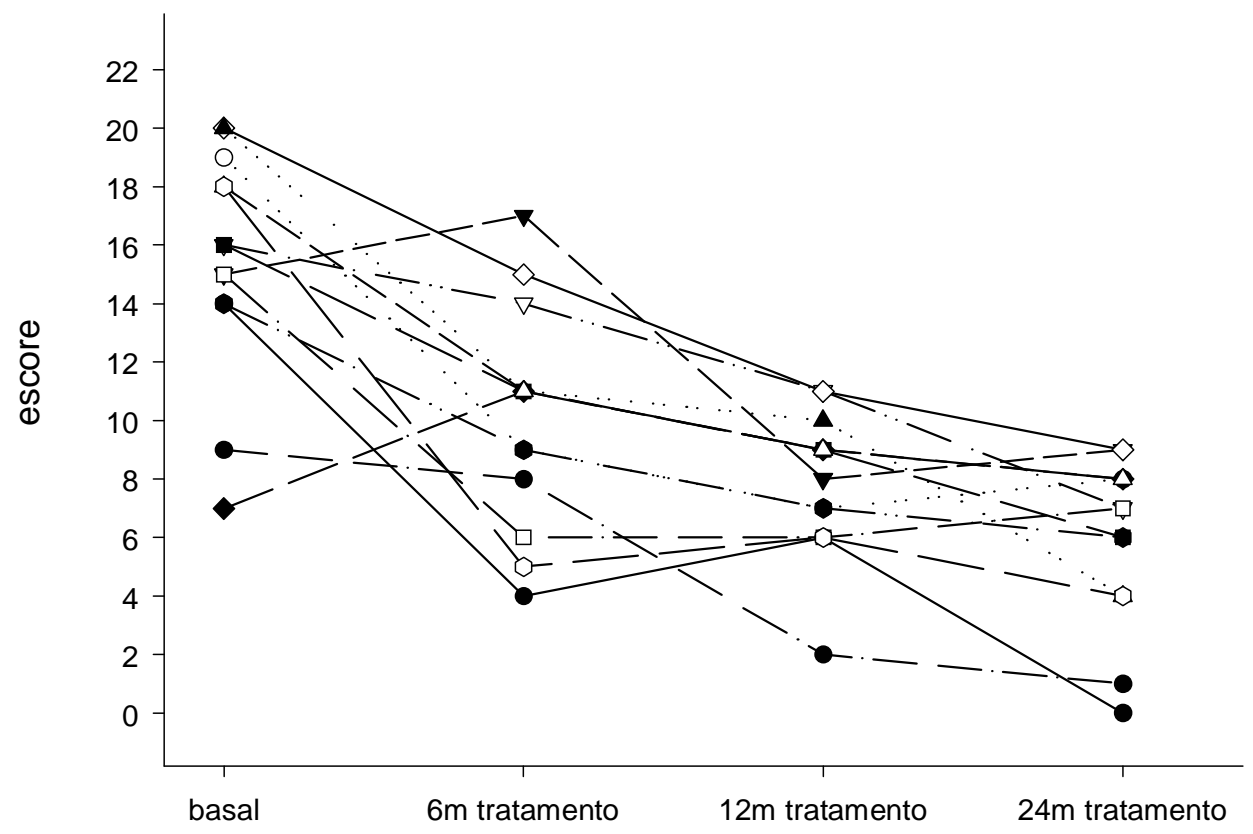

Figura 18 - Variação do escore de sinais e sintomas específicos da rinite dos pacientes do grupo ativo inicial que completaram $24 m$ de tratamento $(n=13)$.

\section{V.2.2.4. Evolução dos pacientes submetidos a 36 meses de tratamento homeopático $(n=13)$}

Dos vinte pacientes que receberam 24 meses de tratamento, cinco do subgrupo placebo inicial anterior ( $n=7 ; 29 \%$ ou $2 / 7$ de abandono) e oito do subgrupo ativo inicial anterior ( $n=13 ; 38 \%$ ou $5 / 13$ de abandono) permaneceram nesta fase. Destes treze pacientes submetidos a 36 meses de tratamento, três apresentaram piora em relação ao escore final da fase anterior (24 meses de tratamento), dois do grupo placebo e um do grupo ativo iniciais. (Figura 19) 
Associado a 36 meses de tratamento homeopático $(n=13)$, dez pacientes (quatro do grupo placebo e seis do grupo ativo iniciais) ou $77 \%$ do total $(10 / 13)$ atingiram escore $\leq 6$ pontos, dois pela primeira vez (grupo ativo inicial) e dois atingindo escore igual a zero (cura momentânea dos sinais e sintomas específicos da rinite). O estudo foi interrompido ao término desta fase.

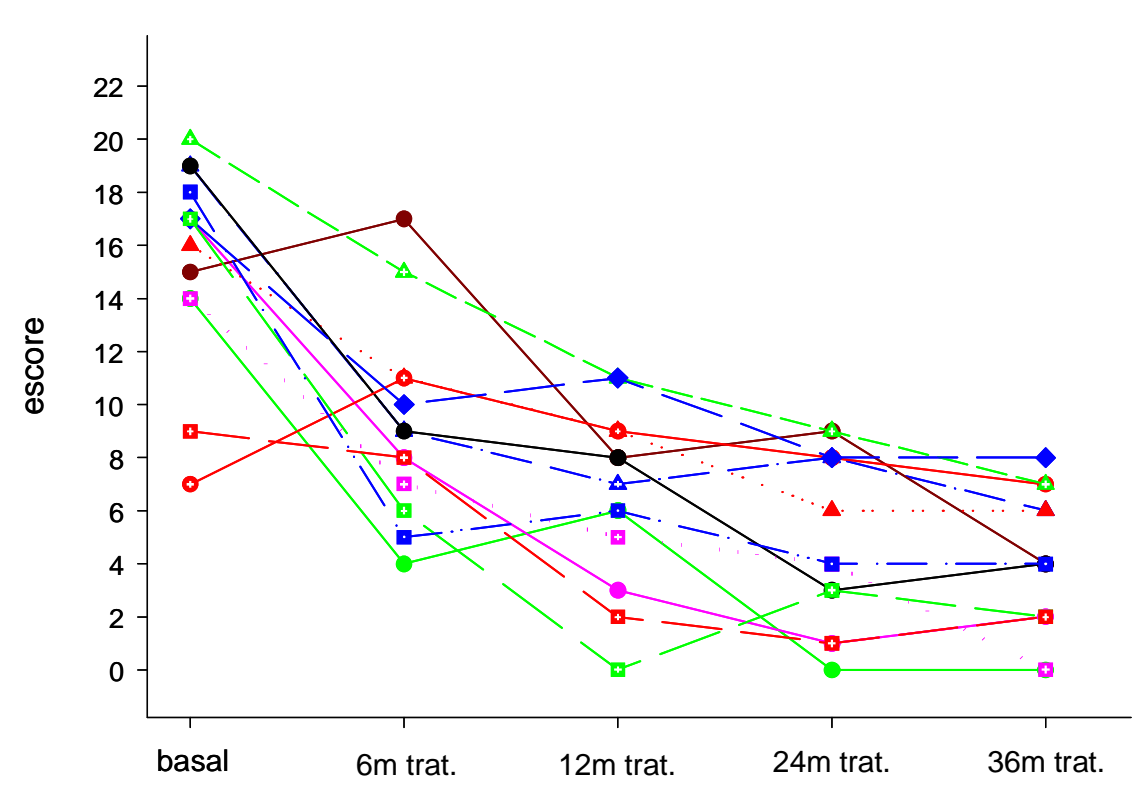

- pac 29 placebo

- pac 30 ativo

$\triangle-$ pac 35 ativo

$\multimap$ pac 37 placebo

$\rightarrow$ pac 42 placebo

.. pac 46 placebo

$\rightarrow$ pac 49 ativo

$\rightarrow$ pac 54 ativo

Figura 19 - Variação do escore de sinais e sintomas específicos da rinite dos pacientes que completaram 36 meses de tratamento homeopático $(n=13)$.

V.2.2.5. Evolução clínica do subgrupo de pacientes que atingiu escore $\leq 6$ pontos ao longo do estudo $(n=16)$ 
Dos dezesseis pacientes (sete do grupo placebo e nove do grupo ativo iniciais) que atingiram escore dos sinais e sintomas específicos da rinite $\leq 6$ pontos em alguma fase do estudo (39\% do total de pacientes ou 16/41), dez pacientes (três do grupo placebo e sete do grupo ativo iniciais) permaneceram no patamar superior (escore 4-6 pontos) e seis pacientes (quatro do grupo placebo e dois do grupo ativo iniciais) atingiram o patamar inferior (escore $\leq 3$ pontos) do menor grau de gravidade da rinite alérgica (grau I: 1-6 pontos), com quatro destes pacientes (três do grupo placebo e um do grupo ativo iniciais) atingindo escore total igual a zero em alguma fase do estudo. (Figura 20)
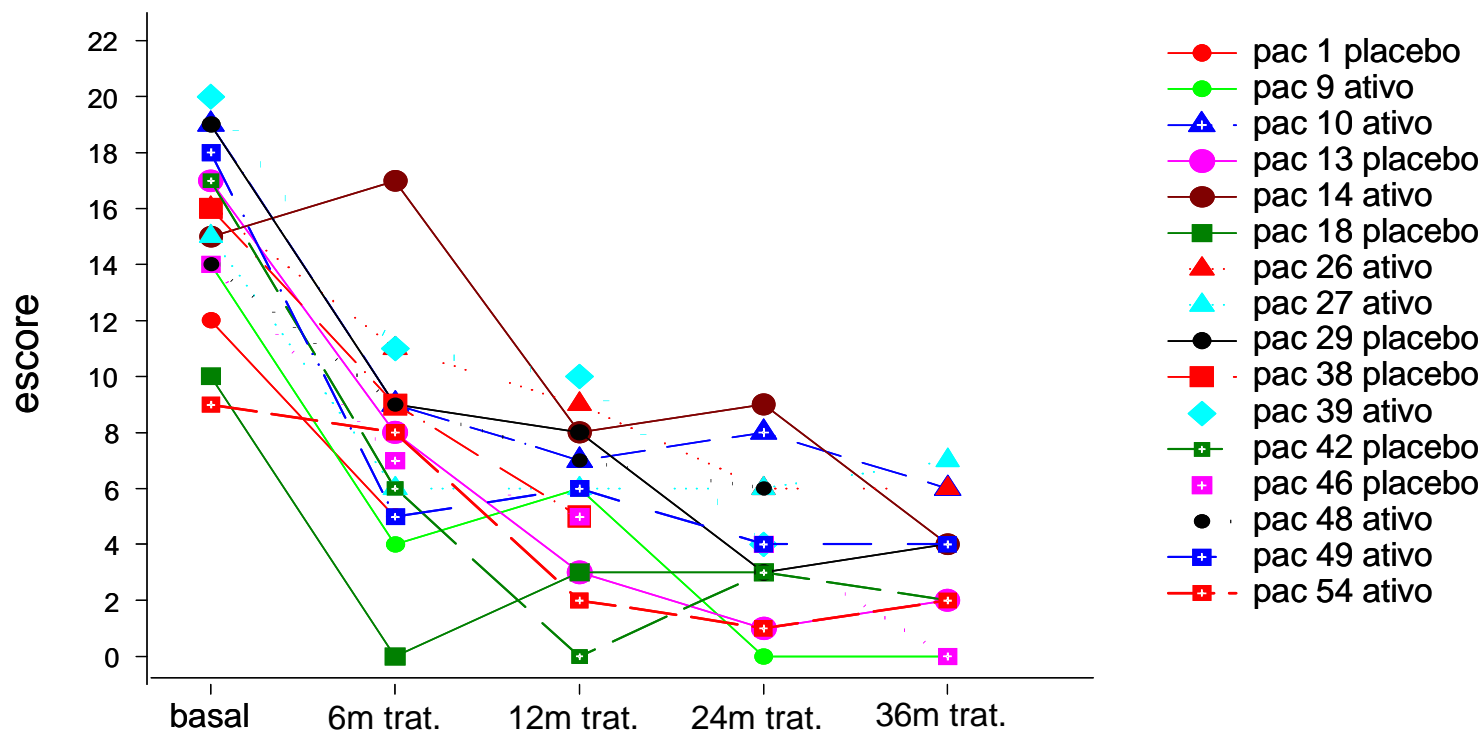

Figura 20 - Evolução clínica dos pacientes que atingiram escore $\leq 6$ pontos em alguma fase do período de 6-36 meses de tratamento homeopático $(n=16)$. 


\section{V.2.2.6. Análise qualitativa dos treze pacientes que completaram 36 meses de tratamento homeopático}

A fim de ilustrar o significado da duração do tratamento na efetividade da resposta clínica homeopática, para que se possa escolher dentre as diversas hipóteses medicamentosas o agente terapêutico semelhante e seja permitido a este medicamento um tempo de ação suficiente para alterar o curso natural da doença crônica, citaremos as particularidades observadas ao longo do período de acompanhamento dos treze pacientes que completaram 36 meses de tratamento, ressaltando elementos relevantes à discussão da efetividade do tratamento homeopático individualizado no médio-longo prazo.

Com o intuito de observar o efeito preventivo (residual ou de longa duração) do medicamento homeopático individualizado, que persiste após a suspensão do tratamento de forma análoga à imunoterapia, solicitamos aos dez pacientes que atingiram o escore de sinais e sintomas específicos da rinite $\leq 6$ pontos ao término dos 36 meses de tratamento homeopático que encaminhassem um relatório por email sobre a evolução da doença até o momento da transcrição destes resultados (04/2008).

V.2.2.6.1. Análise qualitativa dos pacientes que atingiram escore $\leq 3$ pontos

Neste item, iremos estudar qualitativamente cinco pacientes que completaram 36 meses de tratamento homeopático e atingiram escore final dos sinais e sintomas específicos da rinite $\leq 3$ pontos (patamar inferior do grau I de gravidade), três do grupo placebo $(P)$ e dois do grupo ativo $(A)$ iniciais. (Tabela 24) 
Tabela 24. Pacientes que atingiram escore dos sinais e sintomas específicos da rinite $\leq 3$ pontos ao final dos 36 meses de tratamento homeopático

\begin{tabular}{|c|c|c|c|c|c|c|}
\hline & \multicolumn{5}{|c|}{$\begin{array}{l}\text { Escore dos sinais e sintomas específicos da rinite } \\
\text { (desfecho primário) }\end{array}$} \\
\hline & & $\begin{array}{l}\text { Paciente } \\
09(A)\end{array}$ & $\begin{array}{l}\text { Paciente } \\
13(\mathrm{P})\end{array}$ & $\begin{array}{l}\text { Paciente } \\
42(\mathrm{P})\end{array}$ & $\begin{array}{l}\text { Paciente } \\
46(\mathrm{P})\end{array}$ & $\begin{array}{l}\text { Paciente } \\
54(\mathrm{~A})\end{array}$ \\
\hline \multirow{2}{*}{$\begin{array}{l}\mathrm{F} \\
\mathrm{A} \\
\mathrm{S} \\
\mathrm{E}\end{array}$} & Tempo basal & 14 pontos & 17 pontos & 17 pontos & 14 pontos & 9 pontos \\
\hline & $\begin{array}{l}6 \mathrm{~m} \text { iniciais de } \\
\text { acompanhamento }\end{array}$ & \multirow[b]{2}{*}{4 pontos } & 15 pontos & 6 pontos & 8 pontos & \\
\hline \multirow{4}{*}{$\begin{array}{l}F \\
A \\
S \\
E\end{array}$} & $\begin{array}{l}\text { 6m tratamento } \\
\text { homeopático }\end{array}$ & & 6 pontos & 6 pontos & 7 pontos & 8 pontos \\
\hline & $\begin{array}{l}12 \mathrm{~m} \text { tratamento } \\
\text { homeopático }\end{array}$ & 6 pontos & 0 pontos & 0 pontos & 5 pontos & 2 pontos \\
\hline & $\begin{array}{l}24 m \text { tratamento } \\
\text { homeopático }\end{array}$ & 0 pontos & 3 pontos & 3 pontos & 4 pontos & 1 ponto \\
\hline & $\begin{array}{l}36 \mathrm{~m} \text { tratamento } \\
\text { homeopático }\end{array}$ & 0 pontos & 2 pontos & 2 pontos & 0 pontos & 2 pontos \\
\hline
\end{tabular}

NOTA: $\mathrm{P}$ = grupo placebo inicial; $\mathrm{A}$ = grupo ativo inicial.

\section{Paciente 09}

Paciente com 39 anos, sexo feminino, alocada inicialmente no grupo ativo (20/09/2002) e apresentando história de rinite alérgica há 14 anos, com sintomas diários e crises mensais (escore basal de 14 pontos; grau III de gravidade), associadas a crises de sinusite nos últimos três anos, fazendo uso de antihistamínicos $\left(\right.$ Claritin $\left.^{\circledR}\right)$ há dois anos (antigamente usava Polaramine ${ }^{\circledR}$ ). Exames complementares na admissão: $\lg E=283,0 \mathrm{UI} / \mathrm{ml}$. Durante os primeiros 6 meses de tratamento homeopático, utilizou o medicamento Nux vomica em potências e doses diversas (30-200cH; doses únicas semanais e mensais), apresentando crises alérgicas fracas e estado geral oscilante. Nos 6 meses de tratamento homeopático 
seguinte (6-12m de tratamento), utilizou os medicamentos Arsenicum album, Lycopodium clavatum e Argentum nitricum (em diversas potências, em doses únicas semanais, um a cada mês), sem apresentar mudanças significativas no quadro anterior. Ao iniciar o terceiro semestre de tratamento homeopático (12-24m de acompanhamento), a paciente começou a utilizar o medicamento Lachesis muta, com melhora crescente do quadro anterior: ausência completa de crises de rinite e melhora global evidente (humor, sono, TPM, constipação etc.). Com a instalação de melhora significativa, as avaliações e as prescrições das doses únicas mensais passaram a ser realizada a cada 2-3 meses, empregando-se diversas potências (30$2000 \mathrm{cH}$ ) do mesmo medicamento, que permitiram à paciente permanecer sem crises de rinite até completar 36 meses de tratamento homeopático (10/2005).

\section{Paciente 13}

Paciente com 27 anos, sexo feminino, alocada inicialmente no grupo placebo (04/10/2002) e apresentando história de rinite alérgica há 12 anos, com sintomas diários e crises mensais (escore basal de 17 pontos; grau III de gravidade), associadas a crises de sinusite e asma nos últimos quatro anos, fazendo uso de corticosteróide inalatório $\left(\right.$ Budecort $\left.^{\circledR}\right)$ nos últimos 2-3 anos; uso de imunoterapia há cinco anos. Exames complementares na admissão: $\lg \mathrm{E}=872,0 \mathrm{UI} / \mathrm{ml}$. Durante os primeiros seis meses da intervenção placebo, a paciente apresentou crises mensais de rinite e dermatite, IVAS e sinusite, fazendo uso de anti-histamínicos, antiinflamatórios, descongestionantes nasais e antibiótico sistêmico (retornando ao estudo após períodos correspondentes de wash-out). Durante os primeiros 4 meses 
de tratamento homeopático (Fase 2), utilizou os medicamentos Pulsatilla nigricans, Phosphorus, Sepia succus e Calcarea carbonica $(30 \mathrm{cH}$, em doses únicas semanais, um a cada mês), apresentando crises alérgicas fracas e estado geral oscilante. A partir do $5^{0}$ mês de tratamento homeopático, a paciente começou a utilizar o medicamento Lycopodium clavatum, com melhoras progressivas do quadro alérgico e do estado geral (medos, apetite, leucorréia, IVAS etc.). Com a instalação de melhora significativa, a paciente passou a ser avaliada a cada 2-3 meses, recebendo doses únicas de diversas potências $(30-2000 \mathrm{cH})$ do mesmo medicamento, que permitiram à mesma permanecer praticamente sem crises de rinite e IVAS (com dermatites esporádicas) até completar 36 meses de tratamento homeopático (10/2006). Até os dias atuais, a paciente utiliza doses semanais ou mensais do medicamento (contato por telefone), com manutenção do estado de melhora.

\section{Paciente 42}

Paciente com 30 anos, sexo feminino, alocada inicialmente no grupo placebo (26/05/2003) e apresentando história de rinite alérgica há 20 anos, com sintomas diários e crises mensais (escore basal de 17 pontos; grau III de gravidade), associadas a IVAS e fazendo uso de vasoconstritor nasal (Aturgyl $^{\circledR}$ ) esporadicamente. Exames complementares na admissão: $\lg E=73,1 \mathrm{Ul} / \mathrm{ml}$. Durante os primeiros 6 meses da intervenção placebo, apesar de referir melhoras nos aspectos psíquicos e emocionais, a paciente apresentou crises mensais de rinite e IVAS, chegando a utilizar antibiótico sistêmico após broncopneumonia (RX: infiltrado em base de pulmão direito) e retornando ao estudo após período correspondente de 
wash-out. Ao término da fase inicial, ao saber que estava alocada no grupo placebo, a paciente passou a criar obstáculos para comparecer na consulta de seguimento, adiando-a por duas vezes; no retorno, relatou que ficou "com raiva do placebo", sentindo-se "enganada por ele" ("este placebo mexeu com o meu orgulho"), demonstrando desinteresse para continuar no estudo e referindo piora da rinite após saber que estava no grupo placebo. Nos primeiros três meses de tratamento homeopático (Fase 2), utilizou os medicamentos Lachesis muta $(30 \mathrm{cH})$ e Lycopodium clavatum (30 e $200 \mathrm{cH}$ ), sempre em doses únicas semanais e um a cada mês, sentindo o quadro alérgico e o estado geral se agravarem. No $4^{\circ}$ mês de tratamento homeopático (10m de acompanhamento), a paciente começou a utilizar o medicamento Nux vomica, sentindo melhoras evidentes da rinite e do estado geral (humor, sono, intestino, TPM, suscetibilidade climática etc.). De forma análoga às outras pacientes, com a instalação de melhora significativa, doses únicas de diversas potências $(30-2000 \mathrm{cH})$ do mesmo medicamento passaram a serem prescritas a cada 2-3 meses, transmitindo à paciente um estado de bem-estar físico e psíquico crescente até o término dos 36 meses do tratamento homeopático (12/2006).

\section{Paciente 46}

Paciente com 32 anos, sexo feminino, alocada inicialmente no grupo placebo (09/06/2003) e apresentando história de rinite alérgica há 09 anos, com sintomas diários e crises mensais (escore basal de 14 pontos; grau III de gravidade). Exames complementares na admissão: $\lg E=275,0 \mathrm{UI} / \mathrm{ml}$. Durante os primeiros 6 meses da intervenção placebo, apesar de referir melhoras esporádicas, a paciente apresentou 
crises mensais de rinite e IVAS, referindo que "nunca deixou de ter os sintomas da rinite neste período de tratamento". Nos primeiros quatro meses de tratamento homeopático (Fase 2), utilizou os medicamentos Lycopodium clavatum, Sulphur, Natrum muriaticum e Sepia succus $(30 \mathrm{cH}$, em doses únicas semanais, um a cada mês) sem constatar melhoras do quadro alérgico (crises intensas de rinite, dermatite atópica e unhas quebradiças) e do estado geral (humor, insônia, TPM etc.) neste período, ao ponto da paciente relatar que "estava desanimada com o tratamento por não estar vendo retorno no tratamento dela e do filho, com outro homeopata". No $5^{\circ}$ mês de tratamento homeopático (11m de acompanhamento), logo após a ingesta do medicamento Lachesis muta, a paciente passou a observar melhoras evidentes do quadro alérgico (rinite, dermatite atópica e unhas quebradiças) e do estado geral (humor, sono, TPM etc.). De forma análoga às outras pacientes, com a evolução do quadro clínico (desaparecimento completo dos sintomas da rinite a partir do décimo segundo mês de tratamento homeopático), doses únicas de diversas potências (30$2000 \mathrm{cH}$ ) do mesmo medicamento passaram a serem prescritas a cada 2-3 meses, mantendo a paciente em perfeito estado de saúde até o término dos 36 meses de tratamento homeopático (12/2006).

\section{Paciente 54}

Paciente com 44 anos, sexo feminino, alocada inicialmente no grupo ativo (20/10/2003) e apresentando história de rinite alérgica há 20 anos, com sintomas diários e crises mensais (escore basal de 9 pontos; grau II de gravidade), fazendo uso de corticosteróide inalatório $\left(\right.$ Budecort $\left.^{\circledR}\right)$ esporadicamente ao longo do último 
ano. Exames complementares na admissão: $\lg E=213,0 \mathrm{Ul} / \mathrm{ml}$. Durante os primeiros 2 meses de tratamento homeopático, utilizou os medicamentos Arsenicum album e Carbo vegetabilis $(30 \mathrm{cH}$, em doses únicas semanais, um a cada mês), apresentando crises alérgicas e estado geral oscilante (insegurança, impaciência, insônia, constipação, compulsão por doces etc.). Ao iniciar o $3^{0}$ mês de tratamento homeopático, a paciente começou a utilizar o medicamento Lycopodium clavatum, com melhoras gradativas do quadro inicial: diminuição dos sintomas da rinite e melhora global (insegurança, insônia, constipação, compulsão por doces etc.). Com a instalação de melhora significativa, as avaliações e as prescrições mensais passaram a serem realizadas a cada 2-3 meses, empregando-se diversas potências $(30-2000 \mathrm{cH})$ do mesmo medicamento, que permitiram à paciente permanecer sem crises de rinite até completar 36 meses de tratamento homeopático (10/2006).

V.2.2.6.2. Análise qualitativa dos pacientes que atingiram escore entre 4-6 pontos

Neste tópico, iremos estudar qualitativamente cinco pacientes que completaram 36 meses de tratamento homeopático e que atingiram escore final dos sinais e sintomas específicos da rinite entre 4-6 pontos (patamar superior do grau I de gravidade), um do grupo placebo $(P)$ e quatro do grupo ativo $(A)$ iniciais. (Tabela 25) 
Tabela 25. Pacientes que atingiram escore dos sinais e sintomas específicos da rinite entre 4-6 pontos ao final dos 36 meses de tratamento homeopático

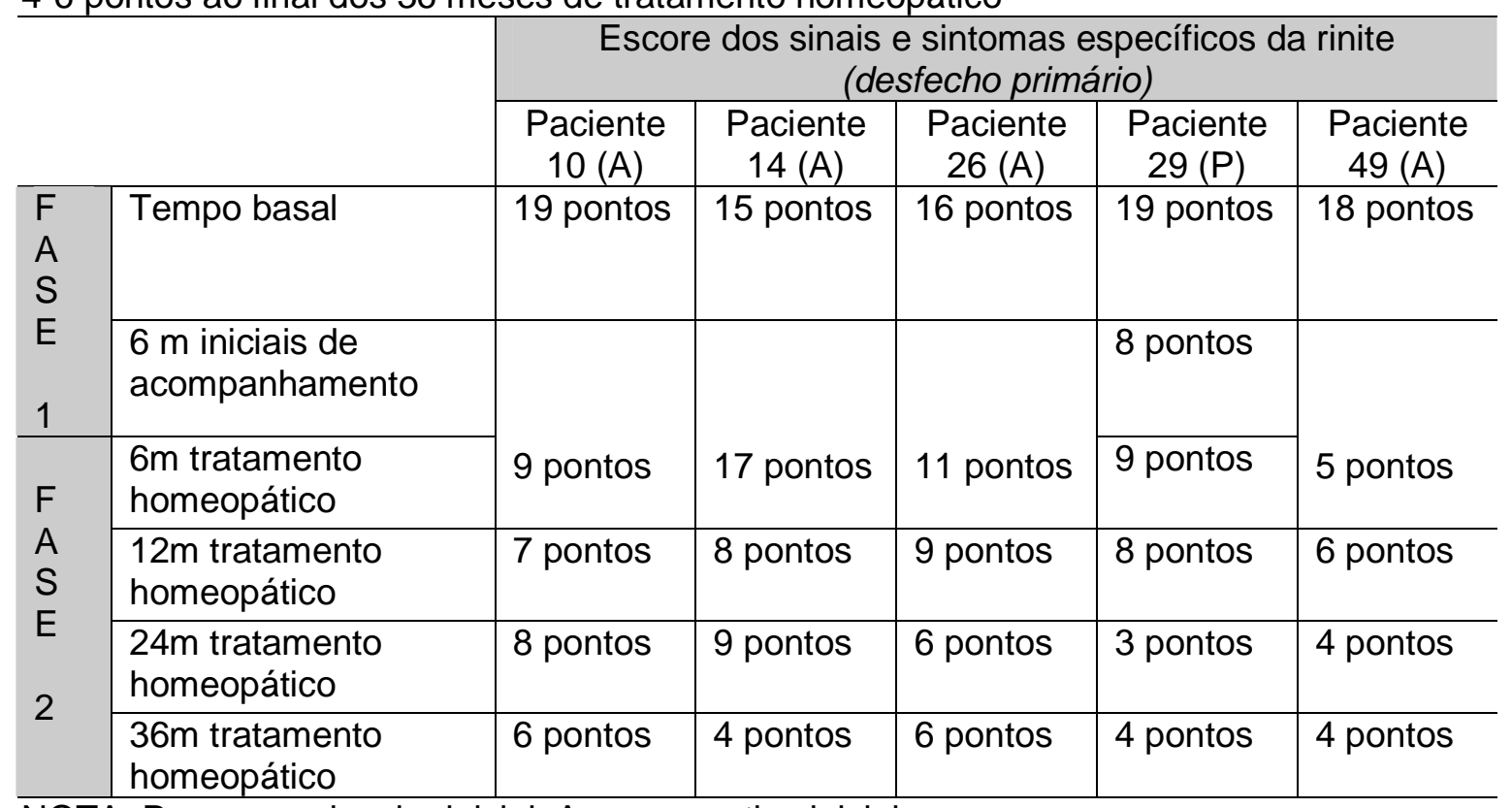

NOTA: $\mathrm{P}=$ grupo placebo inicial; $\mathrm{A}$ = grupo ativo inicial.

\section{Paciente 10}

Paciente com 60 anos, sexo feminino, alocada inicialmente no grupo ativo (23/09/2002) e apresentando história de rinite associada com asma desde a infância, com sintomas diários e crises mensais de rinite (escore basal de 19 pontos; grau IV de gravidade), fazendo uso de antialérgico $\left(\right.$ Polaramine $\left.^{\circledR}\right)$ e inalação com broncodilatador $\left(\right.$ Berotec $\left.^{\circledR}\right)$ esporadicamente; relatava ter feito tratamento com imunoterapia na adolescência durante oito anos. Exames complementares na admissão: $\lg \mathrm{E}=243,0 \mathrm{Ul} / \mathrm{ml}$. Utilizou ao longo de todo o tratamento o medicamento Natrum muriaticum, com melhoras gradativas nos sintomas da rinite e em outras queixas gerais (mal-humor, insônia, desânimo, cefaléia, constipação, onicomicose 
etc.). Com a instalação de melhora significativa, as avaliações e as prescrições mensais passaram a serem realizadas a cada 2-3 meses, empregando-se diversas potências $(30-2000 \mathrm{cH})$ do mesmo medicamento em doses únicas, que permitiram à paciente permanecer sem crises de rinite até completar 36 meses de tratamento homeopático (10/2005).

\section{Paciente 14}

Paciente com 26 anos, sexo masculino, alocado inicialmente no grupo ativo (07/10/2002) e apresentando história de rinite associada com asma grave desde a infância (morou durante sete anos no litoral por causa dos problemas respiratórios), com sintomas diários e crises mensais (escore basal de 15 pontos; grau III de gravidade), fazendo uso de broncodilatador (Atrovent ${ }^{\circledR}$, Berotec $^{\circledR}$ ) por conta própria até o momento da avaliação inicial. Exames complementares na admissão: $\lg E$ = $599,0 \mathrm{UI} / \mathrm{ml}$. Durante os primeiros 12 meses de tratamento homeopático, utilizou os medicamentos Nux vomica, Sulphur, Mercurius solubilis, Phosphorus e Lycopodium clavatum (em diversas potências, em doses únicas semanais, um a cada mês), apresentando crises alérgicas e estado geral oscilante, com indicativos de melhoras apenas com o último medicamento. Permaneceu com o Lycopodium clavatum, em potências crescentes (até $2000 \mathrm{cH}$ ), até a conclusão do estudo (10/2005), com incremento evidente da melhora clínico-alérgica. Utiliza doses semanais ou mensais do mesmo medicamento até os dias atuais (contato por telefone). 


\section{Paciente 26}

Paciente com 26 anos, sexo feminino, alocada inicialmente no grupo ativo (21/03/2003) e apresentando história de rinite e dermatite de contato há 6 anos, com sintomas diários e crises quinzenais (escore basal de 16 pontos; grau III de gravidade), fazendo uso de corticosteróide nasal (Budecort ${ }^{\circledR}$ ) esporadicamente e AAS freqüentemente, referindo tratamento com imunoterapia no passado. Exames complementares na admissão: $\lg E=93,6 \mathrm{Ul} / \mathrm{ml}$. Até a conclusão do período de 12 meses de tratamento homeopático utilizou o medicamento Natrum muriaticum (nas potências $30-2000 \mathrm{cH}$, em doses únicas mensais), apresentando melhoras gradativas nos sintomas da rinite e em outras queixas gerais (humor, insegurança, insônia, TPM, constipação etc.). Durante $02^{\circ}$ e $3^{\circ}$ anos de tratamento, com 0 intuito de incrementar as melhoras, experimentou os medicamentos Sulphur, Lycopodum clavatum, Nux vomica, Sepia succus, Lachesis muta, Staphysagria e Silicea terra, apresentando respostas positivas à rinite com os dois últimos medicamentos, empregando diversas potências e mantendo o quadro de melhora anterior até a conclusão do estudo (04/2006).

\section{Paciente 29}

Paciente com 40 anos, sexo feminino, alocada inicialmente no grupo placebo (31/03/2003) e apresentando história de rinite e dermatite de contato há 10 anos, com sintomas diários e crises quando em contato com produtos de limpeza (escore basal de 19 pontos; grau IV de gravidade), tendo realizado há quatro anos tratamento com imunoterapia e anti-histamínicos $\left(\right.$ Claritin $^{\circledR}$ e Zaditen $\left.{ }^{\circledR}\right)$ durante dois 
anos. Exames complementares na admissão: $\lg E=101,0 \mathrm{Ul} / \mathrm{ml}$. Ao longo do estudo, a paciente utilizou os medicamentos Silicea terra, Natrum muriaticum e Lycopodium clavatum, em diversas potências $(30-2000 \mathrm{cH})$ e doses únicas semanais ou mensais, apresentando melhoras gradativas nos sintomas da rinite e da dermatite, que perduraram até o término do protocolo (04/2006).

\section{Paciente 49}

Paciente com 23 anos, sexo feminino, alocada inicialmente no grupo ativo (02/07/2003) e apresentando história de amidalites purulentas recorrentes e rinite há 15 anos, com sintomas diários e crises bimensais (escore basal de 18 pontos; grau III de gravidade), tendo realizado tratamento no passado com imunoterapia e corticosteróide (sistêmico e nasal), fazendo uso na atualidade de anti-histamínico $\left(\right.$ ClaritinD $\left.{ }^{\circledR}\right)$. Exames complementares na admissão: lgE $=14,5 \mathrm{Ul} / \mathrm{ml}$. Ao longo do estudo, a paciente experimentou os medicamentos Sepia succus, Calcarea carbonica, Arsenicum album, Sulphur, Ignatia amara, Natrum muriaticum, Lachesis muta e Lycopodium clavatum, apresentando melhoras gradativas nos sintomas da rinite e em aspectos gerais (psiquismo, infecções de repetição, constipação etc.) com os três últimos medicamentos, que perduraram até o término do protocolo (10/2006).

V.2.2.6.3. Análise qualitativa dos pacientes que atingiram escore $>6$ pontos

Neste item, iremos estudar qualitativamente três pacientes que completaram 36 meses de tratamento homeopático e atingiram escore final dos sinais e sintomas 
específicos da rinite $>6$ pontos (grau II de gravidade: 7-12 pontos), um do grupo placebo $(\mathrm{P})$ e dois do grupo ativo $(\mathrm{A})$ iniciais. (Tabela 26)

Tabela 26. Pacientes que atingiram escore dos sinais e sintomas específicos da rinite $>6$ pontos ao final dos 36 meses de tratamento homeopático

\begin{tabular}{|c|c|c|c|c|}
\hline & \multicolumn{3}{|c|}{$\begin{array}{l}\text { Escore dos sinais e sintomas específicos da rinite } \\
\text { (desfecho primário) }\end{array}$} \\
\hline & & Paciente $30(\mathrm{~A})$ & Paciente $35(\mathrm{~A})$ & Paciente $37(\mathrm{P})$ \\
\hline \multirow{2}{*}{$\begin{array}{l}\mathrm{F} \\
\mathrm{A} \\
\mathrm{S} \\
\mathrm{E}\end{array}$} & Tempo basal & 7 pontos & 20 pontos & 17 pontos \\
\hline & $\begin{array}{l}6 \mathrm{~m} \text { iniciais de } \\
\text { acompanhamento }\end{array}$ & \multirow[b]{2}{*}{11 pontos } & \multirow[b]{2}{*}{15 pontos } & 9 pontos \\
\hline \multirow{3}{*}{$\begin{array}{l}F \\
A \\
S \\
E\end{array}$} & $\begin{array}{l}6 m \text { tratamento } \\
\text { homeopático }\end{array}$ & & & 10 pontos \\
\hline & $\begin{array}{l}12 \mathrm{~m} \text { tratamento } \\
\text { homeopático }\end{array}$ & 9 pontos & 11 pontos & 11 pontos \\
\hline & $\begin{array}{l}24 \mathrm{~m} \text { tratamento } \\
\text { homeopático }\end{array}$ & 8 pontos & 9 ponto & 8 pontos \\
\hline 2 & $\begin{array}{l}36 \mathrm{~m} \text { tratamento } \\
\text { homeopático }\end{array}$ & 7 pontos & 7 pontos & 8 pontos \\
\hline
\end{tabular}

NOTA: $\mathrm{P}=$ grupo placebo inicial; $\mathrm{A}=$ grupo ativo inicial.

\section{Paciente 30}

Paciente com 50 anos, sexo masculino, alocado inicialmente no grupo ativo (02/04/03) e apresentando história de rinite alérgica há 30 anos com sintomas diários e crises mensais (escore basal de 7 pontos; grau II de gravidade), associadas a crises de sinusite esporádicas, fazendo uso de vasoconstritor nasal até 2000 e corticosteróide intramuscular esporadicamente (lavagem com soro fisiológico nos últimos 3 anos); tabagista importante há 30 anos. Exames complementares na admissão: $\lg E=45,5 \mathrm{Ul} / \mathrm{ml}$. Além dos sintomas da rinite, o paciente apresentava 
quadros de ansiedade, fobia e vertigem. Ao longo do estudo, vários medicamentos foram prescritos mensalmente, em diversas potências, sem que se observasse uma mudança expressiva no quadro alérgico e nos demais sintomas: Arsenicum album, Ignatia amara, Lycopodium clavatum, Sulphur, Nux vomica, Phosphorus, Platinum metallicum, Pulsatilla nigricans, Natrum muriaticum, Lachesis muta e Argentum nitricum. As melhores respostas foram obtidas com os três primeiros medicamentos citados, empregados num amplo espectro de potências $(30-2000 \mathrm{cH})$, sem que fossem observadas melhoras significativas.

\section{Paciente 35}

Paciente com 27 anos, sexo feminino, alocada inicialmente no grupo ativo (23/04/03) e apresentando história de rinite alérgica há 15 anos com sintomas diários e crises mensais (escore basal de 20 pontos; grau IV de gravidade), associadas a crises de asma e sinusite há 20 anos; no passado, fez uso de imunoterapia subcutânea por 2-3 anos e utiliza vasoconstritor nasal (Aturgy $\left.\right|^{\circledR}$ ) freqüentemente; refere piora da rinite nos últimos quatro anos associada ao excesso de umidade da moradia, fazendo inalação com soro fisiológico diariamente. Exames complementares na admissão: $\lg E=971,0 \mathrm{UI} / \mathrm{ml}$. Além dos sintomas da rinite, a paciente apresentava quadros de ansiedade, fazendo uso de ansiolíticos. Ao longo do estudo, vários medicamentos foram prescritos mensalmente, em diversas potências, sem que se observasse uma mudança expressiva no quadro alérgico e nos demais sintomas: Lachesis muta, Arsenicum album, Sepia succus, Lycopodium clavatum, Nux vomica, Pulsatilla nigricans, Phosphorus, Ignatia amara, Sulphur, Kali 
carbonicum, Veratrum album e Spigelia anthelmintica. As melhores respostas foram obtidas com os dois primeiros medicamentos citados, empregados num amplo espectro de potências $(30-2000 \mathrm{cH})$, sem melhoras significativas.

\section{Paciente 37}

Paciente com 27 anos, sexo feminino, alocada inicialmente no grupo placebo (07/05/03) e apresentando história de rinite alérgica há 10 anos, com sintomas diários e crises quinzenais (escore basal de 17 pontos; grau III de gravidade), associadas a crises de asma até a adolescência e crises de amidalites até os 20 anos; fez uso de imunoterapia subcutânea na adolescência e utiliza atualmente vasoconstritor nasal, antialérgicos e anti-histamínicos (Dimetap ${ }^{\circledR}$, Claritin-D ${ }^{\circledR}$ e Alegra $\left.^{\circledR}\right)$ nas crises de rinite. Exames complementares na admissão: $\lg E=484,0$ $\mathrm{Ul} / \mathrm{ml}$. Além dos sintomas da rinite, a paciente apresentava quadros de ansiedade e depressão reativa, sem utilizar medicamentos. Ao longo do estudo, vários medicamentos foram prescritos mensalmente, em diversas potências, sem que se observasse uma mudança expressiva no quadro alérgico e nos demais sintomas: Lycopodium clavatum, Ignatia amara, Arsenicum album, Lachesis muta, Veratrum album, Phosphorus, Lilium tigrinum, Silicea terra, Platinum metallicum, Sulphur, Calcarea carbonica, Pulsatilla nigricans e Delphininum staphysagria. As melhores respostas foram obtidas com os três primeiros medicamentos citados, empregados num amplo espectro de potências $(30-2000 \mathrm{cH})$, sem maiores significâncias clínicas. 
V.2.2.6.4. Avaliação qualitativa da efetividade do tratamento homeopático individualizado no médio-longo prazo (efeito residual ou preventivo)

Para avaliarmos qualitativamente a efetividade do tratamento homeopático individualizado a longo prazo (efeitos residuais ou preventivos), solicitamos aos dez pacientes que receberam um medicamento homeopático completa ou parcialmente individualizado (medicamento homeopático simillimum ou similar, respectivamente) e atingiram escore $\leq 6$ pontos ao término do período de 36 meses de tratamento, para enviarem um relatório por e-mail descrevendo a evolução da rinite após o término do estudo e a suspensão do medicamento, os quais foram transcritos abaixo preservando a identidade dos mesmos.

Dos dez pacientes, apenas três continuaram utilizando medicamento homeopático nestes 2-3 anos após o término do estudo, dois deles na forma de doses únicas periódicas, e um deles tomou apenas uma única dose neste período.

V.2.2.6.4.1. Pacientes que atingiram escore $\leq 3$ pontos ao término do estudo

---- Original Message -----

From: Paciente 09

To: Dr. Marcus Zulian

Sent: Wednesday, April 23, 2008 10:08 PM

Subject: Evolução da Rinite Alérgica

Dr. Marcus,

No dia 18/04/08, mexendo nas minhas anotações, encontrei meu caderninho onde comecei a anotar o início do tratamento homeopático de minha rinite alérgica. Esse começou exatamente no dia 21/09/02. É incrível ler o que me fez sofrer por muitos anos. Lembro-me de sempre coçar muito o nariz (que parecia uma bica e sempre vermelho), olhos (viviam sempre muito vermelhos) e ouvidos (enfiava qualquer coisa que estivesse ao meu alcance para coçá-los). Os espirros eram por demais, principalmente quando mexia em algo guardado, ou chegava a algum lugar diferente (morria de vergonha, pois as pessoas não me olhavam muito bem). Começava pelo entupimento da narina esquerda e logo em seguida estava toda congestionada. Por várias vezes segurava as narinas para soltar 0 ar pelos 
ouvidos. Assim aliviava a sensação de entupimento. Agora, o que mais atrapalhava meu sono era a coceira na garganta, que era insuportável. Por várias vezes pegava a ponta do lençol para coçá-la. As dores de cabeça eram constantes. A secreção que descia pela garganta me incomodava muito, pois sempre estava com um pigarro. Outra coisa que me lembro, era meu mau-humor e minha ansiedade. As tosses eram constantes. É incrível como estou maravilhada e muito agradecida com o tratamento da homeopatia. Sempre acreditei nela, mas ouvia dizer que para essa doença não era tão simples assim. Recordo-me até das dores fortes de estômago no início do tratamento. Demorou um pouco para acertar o remédio. Mas de um tempo pra cá sou uma nova mulher. O mau-humor na época da TPM é normal, mas hoje entro no palco e me sinto a própria "bailaroa flamenca". Quando algo me aborrece consigo por pra fora. A ansiedade está muito mais controlada. Dr. Marcus agradeço muito a você e sua equipe. Depois desses anos de tranqüilidade, no início desse mês de abril, por volta do dia 03/04/08 comecei com coceira nos ouvidos, tosse e secreção descendo pela garganta. No dia 09/04/08, comecei a tomar meu remédio de fundo Lachesis muta $6 \mathrm{cH}$ por uma semana. No dia 19/04/08 já não tinha mais nada. Obrigada mais uma vez.

----- Original Message -----

From: Paciente 13

To: marcus@homeozulian.med.br

Sent: Thursday, April 24, 2008 9:21 PM

Subject: Evolução da Rinite Alérgica

Eu sou uma pessoa alérgica. Comecei a fazer um tratamento homeopático em 2002 no Hospital das Clinicas com o Dr Marcus Zulian. Este tratamento foi criado para um estudo sobre a eficácia da Homeopatia perante a Alergia (Rinite). Sempre quando me envolvia com poeira ou com a mudança de tempo, minha alergia atacava, meus olhos, ouvidos e nariz coçavam constantemente, também tinha coceiras pelo corpo todo. Fiz vários exames, a princípio para descobrir qual era o meu quadro alérgico, foi descoberto que tenho alergia a pó, poeira e mofo (desculpe-me se faltou algum); após o diagnóstico, comecei o tratamento com vários remédios, um de cada vez, sendo alterados mensalmente (ou dosagem ou outra formulação); no começo tive reações, ficando com a alergia bem atacada, mas conforme o tempo foi passando, o Dr descobriu o melhor remédio para mim e o tratamento começou a dar certo, me sentindo cada vez melhor; as alergias começaram a demorar mais para atacar e quando atacavam era com menos intensidade. O tratamento acabou em 24/10/06, mas continuo o tratamento até hoje, pois o Dr Marcus Zulian continua me prescrevendo o remédio. Por fim, eu agradeço ao Dr Marcus Zulian e ao Hospital das Clínicas, por terem me proporcionado uma vida melhor.

----- Original Message -----

From: Paciente 42

To: marcus@homeozulian.med.br

Sent: Monday, April 28, 2008 1:51 PM

Subject: RELATORIO TRATAMENTO HOMEOPATICO

Oi Dr Marcos.

Desde que terminamos o tratamento não tive mais crises de rinite alérgica. $O$ tratamento durou cerca de três anos com acompanhamentos e controles mensais, até o "tateamento" da dosagem correta do meu medicamento de fundo, a Nux vomica. A minha recuperação foi 
surpreendente, sendo que quando eu vejo alguém com rinite sempre recomendo tal tratamento. Eu era bastante incrédula com relação ao tratamento homeopático, no entanto, passei a acreditar a partir do momento em que me vi curada. Agradeço não só ao Dr Marcos pela oportunidade de participar do protocolo experimental, assim como de ter este incômodo, pois a rinite não é uma doença, e sim um incômodo que fazia parte da minha vida. Um abraço. E mais uma vez obrigada.

----- Original Message -----

From: Paciente 46

To: Marcus Zulian Teixeira

Sent: Friday, April 25, 2008 8:33 AM

Subject: Re: Fw: Relatório evolutivo - Rinite

Ao Dr Marcus Zulian Teixeira

Relatório de Evolução da Rinite: Desde que o tratamento ou o acompanhamento próximo foi finalizado, a ausência de sintomas relacionados ao quadro de rinite alérgica se manteve. Não houve mais episódios de "crises", coceira nasal, ocular, espirros e olhos irritados (avermelhados). Quanto à saúde, de maneira geral, também não houve nenhum episódio de "doença" e os sintomas relacionados a outras situações como fluxo menstrual intenso, alterações de humor, TPM, unhas fracas, sono etc., não ocorreram mais. A única questão relacionada à área de saúde que permanece é o nível de hemoglobina baixo (por volta de 10,3) - anemia, que já havia antes do tratamento e que apesar de controle próximo e sistemático através de exames de sangue periódicos e alimentação direcionada, não foi alterado. Com relação à rinite há um fato que ilustra muito bem a melhora ocorrida: No último feriado de Páscoa estava hospedada na casa de amigos e minha amiga foi pegar algumas coisas em um guarda-roupas para me mostrar e voltou espirrando, e comentando sobre como era só ela mexer no armário para já ficar toda congestionada, e eu na mesma hora falei: Não faz isto, fala para mim que eu pego para você. E ela rebateu: Até parece que você não tem rinite também?! Eu completei: Se for possível, acredito que eu tinha e não tenho mais!!

----- Original Message -----

From: Paciente 54

To: marcus@homeozulian.med.br ; mzulian@usp.br

Sent: Friday, April 25, 2008 11:38 AM

Subject: Relato sobre o tratamento da Rinite.

No início do tratamento da Rinite com a Homeopatia, observei algumas melhoras como: não apresentar coriza e espirros no período da manhã. Era rotina: ao levantar da cama e também enquanto dormia, se me expunha à temperatura baixa, despertava com espirros e coceira no nariz. Hoje costumo dizer que, depois do tratamento com a Homeopatia, não sei mais o que é Rinite alérgica! Inicio os meus dias sem coceiras e espirros e assim me mantenho, o dia todo! Aproveito para agradecer, Dr. Marcus Zulian pela atenção dispensada durante o tratamento! Muito Obrigada! 
V.2.2.6.4.2. Pacientes que atingiram escore entre 4-6 pontos ao término do estudo

----- Original Message -----

From: Paciente 10

To: Dr. Marcus Zulian Teixeira

Sent: Friday, April 25, 2008 9:09 AM

Subject: Paciente sem rinite

Relatório: tratamento de rinite alérgica por homeopatia. Situação antes do início do tratamento: rinite muito forte principalmente pela manhã. Coriza e espirros continuados, especialmente ao ler jornais. Durante o tratamento: ao iniciar o tratamento ocorreu melhora significativa. A ocorrência de surtos de coriza e espirros passou a ser esporádica. Em 26/10/05, ao término do tratamento programado, me sentia muito melhor. Após o término do estudo, continuei a ser atendida até o final de 2006. A ocorrência de rinite era esporádica. Em setembro de 2007, ao notar a volta dos sintomas - coriza e espirros continuados - repeti a última dose única prescrita (com autorização do Dr. Marcus) e, desde então, não tenho sentido sintomas que justifiquem a ingestão de novas doses.

----- Original message -----

From: Paciente 14

To: marcus@homeozulian.med.br

Sent: thursday, april 17, 2008 10:49 pm

Subject: carta de tratamento

Eu tinha um quadro alérgico muito forte, eu entrava nos lugares e ficava espirrando direto, eu ia viajar e já ficava com a alergia atacada, quando ficava no meio de poeira, vira e mexe eu ficava ruim, depois que comecei o tratamento de homeopatia em 2002 com o doutor Marcus Zulian, eu melhorei muito, quase não tenho crise alérgica. $O$ tratamento de rinite no Hospital das Clínicas acabou em 2006, mas até hoje eu continuo fazendo o tratamento com o doutor Marcus e eu estou me sentindo muito bem. Eu agradeço ao doutor Marcus Zulian a oportunidade de participar de um tratamento homeopático no qual muito tem me ajudado. Muito obrigado.

----- Original Message -----

From: Paciente 26

To: Marcus Zulian Teixeira

Sent: Monday, April 28, 2008 10:28 PM

Subject: Res: avaliação homeopatia HC

Dr. Marcus,

Segue pequena descrição do período após o tratamento. Após término do acompanhamento no HC (04/2006) os sintomas da rinite não foram tão intensos como antes do tratamento, principalmente crises intensas e prolongadas. Crises esporádicas voltaram a ocorrer, porém 
sem grande significação. Nos últimos seis meses observei aparecimento de coceira na garganta e entupimento parcial do nariz ao acordar. Deve ser levado em conta que nesse período trabalhei em ambiente com concentração de pó de construção e poeira. Melhoras relacionadas a TMP e funcionamento intestinal continuam inalteradas desde o término do tratamento. Desidrose no pé esquerdo piorou consideravelmente. Durante o período de 03/07 a 03/08 realizei outro acompanhamento homeopático, porém não senti alteração do quadro apresentado acima.

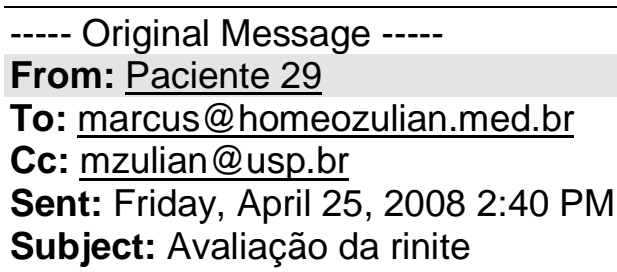

Avaliação após término de tratamento: fiz o tratamento homeopático com término em 12/04/06. Após essa data, fiquei bem durante um bom tempo, passei pelas variações de temperatura muito bem, quando várias pessoas pegavam gripe eu não, não entrei em crises de rinite significativas, percebi que somente em contato com um produto específico de limpeza meus espirros voltavam mas com menos intensidade do que antes do tratamento, assim, evitava o contado direto ou indireto com o produto e quase que instantaneamente passava. Pelo meio do ano de 2007 para o final, comecei a perceber que o cheiro de perfume muito concentrado e adocicado e um certo creme hidratante com cheiro me atacavam a rinite, ou seja, odores, então comecei a perceber que os espirros voltavam, procurei assim, evitá-los. De três meses para cá, as bolinhas de água nos dedos voltaram, inclusive deixando o tato comprometido por causa das rachaduras abertas nos dedos, mas a intensidade foi menor do que antes do tratamento. A coceira nos cantos dos olhos voltou, também com menos intensidade. Ainda não sei qual fator específico desencadeou essa crise, percebo também que com o passar dos dias a rinite começa a incomodar, com as coceiras, bolinhas e espirros, mas ainda assim com menos intensidade que antes do tratamento.

\footnotetext{
----- Original Message -----

From: Paciente 49

To: marcus@homeozulian.med.br

Sent: Friday, April 25, 2008 7:49 AM

Subject: Análise do tratamento

Dr Marcus,

Conforme você me pediu, faço uma análise crítica do tempo de tratamento e minha situação após um ano de suspensão do tratamento, sendo que a última dose de medicação foi em 16 de janeiro de 2007. Quando iniciei o tratamento em 2003, minha situação era a seguinte: andava sempre com uma caixa de lenços, que durava cerca de 4-5 dias, pois a coriza, os espirros e o prurido eram constantes, com períodos de exacerbação cerca de 6-7 ao ano, desencadeados por poeira e mudança de tempo, principalmente. Na época, estava casada, e lembro meu esposo comentar que não agüentava mais me ver limpando o nariz o tempo todo. Isso me incomodava, mas como já tinha feito vários tipos de tratamento (vacinas, antialérgicos, corticóides nasal e sistêmico) sem sucesso, acabei me conformando. Ao iniciar
} 
o tratamento, lembro que nos primeiros meses tive uma piora, alguns episódios de IVAS mais freqüentes, mas depois de seis meses, minha situação melhorou muito! Não tive mais os sintomas perenes de espirros e prurido, embora a coriza ainda continuasse um pouco, principalmente como uma secreção retrofaríngea. Meus sintomas praticamente existiam apenas nas exacerbações, que passaram a ser 2-3 ao ano, durante todo o período de tratamento (três anos). Essas exacerbações eram desencadeadas não mais por fatores climáticos ou ambientais, mas muito pelo estado psicológico e estresse. Meu ex-esposo notou a mudança, pois eu não andava mais com caixa de lenços e limpava o nariz não mais do que 2 vezes ao dia (muitas vezes nenhuma!!!). Durante todo este período, a rinite não voltou, não lembro ter tido exacerbações no ano de 2007, excetuando dois ou três episódios de IVAS que provavelmente passaram rápido, pois não lembro muito deles. Bom, o sumário é o seguinte: tive três anos de tratamento e um ano após o tratamento muito bons, que me deixaram forte para agüentar muitas coisas, sem crises, sem sintomas perenes. Neste último ano, me sentindo mais estressada, estou tendo mais sintomas e mais exacerbações, mas relaciono-as incrivelmente com meu estado psicológico e de estresse. Sinto como se o tratamento homeopático tivesse me ajudado muito a superar problemas e mudanças importantes na minha vida, que sempre surgiram nestes quatro anos. As medicações fizeram com que eu me exteriorizasse menos pela rinite. Agora, como estou tendo novas mudanças e, como parei o tratamento (muito por falta de tempo e vergonha na cara, não por querer parar, pois me sentia muito bem como o tratamento), senti que estou exteriorizando muito mais na minha rinite meu estresse atual. Espero que os meus relatos ajudem na pesquisa. Obrigada. 


\section{DISCUSSÃO}

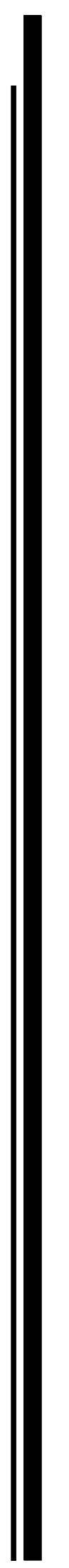




\section{DISCUSSÃO}

Em vista das características intrínsecas do tratamento homeopático, que se propõe a estimular uma reação homeostática curativa do organismo em resposta à administração de substâncias ultradiluídas causadoras de sintomas semelhantes em indivíduos sadios, suas particularidades na avaliação clínica e na resposta terapêutica diferem das premissas observadas no tratamento convencional, devendo ser respeitadas para que se atinja a eficácia e a efetividade clínica desejadas.

Dentre estas peculiaridades, torna-se imprescindível a escolha de um medicamento que englobe a totalidade dos sintomas característicos individuais e um período para atuação do mesmo proporcional à cronicidade e à gravidade da doença, premissas que exigem um tempo de observação, entendimento e tratamento dos pacientes de média a longa duração.

Esta dinâmica semiológica e terapêutica globalizante encontra limitação nos modelos de pesquisa clínica que buscam analisar, em curto prazo, a ação de uma mesma substância medicamentosa num grupo de sintomas ou funções isoladas e comuns a todos os indivíduos portadores de uma mesma doença.

Assim sendo, para que atuemos em conformidade com a racionalidade homeopática, torna-se necessária a elaboração de desenhos de estudos clínicos condizentes com a individualização do tratamento homeopático, estado-da-arte da epidemiologia clínica homeopática, que propomos discutir e aprimorar ao longo deste 
capítulo, em conformidade com o aprendizado adquirido na aplicação do modelo citado anteriormente.

\section{VI.1. Fase 1 (estudo fechado com a duração de 6 meses de acompanhamento)}

\section{VI.1.1. Avaliação basal (tempo 0)}

Em relação à perda de $25 \%$ dos pacientes (14/55) na fase inicial, consideramos expressivo o abandono voluntário de $13 \%$ dos pacientes (7/55) antes de completar o primeiro mês de acompanhamento, apesar dos cuidados no processo de recrutamento realizado, que podemos atribuir a fatores independentes da eficácia do tratamento (desinteresse dos participantes, desconhecimento prévio do modelo homeopático e do cronograma do estudo etc.). Para minimizar os abandonos iniciais dos pacientes em ensaios futuros, sugerimos que palestras explicativas gerais sobre os aspectos semiológico-terapêuticos da homeopatia e o cronograma do estudo sejam proferidas ao grupo de pacientes interessados em semanas prévias à avaliação inicial dos mesmos.

A randomização efetuada permitiu uma distribuição uniforme dos pacientes nos grupos placebo e ativo, não sendo identificadas diferenças estatisticamente significativas em relação às características clínico-alérgicas, laboratoriais e de qualidade de vida, apesar de uma maior cronicidade (idade e tempo total de doença significativamente maiores) e, conseqüentemente, menor reação vital ou resposta terapêutica do grupo ativo. 
O instrumento de avaliação clínico-alérgica (Ficha de Rinite Alérgica), aplicado por avaliador independente, mostrou-se sensível e específico na tradução da condição clínica dos pacientes ao longo do estudo, principalmente na mensuração do escore dos sinais e sintomas específicos da rinite (quadro clínico-alérgico específico ou desfecho primário), que associa aspectos objetivos e subjetivos à gravidade ou intensidade da doença. O mesmo ocorreu para os sintomas alérgicos sistêmicos ou da síndrome alérgica (quadro clínico-alérgico geral ou desfecho secundário). Apesar de menos específicos, os fatores agravantes e/ou precipitantes da rinite (suscetibilidade alérgica) ampliaram a análise da condição clínico-alérgica dos pacientes ao longo do estudo, mantendo uma relação direta e proporcional com os demais escores.

Segundo a intensidade da doença, os grupos placebo e ativo apresentaram na avaliação basal um escore médio dos sinais e sintomas específicos da rinite de 15 pontos (grau III de gravidade: escore de 13-18 pontos), representando uma população com rinite alérgica persistente e de gravidade moderada.

$\mathrm{Na}$ avaliação da qualidade de vida (FACIT-Sp-12), os grupos placebo e ativo apresentaram na avaliação basal uma pontuação média dos aspectos subjetivos gerais e existenciais em torno de 117 pontos, que corresponde a $75 \%$ do escore máximo (117/156). Isto representa que o instrumento de avaliação da qualidade de vida selecionado para o estudo não apresentou especificidade para o quadro clínico analisado, pois os pacientes iniciaram o estudo num patamar bastante elevado. Apesar da escolha do questionário de qualidade de vida ter sido direcionada pelos domínios condizentes com os aspectos subjetivos valorizados pelo modelo homeopático (bem-estar físico, funcional, social-familiar, emocional e 
espiritual/existencial), que supostamente permitiria quantificar estas mudanças ao longo do tratamento homeopático individualizado (avaliação miasmática homeopática), o referido instrumento foi criado, inicialmente, para avaliar pacientes portadores de doenças graves (câncer), mostrando-se inespecífico para mensurar a qualidade de vida de pacientes menos limitados (rinite alérgica).

$\mathrm{Na}$ avaliação laboratorial, os grupos placebo e ativo apresentaram valores basais médios de IgE total superiores ao valor de referência, indicando relação direta com a importância clínica da doença na população estudada. A impossibilidade de empregar as dosagens de IgE específicas, tanto in vivo (teste cutâneo) quanto in vitro (RAST), para mensurar a gravidade da doença e a evolução das intervenções terapêuticas, impediu que tivéssemos uma avaliação objetiva do perfil imunológico dos pacientes ao longo do estudo. Apesar deste impedimento, lembremos que o Consenso da Organização Mundial de Alergia (Canonica et al., 2007) prioriza o escore de sinais e sintomas específicos da rinite como variável padrão-ouro na avaliação clínico-alérgica da doença, estipulando que nenhum exame subsidiário poderá substituí-la.

\section{VI.1.2. Avaliação final (tempo 6meses)}

Após seis meses das respectivas intervenções, os grupos placebo e ativo apresentaram melhoras clínico-alérgicas estatisticamente significativas e da ordem de 20-26\% em relação à avaliação basal, sem diferença significativa entre eles.

Em relação à variável quadro clínico-alérgico específico (desfecho primário), o grupo placebo apresentou $25,86 \%$ de melhora em relação ao escore basal dos sinais 
e sintomas específicos da rinite alérgica, enquanto o grupo ativo apresentou $21,89 \%$. Estas variações representaram diminuição de um grau do patamar de gravidade ou intensidade basal da doença (grau III para grau II).

Em relação à variável quadro clínico-alérgico geral (desfecho secundário), o grupo placebo apresentou $25,51 \%$ de melhora em relação aos sintomas alérgicos sistêmicos basais, enquanto o grupo ativo apresentou 21,25\%. Estes valores mostraram a relação direta entre os quadros clínico-alérgicos geral e específico, reiterando a sensibilidade e a especificidade destes parâmetros na avaliação clínicoalérgica da rinite (desfechos primário e secundário), e a acurácia do avaliador e dos pacientes na observação e na descrição dos fenômenos clínicos.

Em relação à variável suscetibilidade alérgica, o grupo placebo apresentou $20,84 \%$ de melhora em relação aos fatores agravantes e/ou precipitantes basais da rinite alérgica, enquanto o grupo ativo apresentou $20,18 \%$ de melhora, induzindo-nos a inferir uma menor importância deste parâmetro na avaliação clínico-alérgica da rinite, provavelmente em função da ausência em nosso meio de alguns dos fatores investigados (paina, piretro etc.) e da particularidade ou subjetividade de outros fatores (estresse emocional, ciclo menstrual, exercícios etc.).

Em relação à variável qualidade de vida, ambos os grupos não apresentaram diferenças estatisticamente significativas em relação à avaliação basal, o mesmo ocorrendo com a variável IgE total, denotando a baixa especificidade destas variáveis na avaliação clínico-alérgica da rinite.

Não foram observados eventos adversos significativos diretamente relacionados ao tratamento homeopático, fato que reitera a segurança deste método terapêutico. 


\section{VI.1.3. Efeito placebo}

A magnitude do efeito placebo observada nos desfechos primário e secundário ao final dos seis meses de acompanhamento inicial (21-26\%), em conformidade com a média de $25 \%$ das revisões sistemáticas sobre efeito placebo inicialmente citadas (item III.2.6 - Magnitude do efeito placebo), deve ser atribuída, em parte, aos fatores inespecíficos positivos inerentes ao início de qualquer tratamento, tais como os incrementos de melhora clínico-alérgica relacionados ao fato do indivíduo ser submetido à simples observação clínica (efeito hawthorne), aos efeitos benéficos do tratamento adicional ou da atenção médica aumentada (acolhimento médico), às respostas de delicadeza do paciente perante 0 investigador (subordinação experimental) etc.

A própria regressão à média, freqüentemente confundida com o efeito placebo, em que a superestimação dos sintomas pelos pacientes na avaliação inicial diminui nas avaliações subseqüentes, independentemente do tratamento recebido, é um fator que deve ser incorporado ao entendimento da melhora do grupo placebo nesta fase inicial. Para quantificar estes efeitos inespecíficos, seria indispensável a inserção de um grupo controle "sem tratamento" ou um período de wash-out maior, que permitisse uma segunda avaliação dos escores clínico-alérgicos antes da realização da anamnese e do tratamento homeopático.

A abordagem semiológica homeopática globalizante, que estimula o paciente a relatar detalhadamente suas diversas suscetibilidades (psíquicas, emocionais, sociais, familiares, climáticas, alimentares, alérgicas, fisiológicas etc.), a fim de que se possa identificar um medicamento individualizado perante as inúmeras 
possibilidades terapêuticas existentes, mobiliza aspectos intrínsecos da subjetividade psíquica que podem incrementar a resposta placebo, independente do efeito específico do medicamento homeopático. Associemos estes aspectos positivos ao desejo e à expectativa do paciente em encontrar um alívio aos distúrbios crônicos de décadas através de uma proposta terapêutica isenta de efeitos colaterais (modelo desejo-expectativa), e teremos noção do espectro de efeitos positivos inespecíficos que podem contribuir à resposta placebo do tratamento homeopático.

Apesar desta possível gama de efeitos positivos inespecíficos inerentes à dinâmica homeopática, que poderia sugerir um incremento proporcional e crescente na magnitude do efeito placebo neste tipo de abordagem, não observamos este diferencial perante o tratamento convencional das doenças anteriormente citadas (item III.2.6 - Magnitude do efeito placebo), que também apresentavam importante perfil psicossomático. Isto pode ter ocorrido em vista do longo período da fase placebo-controlada (seis meses iniciais), em que a ausência da resposta terapêutica inicialmente esperada (expectativa consciente negativa ou efeito nocebo) pode ter minimizado os efeitos positivos inespecíficos inerentes aos primeiros meses de acompanhamento.

Pelo fato dos pacientes não terem sido submetidos a tratamentos homeopáticos prévios, não podemos atribuir o efeito placebo observado ao mecanismo do condicionamento operante, em que experiências anteriores positivas poderiam contribuir na resposta de melhora atual.

De forma análoga à meta-análise de Shang et al. (2005), que não observou diferenças entre o efeito específico do tratamento homeopático não-individualizado (mesmo medicamento ou mistura de medicamentos para uma queixa clínica comum 
dos pacientes) e o efeito placebo, também não observamos diferenças estatisticamente significativas nesta fase inicial do tratamento homeopático individualizado proposto. Partindo do pressuposto epistemológico de que apenas o tratamento homeopático corretamente individualizado pode despertar uma reação homeostática curativa, responsável pelas diferenças estatisticamente significativas perante a intervenção placebo, inferimos que o período de seis meses de tratamento homeopático foi insuficiente para se atingir o medicamento individualizado segundo a proposta semiológica e a amostra utilizada.

Por outro lado, verificamos que a resposta ao tratamento homeopático individualizado da rinite alérgica perene, num período de seis meses de acompanhamento e com avaliações mensais que permitam mudanças e ajustes na terapêutica, deve ser estatisticamente superior a $26 \%$ de melhora clínico-alérgica (efeito placebo), a fim de que possamos atribuí-la ao efeito específico do medicamento homeopático.

\section{VI.2. Fase 2 (estudo aberto com a duração de 6-36 meses de tratamento homeopático)}

\section{VI.2.1. Efeito placebo}

Comparando a evolução do subgrupo placebo inicial ao longo dos primeiros 12 meses de acompanhamento, em que 6 meses de intervenção placebo foram seguidas por 6 meses de intervenção homeopática, não foram constatadas 
diferenças significativas nos parâmetros clínico-alérgicos entre o primeiro e o segundo semestre de acompanhamento (Tabela 16).

De forma análoga, não foram observadas diferenças significativas nos mesmos parâmetros entre os grupo ativo e subgrupo placebo iniciais submetidos a 6 meses de tratamento homeopático (Tabela 17), e entre os subgrupos placebo e ativo iniciais submetidos a 12 meses de tratamento homeopático (Tabela 18), apesar do grupo placebo apresentar uma maior vitalidade (idade e tempo total de doença significativamente menores) e ter recebido, em ambos os casos, 6 meses de intervenção placebo adicionais perante o mesmo período de intervenção homeopática do grupo ativo.

Conforme aventado anteriormente, em estudos de longa duração como a homeopatia e a imunoterapia, em que a efetividade clínica do tratamento se relaciona ao ajuste gradual do medicamento e das doses à individualidade enferma, este efeito placebo robusto inicial pode se reverter gradativamente em efeito nocebo, caso o paciente se frustre com a resposta ao tratamento (expectativa consciente negativa).

A diminuição da magnitude do efeito placebo ao longo do tempo de acompanhamento homeopático pôde ser observada na análise quantitativa da evolução do subgrupo placebo inicial que, apesar da conscientização dos pacientes de que passariam a receber tratamento homeopático na segunda fase (tratamento "revelado" induzindo uma "expectativa consciente positiva"), não apresentou, em comparação aos primeiros 6 meses, um incremento significativo de melhora clínicoalérgica ao final dos 12 meses de acompanhamento (Tabela 16), contrariando uma 
suposta relação direta e crescente do efeito placebo com o incremento temporal dos aspectos inespecíficos positivos.

A ascendência gradual dos efeitos específicos do medicamento homeopático sobre os efeitos inespecíficos da dinâmica homeopática pôde ser observada nas melhoras quantitativas significativas do subgrupo ativo inicial ao final dos 12 meses de tratamento (Tabela 22), em vista de ter sido revelado aos pacientes ao término da primeira fase de que estavam recebendo tratamento homeopático desde o início do estudo, fato que pode ter frustrado a expectativa de melhora daqueles com resposta terapêutica insuficiente (tratamento "revelado" induzindo uma "expectativa consciente negativa").

$\mathrm{Na}$ análise qualitativa e individual dos pacientes que concluíram o estudo, identificamos a influência da resposta nocebo (expectativa consciente negativa) na piora da condição clínico-alérgica e do estado geral das pacientes 42 e 46 (vide item V.2.2.6.1), que se desinteressaram em permanecer no protocolo por estarem sentindo-se frustradas com as respostas terapêuticas iniciais. Ressaltando a ascendência do efeito específico da resposta homeopática perante o efeito inespecífico da resposta nocebo, ambas pacientes apresentaram melhoras evidentes e duradouras logo após a administração do medicamento homeopático corretamente individualizado, apesar de continuarem alimentando a expectativa consciente negativa pelo tratamento recebido.

Baseados nestas evidências e em conformidade com os estudos sobre o fenômeno placebo-nocebo citados inicialmente, inferimos que o primeiro período semestral de acompanhamento despertou uma importante expectativa nos pacientes por uma resposta clínica positiva (desejo-expectativa), mobilizando um efeito placebo 
de magnitude significativamente superior aos demais períodos semestrais subseqüentes, permitindo utilizá-lo como parâmetro de comparação na avaliação da melhora clínico-alérgica na fase de estudo aberta, em conformidade ao estudo de Bufe et al. (2004).

A ausência de um grupo controle ao longo de todo o período do estudo, aspecto desfavorável à aderência dos pacientes e aos princípios bioéticos da pesquisa clínica, impediu que esta hipótese pudesse ser confirmada estatisticamente, apesar do conjunto das análises quantitativas dos grupos e qualitativas dos pacientes sugerirem a preponderância do efeito placebo inicial e a efetividade clínica crescente do tratamento homeopático individualizado.

Assim como em qualquer tipo de tratamento, não podemos descartar, na análise quantitativa dos grupos, a influência do mecanismo do condicionamento operante (associado ou não à expectativa consciente positiva) nos indivíduos que apresentaram evidente e crescente resposta à terapêutica homeopática ao longo do estudo. Entretanto, na análise qualitativa e individual dos pacientes, apesar da ausência de ambos os mecanismos (expectativa + condicionamento) no período de 12-30 meses após o encerramento do protocolo e a suspensão do tratamento, observamos a manutenção da melhora clínico-alérgica e do estado psíquico-geral (efeitos residuais ou preventivos) devido à diminuição prévia das respectivas suscetibilidades, propiciadas pelo tratamento homeopático individualizado.

\section{VI.2.2. Análise amostral}


Em vista da diminuição acentuada do número de pacientes ao longo dos períodos crescentes de tratamento homeopático da segunda fase $(12,24$ e 36 meses, com 27, 20 e 13 pacientes respectivamente), poder-se-ia aventar a hipótese de que um possível incremento crescente de efetividade clínica estaria relacionado ao viés de seleção dos pacientes, em conseqüência da desistência dos pacientes que não apresentaram melhoras correspondentes às suas expectativas iniciais ou com doença de maior cronicidade ou gravidade.

No entanto, a maior taxa de abandono do subgrupo placebo inicial nos dois primeiros anos de tratamento homeopático indica o oposto (item V.1.2.1 - Amostra analisada), em conseqüência do grupo ativo inicial apresentar maior idade e tempo de doença (maior cronicidade e menor resposta vital curativa). Associando os principais motivos de abandono (Tabela 12) às características descritivas dos pacientes que descontinuaram (Tabela 14) e dos pacientes que permaneceram no estudo (Tabelas 13 e 15), indicativos de que a descontinuação não esteve relacionada à ineficácia do tratamento ou à cronicidade/gravidade da rinite, deduz-se que a permanência dos pacientes ao longo do estudo foi fruto da melhora clínica, geral e psíquica que a individualização gradativa do medicamento homeopático propiciou, contrapondo a hipótese do "efeito seleção". A análise qualitativa reitera este fato.

\section{VI.2.3. Evolução clínico-alérgica dos pacientes}

O subgrupo de pacientes que completou 6 meses de tratamento homeopático ( $\mathrm{n}$ = 35) apresentou $28,8 \%$ de melhora em relação ao escore basal dos sinais e 
sintomas específicos da rinite (desfecho primário) e 27,7\% de melhora em relação ao escore basal dos sintomas alérgicos sistêmicos (desfecho secundário), sem diferenças significativas em relação à resposta da fase inicial. Quanto à gravidade da doença, $17 \%$ (6/35) dos pacientes atingiu escore total dos sinais e sintomas clínicos específicos da rinite $\leq 6$ pontos (grau I de gravidade ou intensidade da doença) ao final deste período de tratamento.

O subgrupo de pacientes que completou 12 meses de tratamento homeopático $(n=27)$ apresentou $50 \%$ de melhora em relação ao escore basal dos sinais e sintomas específicos da rinite (desfecho primário) e 45,3\% de melhora em relação ao escore basal dos sintomas alérgicos sistêmicos (desfecho secundário). Em relação à resposta da fase inicial (6m iniciais ou "efeito placebo"), apresentou $18,70 \%$ de melhora na resposta clínico-alérgica específica $(P=0,003)$ e $21,71 \%$ na resposta clínico-alérgica geral $(P=0,020)$. Quanto à gravidade da doença, 33\% $(9 / 27)$ dos pacientes atingiu escore dos sinais e sintomas específicos da rinite $\leq 6$ pontos ao final deste período de tratamento.

O subgrupo de pacientes que completou 24 meses de tratamento homeopático $(n=20)$ apresentou $64,19 \%$ de melhora em relação ao escore basal dos sinais e sintomas específicos da rinite (desfecho primário) e 63,69\% de melhora em relação ao escore basal dos sintomas alérgicos sistêmicos (desfecho secundário). Em relação à resposta da fase inicial, apresentou $31,15 \%$ de melhora na resposta clínico-alérgica específica $(P=0,001)$ e $33,91 \%$ na resposta clínico-alérgica geral ( $P$ $<0,001)$. Quanto à gravidade da doença, 55\% (11/20) dos pacientes atingiu escore dos sinais e sintomas clínicos específicos da rinite $\leq 6$ pontos ao final deste período. 
O subgrupo de pacientes que completou 36 meses de tratamento homeopático ( $n=13)$ apresentou $71,77 \%$ de melhora em relação ao escore basal dos sinais e sintomas específicos da rinite (desfecho primário) e 68,76\% de melhora em relação ao escore basal dos sintomas alérgicos sistêmicos (desfecho secundário). Em relação à resposta da fase inicial (6 meses iniciais), apresentou 39,65\% de melhora na resposta clínico-alérgica específica $(P=0,004)$ e $36,05 \%$ na resposta clínicoalérgica geral $(P=0,004)$. Quanto à gravidade da doença, $77 \%(10 / 13)$ do total de pacientes atingiu escore dos sinais e sintomas clínicos específicos da rinite $\leq 6$ pontos ao final deste período de tratamento.

Conforme a proposta inicial, a magnitude da resposta clínico-alérgica ou efetividade clínica do tratamento homeopático a médio-longo prazo (12-36 meses de tratamento homeopático) correspondeu aos critérios do consenso da Organização Mundial de Alergia (WAO) para padronização dos ensaios clínicos com imunoterapia em alergias respiratórias (Canonica et al., 2007): melhora estatisticamente significativa (IC $95 \%$ e $P<0,05$ ) e superior a $20 \%$ da resposta da fase inicial controlada ("efeito placebo").

Ao longo dos 36 meses de tratamento homeopático, 39\% do total de pacientes (16/41) atingiu escore dos sinais e sintomas clínicos específicos da rinite $\leq 6$ pontos em alguma fase do estudo, com 24\% (10/41) permanecendo no patamar superior (escore de 4-6 pontos) e 15\% (6/41) atingindo o patamar inferior (escore $\leq 3$ pontos) do menor grau de gravidade da rinite alérgica. Destes últimos, aproximadamente $10 \%(4 / 41)$ atingiram escore igual a zero em alguma fase do estudo. 


\section{VI.2.4. Alterações na qualidade de vida}

Em vista da baixa especificidade do instrumento de avaliação da qualidade de vida empregado (FACIT-Sp-12) para mensurar as alterações subjetivas de pacientes portadores de rinite alérgica, não pudemos utilizar este importante parâmetro na avaliação da resposta global ao tratamento homeopático em todas as fases do estudo.

Contrariamente à avaliação dos desfechos primário e secundário de resposta clínico-alérgica, observamos diferenças estatisticamente significativas nos aspectos da qualidade de vida apenas nos subgrupos de pacientes que completaram 6 meses $(n=35)$ e 24 meses $(n=20)$ de tratamento homeopático, em relação ao escore total basal.

A diferença significativa encontrada no subgrupo que completou 6 meses de tratamento homeopático pode ser atribuída ao tamanho da amostra $(n=35)$, enquanto a variação significativa da qualidade de vida observada no subgrupo que completou 24 meses de tratamento homeopático pode estar relacionada ao fato de que a análise parcial dos subgrupos placebo e ativo iniciais mostrou uma significativa magnitude de resposta clínico-alérgica específica nesta fase (Tabela 22), não observada nos demais períodos do estudo.

\section{VI.2.5. Efeito preventivo do tratamento homeopático}

Pelas semelhanças encontradas entre os pressupostos dos paradigmas homeopático e imunoterápico (tratamentos que visam estimular uma reação homeostática curativa através da administração repetida de ultradiluições de 
substâncias gradualmente individualizadas e que despertam sintomas semelhantes em indivíduos sadios), o tratamento homeopático individualizado apresenta potencial terapêutico semelhante ao da imunoterapia individualizada, modificando o processo e o curso natural das doenças em geral (efeitos preventivos), representando uma opção curativa para diversos distúrbios crônicos.

Com o intuito de documentar e quantificar esta premissa descrita na prática clínica secular, solicitou-se aos dez pacientes que apresentaram resposta clínica satisfatória (escore $\leq 6$ pontos) ao final dos 36 meses de tratamento homeopático que encaminhassem um relatório por e-mail descrevendo a evolução da rinite alérgica, do estado geral e a necessidade de utilização de medicamentos após o término do protocolo.

Nos pacientes que atingiram o patamar inferior do menor grau de gravidade da rinite alérgica (escore $\leq 3$ pontos; $15 \%$ dos pacientes), em conseqüência de terem recebido medicamentos perfeitamente individualizados (medicamento homeopático simillimum), observamos uma modificação evidente e prolongada no curso natural da doença (efeitos preventivos ou residuais), com total ausência de sintomas e a impressão de estarem completamente curados do mal que os afligira continuamente durante décadas, por um período máximo de 30 meses após a suspensão do tratamento. Vale ressaltar que, associado ao efeito residual de melhora absoluta da rinite alérgica, os pacientes referiram incremento semelhante no estado psíquicogeral (humor, ansiedade, insônia, TPM etc.) pelo mesmo período de tempo. Estas narrativas evidenciaram a atuação do tratamento homeopático corretamente individualizado na melhora global e dinâmica do paciente em longo prazo. 
Nos pacientes que atingiram o patamar superior do menor grau de gravidade da rinite alérgica (escore 4-6 pontos; $24 \%$ dos pacientes), em conseqüência de terem recebido medicamentos parcialmente individualizados (medicamento homeopático similar), observamos uma modificação menos evidente e prolongada no curso natural da doença (efeitos preventivos ou residuais), apesar da manutenção da melhora clínico-alérgica por um período médio de 12 meses após a suspensão do tratamento, com a impressão de estarem parcialmente curados e sem a necessidade de utilizarem outros medicamentos. Os pacientes também referiram incremento no estado psíquico-geral (TPM, constipação, IVAS etc.) pelo mesmo período de tempo. Estes depoimentos evidenciaram que um medicamento homeopático parcialmente individualizado (similar) não apresenta a mesma efetividade que o medicamento simillimum, apesar de propiciar uma melhora global e dinâmica ao paciente no médio prazo.

Não consideramos ter atingido um medicamento homeopático individualizado nos três pacientes que terminaram os 36 meses de tratamento homeopático atingindo escore dos sinais e sintomas específicos da rinite entre 7-12 pontos, em vista de apresentarem quadro clínico-alérgico semelhante ao do final da fase inicial ("efeito placebo"). Apesar de aspectos ocupacionais e ambientais agravantes do quadro clínico-alérgico permanecerem durante todo o período do estudo nos pacientes 30 (tabagismo) e 35 (umidade), notamos indícios do efeito específico do medicamento homeopático apenas nesta última paciente, sem que pudéssemos quantificar um alívio evidente no período de tratamento estipulado. 


\section{VI.3. Considerações finais}

\section{VI.3.1. Aplicações dos resultados na prática clínica homeopática}

$\mathrm{Na}$ análise separada dos subgrupos ativo e placebo iniciais que completaram 12, 24, e 36 meses de tratamento homeopático, em comparação aos 6 meses iniciais de acompanhamento dos mesmos pacientes (Tabela 22), observou-se uma porcentagem média de melhora dos sinais e sintomas específicos da rinite alérgica ao redor de $32 \%$ ao final da fase inicial, ou seja, uma porcentagem média de $32 \%$ de melhora clínico-alérgica secundária a fatores inespecíficos, que podem ter permanecido na segunda fase do estudo.

Esta análise generalista tem 0 intuito de reiterar a importância do efeito placebo na abordagem semiológico-terapêutica homeopática, buscando com isto ampliar a consciência da classe homeopática a respeito dos efeitos inespecíficos não-medicamentosos que acompanham os efeitos específicos do medicamento homeopático, a fim de que sejamos mais exigentes com a magnitude da resposta clínica almejada durante o período de ajuste do medicamento homeopático à individualidade enferma. (Teixeira, 2009b)

No caso específico da rinite alérgica perene, para que possamos atribuir ao medicamento homeopático a melhora observada ao longo do tratamento, devemos atingir uma magnitude de resposta clínica estatisticamente superior a $32 \%$ do escore basal dos sintomas da doença. Segundo os resultados apresentados, resposta clínica inferior a $50 \%$ ao longo do tratamento homeopático da rinite alérgica, provavelmente, indica efeito placebo. 
Dentre os aspectos qualitativos citados que importam à prática homeopática, vale ressaltar que não foram observadas dissociações entre as respostas de melhoras psíquico-geral e clínica no subgrupo de pacientes em que se conseguiu selecionar um medicamento homeopático individualizado (39\% ou 16/41), com incrementos gradativos desde o início do emprego das medicações em doses únicas semanais ou mensais, a partir da potência $30 \mathrm{cH}$.

De forma análoga, não foi possível observar relação direta entre o aumento das potências e o incremento de resposta global, pois foram utilizadas escalas de potências crescentes e decrescentes no rastreamento da potência ideal, que variou para cada paciente de acordo ao momento da vida e segundo as próprias suscetibilidades psíquicas, emocionais, climáticas etc. Observamos a existência de potências simillimum, que permitiram a manutenção da melhora psíquico-geralclínica por um período de tempo consideravelmente maior, especificamente quando se atingiu o medicamento simillimum.

\section{VI.3.2. Aplicações dos resultados na pesquisa clínica homeopática}

Refletindo sobre as experiências e dificuldades vivenciadas neste estudo de longa duração, estamos sugerindo possíveis aplicações deste aprendizado em ensaios clínicos homeopáticos futuros.

Em vista do considerável efeito placebo despertado pela dinâmica semiológicoterapêutica homeopática, torna-se imprescindível e obrigatório o emprego de grupos controle em modelos de pesquisa clínica homeopática, para avaliar a 
resposta específica ao medicamento homeopático. Como opções destes grupos, teríamos os que empregam a intervenção placebo ou a intervenção com drogas convencionais.

Os modelos de pesquisa clínica randomizados e placebos-controlados apresentam a capacidade de mensurar a magnitude do efeito específico do medicamento homeopático, descartando o conjunto dos efeitos inespecíficos positivos (efeito placebo ou falso-positivos), segundo determinado modelo e população estudada. No caso da homeopatia, em que faltam dados sobre a eficácia e a efetividade clínica das diversas abordagens terapêuticas nos inúmeros tipos de doenças tratadas, fazem-se necessários estudos de longa duração placeboscontrolados para que estas questões possam ser respondidas.

Esta necessidade em se determinar a eficácia e a efetividade do tratamento homeopático nas diversas condições clínicas autoriza a realização de ensaios controlados com placebo segundo a Declaração de Helsinque (WMA, 2002), desde que os pacientes recebam drogas de resgate e "não fiquem sujeitos a qualquer risco adicional de dano grave ou irreversível".

O desenho de ensaio clínico homeopático individualizado apresentado neste protocolo, que reflete a prática clínica cotidiana dos médicos homeopatas (efetividade ou validade externa), poderia ser utilizado em estudos futuros para quaisquer tipos de doença, desde que adaptemos os métodos diagnósticos específicos para avaliar a resposta terapêutica ao longo do tratamento. Como proposta de aperfeiçoamento ao desenho empregado em futuras pesquisas, sugerimos os seguintes pressupostos básicos: 
- Ensaios clínicos randomizados, duplos-cegos e placebos-controlados, com seguimento posterior de todos os pacientes interessados em estudo aberto por um período de tempo proporcional à cronicidade e à gravidade da doença; inserção de um segundo grupo controle inicial "sem tratamento" ou um período maior de wash-out com avaliações seriadas, a fim de melhor quantificar alguns dos efeitos inespecíficos observados antes da intervenção programada;

- Número de pacientes superior a 100 (estudo multicêntrico com grupos de 50 pacientes);

- Tratamento homeopático individualizado com medicamentos que englobem a totalidade sintomática característica, administrados separadamente e em períodos distintos; na seleção do medicamento individualizado perante as diversas hipóteses medicamentosas, melhoras inferiores a $50 \%$ do escore basal dos sinais e sintomas indicam baixa evidência do efeito específico medicamentoso e do acerto terapêutico;

- Medicamentos de resgate deverão ser fornecidos por todo o período de análise e a necessidade de utilização será outro parâmetro de avaliação da eficácia do tratamento, juntamente com os demais métodos diagnósticos;

- Duração mínima do estudo de 6-12 meses (fase controlada), com avaliações mensais da resposta ao tratamento segundo parâmetros específicos de análise (prognósticos homeopáticos), com a possibilidade de alterações na conduta terapêutica (medicamentos, doses e potências homeopáticas); avaliações clínicas padronizadas (escala analógica visual de sintomas, por exemplo) também deveriam ser realizadas em todas as consultas mensais; 
- Após o término da fase controlada, acrescentar a permanência optativa dos pacientes num estudo aberto durante período mínimo semelhante, com o intuito de propiciar o tratamento homeopático ao grupo placebo inicial e quantificar a melhora objetiva e subjetiva de todos os pacientes num período maior de tratamento homeopático;

- Na fase controlada, inserir avaliações bimestrais da resposta ao tratamento por avaliador independente, segundo parâmetros de análise objetivos (escore de sinais e sintomas, exames subsidiários etc.) e subjetivos (questionário de qualidade de vida); ao contrário da fase aberta, em que as avaliações independentes poderiam ser semestrais, avaliações menos espaçadas na fase controlada permitiriam observações mais precisas sobre o fenômeno placebo-nocebo, juntamente com avaliações da expectativa dos pacientes em relação ao tratamento e ao grupo alocado;

- Escolha de questionários de qualidade de vida específicos por doença e/ou questionários de qualidade de vida gerais próprios à gravidade da doença em estudo;

- Análise estatística dos resultados "por protocolo", associando a significância estatística (IC $95 \%$ e $P<0,05)$ com a diferença entre as variações médias dos grupos, aceitando-se uma eficácia clínica mínima de 20\% acima da resposta da fase controlada inicial ("efeito placebo").

Pela complexidade dos fatores que envolvem a avaliação do paciente e a posterior seleção do medicamento homeopático, diversos pesquisadores discordam sobre a aplicação de ensaios placebos-controlados para demonstrar a eficácia do tratamento homeopático individualizado, alegando interdependência entre os efeitos 
específicos do medicamento e os efeitos inespecíficos da semiologia homeopática, postulando que efeitos específicos do medicamento homeopático podem influenciar na dinâmica da consulta homeopática subseqüente, e vice-versa (Weatherley-Jones et al., 2004). Seguindo estas premissas, sugerem a comparação da eficácia do tratamento homeopático individualizado com outras práticas terapêuticas em desenhos de estudos separados e distintos, valorizando a dinâmica semiológica de cada modalidade em condições amostrais semelhantes.

A simples comparação da eficácia clínica de grupos homogêneos recebendo tratamento homeopático ou convencional segundo abordagens semiológicoterapêuticas específicas e distintas, sugerida pelos autores, não pode ser usada como parâmetro na avaliação do efeito específico do medicamento homeopático, pois estaríamos desprezando a provável influência da dinâmica homeopática na resposta terapêutica. Neste tipo de desenho de pesquisa clínica, estaríamos comparando a somatória dos efeitos específicos e inespecíficos de cada modelo terapêutico, sem que fosse possível distinguir as magnitudes de cada tipo em separado, com o risco de confundir, por exemplo, a eficácia clínica do medicamento homeopático com o incremento terapêutico da relação médico-paciente diferenciada, efeito inespecífico inexistente no modelo convencional.

Através das experiências vivenciadas ao longo deste estudo, podemos estipular que, conduzindo as avaliações semiológicas homeopáticas mensais de forma clássica e considerando todos os pacientes (dos grupos placebo e ativo) "como se estivessem recebendo tratamento homeopático", teremos indícios de ter atingido uma razoável individualização do medicamento homeopático quando constatarmos melhoras clínica, geral e psíquica constantes e superiores a $50 \%$ do parâmetro 
basal, buscando novas opções medicamentosas no caso de permanecermos com respostas terapêuticas inferiores. Pautados na observação da magnitude da reação global homeostática, poderemos diferenciar as manifestações específicas do medicamento das manifestações inespecíficas do acompanhamento homeopático, independente das técnicas de hierarquização e repertorização dos sintomas empregadas na seleção do medicamento individualizado.

Caso optemos por um modelo de pesquisa clínica randomizado utilizando drogas convencionais no grupo controle, estaremos comparando o efeito específico do medicamento homeopático com o efeito específico do medicamento aloenantiopático em determinada condição clínica, em vista de ambos receberem os mesmos efeitos inespecíficos positivos da dinâmica semiológico-terapêutica homeopática.

Em qualquer desenho de pesquisa clínica que compare a eficácia, a efetividade e a eficiência dos tratamentos homeopático e convencional, a propriedade preventiva, globalizante e segura da resposta homeopática devem ser valorizadas em contrapartida à resposta imediata, específica e possivelmente iatrogênica do modelo alo-enantiopático:

- Em vista dos efeitos preventivos observados no tratamento homeopático individualizado a médio-longo prazo, avaliações subseqüentes à suspensão dos tratamentos deveriam ser incorporadas ao protocolo e valorizadas nos desfechos clínicos finais, quantificando possíveis manutenções da melhora clínica após a suspensão do medicamento (efeito residual);

- Outro aspecto fundamental na comparação dos tratamentos estaria relacionado à segurança clínica, valorizando a ocorrência de eventos 
adversos secundários e suas conseqüências, comumente ausentes na abordagem homeopática, assim como prováveis agravamentos das doenças após a suspensão do medicamento enantiopático (efeito rebote);

- Os custos financeiros também deveriam ser incorporados à avaliação dos tratamentos (eficiência), seja no custo direto dos medicamentos ou na melhora global e dinâmica propiciada pelo tratamento homeopático, que pode diminuir os custos indiretos da utilização de outros medicamentos em distúrbios concomitantes.

Outra sugestão para desenho de ensaio clínico homeopático individualizado seria o realizado parcialmente por Bignamini et al. (1987) e citado inicialmente. Neste modelo, que seria utilizado para demonstrar a eficácia do medicamento homeopático em condições específicas (eficácia clínica ou validade interna que não refletiria a prática clínica homeopática usual), a individualização do medicamento seria realizada previamente a randomização, escolhendo dentre uma grande diversidade de pacientes aqueles que apresentassem ampla similitude com um ou vários medicamentos homeopáticos, através de anamneses estruturadas (priorizando os sintomas-chave dos medicamentos em estudo, por exemplo) ou clássicas. Desta forma, diminuiríamos as variáveis relacionadas à diversidade das características individuais dos pacientes que dificultam, na prática clínica diária, a seleção do medicamento simillimum. 


\section{CONCLUSÕES}




\section{CONCLUSÕES}

Neste trabalho, discutimos as premissas indispensáveis à elaboração de ensaios clínicos homeopáticos individualizados e controlados que apresentem semelhança com a prática clínica homeopática cotidiana (efetividade ou validade externa), demonstrando a possibilidade da realização de semelhante tipo de pesquisa com homeopatia.

Após os seis meses iniciais da fase placebo-controlada, a dinâmica semiológicoterapêutica homeopática despertou melhora significativa no quadro clínico-alérgico do grupo placebo, sem diferenças estatísticas em relação ao grupo ativo.

$\mathrm{Na}$ segunda fase do estudo, o tratamento homeopático individualizado apresentou melhoras clínico-alérgicas crescentes e proporcionais ao período de tratamento, com diferenças estatisticamente significativas em relação ao incremento de melhora da fase inicial. 


\section{ANEXOS}

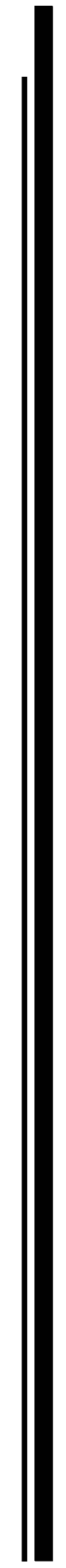




\section{Anexo 1 - Sinopse do estudo}

\begin{tabular}{l|l}
\hline Título do estudo & $\begin{array}{l}\text { Ensaio clínico quali-quantitativo para avaliar a eficácia e a } \\
\text { efetividade do tratamento homeopático individualizado na rinite } \\
\text { alérgica perene. }\end{array}$ \\
\hline Tipo de relato & Protocolo clínico \\
\hline Início e término & 07/2002 a 12/2006. \\
\hline Indicação & Rinite alérgica perene. \\
\hline Objetivo do estudo & $\begin{array}{l}\text { Analisar a eficácia e a efetividade do tratamento homeopático } \\
\text { individualizado em pacientes portadores de rinite alérgica } \\
\text { perene. }\end{array}$ \\
\hline Medicação e dosagem & $\begin{array}{l}\text { Medicamento homeopático individualizado, escolhido segundo } \\
\text { os critérios clássicos, em doses únicas ou repetidas semanais } \\
\text { ou mensais. }\end{array}$ \\
\hline Desenho do estudo & $\begin{array}{l}\text { Estudo clínico placebo-controlado (Fase 1), seguido por } \\
\text { estudo aberto prospectivo (Fase 2), com 40-50 pacientes e a } \\
\text { duração de 6-36 meses de tratamento homeopático, com } \\
\text { acompanhamento em visitas mensais. }\end{array}$ \\
\hline Pacientes maiores de 18 anos, de ambos os sexos e qualquer \\
raça, com diagnóstico de rinite alérgica perene há mais de um \\
ano.
\end{tabular}




\section{Anexo 2 - Modelo de repertorização mecânica computadorizada dos sintomas homeopáticos (Repertório Homeopático Digital II)}

\section{Definição de repertorização}

A repertorização homeopática é o método através do qual o médico, após ter identificado os sintomas do paciente (mentais, gerais e particulares) através da anamnese homeopática, utiliza o Repertório de Sintomas Homeopáticos (índice anatômico e alfabético dos sintomas primários dos medicamentos experimentados em indivíduos humanos, que estão descritos detalhadamente na Matéria Médica Homeopática), na versão livro ou eletrônica, para escolher os medicamentos que englobem a totalidade sintomática característica, ou seja, para levantar as prováveis hipóteses dos medicamentos homeopáticos individualizados mais significativos.

II. Repertorização mecânica ou sem escolha de sintoma diretor

É o método de repertorização que valoriza todos os sintomas homeopáticos característicos selecionados, sem distinção de valor ou hierarquia, selecionando os medicamentos que despertaram o maior número destes sintomas nas experimentações patogenéticas. Apesar de privilegiar a seleção dos medicamentos policrestos (com maior número de sintomas e re-experimentações), não exclui informações de sintomas nem de medicamentos. Com a consulta concomitante à Matéria Médica Homeopática, permite uma análise diferencial das diversas hipóteses medicamentosas levantadas. Nas avaliações consecutivas, com o aumento do conhecimento das características mais idiossincrásicas dos pacientes, os ajustes necessários são realizados, permitindo que se atinjam medicamentos cada vez mais individualizados.

III. Exemplo de repertorização mecânica computadorizada 


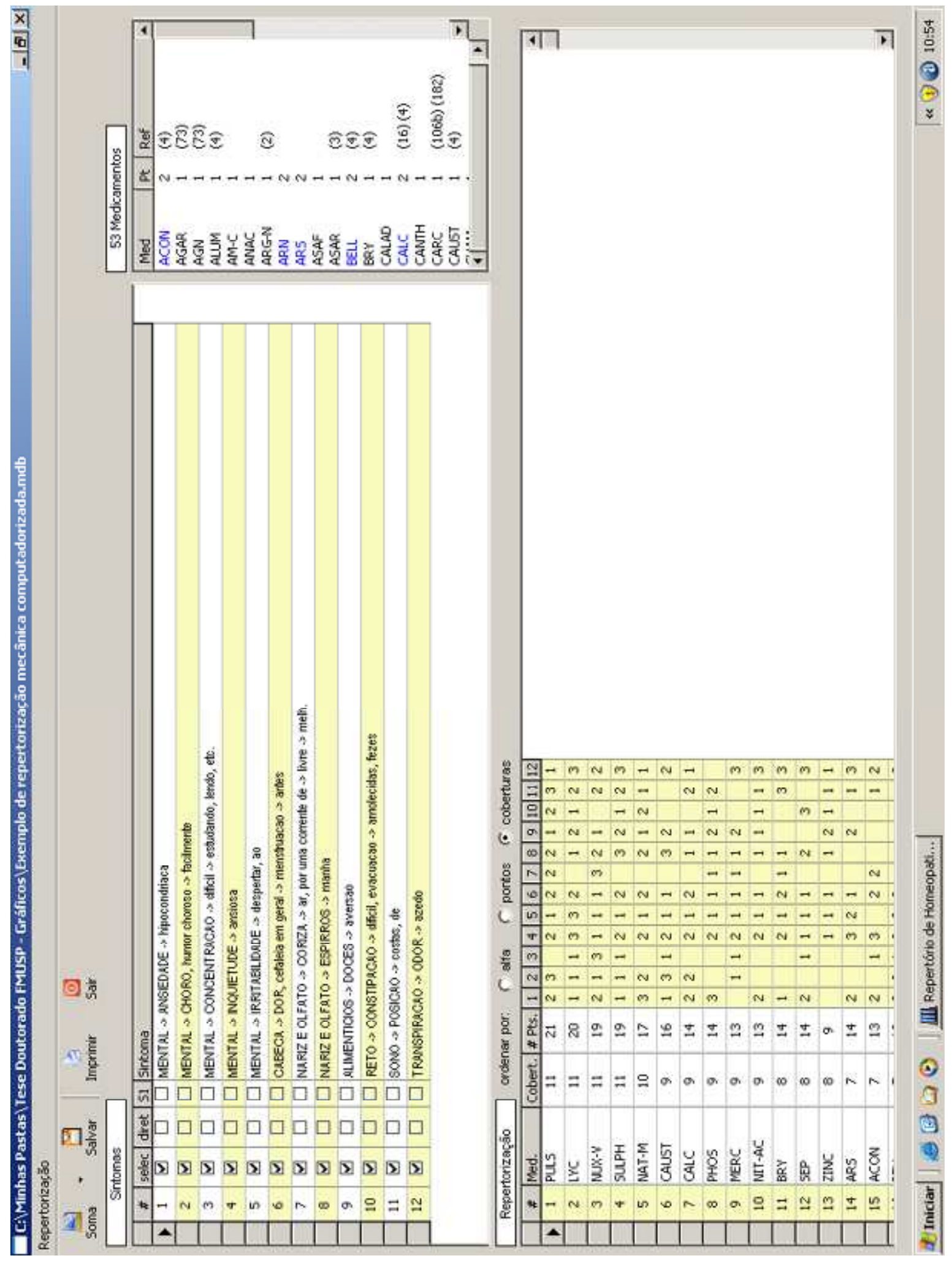




\section{Anexo 3 - Ficha clínica homeopática}

I. Identificação

II. Avaliação homeopática

\begin{tabular}{l|l|l|l|l|l|l}
\hline Visitas & Visita 1 & Visita 2 & Visita 3 & Visita 4 & Visita 5 & Visitas 6-43 \\
Data: & & & & & & \\
\hline Medicamento (M) & & & & & & \\
\hline Dinamização e & & & & & & \\
Escala (DE) & & & & & & \\
\hline $\begin{array}{l}\text { Freqüência das } \\
\text { Doses (FD) }\end{array}$ & & & & & & \\
\hline $\begin{array}{l}\text { Finalidade da } \\
\text { Prescrição (FP) } \\
\text { (C, A, M) }\end{array}$ & & & & & & \\
\hline $\begin{array}{l}\text { Instrumento de } \\
\text { seleção (IS) } \\
\text { (R, MM) }\end{array}$ & & & & & & \\
\hline Diagnóstico & & & & & \\
$\begin{array}{l}\text { Diferencial } \\
\text { Medicamentoso } \\
\text { (DDM) }\end{array}$ & & & & & & \\
\hline $\begin{array}{l}\text { Sensação Subjetiva } \\
\text { de Bem Estar Geral } \\
\text { (SSBEG) }\end{array}$ & & & & & & \\
\hline $\begin{array}{l}\text { Agravação Primária } \\
\text { (AP) }\end{array}$ & & & & & & \\
\hline Agravação \\
Secundária (AS)
\end{tabular}


II. Avaliação homeopática (continuação)

\begin{tabular}{|c|c|c|c|c|c|c|}
\hline $\begin{array}{l}\text { Visitas } \\
\text { Data: }\end{array}$ & Visita 1 & Visita 2 & Visita 3 & Visita 4 & Visita 5 & Visitas 6-43 \\
\hline $\begin{array}{l}\text { Suscetibilidade } \\
\text { Orgânica (SO) }\end{array}$ & & & & & & \\
\hline $\begin{array}{l}\text { Humor e Psiquismo } \\
\text { (HP) }\end{array}$ & & & & & & \\
\hline $\begin{array}{l}\text { Atitude Vital (AV) } \\
\text { (disposição, sono, } \\
\text { apetite etc.) }\end{array}$ & & & & & & \\
\hline $\begin{array}{l}\text { Observações } \\
\text { Prognósticas (OP) }\end{array}$ & & & & & & \\
\hline $\begin{array}{l}\text { Evolução Miasmática } \\
\text { (EM) }\end{array}$ & & & & & & \\
\hline $\begin{array}{l}\text { Critério de } \\
\text { Modificação do } \\
\text { Medicamento (CMM) }\end{array}$ & & & & & & \\
\hline $\begin{array}{l}\text { Critério de } \\
\text { Modificação das } \\
\text { Doses (CMD) }\end{array}$ & & & & & & \\
\hline $\begin{array}{l}\text { Critério de } \\
\text { Modificação da } \\
\text { Potência (CMP) }\end{array}$ & & & & & & \\
\hline $\begin{array}{l}\text { Evolução Clínica } \\
\text { (EC) (rinorréia, } \\
\text { espirros, prurido, } \\
\text { congestão, secreção } \\
\text { retronasal etc.) }\end{array}$ & & & & & & \\
\hline $\begin{array}{l}\text { Utilização de Anti- } \\
\text { Histamínico de } \\
\text { Resgate (AHR) } \\
\end{array}$ & & & & & & \\
\hline $\begin{array}{l}\text { Utilização de Outros } \\
\text { Medicamentos (OM) }\end{array}$ & & & & & & \\
\hline
\end{tabular}




\section{Anexo 4 - Ficha clínica geral}

\section{História médica}

Excluindo a indicação tratada por este protocolo, o paciente apresenta história de alguma anormalidade em um dos seguintes sistemas do corpo? (assinale com um "X" sim ou não). Em caso afirmativo, indique o código, condição, estado e comente para cada código separadamente no espaço abaixo.

Doenças concomitantes (ISDA)

\begin{tabular}{|c|c|c|c|c|c|}
\hline CÓDIGO & NÃO & SIM & CÓDIGO & NÃO & SIM \\
\hline $\begin{array}{l}{[0][2]} \\
\text { OFTALMOLÓGICO }\end{array}$ & 0 & 1 & 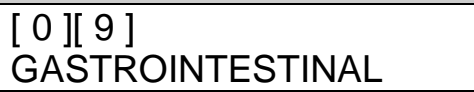 & 0 & 1 \\
\hline 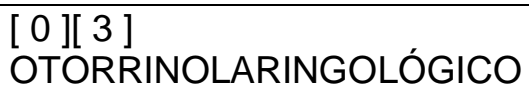 & 0 & 1 & 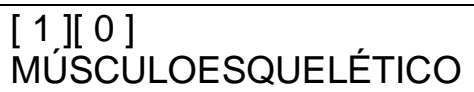 & 0 & 1 \\
\hline $\begin{array}{l}{\left[\begin{array}{l}0 \\
0\end{array}\right]\left[\begin{array}{l}4 \\
\text { ALERGIA A MEDICAMENTOS }\end{array}\right.} \\
\end{array}$ & 0 & 1 & $\begin{array}{l}1 \text { ] }[1] \text { ] } \\
\text { NEUROLÓGICO }\end{array}$ & 0 & 1 \\
\hline $\begin{array}{l}\text { [0][ } 5 \text { ] } \\
\text { ENDOCRINOLÓGICO }\end{array}$ & 0 & 1 & 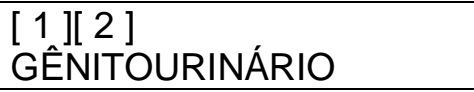 & 0 & 1 \\
\hline $\begin{array}{l}{[0][6]} \\
\text { DERMATOLÓGICO }\end{array}$ & 0 & 1 & $\begin{array}{l}{[1][\text { ] } 3]} \\
\text { HEMATOLÓGICO }\end{array}$ & 0 & 1 \\
\hline $\begin{array}{l}{[0][7]} \\
\text { PULMONAR }\end{array}$ & 0 & 1 & $\begin{array}{l}11][9] \\
\text { IMUNOLÓGICO }\end{array}$ & 0 & 1 \\
\hline $\begin{array}{l}{[0][8]} \\
\text { CARDIOVASCULAR }\end{array}$ & 0 & 1 & $\begin{array}{l}\text { [ } 2 \text { ][ } 0 \text { ] } \\
\text { PSIQUIÁTRICO }\end{array}$ & 0 & 1 \\
\hline
\end{tabular}

CÓDIGO [ ] [ ] CONDIÇÃO:

ESTADO: 0 = RESOLVIDA 1 = ESTÁVEL 2 = INSTÁVEL

COMENTÁRIOS:

CÓDIGO [ ] [ ] CONDIÇÃO:

ESTADO: 0 = RESOLVIDA 1 = ESTÁVEL 2 = INSTÁVEL

COMENTÁRIOS:

CÓDIGO [ ] [ ] CONDIÇÃO:

ESTADO: 0 = RESOLVIDA $1=$ ESTÁVEL $2=$ INSTÁVEL

COMENTÁRIOS:

CÓDIGO [ ] [ ] CONDIÇÃO:

ESTADO: 0 = RESOLVIDA $1=$ ESTÁVEL $2=$ INSTÁVEL

COMENTÁRIOS:

Duração da rinite alérgica meses/anos. Duração deste episódio dias/meses.

O paciente também apresenta: (assinalar com um "X")

Rinite alérgica sazonal? [ ]Sim [ ]Não

Asma? [ ]Sim [ ]Não

Tabagista: S[ ] N[ ]. Parou há meses/anos. Tempo de tabagismo meses/anos. 
II. Exame físico

\begin{tabular}{|c|c|c|c|}
\hline \multicolumn{3}{|c|}{$\begin{array}{l}\text { Assinale com um "X" em cada item: } \\
\text { (1) normal; (2) anormal; (3) não realizado }\end{array}$} & \multirow[t]{2}{*}{$\begin{array}{l}\text { DESCRIÇÃO DE ACHADOS } \\
\text { ANORMAIS }\end{array}$} \\
\hline 01 & APARÉNCIA GERAL & 123 & \\
\hline 02 & CABEÇA & 123 & \\
\hline 03 & OLHOS & 123 & \\
\hline 04 & OUVIDO, NARIZ, GARGANTA & 123 & \\
\hline 05 & PESCOÇO & 123 & \\
\hline 06 & LINFONODOS & 123 & \\
\hline 07 & PELE & 123 & \\
\hline 08 & PULMÕES & 123 & \\
\hline 09 & CORAÇÃO & 123 & \\
\hline$\overline{14}$ & TÓRAX & 123 & \\
\hline 10 & ABDOME & 123 & \\
\hline 32 & GÊNITO-URINÁRIO/ PÉLVICO & 123 & \\
\hline 20 & RETAL & 123 & \\
\hline 11 & MÚSCULO-ESQUELÉTICO & 123 & \\
\hline 12 & NEUROLÓGICO & 123 & \\
\hline
\end{tabular}

III. Sinais vitais

\begin{tabular}{l|l|l|l|l|l}
\hline $\begin{array}{l}\text { Temperatura } \\
\text { Axilar }\left({ }^{\circ} \mathrm{C}\right)\end{array}$ & Pulso (bpm) & PA $(\mathrm{mmHg})$ & FC (bpm) & Peso $(\mathrm{kg})$ & Altura $(\mathrm{cm})$ \\
& & & & & \\
\hline
\end{tabular}

IV. Medicações concomitantes

\begin{tabular}{l|l|l|l|l}
\hline $\begin{array}{l}\text { Nome genérico/ } \\
\text { comercial }\end{array}$ & Dose diária (mg) & Início & Término & Motivo para uso \\
\hline & & & & \\
\hline & & & & \\
\hline & & & & \\
\hline
\end{tabular}




\section{Anexo 5 - Ficha de rinite alérgica}

\section{SERVIÇO DE OTORRINOLARINGOLOGIA \& SERVIÇO DE ALERGIA E IMUNOLOGIA DO HCFMUSP FICHA DE RINITE ALÉRGICA \\ ETIQUETA \\ COR: \\ PROF.: \\ MÉDICO: \\ NATURAL: \\ Data $1^{\circ}$ ATEND.:}

\section{Q.D./ HPMA:}

QUADRO CLÍNICO:(0/+++)

Espirros / prurido: Coriza: Obstrução Nasal:

Epistaxis: Sint. Pulmonar: Sint. cutâneo:

Sint. ocular: Sint. auricular:
Outros:
Secreção retro-nasal: Sint. sinusal:

\section{CARACTERÍSTICAS DOS SINTOMAS}

Idade de início:

Relaciona (o início) com algum fator:

Tendência: piorando: ( ) melhorando: ( )

inalterado: ( )

Sintoma: Perene ( ) Sazonal ( ) Perene c/ exacerb. sazonal ( ) Piora diurna ( ) Piora noturna ( )

Piora c/ variação geográfica ( ) Outros: Duração das crises: Terapêutica anterior:

FATORES AGRAVANTES / PRECIPITANTES: $(0 /+++)$

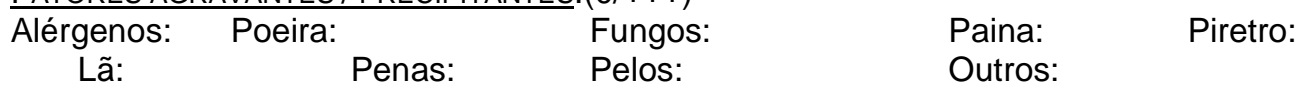

Inespecíficos: Alt. meteorológicas: Exercícios: Stress emocional:

Ciclo menstrual: Drogas (qual?):

Alimentos (qual?):

Outros:

ASPECTOS OCUPACIONAIS:

Função: Exposição: poeira ( ) vapores ( ) fumaça ( )

Tempo de exposição diária:

Medidas de proteção: ( )

gases ( )

ASPECTOS AMBIENTAIS: $\quad$ Adequado ( ) Inadequado ( )

Urbano: ( ) Rural: ( ) Poluente perto?:

Casa: Tipo de construção: Cômodo mal ventilado/úmido qual?

Quarto: Tapete/carpete ( ) Cortina ( ) Colchão: Travesseiro:

Objetos que acumulam pó (identifique):

Animais: Qual?:

Contato: Direto ( ) Indireto: ( )

Outros:

\section{ANTECEDENTES PESSOAIS (GERAIS E ALÉRGICOS):}

\section{ANTECEDENTES FAMILIARES GERAIS E ALÉRGICOS:}

HÁBITOS:

Tabagismo: Direto ( ) Indireto ( )

EXAME FÍSICO:

Olhos: Cianose infra-orbitária ( ) Dennie Morgan ( ) Lacrimejamento ( ) Hiperemia conjuntival ( )

Boca / garganta: Amígdalas: Palato em ogiva: ( )

Coloração:

Edema:

Secreção:

Dentes:

Outros:

Septo:

Faringe: Outros: 
continuação

EXAMES SUBSIDIÁRIOS

Citológico nasal:

Leuc.: PMN Neutróf.:

Cél. Epit.: Planas:

Eos: Basóf.: Linf.: Monóc.: Mast.:

Teste cutâneo: Histamina:

Hemograma:

$\lg \mathrm{E}$ :

$\lg A$ :

Ciliada

Secret. Rompida

Calicif.

RAST:

PPF:

$\mathrm{Rx}$ de seios paranasais:

Peak flow nasal:

Audiometria: normal: ( ) perda: ( ) Descrição:

Rinometria Acústica:

Fibroscopia:

Outros exames:

SUSPEITA DIAGNÓSTICA:

Diagnósticos secundários:

Escore: Sintomas:

Tratamento:
ETIOLOGIA:

Sinais:

Total:

\section{ESCORE DOS SINAIS E SINTOMAS ESPECÍFICOS DA RINITE ALÉRGICA}

\section{Escore dos Sintomas}

Espirros / prurido

0 - Ausente

1- 1-4 por dia / prurido ocasional

2- 5-10 por dia / prurido esporádico

3- 11 ou mais / interfere em atividades

\section{Rinorréia}

0 - Ausente

1- Limpeza 1-4 vezes ao dia

2- Limpeza 5-10 vezes ao dia

3- Limpeza constante

Obstrução nasal

0 - Ausente

1- Pequena e não atrapalha

2- Respiração bucal na maior parte do dia

3- Não respira pelo nariz / interfere atividades

Secreção retro-nasal

0 - Ausente

1- Sensação de secreção na garganta

2- Limpeza freqüente da garganta

3- Tosse e incomoda para falar
Escore dos Sinais

Cornetos - coloração

0- Róseo

1- Avermelhado / rosa pálido

2- Vermelho / pálido

3- Anêmico / azulado

\section{Edema}

0 - Ausente

1- Hipertrofia de corneto inferior ou médio

2- Congestão comprometendo respiração

3- Congestão impedindo respiração

Rinorréia

0 - Ausente

1- Mucosa parece úmida

2- Secreção visível em cornetos /assoalho nasal

3- Profusa / drenando

Inflamação faríngea

0 - Normal

1- Orofaringe discretamente vermelha

2- Orofaringe vermelha e folículos aparentes

3- Muco visível na orofaringe posterior

\begin{tabular}{lll}
\hline ESCORE / GRAVIDADE / TRATAMENTO CLíNICO \\
$0 / 6-$ & I & Cuidados gerais + anti-histamínicos \\
$7 / 12-$ & II & Anterior + corticosteróide tópico+ imunoterapia (s.n.) \\
$13 / 18-$ & III & Item I + corticosteróide tópico+ imunoterapia (s.n) \\
$19 / 24-$ & IV & Item III + corticosteróide sistêmico + imunoterapia \\
\hline
\end{tabular}




\section{Anexo 6 - Avaliação laboratorial (exames complementares)}

Teste cutâneo (aeroalérgenos)

\begin{tabular}{|c|c|c|}
\hline Bateria de Inalantes & braço esquerdo (mm) & braço direito $(\mathrm{mm})$ \\
\hline Aspergillus fumigatus & $\mathrm{x}$ & $\mathrm{x}$ \\
\hline Penicilium notatum & $\mathrm{x}$ & $\mathrm{x}$ \\
\hline Cladosporium herbarum & $x$ & $x$ \\
\hline Dermatophagoides farinae & $x$ & $\mathrm{x}$ \\
\hline D. pteronyssinus & $x$ & $\mathrm{x}$ \\
\hline E. mainei & $\mathrm{x}$ & $\mathrm{x}$ \\
\hline T. putrescentiae & $x$ & $\mathrm{x}$ \\
\hline Blomia tropicalis & $\mathrm{x}$ & $\mathrm{x}$ \\
\hline B. kulagini & $x$ & $\mathrm{x}$ \\
\hline Felis domesticus & $x$ & $\mathrm{x}$ \\
\hline Canis familiaris & $x$ & $\mathrm{x}$ \\
\hline Lolium perene & $x$ & $x$ \\
\hline Solução salina & $x$ & $\mathrm{x}$ \\
\hline Histamina & $x$ & $\mathrm{x}$ \\
\hline
\end{tabular}

RAST (IgE específica)

\begin{tabular}{l|l|l}
\hline Alérgenos & Faixa (KU/L) & Classes (0/1/2/3/4/5/6) \\
\hline Dermatophagoides pteronyssinus (D01) & & \\
\hline Dermatophagoides farinae (D02) & & \\
\hline Fungos (MX1) & & \\
\hline Epitélios de animais (EX1) & & \\
\hline Blomia tropicalis (RD201) & & \\
\hline Poeira Doméstica (HX2) & & \\
\hline
\end{tabular}

Imunoglobulinas totais

Imunoglobulinas totais

$\lg \mathrm{E}$

$\lg A$

$\lg M$

$\lg G$

Hemograma completo

\begin{tabular}{l|r|l|r}
\hline Hemograma & $\mathrm{mm}^{3}$ & Eosinófilos & $\%$ \\
\hline Hemácias & $\mathrm{g} \%$ & Basófilos & $\%$ \\
\hline Hemoglobina & $\%$ & Neutrófilos & $\%$ \\
\hline Hematócrito & $\%$ & Linfócitos & $\%$ \\
\hline Bastonetes & $\%$ & Monócitos & $\%$ \\
\hline Segmentados & &
\end{tabular}




\section{Anexo 7 - Questionário de qualidade de vida (FACIT-Sp-12)}

\begin{tabular}{l|c|c|c|c|c}
\hline BEM-ESTAR FÍSICO & $\begin{array}{c}\text { Nem } \\
\text { um } \\
\text { pouco }\end{array}$ & $\begin{array}{c}\text { Um } \\
\text { pouco }\end{array}$ & $\begin{array}{c}\text { Mais ou } \\
\text { menos }\end{array}$ & Muito & $\begin{array}{c}\text { Muitís } \\
\text { simo }\end{array}$ \\
\hline Estou sem energia & 0 & 1 & 2 & 3 & 4 \\
\hline Fico enjoado & 0 & 1 & 2 & 3 & 4 \\
\hline $\begin{array}{l}\text { Por causa do meu estado físico, tenho } \\
\text { dificuldade em atender às necessidades } \\
\text { da minha família }\end{array}$ & 0 & 1 & 2 & 3 & 4 \\
\hline Tenho dores & 0 & 1 & 2 & 3 & 4 \\
\hline $\begin{array}{l}\text { Sinto-me incomodado(a) pelos efeitos } \\
\text { secundários do tratamento }\end{array}$ & 0 & 1 & 2 & 3 & 4 \\
\hline Sinto-me doente & 0 & 1 & 2 & 3 & 4 \\
\hline Tenho que me deitar durante o dia & 0 & 1 & 2 & 3 & 4 \\
\hline
\end{tabular}

\begin{tabular}{l|c|c|c|c|c}
\hline BEM-ESTAR SOCIAL/ FAMILIAR & $\begin{array}{c}\text { Nem } \\
\text { um } \\
\text { pouco }\end{array}$ & $\begin{array}{c}\text { Um } \\
\text { pouco }\end{array}$ & $\begin{array}{c}\text { Mais ou } \\
\text { menos }\end{array}$ & Muito & $\begin{array}{c}\text { Muitís } \\
\text { simo }\end{array}$ \\
\hline $\begin{array}{l}\text { Sinto que tenho uma boa relação com os } \\
\text { meus amigos }\end{array}$ & 0 & 1 & 2 & 3 & 4 \\
\hline Recebo apoio emocional da minha família & 0 & 1 & 2 & 3 & 4 \\
\hline Recebo apoio dos meus amigos & 0 & 1 & 2 & 3 & 4 \\
\hline A minha família aceita a minha doença & 0 & 1 & 2 & 3 & 4 \\
\hline $\begin{array}{l}\text { Estou satisfeito(a) com a maneira como a } \\
\text { minha família fala sobre a minha doença }\end{array}$ & 0 & 1 & 2 & 3 & 4 \\
\hline $\begin{array}{l}\text { Sinto-me próximo(a) do(a) meu (minha) } \\
\text { parceiro(a) (ou da pessoa que me dá } \\
\text { maior apoio) }\end{array}$ & 0 & 1 & 2 & 3 & 4 \\
\hline
\end{tabular}

\begin{tabular}{l|c|c|c|c|c}
\hline BEM-ESTAR EMOCIONAL & $\begin{array}{c}\text { Nem } \\
\text { um } \\
\text { pouco }\end{array}$ & $\begin{array}{c}\text { Um } \\
\text { pouco }\end{array}$ & $\begin{array}{c}\text { Mais ou } \\
\text { menos }\end{array}$ & Muito & $\begin{array}{c}\text { Muitís } \\
\text { simo }\end{array}$ \\
\hline Sinto-me triste & 0 & 1 & 2 & 3 & 4 \\
\hline $\begin{array}{l}\text { Estou satisfeito(a) com a maneira como } \\
\text { enfrento a minha doença }\end{array}$ & 0 & 1 & 2 & 3 & 4 \\
\hline $\begin{array}{l}\text { Estou perdendo a esperança na luta } \\
\text { contra a minha doença }\end{array}$ & 0 & 1 & 2 & 3 & 4 \\
\hline $\begin{array}{l}\text { Sinto-me nervoso(a) } \\
\begin{array}{l}\text { Estou preocupado(a) com a idéia de } \\
\text { morrer }\end{array}\end{array}$ & 0 & 1 & 2 & 3 & 4 \\
\hline $\begin{array}{l}\text { Estou preocupado(a) que o meu estado } \\
\text { venha a piorar }\end{array}$ & 0 & 1 & 2 & 3 & 4 \\
\hline
\end{tabular}




\begin{tabular}{l|c|c|c|c|c}
\hline BEM-ESTAR FUNCIONAL & $\begin{array}{c}\text { Nem } \\
\text { um } \\
\text { pouco }\end{array}$ & $\begin{array}{c}\text { Um } \\
\text { pouco }\end{array}$ & $\begin{array}{c}\text { Mais ou } \\
\text { menos }\end{array}$ & Muito & $\begin{array}{c}\text { Muitís } \\
\text { simo }\end{array}$ \\
\hline $\begin{array}{l}\text { Sou capaz de trabalhar (inclusive em } \\
\text { casa) }\end{array}$ & 0 & 1 & 2 & 3 & 4 \\
\hline $\begin{array}{l}\text { Sinto-me realizado(a) com o meu trabalho } \\
\text { (inclusive em casa) }\end{array}$ & 0 & 1 & 2 & 3 & 4 \\
\hline Sou capaz de sentir prazer em viver & 0 & 1 & 2 & 3 & 4 \\
\hline Aceito a minha doença & 0 & 1 & 2 & 3 & 4 \\
\hline Durmo bem & 0 & 1 & 2 & 3 & 4 \\
\hline $\begin{array}{l}\text { Gosto das coisas que normalmente faço } \\
\text { para me divertir }\end{array}$ & 0 & 1 & 2 & 3 & 4 \\
\hline $\begin{array}{l}\text { Estou satisfeito(a) com a qualidade da } \\
\text { minha vida neste momento }\end{array}$ & 0 & 1 & 2 & 3 & 4 \\
\hline
\end{tabular}

\begin{tabular}{l|c|c|c|c|c}
\hline $\begin{array}{l}\text { PREOCUPAÇÕES ADICIONAIS } \\
\text { (EXISTENCIAIS/ ESPIRITUAIS) }\end{array}$ & $\begin{array}{c}\text { Nem } \\
\text { um } \\
\text { pouco }\end{array}$ & $\begin{array}{c}\text { Um } \\
\text { pouco }\end{array}$ & $\begin{array}{c}\text { Mais ou } \\
\text { menos }\end{array}$ & Muito & $\begin{array}{c}\text { Muitís } \\
\text { simo }\end{array}$ \\
\hline Sinto-me em paz & 0 & 1 & 2 & 3 & 4 \\
\hline Tenho uma razão para viver & 0 & 1 & 2 & 3 & 4 \\
\hline A minha vida tem sido produtiva & 0 & 1 & 2 & 3 & 4 \\
\hline Custa-me sentir paz de espírito & 0 & 1 & 2 & 3 & 4 \\
\hline Sinto que a minha vida tem um propósito & 0 & 1 & 2 & 3 & 4 \\
\hline $\begin{array}{l}\text { Sou capaz de encontrar conforto dentro de } \\
\text { mim mesmo(a) }\end{array}$ & 0 & 1 & 2 & 3 & 4 \\
\hline Sinto-me em harmonia comigo mesmo(a) & 0 & 1 & 2 & 3 & 4 \\
\hline $\begin{array}{l}\text { Falta sentido e propósito em minha vida } \\
\text { Encontro conforto na minha fé ou crenças } \\
\text { espirituais }\end{array}$ & 0 & 1 & 2 & 3 & 4 \\
\hline $\begin{array}{l}\text { A minha fé ou crenças espirituais me dá } \\
\text { força }\end{array}$ & 0 & 1 & 2 & 3 & 4 \\
\hline $\begin{array}{l}\text { A minha doença tem fortalecido a minha fé } \\
\text { ou crenças espirituais }\end{array}$ & 0 & 1 & 2 & 3 & 4 \\
\hline $\begin{array}{l}\text { Independentemente do que acontecer com } \\
\text { a minha doença, tudo acabará bem }\end{array}$ & 0 & 1 & 2 & 3 & 4 \\
\hline
\end{tabular}




\section{Anexo 8 - Utilização dos medicamentos - Instruções ao paciente}

\section{Utilização do medicamento homeopático}

Ao contrário do que se imagina, a utilização de medicamentos homeopáticos em doses acima das recomendadas pode causar prejuízos à saúde, agravando ainda mais os sintomas da doença; assim sendo, é de fundamental importância que o medicamento seja utilizado de maneira correta. Portanto, preste atenção às instruções do seu médico e siga corretamente os procedimentos abaixo:

1. Agite bem o frasco antes de cada ingesta. Pressione e solte a borracha do contagotas 3 vezes antes de abrir o frasco.

2. Pingue 3 gotas debaixo da língua, 1 vez por semana, pela manhã, em jejum, aguardando meia hora para ingerir bebidas ou alimentos.

\section{I.1. Armazenamento do medicamento homeopático}

Todo medicamento homeopático deve ser guardado em ambiente fresco, seco; afastado do Sol, do calor e de aparelhos eletrodomésticos (computador, televisão, microondas etc.). Guarde-o numa caixa ou gaveta, afastado destas influências.

RETORNE COM O(S) FRASCO(S) EM TODAS AS CONSULTAS

\section{Utilização do anti-histamínico de resgate}

Caso seja necessário, o anti-histamínico (Maleato de Clorfeniramina - $4 \mathrm{mg} / \mathrm{cp}$ ), deve ser utilizado na dosagem de 1 comprimido a cada 6 horas.

É importante que o paciente anote os dias em que fez uso do anti-histamínico.

RETORNE COM A CARTELA DO ANTI-HISTAMÍNICO EM TODAS AS CONSULTAS 
Anexo 9 - Formulário de eventos adversos

\begin{tabular}{|c|c|c|c|c|}
\hline 总 & 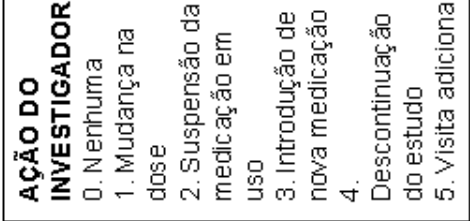 & $\begin{array}{l}\frac{0}{2} \\
- \\
0 \\
0 \\
0 \\
20 \\
20\end{array}$ & $\begin{array}{l}0 \\
0 \\
0 \\
0 \\
0 \\
0 \\
5 \\
0\end{array}$ & $\begin{array}{l}\frac{0}{2} \\
0 \\
0 \\
0 \\
20 \\
20\end{array}$ \\
\hline 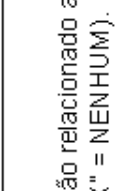 & 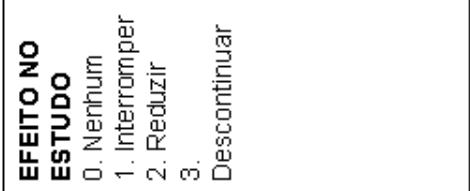 & $\begin{array}{l}a \\
- \\
\sigma\end{array}$ & $\begin{array}{l}\infty \\
\infty \\
- \\
0\end{array}$ & $\begin{array}{l}a \\
- \\
- \\
a\end{array}$ \\
\hline 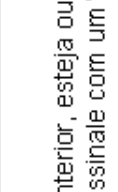 & 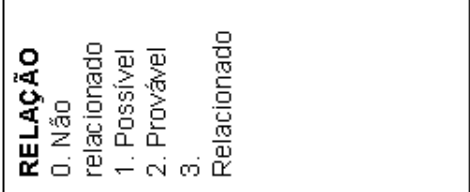 & $\begin{array}{l}\sigma \\
\sigma \\
\sigma\end{array}$ & $\begin{array}{l}a \\
0 \\
- \\
0\end{array}$ & $\begin{array}{l}a \\
\sigma \\
\sigma\end{array}$ \\
\hline 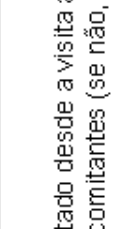 & 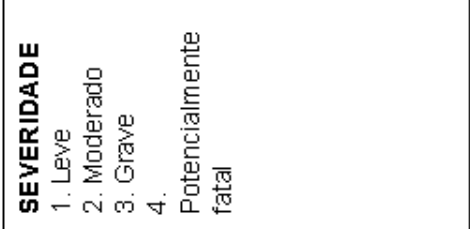 & $\begin{array}{l}0 \\
0 \\
0\end{array}$ & $\begin{array}{l}-1 \\
0 \\
0 \\
0\end{array}$ & $\begin{array}{l}0 \\
0 \\
0\end{array}$ \\
\hline 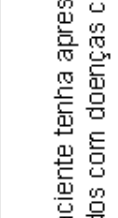 & 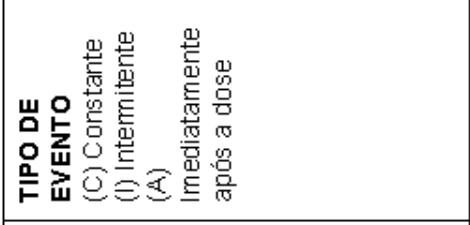 & $\begin{array}{l}-1 \\
- \\
0\end{array}$ & - & $\begin{array}{l}4 \\
- \\
0\end{array}$ \\
\hline 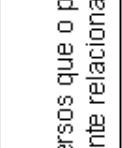 & 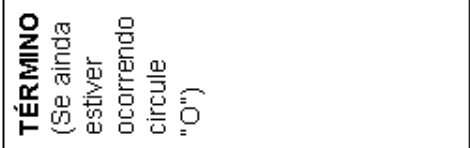 & 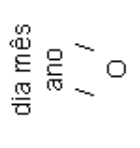 & 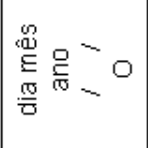 & 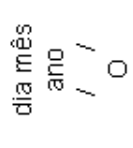 \\
\hline 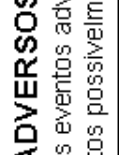 & $\frac{O}{0}$ & 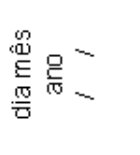 & 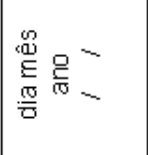 & 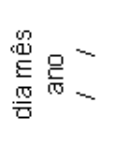 \\
\hline 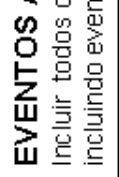 & 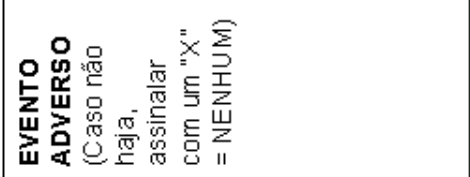 & & & \\
\hline
\end{tabular}




\section{Anexo 10 - Ficha de registro final}

\begin{tabular}{|l|l|l|l|}
\hline № do Paciente: & Data: & Investigador: & Avaliação Final: \\
& & & \\
\hline
\end{tabular}

Quando o paciente aplicou a medicação pela última vez?

O paciente completou o estudo de acordo com o protocolo?

$\operatorname{SIM}($ ) NÃO ( )

1= Evento adverso

2 = Doença concomitante

3 = Ineficácia da medicação em estudo

4 = Não aderência ao tratamento

5 = Violação de protocolo

6 = Descontinuação de tratamento pelo investigador

7 = Outros

Comentários:

Eu revisei todos os dados contidos em todas as páginas desta Ficha Clínica e certifico que eles são exatos, completos e são a verdadeira reflexão dos registros do paciente.

Data, assinatura e carimbo do investigador 
IX. REFERÊNCIAS 
Ader R, Cohen N. Behaviorally conditioned immunosupression and murine systemic lupus erythematosus. Science. 1982;215:1534-6.

Allan LG, Siegel S. A signal detection theory analysis of the placebo effect. Eval Health Prof. 2002;25:410-20.

Alvarez-Cuesta E, Bousquet J, Canonica GW, Durham SR, Malling HJ, Valovirta V. Standards for practical allergen-specific immunotherapy. Allergy. 2006;61:1-3.

Amanzio M, Benedetti F. Neuropharmacological dissection of placebo analgesia: expectation-activated opioid systems versus conditioning-activated subsystems. $J$ Neurosci. 1999;484-94.

Amanzio M, Pollo A, Maggi G, Benedetti F. Response variability to analgesics: a role for non-specific activation of endogenous opioids. Pain. 2001;90:205-15.

Andre J, Zeau B, Pohl M, Cesselin F, Benoliel JJ, Becker C. Involvement of cholecystokininergic systems in anxiety-induced hyperalgesia in male rats: behavioral and biochemical studies. J Neurosci. 2005;25:7896-904.

Asher MI, Montefort S, Björkstén B, Lai CK, Strachan DP, Weiland SK, et al. Worldwide time trends in the prevalence of symptoms of asthma, allergic rhinoconjunctivitis, and eczema in childhood: ISAAC Phases One and Three repeat multicountry cross-sectional surveys. Lancet. 2006;368:733-43. Erratum in: Lancet. 2007;370:1128.

Balbani APS, Mello Júnior JF, Mion O, Butagan O. Atualização em rinites. Rev Bras Med. 2002; 59:2-13.

Barnes J, Resch KL, Ernst E. Homeopathy for postoperative ileus? A meta-analysis. J Clin Gastroenterol. 1997;25:628-33. 
Barsky AJ, Saintfort R, Rogers MP, Borus JF. Nonspecific medication side effects and the nocebo phenomenon. JAMA. 2002;287:622-7.

Bauchau V, Durham SR. Prevalence and rate of diagnosis of allergic rhinitis in Europe. Eur Respir J. 2004;24:758-64.

Bausell RB, lao L, Bergman S, Lee WL, Berman BM. Is acupuncture analgesia an expectancy effect? Preliminary evidence based on participants' perceived assignments in two placebo-controlled trials. Eval Health Prof. 2005;28:9-26.

Beecher HK. The powerful placebo. JAMA. 1995;159:1602-6.

Bell IR, Lewis DA 2nd, Brooks AJ, Schwartz GE, Lewis SE, Walsh BT, et al. Improved clinical status in fibromyalgia patients treated with individualized homeopathic remedies versus placebo. Rheumatology (Oxford). 2004;43:577-82.

Belon P, Cumps J, Ennis M, Mannaioni PF, Roberfroid M, Sainte-Laudy J, et al. Inhibition of human basophil degranulation by successive histamine dilutions: results of a European multi-centre trial. Inflamm Res. 1999;48:S17-8.

Belon P, Cumps J, Ennis M, Mannaioni PF, Sainte-Laudy J, Roberfroid M, et al. Histamine dilutions modulate basophil activation. Inflamm Res. 2004;53:181-8.

Benedetti F, Amanzio M, Maggi G. Potentiation of placebo analgesia by proglumide. Lancet. 1995;346:1231.

Benedetti F. The opposite effects of the opiate antagonist naloxone and the cholecystokinin antagonist proglumide on placebo analgesia. Pain. 1996:64:535-43. Benedetti F. Cholecystokinin type-A and type-B receptors and their modulation of opioid analgesia. News Physiol Sci. 1997;12:263-8. 
Benedetti F, Baldi S, Casadio C, Cavallo A, Mancuso M, Ruffini E, et al. The specific effects of prior opioid exposure on placebo analgesia and placebo respiratory depression. Pain. 1998;75:313-9.

Benedetti F, Amanzio M, Baldi S, Casadio C, Maggi G. Inducing placebo respiratory depressant responses in humans via opioid receptors. Eur J Neurosci. 1999a;11:62531.

Benedetti F, Arduino C, Amanzio M. Somatotropic activation of opioid systems by target-directed expectations of analgesia. J Neurosci. 1999b;19:3639-48.

Benedetti F, Pollo A, Lopiano L, Lanotte M, Vighetti S, Rainero I. Conscious expectation and unconscious conditioning in analgesic, motor, and hormonal placebo/nocebo responses. J Neurosci. 2003;23:4315-23.

Benedetti F, Colloca L, Torre E, Lanotte M, Melcarne A, Pesare M, et al. Placeboresponsive Parkinson patients show decreased activity in single neurons of subthalamic nucleus. Nat Neurosci. 2004;7:587-8.

Benedetti F, Mayberg HS, Wager TD, Stohler CS, Zubieta JK. Neurobiological mechanisms of the placebo effect. J Neurosci. 2005;25:10390-402.

Benedetti F, Amanzio M, Vighetti S, Asteggiano G. The biochemical and neuroendocrine bases of the hyperalgesic nocebo effect. J Neurosci. 2006;26:1201422.

Benedetti F, Lanotte M, Colloca L. When words are painful: unraveling the mechanisms of the nocebo effect. Neuroscience. 2007;147:260-71.

Benveniste J, Davenas E, Ducot B, Cornillet B, Poitevin B, Spira A. L'agitation de solutions hautement diluées n'induit pas d'activité biologique spécifique. $C R$ Acad Sci Paris. 1991;312:461-6. 
Benveniste J, Davenas E, Ducot B, Spira A. Basophil achromasia by dilute ligand: a repraisal. FASEB J. 1991;5:A3706.

Bignamini M, Bertoli A, Consolandi A, Dovera N, Felisi E, Saruggia M, et al. A controlled double-blind clinical study of $15 \mathrm{CH}$ barium carbonate vs placebo in a group of hypertensive inmates of 2 homes for the aged. Clin Ter. 1987;122:429-36.

Bousquet J, Van Cauwenberge P, Khaltaev N, Aria Workshop Group; World Health Organization. Allergic rhinitis and its impact on asthma. $J$ Allergy Clin Immunol. 2001;108:S147-334.

Bousquet J, Khaltaev N, Cruz AA, Denburg J, Fokkens WJ, Togias A, et al. Allergic Rhinitis and its Impact on Asthma (ARIA) 2008 update (in collaboration with the World Health Organization, GA(2)LEN and AllerGen). Allergy. 2008; 63 Suppl 86:8-160.

Brody $\mathrm{H}$. The placebo response: recent research and implications for family medicine. J Fam Pract. 2000;49:649-54.

Brown V, Ennis M. Flow-cytometric analysis of basophil activation: inhibition by histamine at conventional and homeopathic concentrations. Inflamm Res. $2001 ; 50: S 47-8$.

Bufe A, Ziegler-Kirbach E, Stoeckmann E, Heidemann P, Gehlhar K, Holland-Letz T, et al. Efficacy of sublingual swallow immunotherapy in children with severe grass pollen allergic symptoms: a double-blind placebo-controlled study. Allergy. 2004;59:498-504.

Buxton M. Assessing the cost-effectiveness of homeopathic medicines: are the problems different from other health technologies? Br Homeopath J. 2000;89:S20-2. 
Calabrese EJ, Brain R. The occurrence of hormetic dose responses in the toxicological literature, the hormesis database: an overview. Toxicol Appl Pharmacol. 2005;202:289-301.

Calamita Z, Saconato H, Pelá AB, Atallah AN. Efficacy of sublingual immunotherapy in asthma: systematic review of randomized-clinical trials using the Cochrane Collaboration method. Allergy. 2006; 61:1162-72.

Canonica G W, Baena-Cagnani CE, Bousquet J, Bousquet PJ, Lockey RF, Malling HJ, et al. Recommendations for standardization of clinical trials with Allergen Specific Immunotherapy for respiratory allergy. A statement of a World Allergy Organization (WAO) taskforce. Allergy. 2007;62:317-24.

Castro FFM. Rinite Alérgica: modernas abordagens para uma clássica questão. $2^{\mathrm{a}}$ ed. São Paulo: Lemos Editorial; 1998.

Cechetto DF, Saper CB. Evidence for a viscerotopic sensory representation in the córtex and thalamus in rat. J Comp Neurol. 1987;262:27-45.

Chaplin MF. The memory of water: an overview. Homeopathy. 2007;96:143-50.

Cho HJ, Hotopf M, Wessely S. The placebo response in the treatment of chronic fatigue syndrome: a systematic review and meta-analysis. Psychosom Med. 2005; 67:301-13.

Chvetzoff G, Tannock IF. Placebo effects in oncology. J Natl Cancer Inst. 2003; 95:1929.

Colloca L, Lopiano L, Lanotte M, Benedetti F. Overt versus covert treatment for pain, anxiety, and Parkinson's disease. Lancet Neurol. 2004;3:679-84. 
Cruz AA, Popov T, Pawankar R, Annesi-Maesano I, Fokkens W, Kemp J, et al. Common characteristics of upper and lower airways in rhinitis and asthma: ARIA update, in collaboration with GA(2)LEN. Allergy. 2007; 62 Suppl 84:1-41.

Cucherat M, Haugh MC, Gooch M, Boissel JP. Evidence of clinical efficacy of homeopathy. A meta-analysis of clinical trials. HMRAG. Homeopathic Medicines Research Advisory Group. Eur J Clin Pharmacol. 2000;56:27-33.

Dannecker EA, Price DD, Robinson ME. An examination of the relationships among recalled, expected, and actual intensity and unpleasantness of delayed onset muscle pain. J Pain. 2003;4:74-81.

Dantas F, Fisher P, Walach H, Wieland F, Rastogi DP, Teixeira H, et al. A systematic review of the quality of homeopathic pathogenetic trials published from 1945 to 1995. Homeopathy. 2007;96:4-16.

Davenas E, Beauvais F, Amara J, Oberbaum M, Robinzon B, Miadonna A, et al. Human basophil degranulation triggered by very dilute antiserum against IgE. Nature. 1988;333:816-8.

de Craen AJ, Kaptchuk TJ, Tijssen JG, Kleijnen J. Placebos and placebo effects in medicine: historical overview. J R Soc Med. 1999;92:511-5.

de la Fuente-Fernandez R, Ruth TJ, Sossi V, Schulzer M, Calne DB, Stoessl AJ. Expectation and dopamine release: mechanisms of the placebo effect in Parkinson's disease. Science. 2001;293:1164-6.

de la Fuente-Fernandez R, Phillips AG, Zamburlini M, Sossi V, Calne DB, Ruth TJ, et al. Dopamine release in human ventral striatum and expectation of reward. Behav Brain Res. 2002a;136:359-63. 
de la Fuente-Fernandez R, Stoessl AJ. The biochemical bases for reward. Implications for the placebo effect. Eval Health Prof. 2002b;25:387-98.

de la Fuente-Fernandez R, Schulzer M, Stoessl AJ. Placebo mechanisms and reward circuitry: clues from Parkinson's disease. Biol Psychiatry. 2004;56:67-71.

De Pascalis V, Chiaradia C, Carotenuto E. The contribution of suggestibility and expectation to placebo analgesia phenomenon in an experimental setting. Pain. 2002;96:393-402.

Del Giudice E, Preparata G, Vitiello G. Water as a free electric dipole laser. Phys Rev Lett. 1988;61:1085-8.

Durham SR, Walker SM, Varga EM, Jacobson MR, O'Brien F, Noble W, et al. Longterm clinical efficacy of grass-pollen immunotherapy. N Engl J Med. 1999;341:468-75. Egger M, Juni P, Holenstein F, Sterne JA. Are the Clinical Effects of Homeopathy Bias Effects? Bristol, United Kingdom: Department of Social Medicine, University of Bristol; 2001.

Endler PC, Pongratz W, Kastberger G, Wiegant FA, Schulte J. The effect of highly diluted agitated thyroxine on the climbing activity of frogs. Vet Hum Toxicol. 1994;36:56-9.

Endler PC, Pongratz W, Smith CW, Schulte J. Non-molecular information transfer from thyroxine to frogs with regard to homeopathic toxicology. Vet Hum Toxicol. 1995;37:259-60.

Ernst E, Pittler MH. Efficacy of homeopathic arnica: a systematic review of placebocontrolled clinical trials. Arch Surg. 1998;133:1187-90.

Ernst E. Homeopathic prophylaxis of headaches and migraine? A systematic review. J Pain Symptom Manage. 1999;18:353-7. 
FACIT. Functional Assessment of Chronic Illness. Functional Assessment of Chronic Illness Therapy - Spiritual Well-Being. Available in: http://www.facit.org. Accessed in September/2008.

Farmacopéia Homeopática Brasileira, Parte I, Métodos Gerais. $2^{\underline{a}}$ ed. São Paulo: Editora Atheneu, 2002.

Fiorillo CD, Tobler PN, Schultz W. Discrete coding of reward probability and uncertainly by dopamine neurons. Science. 2003;299:1898-902.

Flaten MA, Simonsen T, Olsen H. Drug-related information generates placebo and nocebo responses that modify the drug response. Psychosom Med. 1999;61:250-5.

Food and Drug Administration. Guidance for Industry - Acceptance of Foreign Clinical Studies. Clinical Medical. March 2001. Disponível em: http://www.fda.gov/cder/guidance/fstud.htm. Acessado em 14/12/2008.

Frei H, Everts R, von Ammon K, Kaufmann F, Walther D, Hsu-Schmitz SF, et al. Homeopathic treatment of children with attention deficit hyperactivity disorder: a randomised, double blind, placebo controlled crossover trial. Eur $J$ Pediatr. 2005;164:758-67.

Frei H, Everts R, von Ammon K, Kaufmann F, Walther D, Schmitz SF, et al. Randomised controlled trials of homeopathy in hyperactive children: treatment procedure leads to an unconventional study design. Experience with open-label homeopathic treatment preceding the Swiss ADHD placebo controlled, randomised, double-blind, cross-over trial. Homeopathy. 2007;96:35-41.

Fricchione G, Stefano GB. Placebo neural systems: nitric oxide, morphine and the dopamine brain reward and motivation circutries. Med Sci Monit. 2005;11:MS54-65. 
Furia CLB. Qualidade de vida em pacientes tratados de câncer de cavidade oral, faringe e laringe em São Paulo: estudo multicêntrico. Radiol Bras. 2006;39:252.

Geers AL, Weiland PE, Kosbab K, Landry SJ, Helfer SG. Goal activation, expectations, and the placebo effect. J Personal Soc Psychol. 2005;89:143-59.

Geers AL, Helfer SG, Weiland PE, Kosbab K. Expectations and placebo response: a laboratory investigation into the role of somatic focus. J Behav Med. 2006;29:171-8.

Giang DW, Goodman AD, Schiffer RB, Mattson DH, Petrie M, Cohen N, et al. Conditioning of cyclophosphamide-induced leukopenia in humans. $J$ Neuropsychiatry Clin Neurosci. 1996;8:194-201.

Goebel MU, Trebst AE, Steiner J, Xie YF, Exton MS, Frede S, et al. Behavioral conditioning of immunosuppression is possible in humans. FASEB J. 2002;16:186973.

Gracely RH, Dubner R, Wolskee PJ, Deeter WR. Placebo and naloxone can alter post-surgical pain by separate mechanisms. Nature. 1983;306:264-5.

Greenberg RP, Bornstein RF, Greenberg MD, Fisher S. A meta-analysis of antidepressant outcome under "blinder" conditions. J Consult Clin Psychol. 1992;60:664-9.

Grossman J. One airway, one disease. Chest. 1997;111:11-16S.

Guedes JR, Ferreira CM, Guimarães HM, Saldiva PH, Capelozzi VL. Homeopathically prepared dilution of Rana catesbiana thyroid glands modifies its rate of metamorphosis. Homeopathy. 2004;93:132-7.

Guez S, Vatrinet C, Fadel R, André C. House-dust-mite sublingual-swallow immunotherapy (SLIT) in perennial rhinitis: a double-blind, placebo-controlled study. Allergy. 2000;55:369-75. 
Guggisberg AG, Baumgartner SM, Tschopp CM, Heusser P. Replication study concerning the effects of homeopathic dilutions of histamine on human basophil degranulation in vitro. Complement Ther Med. 2005;13:91-100.

Guthlin C. The cost-effectiveness of homeopathy: the perspective of a scientist and mother. Homeopathy. 2005;94:1-2.

Hahnemann S. Organon da arte de curar, 6 $6^{\mathbf{a}}$ ed. Ribeirão Preto: Museu de Homeopatia Abrahão Brickmann; 1995.

Hebb ALO, Poulin J-F, Roach SP, Zacharko RM, Drolet G. Cholecystokinin and endogenous opioid peptides: interactive influence on pain, cognition, and emotion. Prog Neuropsychopharmacol Biol Psychiatry. 2005;29:1225-38.

Hemming K, Hutton JL, Maquire MJ, Marson AG. Open label extension studies and patient selection biases. J Eval Clin Pract. 2008;14:141-4.

Hirst SJ, Hayes NA, Burridge J, Pearce FL, Foreman JC. Human basophil degranulation is not triggered by very dilute antiserum against human IgE. Nature. 1993;366:525-7.

Hoffman GA, Harrington A, Fields HL. Pain and placebo. Perspect Biol Med. 2005;48:248-65.

Hrobjartsson A, Gotzsche PC. Is the placebo powerless? An analysis of clinical trials comparing placebo treatment with no treatment. N Engl J Med. 2001;344:1594-602. Hrobjartsson A, Gotzsche PC. Is the placebo powerless? Update of a systematic review with 52 new randomized trials comparing placebo with no treatment. $J$ Intern Med. 2004a;256:91-100.

Hrobjartsson A, Gotzsche PC. Placebo interventions for all clinical conditions. Cochrane Database Syst Rev. 2004b;CD003974. 
Hsieh JC, Stone-Elander S, Ingvar M. Anticipatory coping of pain expressed in the human anterior cingulated cortex: a positron emission tomography study. Neurosci Lett. 1999;262:61-4.

Hunsley J, Westmacott R. Interpreting the magnitude of the placebo effect: mountain or Molehill? J Clin Psychol. 2007;63:391-9.

Inyckyj A, Greenberg H, Bernstein CN. Quantification of the placebo response in ulcerative colitis. Gastroenterology. 1997;112:1854-8.

International Consensus Report on the diagnosis and management of rhinitis. International Rhinitis Management Working Group. Allergy. 1994;49:1-34.

Jacobs J, Jonas WB, Jiménez-Pérez M, Crothers D. Homeopathy for childhood diarrhea: combined results and metaanalysis from three randomized, controlled clinical trials. Pediatr Infect Dis J. 2003;22:229-34.

Jain A. Does homeopathy reduce the cost of conventional drug prescribing? A study of comparative prescribing costs in general practice. Homeopathy. 2003;92:71-6.

Jonas WB, Kaptchuk TJ, Linde K. A critical overview of homeopathy. Ann Intern Med. 2003;138:393-9.

Joyce DP, Jackevicius C, Chapman KR, Mclvor RA, Kesten S. The placebo effect in asthma drug therapy trials: a meta-analysis. J Asthma. 2000; 37:303-18.

Kaptchuk TJ. Powerful placebo: the dark side of the randomised controlled trial. Lancet. 1998;351:1722-5.

Kaptchuk TJ. The placebo effect in alternative medicine: can the performance of a healing ritual have clinical significance? Ann Intern Med. 2002;136:817-25. 
Kaptchuk TJ, Kelley JM, Conboy LA, Davis RB, Kerr CE, Jacobson EE, et al. Components of placebo effect: randomised controlled trial in patients with irritable bowel syndrome. BMJ. 2008;336:999-1003.

Keltner JR, Furst A, Fan C, Redfern R, Inglis B, Fields HL. Isolating the modulatory effect of expectation on pain transmission: a functional magnetic resonance imaging study. J Neurosci. 2006;26:4437-43.

Khinchi MS, Poulsen LK, Carat F, André C, Hansen AB, Malling HJ. Clinical efficacy of sublingual and subcutaneous birch pollen allergen-specific immunotherapy: a randomized, placebo-controlled, double-blind, double-dummy study. Allergy. 2004;59:45-53.

Kienle GS, Kiene H. The powerful placebo effect: fact or fiction? J Clin Epidemiol. $1997 ; 12: 1311-8$.

Kirsch I, Sapirstein G. Listening to Prozac but hearing placebo: a meta analysis of antidepressant medication. Prevention \& Treatment. 1998, 1 Article 0002a. Disponível em: http://journals.apa.org/prevention/volume1/toc-jun26-98.html. Acessado em 14/12/2008.

Kleijnen J, Knipschild P, ter Riet G. Clinical trials of homoeopathy. BMJ. $1991 ; 302: 316-23$.

Kleijnen J. What research is needed to show the effectiveness of homeopathy? $\mathrm{Br}$ Homeopath J. 2000;89:S1-2.

Koh YY, Kim CK. The development of asthma in patients with allergic rhinitis. Curr Opin Allergy Clin Immunol. 2003;3:159-64.

Koyama T, Tanaka YZ, Mikami A. Nociceptive neurons in the macaque anterior cingulated activate during anticipation of pain. Neuroreport. 1998;9:2663-7. 
Koyama T, McHaffie JG, Laurienti PJ, Coghill RC. The subjective experience of pain: where expectations become reality. Proc Natl Acad Sci USA. 2005;102:12950-5.

La Mantia L, Eoli M, Salmaggi A, Milanese C. Does a placebo-effect exist in clinical trials on multiple sclerosis? Review of the literature. Ital J Neurol Sci. 1996;17:135-9.

Labrecque M, Audet D, Latulippe L. Homeopathic treatment of plantar warts. CMAJ. 1992;146:1749-53.

Leigh R, MacQueen G, Tougas G, Hargreave FE, Bienenstock J. Change in forced expiratory volume in 1 second after sham bronchoconstrictor in suggestible but not suggestion-resistant asthmatic subjects: a pilot study. Psychosom Med. 2003;65:7915.

Leite F. Homeopatia ganha espaço no SUS, mas só 110 municípios a adotam. O Estado de S. Paulo, São Paulo. 2008, mai 03; Supl Vida \& Saúde.

Lemos CM, Wilhelmsen NSW, Mion O, Mello Júnior JF. Alterações Funcionais do Sistema Estomatognático em Pacientes com Rinite Alérgica. Arq Int Otorrinolaringol. 2007;11:380-6.

Leuchter AF, Cook IA, Witte EA, Morgan M, Abrams M. Changes in brain function of depressed subjects during treatment with placebo. Am J Psychiatry. 2002;159:122-9. Leuchter AF, Morgan M, Cook IA, Dunkin J, Abrams M, Witte E. Pretreatment neurophysiological and clinical characteristics of placebo responders in treatment trials for major depression. Psychopharmacology (Berl). 2004;177:15-22.

Levine JD, Gordon NC, Fields HL. The mecanisms of placebo analgesia. Lancet. 1978;2:654-7.

Levine JD, Gordon NC, Bornstein JC, Fields HL. Role of pain in placebo analgesia. Proc Natl Acad Sci USA. 1979;76:3528-31. 
Levine JD, Gordon NC, Smith R, Fields HL. Analgesic responses to morphine and placebo in individuals with postoperative pain. Pain. 1981;10:379-89.

Levine JD, Gordon NC. Influence of the method of drug administration on analgesic response. Nature. 1984;312:755-6.

Levine ME, Stern RM, Koch KL. The effects of manipulating expectations through placebo and nocebo administration on gastric tachyarrhythmia and motion-induced náusea. Psychosom Med. 2006;68:478-86.

Linde K, Jonas WB, Melchart D, Worku F, Wagner H, Eitel F. Critical review and meta-analysis of serial agitated dilutions in experimental toxicology. Hum Exp Toxicol. 1994;13:481-92.

Linde K, Clausius N, Ramirez G, Melchart D, Eitel F, Hedges LV, et al. Are the clinical effects of homeopathy placebo effects? A meta-analysis of placebo-controlled trials. Lancet. 1997;350:834-43.

Linde K, Melchart D. Randomized controlled trials of individualized homeopathy: a state-of-the-art review. J Altern Complement Med. 1998;4:371-88.

Linde K, Witt CM, Streng A, Weidenhammer W, Wagenpfeil S, Brinkhaus B, et al. The impact of patient expectations on outcomes in four randomized controlled trials of acupuncture in patients with chronic pain. Pain. 2007;128:264-71.

Lipman JJ, Miller BE, Mays KS, Miller MN, North WC, Byrne WL. Peak B endorphin concentration in cerebrospinal fluid: reduced in chronic pain patients and increased during tha placebo response. Psychopharmacology (Berl). 1990;102:112-6.

Lo SY, Lo A, Chong LW, Tianzhang L, Hua LH, Geng X. Physical properties of water with IE structures. Mod Phys Lett B. 1996;10:921-30.

Lo SY, Li WC, Huang SH. Water clusters in life. Med Hypotheses. 2000;54(6):948-53. 
Lorenz J, Hauck M, Paur RC, Nakamura Y, Zimmermann R, Bromm B, Engel AK. Cortical correlates of false expectations during pain intensity judgments: a possible manifestation of placebo/nocebo cognitions. Brain Behav Immun. 2005;19:283-95.

Lunet N, Severo M, Barros H. Desvio padrão ou erro padrão. ArquiMed. 2006;20:55-

9.

Lurie P, Wolfe SM. Unethical trials of interventions to reduce perinatal transmission of the human immunodeficiency virus in developing countries. $N$ Engl $J$ Med. $1997 ; 337: 853-6$

Macedo A, Baños JE, Farré M. Placebo response in the prophylaxis of migraine: a meta-analysis. Eur J Pain. 2008;12:68-75.

Maddox J, Randi J, Stewart WW. "High-dilution" experiments a delusion. Nature. 1988;334:287-91.

Maquire MJ, Hemming K, Hutton JL, Marson AG. Reporting and analysis of openlabel extension studies of anti-epileptic drugs. Epilepsy Res. 2008; 81:24-9.

Mayberg HS, Silva JA, Brannan SK, Tekell JL, Mahurin RK, McGinnis S, et al. The functional neuroanatomy of the placebo effect. Am J Psychiatry. 2002;159:728-37.

McCarthy M. Critics slam draft WHO report on homeopathy. Lancet. 2005;366:705-6.

McKenzie JN. The production of the so-called "rose-cold" by means of an artificial rose. Am J Med Sci. 1896;91:45.

McRae C, Cherin E, Yamazaki TG, Diem G, Vo AH, Russel D, et al. Effects of perceived treatment on quality of life and medical outcomes in a double-blind placebo surgery trial. Arch Gen Psychiatry. 2004;61:412-20.

Meissner K, Distel H, Mitzdorf U. Evidence for placebo effects on physical but not on biochemical outcome parameters: a review of clinical trials. BMC Med. 2007;5:3. 
Meissner K, Gluender H, Mitzdorf U. Placebo effects on gastric slow wave frequency [abstract]. Psychophysiology. 2005;42:S15-16.

Mello Júnior JF, Mion O. Rinite Alérgica. In: Campos CAH, Costa HOO. Tratado de Otorrinolaringologia. Sociedade Brasileira de Otorrinolaringologia. 2002;3:68-87.

Meltzer EO, Schatz M, Zeiger RS. Allergic and nonallergic rhinitis. In: Middleton E Jr, Reed CE, Ellis EF, Adkinsons NF Jr, Yunginger Jw (eds.). Allergy: principles and practice. vol.2. St Louis, C. V. Mosby, 1988.

Mercado R, Constantoyannis C, Mandat T, Kumar A, Schulzer M, Stoessl AJ, et al. Expectation and the placebo effect in Parkinson's disease patients with subthalamic nucleus deep brain stimulation. Mov Disord. 2006;21:1457-61.

Miller NE. Learning of visceral and glandular reponses. Science. 1969;163:434-45.

Möller C, Dreborg S, Ferdousi HA, Halken S, Høst A, Jacobsen L, et al. Pollen immunotherapy reduces the development of asthma in children with seasonal rhinoconjunctivitis (the PAT-study). J Allergy Clin Immunol. 2002;109:251-6.

Mungan D, Misirligil Z, Gurbuz L. Comparison of the efficacy of subcutaneous and sublingual immunotherapy in mite-sensitive patients with rhinitis and asthma - a placebo controlled study. Ann Allergy Asthma Immunol. 1999; 82:485-90.

Oberbaum M, Vithoulkas G, Van Haselen R. Clinical trials of classical homeopathy: reflections on appropriate research designs. J Altern Complement Med. 2003;9:10511.

Olness K, Ader R. Conditioning as an adjunct in the pharmacotherapy of lupus erythematosus. J Dev Behav Pediatr. 1992;13:124-5. 
Olshansky B. Placebo and nocebo in cardiovascular health: implications for healthcare, research, and the doctor-patient relationship. J Am Coll Cardiol. $2007 ; 49: 415-21$.

Ovelgonne $\mathrm{JH}$, Bol AW, Hop WC, van Wijk R. Mechanical agitation of very dilute antiserum against $\lg E$ has no effect on basophil staining properties. Experientia. 1992;48:504-8.

Pacheco-López G, Engler H, Niemi MB, Schedlowski M. Expectations and associations that heal: Immunomodulatory placebo effects and its neurobiology. Brain Behav Immun. 2006;20:430-46.

Panzini RG, Rocha NS, Bandeira DR, Fleck MPA. Qualidade de vida e espiritualidade. Rev Psiquiatr Clin. 2007;34:105-15.

Passalacqua G, Ciprandi G, Canonica GW. The nose-lung interaction in allergic rhinitis and asthma: united airways disease. Curr Opin Allergy Clin Immunol. 2001;1:7-13.

Passalacqua G, Canonica GW. Long-lasting clinical efficacy of allergen specific immunotherapy. Allergy. 2002;57:275-6.

Patel SM, Stason WB, Legedza A, Ock SM, Kaptchuk TJ, Conboy L, et al. The placebo effect in irritable bowel syndrome trials: a meta-analysis. Neurogastroenterol Motil. 2005;17:332-40.

Penagos M, Compalati E, Tarantini F, Baena-Caqnani R, Huerta J, Passalacqua G, et al. Efficacy of sublingual immunotherapy in the treatment of allergic rhinitis in pediatric patients 3 to 18 years of age: a meta-analysis of randomized, placebo-controlled, double-blind trials. Ann Allergy Asthma Immunol. 2006;97:141-8. 
Petrovic P, Kalso E, Petersson KM, Ingvar M. Placebo and opioid analgesia - imaging a shared neural network. Science. 2002;295:1737-40.

Pollo A, Amanzio M, Arslanian A, Casadio C, Maggi G, Benedetti F. Response expectancies in placebo analgesia and their clinical relevance. Pain. 2001;93:77-84.

Pollo A, Torre E, Lopiano L, Rizzone M, Lanotte M, Cavanna A. Expectation modulates the response to subthalamic nucleus stimulation in Parkinsonian patients. Neuroreport. 2002;13:1383-6.

Pollo A, Vighetti S, Rainero I, Benedetti F. Placebo analgesia and the heart. Pain. 2003;102:125-33.

Porro CA, Baraldi P, Pagnoni G, Serafini M, Facchin P, Maieron M, Nichelli P. Does anticipation of pain affect cortical nociceptive ystems? J Neurosci. 2002;22:3206-14.

Porro CA, Cettolo V, Francescato MP, Baraldi P. Functional activity mapping of the mesial hemispheric wall during anticipation of pain. Neuroimage. 2003;19:1738-47.

Price DD, Milling LS, Kirsch I, Duff A, Montgomery GH, Nicholls SS. An analysis of factors that contribute to the magnitude of placebo analgesia in an experimental paradigm. Pain. 1999;83:147-56.

Price DD. Psychological and neural mechanisms of the affective dimension of pain. Science. 2000;288:1769-72

Price DD. Assessing placebo effects without placebo groups: an untapped possibility? Pain. 2001;90:201-3.

Price DD, Finniss DG, Benedetti F. A comprehensive review of the placebo effect: recent advances and current thought. Annu Rev Psychol. 2007a;59:565-90. 
Price DD, Craggs J, Verne GN, Perlstein WM, Robinson ME. Placebo analgesia is accompanied by large reductions in pain-related brain activity in irritable bowel syndrome patients. Pain. 2007b;127:63-72.

Quirino T, lemoli E, Siciliani E, Parmiani S, Milazzo F. Sublingual versus injective immunotherapy in grass pollen allergic patients: a double blind (double dummy) study. Clin Exp Allergy. 1996;26:1253-61.

Quitkin FM. Placebos, drugs effects, and study design: a clinician's guide. Am J Psychiatry. 1999;156:829-36.

Reilly DT, Taylor MA. Potent placebo or potency? A proposed study model with initial findings using homoeopathically prepared pollens in hay fever. $\mathrm{Br}$ Homoeopathic $\mathrm{J}$. 1985;74:65-75.

Reilly DT, Taylor MA, McSharry C, Aitchison T. Is homoeopathy a placebo response? Controlled trial of homoeopathic potency, with pollen in hayfever as model. Lancet. 1986;2:881-6.

Reilly DT, Taylor MA, Beattie NG, Campbell JH, McSharry C, Aitchison T, et al. Is evidence for homoeopathy reproducible? Lancet. 1994; 344:1601-6.

Rey LR. Thermoluminescence of ultra-high dilutions of lithium chloride and sodium chloride. Phisica A. 2003;323:67-74.

Ribeiro Filho A. Repertório Homeopático Digital II (Edição Eletrônica). São Paulo: Organon; 1998.

Robertson A, Suryanarayanan R, Banerjee A. Homeopathic Arnica montana for posttonsillectomy analgesia: a randomised placebo control trial. Homeopathy. 2007;96:17-21. 
Sainte-Laudy J. Standardization of basophil degranulation for pharmacological studies. J Immunol Methods. 1987;98:279-82.

Sainte-Laudy J, Belon P. Analysis of immunosuppressive activity of serial dilutions of histamine on human basophil activation by flow cytometry. Inflamm Res. 1996;45:S33-4.

Sainte-Laudy J, Belon P. Application of flow cytometry to the analysis of the immunosupressive effect of histamine dilutions on human basophil activation: effect of cimetidine. Inflamm Res. 1997;46:S27-8.

Sainte-Laudy J. Modulation of allergen and anti-IgE induced human basophil activation by serial histamine dilutions. Inflamm Res. 2000;49:S5-6.

Sainte-Laudy J, Belon P. Use of four different flow cytometric protocols for the analysis of human basophil activation. Application to the study of the biological activity of high dilutions of histamine. Inflamm Res. 2006;55:S23-4.

Sauro MD, Greenberg RP. Endogenous opiates and the placebo effect. A metaanalytic review. J Psychosom Res. 2005;58:115-20.

Scadding GK, Durham SR, Mirakian R, Jones NS, Leech SC, Farooque S, et al. $\mathrm{BSACl}$ guidelines for the management of allergic and non-allergic rhinitis. Clin Exp Allergy. 2008;38:19-42.

Shang A, Huwiler-Müntener K, Nartey L, Jüni $P$, Dörig $S$, Sterne JA, et al. Are the clinical effects of homoeopathy placebo effects? Comparative study of placebocontrolled trials of homoeopathy and allopathy. Lancet. 2005;366:726-32.

Shapiro AK. A historic and heuristic definition of the placebo. Psychiatry. 1964;27:528. 
Shipley M, Berry H, Broster G, Jenkins M, Clover A, Williams I. Controlled trial of homoeopathic treatment of osteoarthritis. Lancet. 1983;1:97-8.

Solé D, Wandalsen GF, Camelo-Nunes IC, Naspitz CK; ISAAC - Brazilian Group. Prevalence of symptoms of asthma, rhinitis, and atopic eczema among Brazilian children and adolescents identified by the International Study of Asthma and Allergies in Childhood (ISAAC) - Phase 3. J Pediatr (Rio J). 2006;82:341-6.

Spiegel D, Kraemer H, Carlson RW. Is the placebo powerless? $N$ Engl $J$ Med. $2001 ; 345: 1276-9$.

Stefano GB, Fricchione GL, Slingsby BT. Is stress stress? Placebo. 2001;3:101-10.

Steinsbekk A, Fonnebo V, Lewith G, Bentzen N. Homeopathic care for the prevention of upper respiratory tract infections in children: a pragmatic, randomised, controlled trial comparing individualised homeopathic care and waiting-list controls. Complement Ther Med. 2005;13:231-8.

Strachan D, Sibbald B, Weiland S, Ait-Khaled N, Anabwani G, Anderson HR, et al. Worldwide variations in prevalence of symptoms of allergic rhinoconjunctivitis in children: the International Study of Asthma and Allergies in Childhood (ISAAC). Pediatr Allergy Immunol. 1997;8:161-76.

Straumshein P, Borchgrevink C, Mowinckel P, Kierulf H, Hafslund O. Homeopathic treatment of migraine: a double blind, placebo controlled trial of 68 patients. $\mathrm{Br}$ Homeopath J. 2000;89:4-7.

Su C, Lichtenstein GR, Krok K, Brensinger CM, Lewis JD. A meta-analysis of the placebo rates of remission and response in clinical trials of active Crohn's disease. Gastroenterology. 2004;126:1257-69. 
Sysko R, Walsh BT. A systematic review of placebo response in studies of bipolar mania. J Clin Psychiatry. 2007;68:1213-7.

Taylor MA, Reilly D, Llewellyn-Jones RH, McSharry C, Aitchison TC. Randomised controlled trial of homoeopathy versus placebo in perennial allergic rhinitis with overview of four trial series. BMJ. 2000;321:471-6.

Teixeira MZ. Estudo sobre doses e potências homeopáticas. Rev Homeopatia. 1995;60:3-23.

Teixeira MZ. Agravação e prognóstico em homeopatia: uma sistematização de conceitos. Rev Homeopatia. 1997;62:27-68.

Teixeira MZ. Semelhante cura semelhante: o princípio de cura homeopático fundamentado pela racionalidade médica e científica. São Paulo: Editorial Petrus; 1998.

Teixeira MZ. Similitude in modern pharmacology. Br Homeopath J. 1999;88:112-20.

Teixeira MZ. Pesquisa básica em homeopatia: revisão bibliográfica. Rev Homeopatia. 2001a;66:5-26.

Teixeira MZ. Protocolo para pesquisa clínica em homeopatia: aspectos fundamentais. Diagn Tratamento. 2001b;6:11-8.

Teixeira MZ. Distúrbios do climatério e tratamento homeopático. Homeopatia Brasileira. 2002a;8:29-43.

Teixeira MZ. Avaliação miasmática na pesquisa clínica homeopática: emprego de questionário de qualidade de vida. Rev Homeopatia. 2002b;67:5-16.

Teixeira MZ. Homeopathic use of modern medicines: utilisation of the curative rebound effect. Med Hypotheses. 2003;60:276-83. 
Teixeira MZ. Panorama da pesquisa em homeopatia: iniciativas, dificuldades e propostas. Diagn Tratamento. 2004;9:98-104.

Teixeira MZ, Lin CA, Martins MA. O ensino de práticas não-convencionais em saúde nas faculdades de medicina: panorama mundial e perspectivas brasileiras. Rev Bras Educ Med. 2004;28:51-60.

Teixeira, MZ. "Paradoxical strategy for treating chronic diseases": therapeutic model used by homeopathic paradigm for more than two centuries. Homeopathy. 2005; 94:265-6.

Teixeira MZ, Lin CA, Martins MA. Homeopathy and acupuncture teaching at Faculdade de Medicina da Universidade de São Paulo: the undergraduates' attitudes. Sao Paulo Med J. 2005;123:77-82.

Teixeira MZ. Evidence of the principle of similitude in modern fatal iatrogenic events. Homeopathy. 2006a;95:229-36.

Teixeira MZ. Homeopatia: ciência, filosofia e arte de curar. Rev Med (São Paulo). 2006b;85:30-43.

Teixeira MZ. Será mesmo o fim da homeopatia? Diagn Tratamento. 2006c;11:61-3.

Teixeira MZ. Homeopatia: prática médica humanística. Rev Assoc Med Bras. 2007a;53:547-9.

Teixeira MZ. Homeopatia: desinformação e preconceito no ensino médico. Rev Bras Educ Med. 2007b;31:15-20

Teixeira MZ. NSAIDs, Myocardial infarction, rebound effect and similitude. Homeopathy. 2007c;96:67-8.

Teixeira MZ. Bronchodilators, fatal asthma, rebound effect and similitude. Homeopathy. 2007d;96:135-7. 
Teixeira MZ. Brief homeopathic pathogenetic experimentation: a unique educational tool in Brazil. Evid Based Complement Alternat Med. 2007e;Oct 4. [Epub ahead of print].

Teixeira MZ. Homeopatia: prática médica coadjuvante. Rev Assoc Med Bras. 2007f;53:547-9.

Teixeira MZ. Tratamento homeopático dos distúrbios emocionais e comportamentais da infância e da adolescência. Pediatria (São Paulo). 2008a;29:286-96.

Teixeira MZ. Pesquisa clínica em homeopatia: evidências, limitações e projetos. Pediatria (São Paulo). 2008b;30:27-40.

Teixeira MZ, Leal SM, Ceschin VMFA. Homeopathic practice in Intensive Care Units: objective semiology, symptoms selection and a series of sepsis cases. Homeopathy. 2008;97:206-13.

Teixeira MZ. Antidepressants, suicidality and rebound effect: is a new evidence of the similitude natural law? Homeopathy. 2009a. In press.

Teixeira MZ. Bases psiconeurofisiológicas do fenômeno placebo-nocebo: evidências científicas que valorizam a humanização da relação médico-paciente. Rev Assoc Med Bras. 2009b. No prelo.

Temple R, Ellenberg SS. Placebo-controlled trials and active-control trials in the evaluation of new treatments. Part 1: ethical and scientific issues. Ann Intern Med. 2000;133:455-63.

Tenery R, Rakatansky H, Riddick FA Jr, Goldrich MS, Morse LJ, O'Bannon JM 3rd, et al. Surgical "placebo" controls. Ann Surg. 2002;235:303-7. 
Tonnel AB, Scherpereel A, Douay B, Mellin B, Leprince D, Goldstein N, et al. Allergic rhinitis due to house dust mites: evaluation of the efficacy of specific sublingual immunotherapy. Allergy. 2004;59:491-7.

Trichard M, Lamure E, Chaufferin G. Study of the practice of homeopathic general practitioners in France. Homeopathy. 2003;92:135-9.

Turato ER. Métodos qualitativos e quantitativos na área da saúde: definições, diferenças e seus objetos de pesquisa. Rev Saúde Pública. 2005;39:507-14.

Universidade Federal do Estado do Rio de Janeiro. Edital do Concurso de Seleção para Médicos Residentes (2004). Disponível em: http://www.unirio.br/propg/posgrad/editais/edit_res_medica_2004.doc. Acessado em 14/12/2008.

van Cauwenberge P, Bachert C, Passalacqua G, Bousquet J, Canonica GW, Durham SR, et al. Malling Consensus statement on the treatment of allergic rhinitis. European Academy of Allergology and Clinical Immunology. Allergy. 2000;55:116-34.

van Haselen R. The economic evaluation of complementary medicine: a staged approach at the Royal London Homeopathic Hospital. Br Homeopath J. 2000;89:S236. Vandenbroucke JP. Homoeopathy and "the growth of truth". Lancet. 2005;366:691-2. Vase L, Robinson ME, Verne GN, Price DD. The contributions of suggestion, expectancy and desire to placebo effect in irritable bowl syndrome patients. Pain. 2003;105:17-25.

Vase L, Robinson ME, Verne GN, Price DD. Increased placebo analgesia over time in irritable bowel syndrome (IBS) patients is associated with desire and expectation but not endogenous opioid mechanisms. Pain. 2005;115:338-47. 
Verne GN, Robinson ME, Vase L, Price DD. Reversal of visceral and cutaneous hyperalgesia by local rectal anesthesia in irritable bowl syndrome (IBS) patients. Pain. 2003;105:223-30.

Vickers AJ, Smith C. Homoeopathic Oscillococcinum for preventing and treating influenza-like syndromes. Cochrane Database Syst Rev. 2000;CD001957.

Wager TD, Rilling JK, Smith EE, Sokolic A, Casey KL, Davidson RJ, et al. Placeboinduced changes in fMRI in the anticipation and experience of pain. Science. 2004;303:1162-7.

Walach H. Unspezifishe Therapie-Effkte. Das Beispiel Homöopathie [thesis]. Freiburg, Germany: Psychologische Institut, Albert-Ludwigs-Universität Freiburg; 1997.

Walsh BT, Seidman SN, Sysko R, Gould M. Placebo response in studies of major depression: variable, substantial, and growing. JAMA. 2002;287:1840-7.

Wampold BE, Minami T, Tierney SC, Baskin TW, Bhati KS. The placebo is powerful: estimating placebo effects in medicine and psychotherapy from randomized clinical trials. J Clin Psychol. 2005;63:373-7.

Wawer MJ, Sewankambo NK, Serwadda D, Quinn TC, Paxton LA, Kiwanuka N, et al. Control of sexually transmitted diseases for AIDS prevention in Uganda: a randomised community trial. Rakai Project Study Group. Lancet. 1999; 353:525-35. Weatherley-Jones E, Thompson EA, Thomas KJ. The placebo-controlled trial as a test of complementary and alternative medicine: observations from research experience of individualised homeopathic treatment. Homeopathy. 2004;93:186-9.

Weinmayr G, Forastiere F, Weiland SK, Rzehak P, Abramidze T, Annesi-Maesano I, et al.; the ISAAC Phase Two Study Group*. International variation in prevalence of 
rhinitis and its relation with sensitization to perennial and seasonal allergens. Eur Respir J. 2008;Jun 25. [Epub ahead of print].

Whalen CC, Johnson JL, Okwera A, Hom DL, Huebner R, Mugyenyi P, et al. A trial of three regimens to prevent tuberculosis in Ugandan adults infected with the human immunodeficiency virus. Uganda-Case Western Reserve University Research Collaboration. N Engl J Med. 1997;337:801-8.

Wiesenauer M, Lüdtke R. A meta-analysis of the homeopathic treatment of pollinosis with Galphimia glauca. Forsch Komplementärmed. 1996;3:230-6.

Wilson AM, O'Byrne PM, Parameswaran K. Leukotriene receptor antagonists for allergic rhinitis: a systematic review and meta-analysis. Am J Med. 2004;116:338-44. Wilson DR, Lima MT, Durham SR. Sublingual immunotherapy for allergic rhinitis. Cochrane Database Syst Rev. 2003;CD002893.

Wilson DR, Lima MT, Durham SR. Sublingual immunotherapy for allergic rhinitis: systematic review and meta-analysis. Allergy. 2005;60:4-12.

Wolf M, Tamaschke C, Mayer W, Heger M. Efficacy of Arnica in varicose vein surgery: results of a randomized, double-blind, placebo-controlled pilot study. Forsch Komplementarmed Klass Naturheilkd. 2003;10:242-7.

World Health Organization. International ethical guidelines for biomedical research involving human subjects. Geneva: Council for International Organizations of Medical Sciences, 1993.

World Medical Association Declaration of Helsinki - Ethical Principles for Medical Research Involving Human Subjects $-52^{\text {nd }}$ WMA General Assembly, Edinburg, Scotland, October 2000. Disponível em: http://www.wma.net/e/policy/b3.htm. Acessado em 14/12/2008. 
World Medical Association Declaration of Helsinki - Ethical Principles for Medical Research Involving Human Subjects - Note of clarification on paragraph 29 added by WMA General Assembly, Washington, USA, 2002. Disponível em: http://www.wma.net/e/policy/b3.htm. Acessado em 14/12/2008. 
APÊNDICES 
APÊNDICES

Apêndice 1 - Documentação aprovada pela CAPPesq (Fases 1 e 2) 


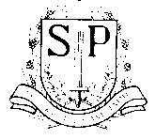

\title{
HOSPITAL DAS CLINICAS
}

FACULDADE DE MEDICINA DA UNIVERSIDADE DE SẢO PAULO

CAIXA POSTAL, 3671

SAO PALLO - BRASII

DIRETORIA CLÍNICA

Comissão de Ética para Análise de Projetos de

\section{Pesquisa}

\section{APROVACÃO}

A Comissão de Ética para Análise deProjetos de Pesquisa - CAPPesq da Diretoria Clínica do Hospital das Clínicas e da Faculdade de Medicina da Universidade de São Paulo, em sessão de 11/04/01. APROVOU o Protocolo de Pesquisa $n^{\circ} 130 / 01$, intitulado: "Estudo duplo-cego, randomizado de eficácia do tratamento homeopático individualizado na rinite alérgica perene", apresentado pelo(a) pesquisador(a) Marcus Zulian Teixeira, do Departamento de Clínica Médica, bem como o Termo de Consentimento Livre e Esclarecido.

CAPPesq, 16 de abril de 2001.

\author{
torecely \\ PROF. DR. IORGE KALIL FILHO \\ Presidente da Comissão Ética para Análise \\ de Projetos de Pesquisa
}

\footnotetext{
OBSERVAÇÃO: Cabe ao pesquisador elaborar e apresentar à CAPPesq, os relatórios parciais e final sobre a pesquisa (Resolusăo do Conselho Nacional de Saúde $n^{\circ}$ 196, de 10.10.1996, inciso IX.2, letra "c")
} 


\section{HOSPITAL DAS CLÍNICAS}

DA

FACULDADE DE MEDICINA DA UNIVERSIDADE DE SÃO PAULO

CAIXA POSTAL, 3671

SÄO PAULO-BRASIL

\section{DIRETORIA CLÍNICA}

\section{Comissão de Ética para Análise de Projetos de Pesquisa}

\section{APROVAÇÃO}

A Comissão de Ética para Análise de Projetos de Pesquisa - CAPPesq da Diretoria Clínica do Hospital das Clínicas e da Faculdade de Medicina da Universidade de São Paulo, em sessão de 10.07.02, APROVOU EMENDA referente ao Protocolo de Pesquisa $n^{\circ} 130 / 01$, intitulado: "Estudo duplo-cego, randomizado de eficácia do tratamento homeopático individualizado na rinite alérgica perene", apresentado pelo Departamento de CLÍNICA MÉDICA, bem como novo Termo de Consentimento Livre $e$ Esclarecido.

Pesquisador Responsável: Prof. Dr. Milton de Arruda Martins

Pesquisador Executante: Dr. Marcus Zulian Teixeira

C.APPesq, 10 de Julho de 2002.

PROF. DR. JURGE KALIL FILHO

Presidente da Comissão Ética para Análise de Projetos de Pesquisa

- OBSERVAÇÃO: Cabe ao pesquisador elaborar e apresentar à CAPPesq, os relatórios parciais e final sobre a pesquisa (Resolução do Conselho Nacional de Saúde $n^{\circ} 196$, de 10.10.1996, inciso IX.2, letra "c"). 


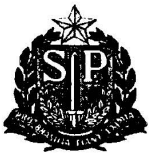

\author{
HOSPITAL DAS CLINICAS \\ DA FACULDADE DE MEDICINA DA UNIVERSIDADE DE SÃo PAULO \\ CAIXA POSTAL, 8091 - SÃO PAULO - BRASIL
}

DIRETORIA CLÍNICA

\title{
Comissão de Ética para Análise de Projetos de Pesquisa
}

\section{APROVAÇÃO}

A Comissão de Ética para Análise de Projetos de Pesquisa - CAPPesq da Diretoria Clínica do Hospital das Clínicas e da Faculdade de Medicina da Universidade de São Paulo, em sessão de 12.03.03, APROVOU Emenda II ao Protocolo de Pesquisa $n^{\circ}$ 130/01, intitulado: "Estudo duplocego randomizado de eficácia do tratamento homeopático individualizado na rinite alérgica perene" apresentado pelo Departamento de CLÍNICA MÉDICA, bem como o novo Termo de Consentimento Livre e Esclarecido.

Pesquisador(a) Responsável: DR. MARCUS ZULIAN TEIXEIRA

CAPPesq, 12 de Março de 2003.

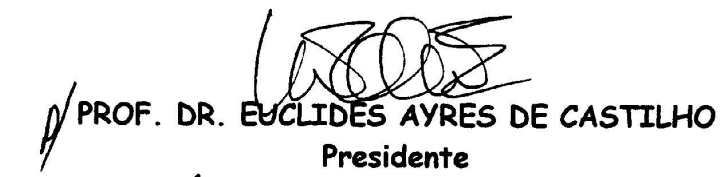

Comissão de Ética para Análise de Projetos de Pesquisa

OBSERVAÇÃO: Cabe ao pesquisador elaborar e apresentar à CAPPesq, os relatórios parciais e final sobre a pesquisa (Resolução do Conselho Nacional de Saúde $n^{\circ} 196$, de 10.10.1996, inciso IX.2, letra " $c$ ") 


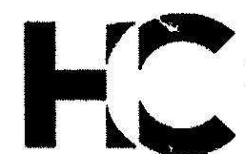

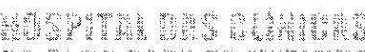

DIRETORIA CLÍNICA

Comissão de Ética para Análise de Projetos de Pesquisa

\section{APROVAÇÃO}

A Comissão de Ética para Análise de Projetos de Pesquisa - CAPPesq da Diretoria Clínica do Hospital das Clínicas e da Faculdade de Medicina da Universidade de São Paulo, em sessão de 11.08.04, APROVOU Emenda III ao Protocolo de Pesquisa $n^{\circ} 130 / 01$, intitulado: "Estudo duplo-cego, randomizado de eficácia do tratamento homeopático individualizado na rinite alérgica perene" apresentado pelo Departamento de CLÍNICA MÉDICA, bem como o novo Termo de Consentimento Livre e Esclarecido.

Pesquisador(a) Responsável: Prof. Dr. Milton de Arruda Martins

CAPPesq, 11 de Agosto de 2004.

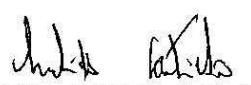

PROF. DR. EUCLIDES AYRES DE CASTILHO Presidente da Comissão de Ética para Análise de Projetos de Pesquisa

OBSERVAÇÃO: Cabe ao pesquisador elaborar e apresentar à CAPPesq, os relatórios parciais e final sobre a pesquisa (Resolução do Conselho Nacional de Saúde n० 196, de 10.10.1996, inciso IX.2, letra "c") 


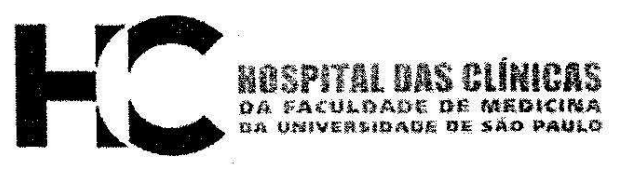

\section{APROVAÇÃO}

A Comissão de Ética para Análise de Projetos de Pesquisa - CAPPesq da Diretoria Clínica do Hospital das Clínicas e da Faculdade de Medicina da Universidade de São Paulo, em sessão de 16.02.05, APROVOU documentos abaixo mencionados referente ao Protocolo de Pesquisa $n^{\circ}$ 130/01, intitulado: "Estudo duplo-cego, randomizado de eficácia do tratamento homeopático individualizado na rinite alérgica perene" apresentado pelo Departamento de CLÍNICA MÉDICA.

- Emenda IV.

- Novo Termo de Consentimento Livre e Esclarecido.

- Alteração do título para: "Ensaio clínico quali-quantitativo sobre a eficácia e efetividade do tratamento homeopático individualizado na rinite alérgica perene"

Pesquisador(a) Responsável: Dr. Marcus Zulian Teixeira CAPPesq, 16 de Fevereiro de 2005.

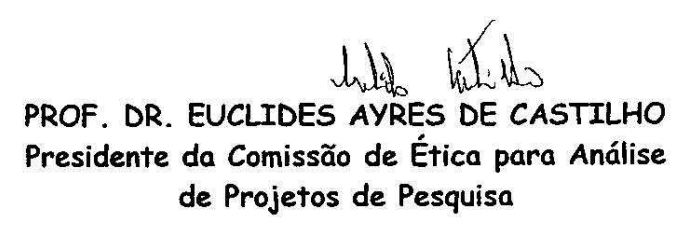
de Projetos de Pesquisa

Comissão de Ética para Análise de Projetos de Pesquisa do HCFMUSP e da FMUSP Diretoria Clínica do Hospital das Clínicas da Faculdade de Medicina da Universidade de São Paulo Rua Ovidio Pires de Campos. 225, $5^{\circ}$ andar - CEP 05403010 - São Paulo - SP 


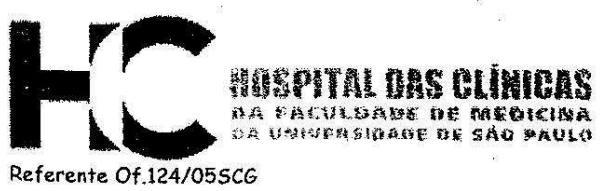

Ao

Departamento de Clínica Médica

O Presidente da Comissão de Ética para Análise de Projetos de Pesquisa - CAPPesq da Diretoria Clínica do Hospital das Clínicas da Faculdade de Medicina da Universidade de São Paulo, em 04.07.05, tomou conhecimento que o Protocolo de Pesquisa $n^{\circ}$ 130/01, intitulado "Ensino Clínco Quali-Quantitativo para avaliar a eficácia e a efetividade do tratamento homeopático individualizado na rinite Alérgica Perene", será tese de doutorado do aluno Marcus Zulian Teixeira.

Pesquisador Responsável: Prof.Dr. Milton de Arruda Martins

São Paulo, 04 de julho de 2005

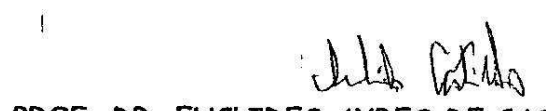

PROF. DR. EUCLIDES AYRES DE CASTILHO

Presidente da Comissão de Ética para Análise de Projetos de Pesquisa

Comissão de Ética para Análise de Projetos de Pesquisa do HCFMUSP e da FMUSP
Diretoria Clínica do Hospital das Clínicas da Faculdade de Medicina da Universidade de São Paulo

Rua Ovídio Pires de Campos. $225,5^{\circ}$ andar - CEP 05430010 - São Paulo - SP

Fone: 011 - 30696442 fax: 011 - 30696492 - e-mail : cappesg@honet.usp.br / secretariacappesq@hcnet.usp.br 


\section{Apêndice 2 - Consentimento livre e esclarecido - Fase 1}

Fase 1 - Estudo clínico randomizado, duplo-cego e placebo-controlado, com a duração equivalente a seis meses de acompanhamento

Dados de identificação dos sujeitos da pesquisa ou responsável legal:

1 - Nome do paciente

Documento de identidade $\mathrm{n}^{0}$

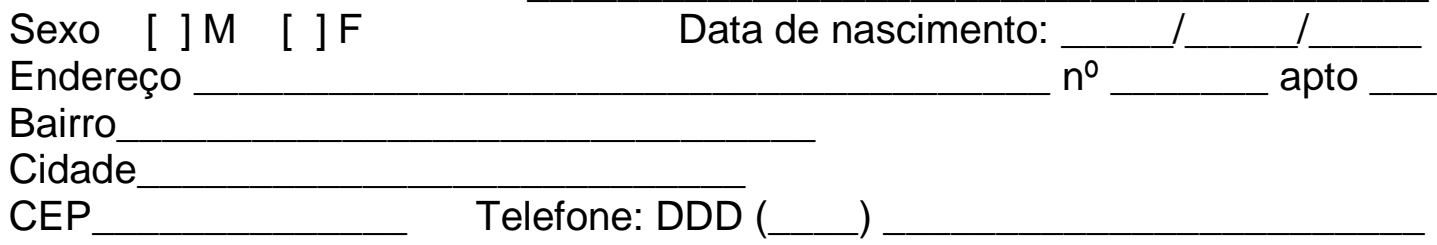

2 - Responsável legal

Natureza (grau de parentesco, tutor, curador)

Documento de identidade no

Sexo [ ] M [ ] F Data de nascimento:___ _ _

Endereço

Bairro

Cidade

CEP

Telefone: DDD

Introdução: Você está sendo convidado(a) como voluntário(a) a participar desta pesquisa clínica, porque você é portador(a) de rinite alérgica perene e acredita-se que, no momento, você apresente os sintomas da mesma, necessitando de tratamento medicamentoso. Este é um estudo sobre a eficácia do tratamento homeopático na rinite alérgica perene.

O objetivo deste estudo será avaliar o tratamento homeopático individualizado nesta doença, seguindo-se o modelo clássico da Homeopatia.

Este é um estudo fechado, duplo-cego, o que significa que você e o seu médico não saberão se o medicamento que você está recebendo é ativo ou placebo (substância inerte).

Procedimentos: Espera-se que seja incluído em torno de 40 pacientes, divididos em dois grupos de aproximadamente 20 pacientes, cada grupo recebendo medicamento homeopático ativo ou placebo, sendo os pacientes distribuídos nos grupos de uma forma aleatória (sorteio). Nesta consulta será coletado sangue e urina para análise, bem como um teste cutâneo para comprovação da rinite alérgica. Se qualquer dos resultados dos exames estiver alterado, você pode ser considerado neste momento inapto para continuar este estudo. Caso você preencha todos os critérios de inclusão, você poderá entrar no estudo.

Se você concordar em participar, será avaliado durante o mesmo seguindo o cronograma abaixo. 
1) Antes da inclusão ou visita 0 (semana -1):

História clínica completa

Avaliação dos sinais e sintomas

Exame clínico

Amostra de sangue

Teste cutâneo

2) Após cumprida a semana sem medicação ou visita 1 (semana 0)

História clínica completa

Avaliação dos sinais e sintomas

Exame clínico

História homeopática completa

Orientação para o início da medicação homeopática

Preenchimento do "Questionário de Qualidade de Vida".

3) Durante as visitas 2, 3, 4, 5 e 6 de retornos (semanas 4, 8, 12, 16 e 20 respectivamente)

História clínica completa

Avaliação dos sinais e sintomas

Exame clínico

História homeopática

Orientação quanto à medicação homeopática ou alopática (anti-histamínico de escape)

4) Última visita (visita 7; semana 24)

História clínica completa

Avaliação dos sinais e sintomas

Exame clínico

História homeopática

Amostra de sangue

Preenchimento do "Questionário de Qualidade de Vida"

$\mathrm{O}$ (s) medicamento(s) homeopático(s) será(ão) fornecido(s) em frascos de $20 \mathrm{ml}$ com conta-gotas próprio. A partir da visita dois você será solicitado a pingar 3 gotas do "medicamento constitucional" (C), na boca, em jejum, uma vez por semana. Após a visita 4 o(s) medicamento(s) homeopático(s) será(ão) mantido(s) ou modificado(s), podendo-se optar pela introdução de um anti-histamínico de escape concomitantemente. A freqüência de utilização do anti-histamínico deverá ser anotada pelo paciente num diário pessoal e informada ao médico a cada retorno. $\mathrm{O}$ médico estará orientando no que diz respeito à forma de aplicação.

Você deverá estar ciente de que cada frasco de medicação é suficiente para o período de tratamento especificado, portanto utilize-o conforme a indicação médica.

Não se esqueça de que o excesso de doses do medicamento homeopático, além do recomendado, pode trazer efeitos adversos e prejudiciais à sua saúde.

Benefícios: Não são garantidos benefícios a partir deste estudo. Sua participação pode contribuir para o desenvolvimento de um tratamento alternativo para o tratamento da rinite alérgica.

Desconfortos e riscos: Estudos de pesquisas freqüentemente envolvem alguns riscos, sendo que nem todos são conhecidos atualmente.

A coleta de sangue pode provocar desconforto, desmaio (infreqüente) e infecção no local de penetração da agulha (rara). 
Você poderá vir a sentir algum desconforto durante o tratamento homeopático, devido à ocorrência de reações adversas. As principais reações adversas relatadas no tratamento homeopático são: agravação inicial dos sintomas da rinite (prurido, espirros, obstrução nasal e rinorréia), retorno de sintomas antigos (de qualquer tipo, desaparecidos há algum tempo) e surgimento de sintomas novos (nunca antes manifestados). É importante que qualquer evento que venha a ocorrer durante o estudo seja anotado num diário e prontamente relatado ao médico.

Se você é mulher em idade fértil, não pode estar grávida, nem engravidar e nem amamentar durante o período de tratamento e durante 28 dias depois de completar o tratamento. Você precisa usar um método de contracepção confiável.

Tratamentos alternativos: Existem outros medicamentos para tratar a rinite (por exemplo, agentes anti-histamínicos e costicosteróides).

Você não precisa participar deste estudo para que o seu problema seja tratado com as terapêuticas já aprovadas. Se você decidir não participar do estudo, vai receber o tratamento considerado adequado para a sua condição.

Sigilo: Seus médicos vão tratar sua identidade com padrões profissionais de sigilo. Seu prontuário vai permanecer confidencial. O Comitê de Ética envolvido no estudo pode solicitar revisão de seu prontuário, tendo acesso a este; no entanto, ele vai continuar em sigilo, porque apenas um número e iniciais serão usados para identificação. Os nomes dos participantes ou o material que identifique os participantes não serão liberados sem permissão por escrito, exceto se exigidos pela lei. Os participantes não serão identificados em nenhuma publicação que possa resultar deste estudo. Uma cópia deste consentimento informado será arquivada em seu prontuário médico e uma será fornecida a você.

Participação / Encerramento: Você é livre para se recusar a participar ou retirar seu consentimento e interromper o tratamento a qualquer momento. A participação é voluntária e a recusa em participar não irá acarretar qualquer penalidade ou perda de benefícios. A recusa ou interrupção não prejudicará de forma alguma o benefício de receber tratamento, agora ou no futuro, nesta Instituição.

Durante o decorrer deste estudo, novos achados, positivos ou negativos, podem surgir. Neste caso você será informado. Se estes novos achados tornarem necessário reavaliar a sua situação individual ou interromper a sua participação no estudo, seu médico irá discutir isto exaustivamente. Consultas adicionais com o médico ou exames laboratoriais de seguimento podem ser necessários, se houver alterações em seus resultados de exames laboratoriais ou se seu estado clínico se alterar.

Pode haver circunstâncias em que você será afastado do estudo. Estas incluem piora marcante da sua condição, não adesão à medicação em estudo, se o pesquisador considerar que é de seu melhor interesse ou se o estudo for interrompido. Você poderá ser afastado sem a necessidade de seu consentimento.

Custos da participação: Todos os medicamentos, procedimentos e consultas para este estudo serão fornecidos gratuitamente. A assistência médica não relacionada a este estudo será de sua responsabilidade como, por exemplo, qualquer outro exame ou tratamento relacionado com seu tratamento para rinite alérgica que não esteja identificado no protocolo em estudo.

Declaração do paciente: Eu tive tempo para ler e pensar sobre a informação contida no formulário de consentimento antes de entrar para o estudo. O programa 
proposto foi explicado claramente. Eu concordei voluntariamente em participar deste estudo e com o tratamento estabelecido anteriormente, com a compreensão de que nem todos os riscos de tal tratamento podem ser completamente conhecidos. Compreendo que a recusa em participar deste estudo não irá envolver qualquer sanção e nem perda de benefícios. Também compreendo que posso retirar meu consentimento e interromper o tratamento a qualquer momento sem penalidade e sem prejuízo para tratamento futuro ou alternativo nesta Clínica.

Se qualquer problema ou questão aparecer durante o estudo em relação aos meus direitos, enquanto participante do estudo de pesquisa clínica, ou com relação à lesão relacionada à pesquisa, compreendo que devo entrar em contato com o

Dr. Telefone ( )

Assinatura do paciente

Assinatura da testemunha

Assinatura do pesquisador

Data - 


\section{Apêndice 2 - Consentimento livre e esclarecido - Fase 2}

\section{Fase 2 - Estudo aberto prospectivo, com a duração equivalente a 6-36 meses de tratamento homeopático}

Estamos convidando você a continuar participando deste estudo no qual todos os pacientes receberão apenas a forma de medicamento ativo, ou seja, que tem o objetivo de alcançar a melhora dos seus sintomas. Nenhum paciente receberá placebo como forma de tratamento, ao contrário da primeira fase do estudo onde alguns pacientes foram sorteados para recebê-lo.

Você continuará a ser tratado pelos mesmos profissionais que cuidaram de você na primeira fase e os exames aos quais você será submetido (na última visita de cada período) serão os mesmos: teste de punctura (prick test), coleta de sangue para análise laboratorial e questionário de qualidade de vida, bem como o recebimento de medicamento de resgate, caso você e o seu médico considerem necessários.

Sua opção por continuar neste estudo é voluntária e você pode desistir do mesmo a qualquer momento, não havendo qualquer prejuízo no seu tratamento habitual nesta Instituição.

Li e compreendi este termo e concordo em participar deste estudo.

Nome do voluntário

Assinatura do voluntário

Data (preenchida pelo voluntário)

Médico responsável

Testemunha 